\title{
Hidden Voices: the participation of people with learning disabilities in the experience of public open space.
}

\author{
Alice Robin Mathers \\ Doctor of Philosophy (PhD)
}

The Department of Landscape,

The University of Sheffield, UK.

November 2008 


\section{Hidden Voices}

\section{Extended Contents Page}

\section{Acknowledgements}

\section{Abstract}

\section{Introduction}

\section{Literature Review $\quad 8$}

2.1 Disability and learning disability: the people 8

2.1.1 Definitions and disagreements 8

2.1.2 Looking with a clinical eye at the universal stage 8

2.1.3 Activism in the UK 10

2.1.4 The social model and its legislative influence 11

2.1.5 Further definition difficulties 13

$\begin{array}{lll}\text { 2.1.6 Historic advances } & 14\end{array}$

2.1.7 Valuing People 15

2.1.8 Social inclusion and advocacy 16

$\begin{array}{lll}2.2 & \text { Communication: the means } & 17\end{array}$

2.2.1 Communication equals power 18

2.2.2 A picture speaks a thousand words $\quad 21$

2.2.3 My image on film 23

2.2.4 Unique hand-drawn worlds 24

2.2.5 Verbal communication and semi-structured interviews 25

2.3 Public open spaces: the context 27

$\begin{array}{lll}\text { 2.3.1 The healing legacy } & 27\end{array}$

2.3.2 Exclusion in the environment 30

2.3.3 Development of social design strategies 33 
2.3.4 Reflection on public participation 36

$\begin{array}{lll}2.4 & \text { Conclusion } & \mathbf{4 0}\end{array}$

\section{Methodological Approaches in Analysis 41}

3.1 Introduction 41

3.2 Non-disabled researcher in a disabled world 41

3.2.1 Qualitative research: a matter of people not percentages 42

3.2.2 Inclusive and participatory disability research 44

3.3 The Big Three 46

3.3.1 Phenomenology 46

$\begin{array}{ll}\text { 3.3.2 Grounded theory } & 47\end{array}$

3.3.3 Participatory action research 49

3.4 DIDEC analysis: A combination approach $\quad 50$

$\begin{array}{ll}3.4 .1 & \text { Data spreadsheet } \\ 3.4 .2 & 50\end{array}$

3.4.2 Individual transcript memos 51

3.4.3 Diagramming 55

3.4.4 Elicitation of key themes and central premise 56

3.4.5 Comparative analysis 56

$\begin{array}{lll}3.5 & \text { Summary } & 56\end{array}$

3. Pilot Study 58

4.1 Introduction $\quad 58$

4.1.1 The setting of a stage and writing of a script 58

4.2 Context and scene setting: literature made life 60

4.2.1 The move away from professionalism into partnership 60

4.2.2 Studies into recruitment of learning disability participants 62

4.2.3 The choice of a pilot study base and participants 63

4.2.4 Becoming part of the community 65

4.2.5 Summary 66

$\begin{array}{lll}\text { 4.3 } & \text { Our Parks and Gardens } & 68\end{array}$ 
4.3.1 Evolution of the research methodology through participant action and researcher reaction

4.3.2 Research introductions and the idea of park

4.3.3 The first landscape

4.3.4 Camera conduct 74

4.3.5 Drawing and painting 78

4.3.6 Summary 80

\subsection{Exploring art and interview}

4.4.1 A discussion of sculptures and statues

4.4.2 Researcher and participant preparation

4.4.3 Power relations

4.4.4 A brief discussion of ethics surrounding participant anonymity in research

4.4.5 The interview process $\quad 84$

4.4.6 Summary 88

\subsection{The Yorkshire Sculpture Park:}

a coming together of methodological techniques 89

4.5.1 What we will need 89

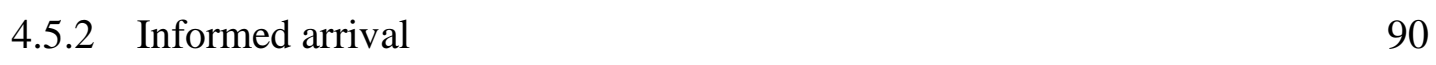

4.5.3 Indoor visual communication $\quad 92$

4.5.4 Going outside 93

4.5.5 Space and shape $\quad 94$

4.5.6 Stimulation in the landscape $\quad 97$

$\begin{array}{lll}\text { 4.5.7 Personal perception } & 100\end{array}$

4.5.8 Emerging experiential themes 102

4.5.9 Language: verbal and visual 106

$\begin{array}{ll}\text { 4.5.10 Staff perception } & 107\end{array}$

$\begin{array}{ll}\text { 4.5.11 Summary } & 113\end{array}$

4.6 Communicating with the community: the importance of $\begin{array}{ll}\text { dissemination and project ownership } & 115\end{array}$

$\begin{array}{lll}\text { 4.6.1 Participant self-advocacy } & 115\end{array}$ 
4.6.2 Exhibitions at the cinema and Day Service centre 116

$\begin{array}{lll}\text { 4.6.3 Presentation at the Peoples' Parliament } & 118\end{array}$

$\begin{array}{ll}\text { 4.6.4 Audience opinion } & 119\end{array}$

$\begin{array}{lll}\text { 4.6.5 Summary } & 123\end{array}$

$\begin{array}{lll}4.7 & \text { Conclusion } & 123\end{array}$

\section{Evolved Methodology 125}

5.1 Introduction: a worthwhile dichotomy 125

5.2 A process of parts: the seven step visual communication toolkit 127

$\begin{array}{lll}\text { 5.2.1 Informed consent } & 127\end{array}$

$\begin{array}{lll}5.2 .2 \text { Site visit } & 128\end{array}$

$\begin{array}{ll}\text { 5.2.3 Drawing workshop } & 130\end{array}$

5.2.4 Individual canvas workshop 131

5.2.5 Photo-elicitation interviews 132

5.2.6 Staff questionnaire 132

5.2.7 Public exhibition 133

5.3 Lessons learnt in preparation for the main study 133

5.3.1 Time allowance 133

5.3.2 Flexible, individualised communication 134

5.3.3 The important role of support agency 135

5.3.4 Participant - researcher relations 135

$\begin{array}{lll}5.4 & \text { Summary } & 136\end{array}$

6. Main Studies 137

$\begin{array}{lll}\text { 6.1 Introduction } & 137\end{array}$

6.1.1 The shock of the relatively new 137

6.1.2 Study centre similarities and differences 138

6.1.3 SC1 and SC2 aims and objectives 141

6.2 A tale of two studies: part 1 142

$\begin{array}{lll}\text { 6.2.1 SC1 Project arrangement } & 142\end{array}$ 
6.2.2 The urban green space experience 143

6.2.2.1 Summary 153

6.2.3 Confronting ghosts amongst the graves 154

6.2.3.1 Summary 154

6.2.4 Staff reflections $\quad 154$

$\begin{array}{lll}\text { 6.2.5 Showroom exhibition } & 168\end{array}$

$\begin{array}{lll}\text { 6.2.6 Participant and staff feedback } & 168\end{array}$

$\begin{array}{lll}\text { 6.2.7 SC1 Conclusion } & 168\end{array}$

6.3 A tale of two studies: part $2 \quad 170$

$\begin{array}{lll}\text { 6.3.1 SC2 Project arrangement } & 170\end{array}$

6.3.2 The remote countryside and town park 172

$\begin{array}{ll}\text { 6.3.2.1 Summary } & 178\end{array}$

$\begin{array}{lll}\text { 6.3.3 The developed coast } & 179\end{array}$

6.3.3.1 Summary 186

$\begin{array}{lll}\text { 6.3.4 The urban riverside } & 186\end{array}$

$\begin{array}{ll}\text { 6.3.4.1 Summary } & 190\end{array}$

$\begin{array}{lll}\text { 6.3.5 The wetlands } & 190\end{array}$

$\begin{array}{ll}\text { 6.3.5.1 Summary } & 195\end{array}$

6.3.6 Canvas conceptualisation 195

$\begin{array}{lll}\text { 6.3.7 The rural coast } & 197\end{array}$

$\begin{array}{ll}\text { 6.3.8 The formal gardens } & 199\end{array}$

6.3.8.1 Summary 204

6.3.9 Dissemination and reflection: Queens Hall exhibition 204

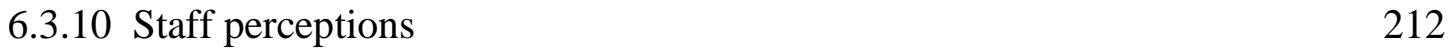

6.3.11 SC2 Conclusion 216

\subsection{Conclusion:}

SC1 and SC2 similarities, differences, successes and limitations $\quad 218$

\section{Toolkit and Findings 223}

$\begin{array}{lll}7.1 & \text { Introduction } & 223\end{array}$

$\begin{array}{lll}7.2 & \text { The Toolkit } & 224\end{array}$ 
7.2.1 TOOL 1: Informed consent 225

7.2.2 TOOL 2: Site visits 226

$\begin{array}{lll}\text { 7.2.3 TOOL 3: Drawing workshop } & 228\end{array}$

7.2.4 TOOL 4: Individual canvas workshop 230

7.2.5 TOOL 5: Photo-elicitation interviews 231

7.2.6 TOOL 6: Staff questionnaire 233

7.2.7 TOOL 7: Public exhibition 234

$\begin{array}{lll}7.2 .8 & \text { Summary } & 237\end{array}$

$\begin{array}{lll}7.3 & \text { Experiential findings } & 237\end{array}$

7.3.1 THEME 1: Daily life experience 237

7.3.2 THEME 2: Communication methods 239

7.3.3 THEME 3: Environmental choice 240

7.3.4 THEME 4: Social experience 243

7.3.5 THEME 5: Activity in the landscape 246

7.3.6 THEME 6: Experiential benefits 249

7.3.7 Diagramming the six key themes 251

7.3.8 CENTRAL PREMISE: Limited environmental experience 258

$\begin{array}{lll}7.4 & \text { Conclusion } & \mathbf{2 6 2}\end{array}$

8. Conclusion $\quad 264$

$\begin{array}{lll}\text { 8.1 Introduction } & \mathbf{2 6 4}\end{array}$

$\begin{array}{lll}\text { 8.2 } & \text { Research response } & 264\end{array}$

8.2.1 Visual communication toolkit 264

$\begin{array}{lll}\text { 8.2.2 DIDEC analysis } & 265\end{array}$

8.2.3 Experiential findings 266

$\begin{array}{ll}\text { 8.3 Benefits and beyond } & \mathbf{2 7 0}\end{array}$

$\begin{array}{lll}8.4 & \text { Operational considerations } & \mathbf{2 7 0}\end{array}$

$\begin{array}{lll}\text { 8.5 } & \text { Broader implications } & 273\end{array}$

8.5.1 Learning disability participation 273

8.5.2 Healthy spaces for life inclusion 275

$\begin{array}{lll}\text { 8.6 } & \text { The hereafter's already here } & 277\end{array}$ 
$\begin{array}{ll}\text { III. References } & 278\end{array}$

$\begin{array}{ll}\text { IV. Appendices } & \mathbf{2 8 7}\end{array}$ 
I.

\section{Acknowledgements}

\section{Dedicated to my parents John and Jenny, my sister Hannah and Ben. \\ Always the four most important people in my life.}

This is a thesis about, and driven by, people. During the course of this research I have been honoured to have worked with some truly inspiring individuals. In particular I would like to thank all the participants, staff and volunteers at Sheffield Mencap Day Services and Dilston College of Further Education. I am humbled to have been so accepted and supported by you all. At Sheffield Mencap Day Services I feel I have become part of the community and hope to remain included for the foreseeable future. The friendships I have made and memories I hold are as valuable as any I have experienced.

I would like to thank Kevin Thwaites and Helen Woolley for my academic supervision. Kevin, you have always been so knowledgeable and interested. Without you this thesis would be a pale imitation of what has actually been achieved. Helen, I would like to thank you for your support and the opportunities you have provided for me.

To those with whom I have journeyed through this $\mathrm{PhD}$ experience; my research room, Ian Simkins and Rebecca Mallett. All of you have been my reflection and my reassurance. Ian, your words have always been the truth and I look forward to our future work and discussions. Rebecca, I am so pleased to have met you. Everything we have shared (in KL) and beyond has been so important in how I think about think about my work.

I also wish to thank my friends. Many names, but to reel off a few: Kez, Mand, Mad, Japs, Bruce, Claire, Ol, Paul, Charles, Jools, Dan, Heather and Cole. I have been unreliable, absent and exhausted. I promise you will have me back on form - with only the necessary provision of anchovies to get me kick started.

This PhD has taught me so many things particularly what I never knew I could do (to be confident and assertive). I hope this work is the strong foundation that I believe it can be, for my future research and career.

Finally, I am grateful to the Economic and Social Research Council (ESRC) for funding this research through an ESRC studentship (No. PTA-030-2004-00895). 
II.

\section{Hidden Voices: the participation of people with learning disabilities in the experience of public open space.} Abstract

The self-advocacy of people with learning disabilities is an issue of high current importance. In the UK 210,000 people have severe and profound learning disabilities, whilst twenty-five in every thousand of the population in England has a mild to moderate learning disability (Department of Health, 2001). At the most restricted end of the communication spectrum, people with learning disabilities are often forgotten members of their communities, whose label learning disabled wrongly causes confusion and fear.

The Disability Discrimination Act (DDA) 1995 ensured reasonable adjustments must be made to environments and buildings so they are accessible to all. However, DDA legislation remains a predominately physical access issue with great attention focused on the built environment and little attention given to the experience of place or external environments. Researchers argue that it is attitudes and interactions in the person-environment relationship that have allowed our disablist society to label and segregate members of its community as disabled.

The research comprised a longitudinal qualitative study working with learning disabled participants at two sites in Yorkshire and the North East of England. In this thesis the researcher examines the story of these studies and the significant results they generated. Produced are a novel visual communication toolkit, a set of six experiential themes (daily life experience, communication methods, environmental choice, social experience, activity in the landscape and experiential benefits) and a central research premise (limited environmental experience). Through these results, we as researchers and landscape professionals are able to unlock the experience of public open spaces by people with learning disabilities. When used in context, the visual communication toolkit provides a new methodology to reduce social exclusion and aid greater social participation.

\section{Key words:}

Learning disability, visual communication, public open space and participation. 


\section{Chapter 1}

\section{Introduction}

"I think that parks are for the other children now."

(Warren ${ }^{1}$, research participant, 2006)

The story of this research is one borne of personal frustration and observed exclusion. The author is a non-disabled researcher who through academic and professional training as a landscape architect became increasingly aware of the frequent absence of the disabled viewpoint in the planning and design of public open space environments. Furthermore, the absence of this voice is not the absence of a singular opinion, of a homogenous group, but the omission of a multiplicity of individual standpoints collectively defined by the label disabled people. Beneath the umbrella term of disability, further inequality and exclusion exists.

Society's increased understanding, inclusion and acceptance of disabled people as equal, legitimate members of the community does not always extend to the diversity of disabled groups, leaving several noticeably more vulnerable, isolated and excluded. For many people living and working outside the field of disability, without personal connection to the disabled experience, the public face of disability is sometimes reduced to a visual stereotype of the physically impaired wheelchair user. Indeed, the symbolic representation for disabled people, employed by both organisations in the public and private sphere, is more often than not just that; an individual in a wheelchair. Other impairments are more hidden. People with learning disabilities are key citizens in this population of hidden disabled people who remain disempowered. The recently published UK government Public Service Agreement (PSA) 16 (2007) identified adults with moderate to severe learning disabilities as one of the UK's four "at-risk client groups" (HMG, 2007, p.3) from social exclusion. Whilst policy such as the White Paper Valuing People (Department of Health, 2001) and related practice such as person-centred planning, an individualised approach that intends "to reflect the unique circumstances of

\footnotetext{
${ }^{1}$ Warren is pseudonym.
} 
the individual person with intellectual disabilities in both assessing and organizing what should be done" (Mansell \& Beadle-Brown, 2004), have begun to acknowledge and address the exclusion people with learning disabilities face in everyday life, across many academic disciplines, research has been slow to follow let alone suggest solutions.

People with learning disabilities are greatly underrepresented in research arenas such as social and cultural geography (Park et al., 1998; Butler and Parr, 1999; Gleeson, 1999; Hall, 1999; Hall, 2004) whilst landscape academics have chosen to exclude them altogether: "mentally disabled were not interviewed, as it was considered too difficult to interview them" (Seeland and Nicolè, 2006, page 30). Therefore, in seeking to address social exclusion from a landscape research perspective, the author turned attention towards parks and public open spaces, which are deemed to provide opportunities for "social inclusion, community development and citizenship" (Urban Green Spaces Taskforce, 2002, p.12). The Urban Green Spaces Taskforce envisaged public participation as playing a key role to achieving these goals:

"Giving people the chance to participate in the design, management and care of their spaces can foster local pride. Well-managed green spaces can create welcoming environments for vulnerable groups (eg children and wheelchair users), helping them socialise and take part in community life ... In terms of equality for all sectors of society, free-access green spaces offer a uniquely affordable alternative to commercial leisure activities"

(Urban Green Spaces Taskforce, 2002, p.12).

Although, the Urban Green Spaces Taskforce's vulnerable groups are rather limited, their intention of the role parks and green spaces have to play in encouraging social inclusion is an interesting one. People with learning disabilities may be vulnerable and live today with a legacy of institutionalisation, social exclusion and community neglect, yet participation in their local environments is one means by which they become visible and included. However, with other landscape researchers considering the views of people with learning disabilities too difficult to extract, little information was available to suggest how this process of participation to elicit opinions on design, management and care of public spaces might be achieved. Identified was the need for a research commitment to extend participation through inclusive approaches to communication 
(Cambridge \& Forrester-Jones, 2003, p.20). Therefore, the following research question was evolved, with an associated aim to drive the direction of study:

Research question: How may we better understand the public open space experience of people with learning disabilities?

Research aim (primary): To produce a toolkit of effective communication methods with people with learning disabilities.

Successful completion of this primary aim, the production of an effective communication toolkit, would facilitate three associated secondary aims, which were to:

\section{Research aims (secondary):}

- Help to create an open process of communication between the developers of public open space and people with learning disabilities.

- Suggest how public open spaces might be improved for people with learning disabilities.

- Reveal social factors that influence people with learning disabilities experience of public open space.

In outlining the research question and aims, it became clear that this would be a project led by the lived experiences and personal knowledge of the people with learning disabilities who volunteered to participate. As the researcher notes in the second sentence of this introduction, she is a non-disabled person. Therefore, although having personal experience of learning disability through over a decade of family friendships and in a professional role as a support worker and tutor, an awareness existed that this did not, and could not, represent the true experience of a person growing up and living with learning disability. The researcher's experience is rather like a fun fair mirror, showing some truths but distorting much of reality. In this respect the researcher concurs with Gill as cited by Shakespeare: "Non-disabled people, no matter how much they love us, do not 
know the inside experience of being disabled. Moreover they are in the position to escape the stigma" (Gill, 1994, in Shakespeare, 2006, p.185).

In light of this, the researcher was committed to undertaking an ethnographic research approach. Ethnography is defined as taking "the position that human behaviour and the ways in which people construct and make meaning of their worlds and their lives are highly variable and locally specific" (LeCompte \& Schensul, 1999, p.1). This approach is employed in order to adequately respond to the complexities of researching and writing about the experiences of participants with learning disabilities; whilst being unable to experience them from a firsthand, individual perspective. With this in mind, the researcher finds a shared ethical and methodological stance in the words of LeCompte \& Schensul who say, "ethnography assumes that we must first discover what people actually do and the reasons they give for doing it before we can assign to their actions interpretations drawn from our own personal experiences or from our professional or academic disciplines" (LeCompte \& Schensul, 1999, p.1 - 2). This ethnographic approach then evolved the following research objectives, decided upon in order to abide by a truthful representation of the experiences of the learning disabled participants:

\section{Research objectives:}

- To ethically identify, approach and recruit learning disabled participants.

- To treat participants with due respect and consideration.

- To explore a variety of visual and verbal communication methods with participants.

- To adhere to the principles of participatory learning disability research.

- To explore personal experience of a range of local public open spaces with participants.

The research question, aims and objectives were successfully answered through commitment to ethnographic study in association with a longitudinal research approach. Longitudinal research has predominantly focused upon, "repeat interview study, although other established traditions of longitudinal qualitative study include long-term ethnography and follow-ups or restudies of classic research projects" (Thompson, 2007, 
p.571, citing Holland et al., 2004). This "long view" approach was vital as it afforded, "the possibility of developing more complex and thus realistic understanding of how and why individuals and communities live as they do" (Thompson, 2007, p.572). For the researcher being able to competently interpret and analyse the experiences of the participants, meant being subsumed into their weekly routine over an extended period of time.

The research took place at two study centres (SC1 (Study Centre 1, where the pilot study also ran) and SC2 (Study Centre 2)). At SC1, involvement in the practical study lasted three years. The researcher began work with SC1 participants in late 2003, and the study was completed in the summer of 2006. At SC2 the length of study was focused over six months. However, the story of the SC1 research collaboration did not end with the conclusion of this research project. The research relationship developed with SC1 participants was so beneficial, constructive and revealing for all involved, that it continued beyond the remit of this study in the form of two subsequent research projects (Chapter 8, Conclusion).

The thesis is broken down into eight chapters. These follow the developing story of working ethnographically over a number of years with participants from the local learning disability community. In Chapter 2, the literature review discusses the broad range of academic disciplines between which this study sits and how individual strands of research within these have shaped the approach taken. Chapter 3, Methodological Approaches, bridges the gap between knowledge garnered from the literature and the practical approach taken to fieldwork and analysis. At this juncture, the three theoretical cornerstones (grounded theory, phenomenology and participatory action research) of the research's underpinning are explored. Elements from each are taken forward to drive direction of study. Chapter 4 describes what happened when the researcher set up the pilot study in conjunction with a local learning disability Day Service Centre. This chapter charts the researcher's progress towards construction of an operational communication toolkit and the practical experience of working in partnership with learning disabled participants. In Chapter 5, Evolved Methodology, the researcher reviews the unique toolkit developed and the methodologies applied. Here, the reader is encouraged to understand the individual function of each participation tool within the 
toolkit. The Main Studies of Chapter 6, consider how employment of the evolving toolkit at two comparative study sites (a Day Service Centre and Further Education College), with two groups of participants, reveals a wealth of information regarding the public open space experience of people with learning disabilities. This chapter also illustrates the adaptability of the toolkit to respond to the needs of individual projects and participants. Chapter 7, Toolkit and Findings, reports how the primary and secondary aims of the study have been met. Firstly, the results of this chapter detail the operational communication toolkit produced (the primary result, see Image 1.1 over the page). Secondly, through qualitative analysis of the participant information generated, six key experiential themes and the central research premise are exposed (secondary results). These six key themes are: daily life experience, communication methods, environmental choice, social experience, activity in the landscape, experiential benefits with a central premise of limited environmental experience. Finally, in Chapter 8, Conclusion, the researcher reflects upon the successes and limitations of the study. Suggested are positive implications for current landscape participation practice if the communication toolkit is employed. In addition, the researcher foresees how the inherent flexibility of the toolkit lends itself to operation outside the sphere of landscape architecture, to employment with other underrepresented groups in order to facilitate meaningful participation and inclusion. 
1.1

Visual communication toolkit: components and purpose

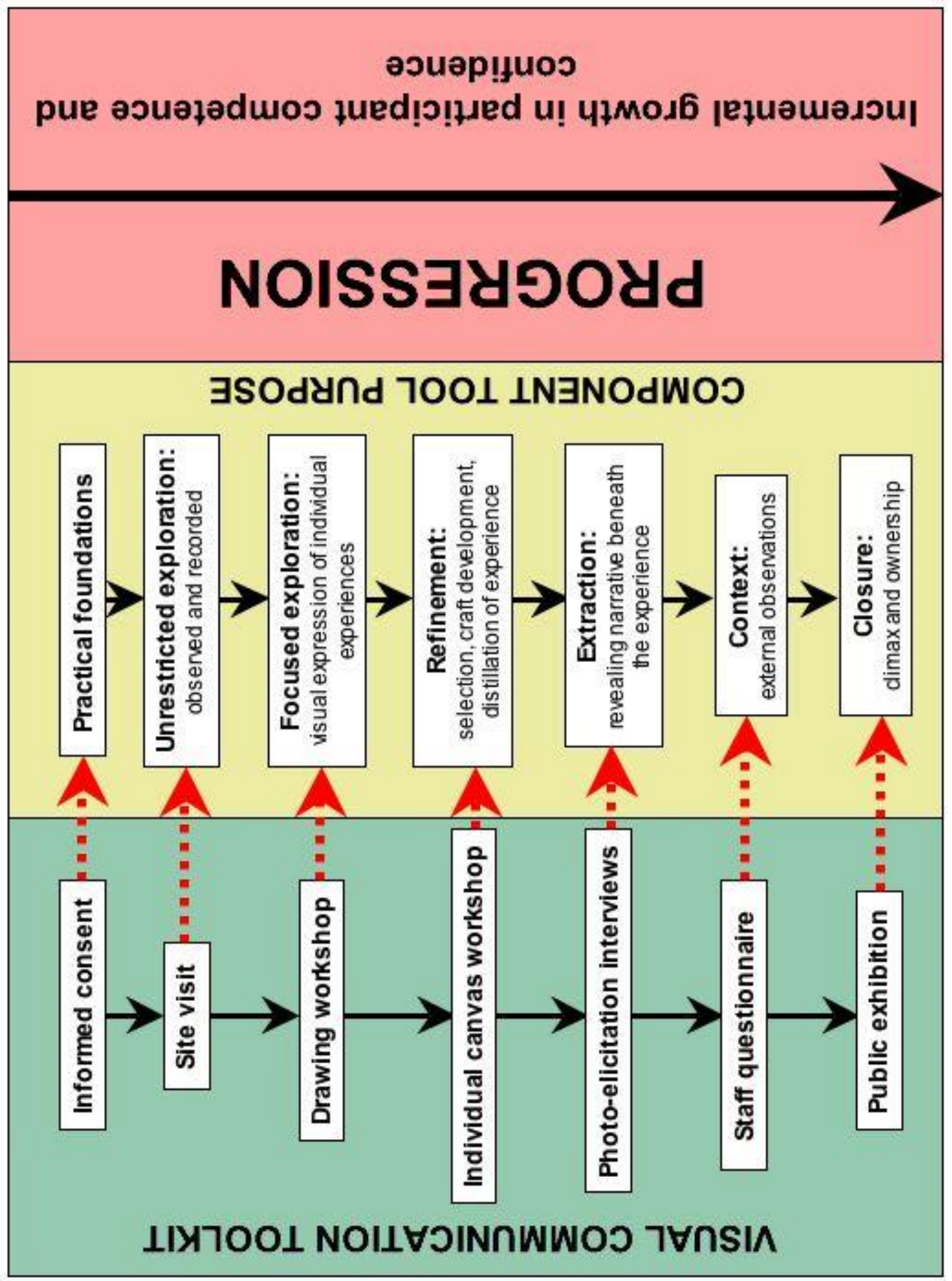




\section{Chapter 2}

\section{Literature Review}

\subsection{Disability and learning disability: the people}

\subsubsection{Definitions and disagreements}

The study of disability and its definition is an evolving and contentious field of research and debate. The gratifying idea of one universal, defining truth that would unite all disabled people under one theoretical umbrella may yet prove ultimately too simplistic to adequately encompass "the extensive variety in the nature of the problem" (Slater et al., 1974; Altman, 2001). Outside the alternate views of individuals lie layers of confusing and contrasting classification by academics, policy makers and those in practice, and beyond this sit the international debate. The importance of being identified as disabled is dependent upon the individual's viewpoint and the interpretation of positive or negative connotations that that definition brings.

In the context of these circumstances, this section (2.1) has four key objectives. Firstly, to chart the historical twists and turns of medical model, disability activism, and the subsequent rise of disability studies as an academic field (with focus on the United Kingdom context). Secondly, with reference to the experiences of the participants' in this research as disabled people, to recognise appropriate definitions (with noted reservations) for the terms disability and more precisely learning disability. Thirdly, to explore the barriers and opportunities for social inclusion of this group of disabled people through understanding the roles external environments (such as parks and other public spaces) and communication have played as exclusionary devices. Finally to establish how this research aims to contribute to the advocacy movement of people with learning disabilities in the United Kingdom today.

\subsubsection{Looking with a clinical eye at the universal stage}

Until relatively recently the medical and psychological spheres had a monopoly over the field of disability. At face value this can be explained by the fact that disability has always been with us, a part of our humanity, and running parallel to this the long history 
of medicine with its definitions of disease and disability. Diagnosis legitimises individuals to treatment and rehabilitation through the identification of what a doctor might see as their patient's 'problem'. Barbara Altman in her chapter 'Disability Definitions, Models, Classification, Schemes, and Applications' in the 2001 Handbook of Disability Studies describes how in the medical world "clinical definitions are associated with the pathology that medical practitioners identify within the individual and the prognosis that the practitioner expects relative to the type of condition and characteristics of the patient" (Altman, 2001, p.100).

It would be impossible to argue that accurate identification of an individual's medical impairment issues are not necessary in order to help alleviate pain and aid a more healthy and active life. However, the question arises that, if disability is regarded from a purely medical stance (ICIDH-1, WHO, 1980) are not gross assumptions being made about a world (outside the individual body) of social, financial and environmental equality? On examination of the ICIDH-1 principles it is easy to understand why it incited such a backlash amongst disability activists. In this model impairment, typified by a loss or abnormality of a body's structure or function, combined with disability (a lack of normal ability) to create handicap in an individual. Nowhere was there mention of the impact social and environment factors had on disabling individuals experience and ability to live equally as part of the community, and as UK disability academic Michael Oliver later stated "a further criticism of both the WHO and OPCS schemes is that, in attempting to make concrete that which is not and never can be, they present disability as a static state and violate its situational and experiential components" (Oliver, 1990, p.5).

A review of the WHO model did not begin until 1992, and it would be a further three years of deliberation and consultation until the presentation of the Disability Creation Process (DCP) at the Quebec City conference in 1995 (Fougeyrollas, P. and Line, B., 2001). Here, through presentations by the Environmental Factors Taskforce, was acknowledgement of the part environmental factors had to play in the disablement process (Whiteneck and Fougerollas, 1996; Whiteneck et al., 1997). Importantly there are a number of key environmental factors ('Major Environmental Factor Categories'), identified by Fougeyrollas and his fellow researchers, which have the power to positively (facilitate) or negatively (effect) an individual's (disabled or non-disabled) environmental 
quality. These are directly applicable to this study of the participation of people with learning disabilities in the experience of public open space. For example under Fougeyrollas' categorisation, within social factors (and the sub-grouping of political economic factors) community organisations are identified. Within this research, this would relate to the power of charities such as Mencap to raise the profile and secure funds to ensure the advocacy of people with learning disabilities. Therefore, when interacting with an individual with learning disabilities personal factors, this would result in the ability for greater participation in a life habit, where life habit is defined as "a daily activity or social role valued by the person or his or her sociocultural context according to his or her characteristics (age, gender, sociocultural identity, and others)" (Fougeyrollas et al., 1996). Within the other Major Environmental Factor Categories, applicable to the aims of this research are the review and modification of existing sociocultural factors (social networks and social rules), and within the category of physical factors (sub-group nature) physical geography, and (sub-group development) architecture (taken in the broader sense, and therefore referring also to landscape architecture) and national and regional development.

On balance it can be seen that the Quebec presentations did have a positive impact towards the WHO's acceptance of the role environmental factors (as previous described) have to play in disability. In 1999 the WHO released the Beta-2 draft of the ICIDH-2, which announced that within the model "environmental factors have an impact on all three dimensions and are organised from the individual's immediate environment to the general environment" (WHO, 1999).

\subsubsection{Activism in the UK}

In the United Kingdom, a growing unrest resulted in an alternate 'social oppression' approach to disability. From the 1851 census of the blind and deaf, through the 1944 Disabled Persons (Employment) Act and subsequent National Assistance Act of 1948, disability legislation and conscientiousness had retained a continual low profile in matters of national awareness and importance. Only in the 1960's was a gulf in knowledge as to the numbers and needs of people with disabilities in the UK recognised (Oliver 1983, p.38). Legislation came in the form of The Chronically Sick and Disabled Persons Act 
(1970) and through the commissioned 'Surveys of disability in Great Britain' by the Office of Population Censuses and Surveys (Harris, 1971). The dominant medically driven definitions that espoused a view of disability as 'personal tragedy or disaster' (Oliver 1983, p.33) were finally challenged by a group of disabled people responding to an article in the Guardian in 1972. This group would become known as UPIAS, The Union of Physically Impaired Against Segregation. For disabled people and disability activists angered by their exclusion from what was supposed representation of their own experience, the monumental turning point to future empowerment came on the $22^{\text {nd }}$ November 1975 with a meeting between UPIAS and The Disability Alliance. The results of the discussion between these two organisations bore fruit in the form of the 'Fundamental Principles of Disability' published by UPIAS in 1976. Vic Finkelstein, an original UPIAS member, reflecting on the UPIAS standpoint later wrote "the agreed UPIAS interpretation was that, although it may be a personal tragedy to have an impairment, at the social level it is the construction of the social and physical environment that disables us (prevents us from functioning)" (Finkelstein, 2004, p.15). The UPIAS's work though instrumental still concentrated on disability from a predominately physically impaired viewpoint. In opening up the disability rights debate to the entire community, the voices of less empowered groups, such as people with learning disabilities and those with mental health issues, still remained marginalised.

\subsubsection{The social model and its legislative influence}

Following UPIAS's 'Fundamental Principles' the work of Michael Oliver culminated in 1983 in what would become known as the social model of disability. The academic movement behind the social model has in current years gathered much force and momentum (Bury, 1996; Oliver, 1996). Many people with disabilities and their supporters have used this disability model as an empowering a way to fight social oppression. In petitioning for his alternative social model that he hoped would end the detrimental dominance of the 'personal tragedy' attitude and instead cement a collective experience of disablement, Oliver wrote "as far as disability is concerned, if it is seen as a tragedy, then disabled people will be treated as if they are victims of some tragic happening or circumstance. This treatment will occur not just in everyday interactions but 
will also be translated into social policies which will attempt to compensate these victims for the tragedies that have befallen them" (Oliver, 1990, p.2).

As Oliver acknowledges, the social model has in recent years undergone academic criticism primarily through interpretation that it, "ignores or is unable to deal adequately with the realities of impairment" (Oliver, 2004, p.8). He has defended this as misinterpretation, that the social model was never aimed at the personal level, always at the collective disability experience. However, the methodological approach to the researcher's research echoes the future Tom Shakespeare proposed in his closing speech at the 2006 Disability Studies Association Conference. Disability should be acknowledged as an individual as well as a collective experience, an interaction between intrinsic factors (such as type of impairment, severity of impairment, individual motivation, attitude towards impairment, goals, self-esteem, confidence etc.) and extrinsic factors (physical environments, social arrangements, structures, expectations and roles, cultural meanings and representation). The individual experiences of the learning disabled participants in this research are as rich in value, as their collective identity as a disability group is in methodological implications. One is not separate from the other and neither should it be.

Today, it seems that the social model has found a legislative voice. Provisions made by the Disability Discrimination Act (DDA) 1995, enforced in October 2004 have ensured reasonable adjustments must be made to environments and buildings so they are accessible to all. The DDA legislation has remained primarily a physical access issue, with greater attention focused on the built environment, and little interest given to the experience of place or external environments. This sadly reflects the stereotype of disabled people primarily as wheelchair users (who have been the most vocal regarding their rights). Little interest or consideration has been given to people with sensory impairments, learning disabilities or mental health problems. Architects (and landscape architects) implementing the legislation of the DDA continue this legacy with research showing that "the types of design features which tend to be incorporated into buildings include accessible toilets, ramps and level entry or access points. In contrast, induction loops, tactile paving and colour contrasts are seen as secondary considerations. Little or nothing which addresses the needs of people with learning difficulties is incorporated into 
much contemporary building and design processes" (Imrie and Hall, 2001, p.97). This research focuses upon one of these less vocal branches of the disability community, the hidden voices of people with learning disabilities.

\subsubsection{Further definition difficulties}

As with the term disability, a complex debate surrounds the correct language to be used in regard to the disabled participants in this research (whether it be people with learning disabilities or learning difficulties). "Supporters of the social model currently favour the term learning difficulty as they believe learning disability is UK restrictive, a label unattractive to those who wear it and that disabling learning has little meaning outside describing discriminatory educational practices" (Race, 2002, p.4). However in this research, the term learning disability was chosen, over learning difficulties, for a number of reasons. Firstly to avoid confusion over definition focus or breadth, a point highlighted in the report 'Good Signs, Improving signs for people with a learning disability' (DRC, 2003). The DRC voiced the following:

“some organisations reject the term 'learning disability' and instead use 'learning difficulty'. We felt that the term 'learning difficulty' was not appropriate for this report in that it was too 'broad', including as it does people with dyslexia, for example". 'Learning difficulty' is a term frequently employed by educational professionals. 'People with a learning disability is a term used by Mencap and the Government and is the choice of many people previously labelled as having a 'mental handicap'."

(Disability Rights Commission, 2003, B, 1.2.2)

The research study was completed in England through collaboration with a Mencap Day Service Centre and Further Education College, both of who use the term learning disability. The research was based in a purely English context, and results using the evolved methodology might therefore prove very different if applied to an American or Scandinavian study, for example. Secondly, in making the research accessible to the wider community through various means of dissemination, it has become apparent the term learning disability has greater public understanding than learning difficulty. Finally, there is concern that should the term learning difficulty become dominant, it would lose 
vital connection and power to the disability movement in the minds of many, purely through the change in phrase. As a consequence, people with learning disabilities might suffer further marginalisation, never to be truly subsumed, understood or accepted by a society that has yet to value these individuals within their own communities.

\subsubsection{Historic advances}

People with learning disabilities have long suffered society's general misconceptions and fear. Their otherness was a condition that in classical Greece could legitimise infanticide, and slavery in ancient Rome (Stainton, 1994). In more recent history their plight took an even darker turn when at the turn of the $20^{\text {th }}$ century the eugenics movement was born. In Britain a Royal Commission was assembled to make recommendations as to, "the care of the feebleminded then extended to include idiots and lunatics" (Race, 2002, p.28). A.F Tredgold a member of the Commission, led the view of the eugenics movement saying, "as soon as a nation reaches that stage of civilisation in which medical knowledge and humanitarian sentiment operate to prolong the existence of the unfit, then it becomes imperative upon that nation to devise such social laws as will ensure that those unfit do not propagate their kind"' (Tredgold, 1909, p.8). The solution presented by Tregold's Commission, and legislated by the 1913 Mental Deficiency Act for 'mental defectives' (Tredgold, 1909) was institutionalisation. Immorality could supposedly be linked to low intelligence (Goddard, 1912) and therefore people with learning disabilities could be institutionalised minimising the danger these high-grade defectives posed to society. David Race argues that in retrospect we can see a subconscious understanding that learning disability has always been a social issue, through the method of classification of defective categories outlined by the Act which relied on social issues rather than medical definitions. He says, "all definitions are written in terms which describe the effect of the so-called defect rather than any empirically measurable definition of what the defect actually is, and all contain descriptive statements which are bound up with the transitory norms and understandings of a particular society" (Race, 2002, p.30).

The exclusion and institutionalisation of people with learning disabilities would never allow a true range of physical, and social, environmental factors (now taken into account in the ICIDH-2 (Beta-2 draft)) to be experienced. Therefore in retrospect there 
could be no true gauge, had it been sought, of a person's competence in performing a life habit under these conditions. The 1960's and 1970's saw a move away from this way of thinking, spearheaded by the arrival of Bengt Nirje's Normalisation Principle. This stated that "you act right when making available to all persons with intellectual or other impairments or disabilities pattern of life and conditions of every day living which are as close as possible to or indeed the same as the regular circumstances and ways of their communities" (Nirje 1992, p.16). In Britain in 1971, the White Paper 'Better Services for the Mentally Handicapped' introduced the recommendation of measures such as a substantial drop in institutional provision, and the use of the term mental handicap in preference to other terms such as subnormality (Race, 2002, p.38). Across Europe, America and Australia a broad sweep of de-institutionalisation began, and the subsequent championing of the Community Living Movement, with the aim that people with learning disabilities could easily assimilate into the everyday life of society.

\subsubsection{Valuing People}

In the UK approximately 210,000 people have severe and profound learning disabilities, whilst 25 in every 1000 of the population in England has a mild to moderate learning disability (Department of Health, 2001). At the most restricted end of the communication spectrum, people with learning disabilities may often be seen as silent, hidden members of their communities. The White Paper Valuing People (Department of Health, 2001) outlined evidence of individuals who display a learning disability as the presence of:

"A significantly reduced ability to understand new or complex information, to learn new skills (impaired intelligence), with; a reduced ability to cope independently (impaired social functioning); which started before adulthood, with a lasting affect on development."

(Department of Health, 2001, p.14).

People may live with one or multiple learning disabilities of varying profundity. Numbers of the population who live with learning disabilities are predicted to rise annually at one percent over the next fifteen years. With increased life expectancy, growing numbers of children with complex or multiple disabilities surviving into 
adulthood, the sharp rise in children detected with autism and a greater prevalence among some minority ethnic populations, provision for people with learning disabilities is set to become an issue of increasing importance.

Valuing People set out with four key principles: legal and civil rights, independence, choice and inclusion (Department of Health, 2001, p.23-24). It recognised two important shortcomings in the current involvement of people with learning disabilities in decision-making. Firstly that people with learning disabilities and their families were not central to personal planning processes, which Valuing People responded to with the introduction of Direct Payments and A Person-Centred Approach to Planning (Department of Health, 2001, p.48-49). Secondly, that in all discussions not enough effort was being made to communicate in accessible ways. Although Valuing People identified these problems, when it came to matters of consultation for leisure provision and involvement in the decision making process, little advice was forthcoming as to means of self-advocacy.

\subsubsection{Social inclusion and advocacy}

Advocacy and more specifically self-advocacy, reflects the ability (and on society's part) the opportunity for people to be able to communicate their needs and choices thereby influencing decisions that affect them. Therefore when advocacy works, it is a very powerful tool in the fight for the social inclusion of people with learning disabilities. Valuing People has been instrumental in moving the learning disability agenda up the political ladder with positive outlook towards future developments. However some of this has been to the partial exclusion of people with more profound learning disabilities, with Valuing People taking the more public (and Government financial) friendly approach, through, "a kind of romanticism about learning disabled people, so that significant impairments and the personal histories that produce human damage, are not so much denied as glossed over, making the real difficulties in providing supports to enable inclusion, autonomy, good health, meaningful activity and acceptance appear insignificant (Aylott, 2001), and thereby not requiring substantial additional investment" (Burton \& Kagan, 2006, p.305). "True social inclusion of all people with learning disabilities requires a social transformation” (Burton\& Kagan, 2006, p.306). This is not a 
straightforward solution, and for it to be successful long term we need to understand the legacy that survives today:

"deinstitutionalization, then, is not just something that happened to people with intellectual disabilities and their families. It also happened to decision-makers and staff in services and researchers. They have to shift their attention to new problems and issues in the community ... But they had also to recognize that institutions were the expression of beliefs in society and that their demise may leave those beliefs and the practices they under pin still to be tackled in the community. This is surely the greatest challenge for all societies: how to build and sustain social solidarity and mutual commitment among people with different needs, talents and aspirations, so that everyone may flourish and prosper."

(Parmenter, 2001, p.279, citing Mansell \& Ericsson, 1996, p.252 - 53).

To enable advocacy and social inclusion of people with learning disabilities to occur, the community, researchers and supportive organisations need more inclusive methods of communication. Section 2.2 explores an avenue of alternative methods of communication, both visual and verbal. The communication toolkit developed using these methods is then employed in practical studies to unlock the experience of external environments for people with learning disabilities, a subject little understood or considered until now.

\subsection{Communication: the means}

"Since the ability to communicate using a commonly understood language is fundamental to the way in which all human beings function in society, it follows that those who are unable to do it are automatically excluded from that society. There is no simple, universal solution and any attempts to remedy the situation involve society broadening its view of acceptable ways of communicating and being prepared to learn those ways too."

(Jones, 2000, p.20) 


\subsubsection{Communication equals power?}

The ability to communicate empowers individuals, enabling them to share information, needs, experiences, thoughts and feelings with others (Cockerill, 2002, p.73). For the majority of us, the general reliance in society upon verbal and written communication goes unnoticed and unconsidered. For the minority (including people with learning disabilities) physiological, psychological and social barriers may make verbal and written communication extremely frustrating, limited or impossible, thus excluding them from participation in decision-making society. Being language proficient is crucial in the citizenship of people or, "the extent to which they may have a liveable place in society" (Valentine and Skelton, 2007, p.124 citing van Gunsteren, 1998). Mirrored in the field of academic study, researchers cite the two most critical problems being, "extensive and valid elicitation of data from learning disabled participants, and meaningful incorporation of views of those who cannot easily communicate verbally" (Ramcharan and Grant, 2001, p.356).

Nevertheless, communication as a means to an emancipatory end has come under recent criticism, particularly regarding the debate surrounding communicative rationality. Although not yet developed in the academic arena of landscape architecture, for over a decade theorists in the field of planning practice have been involved in the rise and critique of the importance of communication, through which the advance of communicative rationality has led to the emergence of communicative and collaborative planning. This a key debate with which the researcher must engage, in order to ask the question: is it possible that people with learning disabilities, on being encouraged to enter into the planning or landscape practice debate,- can indeed achieve empowerment and move towards equality? Or on reflection is this in fact a naïve unreality?

Communicative rationality first appeared in the early 1980's through the work of Jürgen Habermas of Frankfurt's critical theory school. As a sociologist and philospher Habermas conceived the hypothesis of 'ideal speech' where "communication will no longer be distorted by the effects of power, self-interest or ignorance" (Tewdwr-Jones and Allmendinger, 1998, p. 1975 citing Norris, 1985, p. 149), and therefore might form "the basis for consensus and action" (Tewdwr-Jones and Allmendinger, 1998, p. 1976). The theoretical foundations for communicative rationality found in Habermas's work are 
reinforced by Michel Foucault's power analytics (Fischler, 1995; Flyvberg, 1998a; 1998b; Richardson, 1996; Healey; 1999) and from the American angle by neopragmatists Tom Harper and Stan Stein (Harper and Stein, 1995). Driven forward into planning philosophy by the idea of communicative action or:

" the interaction of at least two subjects capable of speech and action who establish interpersonal relations. [where] The individuals seek to reach an understanding about a situation and their plans of action in order to coordinate their plans by way of agreement or consensus."

(Tewdwr-Jones and Allmendinger, 1998, p. 1976)

A number of new (yet closely related and in some instances interchangeable) approaches to planning have emerged. These include communicative planning (Forester, 1989), argumentative planning (Forester, 1993), planning through debate (Healey, 1992), inclusionary discourse (Healey, 1994) and collaborative planning (Healey, 1997). Within this new planning paradigm, Patsy Healey, one of Britain's most vocal academic supporter's of the communicative turn, describes how this approach moves away from the traditional role of the planning professional which was to "maximise welfare and solve problems ... through designing strategies and policy instruments to achieve desired outcomes" (Healey, 1999, p.1129). Instead Healey sees planners as adopting "an interactive, communicative activity and [planners] deeply embedded in the fabric of community, politics and public decision-making” (Healey, 1999, p.1129 citing Innes, 1995, p.183).

Towards the end of the twentieth century, in the late 1990's, with communicative planning gaining a more visible profile, an academic debate erupted as to; it's practical effectiveness, its value to the planning profession and its theoretical rigor. Regarding concern over its practical operation, a basic criticism as voiced by Tewdwr-Jones and Allmendinger was that:

"Communicative rationality also assumes that all sections of the community can be included within the collaborative planning discourse, although little has been said on how this could be achieved, or even how all these stakeholders can be identified, and by whom." 
(Tewdwr-Jones and Allmendinger, 1998, p. 1980)

For the learning disability community this is a key issue. Currently some of the most excluded members of society as a result of communicative isolation, often accompanied by financial and social deprivation, it might be seen that people with learning disabilities would be at an extreme disadvantage when trying to enter into the arena of public debate. With little previous experience in such discourse and limited confidence or capacity for written and spoken language, people with complex communication needs could be seen as debate bystanders rather than active participants. Aligned with this argument, TewdwrJones and Allmendinger cite the existence of visible stakeholder power imbalances as another reason why communicative planning and the goal of consensus building is unlikely to be achieved. Where unequal power relations are evident, Tewdwr-Jones and Allmendinger believe that the outcome will always be in favour of the stronger, more influential party. Similarly in this respect, it would seem that should people with learning disabilities wish to be to able to affect real change, their current lack of social, political and economic standing in comparison to other more powerful stakeholders will only lead to individual frustration and disappointment.

However, in response to these criticisms, Healey (1999) outlined the following defence. Firstly, that through collaborative approaches "individuals might learn new identities and construct their interests differently through social learning encounters" (Healey, 1999, p.1132), by which Healey suggests that our identities are not static but are ever evolving dependent on the experiences we have. Through adoption of this principle it is possible to conceive that both people with learning disabilities, and other stakeholders they encounter, will be changed through participation in a shared discourse and gain a greater understanding of each others position. Without this opportunity for exchange and re-conceptualisation of one's position, it is likely that individual positions and understanding become entrenched, with little regard for alternative viewpoints. Secondly, Healey challenges the issue of power relations, responding to Tewdwr-Jones and Allmendinger's argument by saying that it does not "capture the dimensions of the power struggle" (Healey, 1999, p.1132). For Healey, the conflicts that are involved in discourse on the way to consensus can be liberating as well as oppressive and "offers the 
potential to challenge and change not merely the overt and formal holders of powerful roles, but the assumptions and values embedded in everyday practices" (Healey, 1999, p.1131-2). Healey identifies that the key issue to address is no longer whether collaborative or communicative planning is an effective approach, but rather what has forced the planning system into becoming an "introverted regulatory function of the state" (Healey, 1999, p.1134)? In addition, we should focus upon how we can modify the culture of planners (and other professionals involved in shaping our environments) who seem (for the majority) uninterested in participation practices which might be perceived as challenging or damaging to their professionalism (Tewdwr-Jones and Allmendinger, 1998; Allmendinger, 1996; Kaufman and Escuin, 1996; Tewdwr-Jones, 1996). Through this study the researcher seeks not to replace the role of the professional. Instead the researcher sees worth in augmenting and challenging the techniques that a professional might employ and underrepresented communities might engage with. In order to do this, forms of communication must be explored in more detail, and their suitability to this study context and participants determined.

This research aims to create a communication toolkit that would not be reliant upon written and verbal communication methods, which are often exclusionary and heavily laden with power infused language and jargon. Instead, a research commitment to extending participation through inclusive approaches to communication is abided by (Cambridge \& Forrester-Jones, 2003, p.20). Therefore, the researcher now discusses:

- Alternative means of communication

- Their evolution and their suitability for application in this research context

- Describes the methods that will be taken forward into the pilot study

- Determines at what stage of the pilot study each method will be employed and why.

\subsubsection{A picture speaks a thousand words}

Although arguably an over used, and somewhat clichéd phrase, 'a picture speaks a thousand words' highlights the great potency of visual communication techniques for effective social inclusion of people with learning disabilities. 
Mencap, Britain's leading learning disability charity, has produced a set of visual communication guidelines in the form of the document 'Am I Making Myself Clear?' (2000). Their aim is to aid the challenges faced by people with learning disabilities in receiving the information they need and equipping them with methods that allow their choices to be easily communicable to others. These practice guidelines have been seminal across the UK in providing a range of techniques that may be suitable as alternative (and complimentary) communication methods for people with learning disabilities including, symbols, photography, drawings, plain English and advice on layout and design.

Practice recommendations that steer away from a reliance upon spoken language as the sole means of communication can be linked to the respected rise of AAC (augmentative and alternative communication). The impact of this approach, and the broad shift in understanding it has brought, is voiced clearly by specialist speech and language therapist Helen Cockerill who says, "Probably, the most important development in intervention for children with learning and communication disabilities over the past 25 years has been augmentative and alternative communication (AAC)" (Cockerill, 2002, p.74). Clarifying the elements involved she defines the approach as "AAC is the use of non-speech modes of communication to supplement or provide a substitute for speech. Examples of non-speech modes include manual signing, pointing to picture symbols, and electronic communication aids with speech output" (Cockerill, 2002, p.74). Following this, work done in the mid 1990's by the AAC research team led to the creation of Talking Mats. Talking Mats employs picture symbols created using Boardmaker ${ }^{\mathrm{TM}}$ software to illustrate an individual's issues, emotions and influences (Murphy, 1998). The picture symbols are attached to a textured mat using Velcro ${ }^{\mathrm{TM}}$ for ease of manoeuvrability, allowing the symbols to change and reflect the new views and needs of the user. Talking Mats has aided the move towards individualised communication but still relies upon an external source (graphic designer of symbols) for interpretation of concepts. This is not always as accurate or meaningful as, for example, a photographic image taken by the person with learning disabilities at a particular moment, on a particular day. In this way Talking Mats shows a limitation or generalisation about personal experience, which is why they were disregarded as a potential communication method in this research study. 


\subsubsection{My image on film}

The current use and support of photography as a communication method by organisations such as Mencap led the researcher to explore its potential as a possible toolkit component. The use of photo-elicitation in this research is particularly appropriate when working with people with learning disabilities, because Mencap has been highly in favour of alternative visual communication techniques to enable people with low literacy skills to be active contributors in conversation (Mencap, 2000). Photo-elicitation is a technique whereby photographs are used as tool to prompt contribution and memory-awakening in conversation (Banks 2001, p.87). A relatively new method of social research, it was first utilised by Yannick Geffroy in the 1970's, when researching methods to prompt memory recognition (Geffroy, 1990). Since then the merits of photo-elicitation as not only a method of memory stimulation, but also a way to lessen awkwardness of an interviewee, act as a neutral third party, reduce fear of being tested, equalise status of interviewer and interviewee and act as an instant conversation starter have been well documented (Banks, 2001).

Photographs may be used not only to elicit information during interviews but also in the development of fieldwork. Ethnographic researcher Gemma Orobitg Canal used photographs throughout her time working with the Pumé Indians of Venezuela from 1990 to 2000. She observed how photographs served as a notebook for 'memory, illustration and testimony' in common with other visual methods (Buxó, 1999; Orobitg Canal, 2004). The photographs also offered another a method of communication, producing alternative narratives to verbal dialogue, and acting as a means to 'reconstruct the imaginary' (Orobitg Canal 2004, p.32). In light of this evidence, photographs appear a suitable communication method to be applied in this research study; from project inception to completion, in interviews and on site, as a first hand means of communication and a tool through which complex ideas can be identified and then explored using other visual medium.

Photographs are however, a complicated tool and knowingly subjective (both from the point of view of photographer and situation to be photographed). Both Banks 
and Orobitg Canal were well aware of this issue when describing how "issues of photographic multivocality and the complexity of the photographic objects in human social relations means that photo-elicitation is not always straightforward in practice" (Orobitg Canal, 2004, p.38 citing Banks, 2001, p.88). Photo-elicitation has taken many forms including; autodriving (where photographs used in interviews are taken by participants not researcher, or from an external source), reflexive photography (where participants are given a subject, environment etc. to photograph and these are used in interviews), photo novella also known as auto-photography or self-directed photography (where cameras are not entrusted to researchers or professional photographers but rather given to children, the elderly or other marginalised groups in order to discuss life as they see it) and most recently photovoice (a process by which people can identify, represent and enhance their community through a specific photographic technique) (Wang and Burris, 1997; Hurworth, 2003). Of these photographic approaches photo-novella is cited as tool of empowerment enabling those with little money, power or status to communicate to policy makers where change should occur (Wang and Burris, 1994; Hurworth, 2003). This was therefore identified as one approach that should be taken forward with the learning disability participants. Showing the landscape through their eyes would reveal far more of their experience than capturing their movements from an outside observer position alone. The researcher and participant support staff would also be involved in taking photographs, but only to aid the participant in remembering the context in which his/her photograph had been taken.

\subsubsection{Unique hand-drawn worlds}

Free-hand images are often used in the landscape design and planning process to convey impressions of a current situation and elements of its future potential. The work of AlKodmany has shown that when using artist sketches (free-hand drawing) in a project to enhance public participation through visualisation, the artist was able to provide "an avenue for residents to actively participate in the design creation by quickly capturing ideas and discussions into sketches" (Al-Kodmany, 1999). The initial sketches were then explored through a series of workshops to develop a more sophisticated, comprehensive and accessible interpretation. This aimed to be easily read by all, those who had been 
involved in the project and those who were approaching it from the outside. The use of drawing in this research with people with learning disabilities builds upon work by AlKodmany and the principle that "visualisation is the key to effective participation, as it overcomes barriers as it is a common language for all participants, professional, nonprofessional, technical, non-technical' (King et al., 1989).

However, images produced by artists for the benefit of participants can only relay information from a secondary perspective (i.e. they interpret the information of others), and have therefore an intrinsic limitation in expounding personal experience. Ana Isabel Afonso during her research re-creating social memories with villagers in northeast Portugal, employed anthropological researcher and artist Manuel João Ramos to produce illustrations for interviews with participants. The drawings provided an initial discussion point, from which additional information was elicited and then utilized to create a revised version of the illustration. Afonso describes how this new version was far richer in experience: deepening participant involvement (as sources, checkers and authenticators); acting as a trigger for social memory; and transcending the limits of linear representation (Afonso, 2004, p.76). She goes on to say 'by offering the informants the possibility of actively participating in creating and modifying sketches, I could see that we were involving them in further constructing their discourses and reinterpreting their memories, which contributed to give coherence to fragmentary accounts and allowed the successive incorporation of new details into the narrative (Afonso, 2004, p.79).

This research employed the use of participant drawings and paintings, in firsthand elicitation of experience and narrative gleaned from photographs taken on site. The participant drawings were connective components of the methodology providing a series of visual communication steppingstones between the initial landscape experience and its unwrapping during the semi-structured interview.

\subsubsection{Verbal communication and semi-structured interviews}

Having identified the two methods of communication (digital photography and participant drawings) that would begin the unwrapping of public open space experience of people with learning disabilities, a means was sought to distil the wealth of generated visual information through coding into themes. The participants have a range of learning 
disability needs and therefore not all have spoken and written language. It is understood from the outset that the next proposed stage of the communication toolkit (the semistructured interview) is more accessible to those with some or more verbal communication. The photographic and drawn material produced earlier in the project enables a greater range of participants to communicate through gesture as well as speech during interviews (rather than a sole reliance upon verbal communication).

In Rosalind Hurworth's review of the use of photographic sources in interview situations (Hurworth, 2003) she highlights the work of the Colliers (Collier, 1979; Collier \& Collier, 1986) who observed how photographic interviews held many benefits over those that relied purely on verbal communication. The presence of photographs eased flow of conversation, provided encyclopaedic community information and prevented communication difficulties and memory blocks (Collier, 1979, p. 281). These are all issues that would be of exaggerated importance when interviewing people with learning disabilities, a known fact being that people with Down syndrome, and those with autism have better visual processing than auditory processing skills (Cockerill, 2002, p.74). During the semi-structured interviews a virtual journey back through the site visit is taken, with the help of a digital slideshow of photographs. The participants' drawings and paintings are involved to draw particular attention to individual experiences distilled as important during drawing-photo-elicitation workshops.

Through the decision to include the aforementioned visual and verbal research methods, a structure and order for the fieldwork emerges. However, what remained fluid at the outset of the fieldwork was: the format of these elements; addition of supplementary communication methods; and expectations of experiential results drawn out by their application. Chapter 3, Methodological Approaches in Analysis, discusses how a qualitative phenomenological approach and research methodologies such as grounded theory and action research have informed an attitude towards this research design. 


\subsection{Public open space: the context}

"Excluding users in the design and planning process, based on the assumption that all people are the same, usually results in solutions that are totally uniform, in which everyone is assumed to have identical requirements."

(Sanoff, 2000, p.22)

It would seem that within literature, policy and practice guidance, designers and landscape architects of public space, have access to more information than ever regarding methods to meet the diversity requirements of the general population. However, reading a little more deeply it becomes apparent that this diversity still has its limits and constraints. People with learning disabilities are regularly excluded from social research (Hall, 2004, p.298) and therefore maintain near invisibility in practice aims. In a recent publication intended to unlock the relationship between public green space and use by the disability community, the authors began their explanation of methodology by an admittance that 'mentally disabled were not interviewed, as it was considered too difficult to interview them' (Seeland and Nicolè, 2006, p.30). Without the inclusion of people with learning disabilities in the study, any generalised findings about disabled peoples' use of public space are immediately called into question. Within a field that looks to develop inclusion for all, exclusionary practices are already in place.

\subsubsection{The healing legacy}

Due to the inheritance of institutionalisation suffered by people with learning disabilities, their participation in the landscape has had a tendency to focus upon methods by which rehabilitation or therapeutic benefits may be gained from the environment.

In the UK, research conducted in association with the charitable organisation Thrive, sought to evaluate the benefits and limitations of Social and Therapeutic Horticulture (STH). This was achieved through assessment of the gardening project network established by Thrive (Sempik et al., 2005, p.2). The organisation's aim of 'promoting and supporting the use of horticulture for vulnerable people' (Sempik et al., 
2005, p.2) involves many social groups, including people with learning disabilities.

Through this research a number of themes were identified as important to the garden clients: "nature, freedom and space; the social dimension of gardening projects; issues relating to work and employment; physical activity, health and well-being; development of self-confidence and self-esteem; the involvement of vulnerable clients in the research process; garden projects and environmental philosophies" (Sempik et al., 2005, p.39). With specific reference to people with learning disabilities, the research cites how 'for particularly vulnerable adults, for example those with learning difficulties, the friendships formed while attending STH sessions are important because they often have limited opportunities to make new friends in their daily lives' (Sempik et al., 2005, p.66). Through the research, it is evident that gardening projects do provide many benefits for people with learning disabilities. In addition, methodologies employed by the researchers to understand clients' needs were sensitive to the communication requirements of people with learning disabilities, through the use of photographic participation and elicitation to promote 'sensory approaches that did not rely heavily on verbal capacity' (Sempik et al., 2005, p.100). For people with learning disabilities who might otherwise feel socially, physically and psychologically isolated, the gardening projects provide the opportunity to overcome some of these barriers in a safe environment.

Following work by Sempik et al., the human geographer Hester Parr has recently written on the importance of "particular human - nature relations ... in order to explore issues of human well-being" (Parr, 2007, p.539). Focusing upon an ethnographic study of two urban gardening projects attended by people with mental health problems, Parr poses the question "are these activities transformative in both personal and social terms [?]" (Parr, 2007, p.538). Clear parallels may be drawn between the participants with mental health problems in Parr's study, and the social group participating in the fieldwork of this research. Both people with learning disabilities and mental health problems have been subjected to historic institutionalisation and exclusion. In addition, both have a record (existing to this day) of involvement in outdoor occupational therapy. Parr compares and contrasts the approaches and aims of the two study sites; the first an allotment space in Nottingham concerned solely with people with mental health problems, and the second a voluntary sector project in Glasgow who work with a range of 'volunteers' including 
people with mental-health problems, addiction problems and learning disabilities. Parr relays how the Nottingham project, although endeavouring (and to a degree succeeding) to create a tranquil space for its volunteers, fails to further their more general social inclusion through its removed physical location (separated from other allotment plots and the outside world by high hedges and a maze work of pathways), combined with a lack of formal training or qualification opportunities for its "small group of volunteers ... who have not moved on to jobs" (Parr, 2007, p.549). The second project provides a much more promising example of social change, whereby the volunteers are actively involved in a number of tasks one of which is "landscaping gap sites around the neighbourhood" (Parr, 2007, p.551). In this case Parr suggests that, "there is a sense in which such schemes also facilitate 'other' kinds of contributions in the making of participatory citizenship" (Parr, 2007, p.552 citing Barnes, 1997, p.169). As a result, the volunteers at this site benefit from a marked change in social status, frequenting local pubs, engaging the support of neighbours, sharing tools, gaining commission for work and forming casual friendships with the rest of the community.

The great difference between these two gardening work examples is the territorial nature of their project locations. In Nottingham, the site continues a legacy of segregation by being a removed, private space. In contrast the Glasgow project is located in the heart of the local neighbourhood, in plain view of all and where "the gardening activities of the workers in this project create aesthetically pleasing and productive public spaces that are then available to be utilised by the wider community" (Parr, 2007, p.552). The message seems clear, in order for the general public to re-evaluate and redress their preconceived notions of marginalised communities (and witnesses the social contribution they have to offer); those who are marginalised and their actions must be made visible. If not, whilst garden projects will continue to produce onsite opportunities for inclusion of people with mental health problems, learning disabilities etc., once they leave the safety of that environment the world outside and landscape that greets them is very different. This suggests that true inclusion of people with learning disabilities, which will lead to acceptance and value by the community, must come through participation in our shared public spaces. 


\subsubsection{Exclusion in environment}

In addressing the issue of social exclusion of people with learning disabilities in public open spaces, first we must understand why it exists and secondly what policy and practice must be adopted for its reversal. In order to gain comprehension of the current social exclusion situation we must first battle with the concept that we would rather 'understand PWLD [people with learning disabilities] as excluded - rather than as experiencing material and representational discrimination and poverty - is to see them as not part of mainstream society, a situation that seems acceptable to many in society' (Enable, 1999 cited by Hall, 2004, p.300).

Earlier, in section 2.1, the researcher discussed the unjust concept of otherness, which people with learning disabilities have been tarred with, throughout centuries of isolation, fear and mistrust. This fallacy is still amongst us, and therefore extreme sensitivity is justly required when dealing with issues of social exclusion language. Hall (2004) citing Sibley (1995) explains that to achieve normality where people with learning disabilities are not viewed as other, but as equals (with equal rights to oppose discrimination) they would have to reflect what the majority sees in themselves and their daily experiences. This would encompass 'bodily behaviour and appearance, social location (ideally independent living, at least community housing) and/or economic engagement' (Sibley, 1995; Hall, 2004, p.300). This is normality that does not respect diversity in society, and substitutes it for a homogenous fantasy, bland as it is unreal.

Public open spaces such as parks should provide a literal level playing field, where all the community may interact without social hierarchy or segregation. However, the Urban Green Spaces Taskforce survey paints a very different picture of the current situation. Daily nuisances caused by the social 'interaction between different users, with potential conflict, prejudice and misunderstanding' (Urban Green Spaces Taskforce, 2002, p.63) are raised as an issue of public concern amongst park users. For more vulnerable groups such as people with learning disabilities, their sometimes visible and behavioural differences mark them out to others as targets for abuse and exclusion. Studies by Todd (2000) and Ryan (2005) demonstrate strong negative reactions to people 
with learning disabilities when out in public spaces. The results of Ryan's study, working alongside mothers of children with learning disabilities, revealed four governing factors in the extent to which the children were included in the 'mainstream life' of spaces; 'structural constraints, the attitudes and responses of others, the attitudes of the mothers and impairment effects' (Ryan, 2005, p.68). Ryan also observes how 'the use of nonmainstream activities, clubs and holiday schemes appears to increase as the child grows older ... their experiences with their children have gradually edged them towards a path of exclusion' (Ryan, 2005, p.71).

Others authors in this subfield of 'disability geography' also identify extreme difficulties for disabled people living in a 'non-disabled-centric' world. Nancy Hansen's and Chris Philo's 2007 paper 'The Normality of Doing Things Differently: Bodies, spaces and disability geography' examines the experiences of disabled women dealing with impaired bodies in non-disabled spaces and the adjustments they are expected to make to become more accepted in public places. Drawing heavily upon Hansen's 2002 doctoral thesis, the authors state that "Part of the story for Hasen's respondents was the seeming unacceptability of their impaired bodies in many different social contexts and public spaces" (Hansen \& Philo, 2007, p.495). These contexts include streets, parks, shops, settlements and whole regions (Hansen \& Philo, 2007). Like Ryan, Hansen and Philo identify the attitudes of non-disabled people towards the behaviour of those with impairments, as being of equal importance as the disabled person's physical appearance in instigating exclusion:

" importantly though it is not only a matter of appearance, for what also comes into play are the differences of how impaired bodies do things, whether moving, gesturing, speaking, undertaking a task at work such as telephoning or typing, and so on."

Therefore:

"Many kinds of bodies have arguably yet to 'belong' in such places and it is as if their presence is treated as a form of trespass, unwanted or disruptive to silent conventions, thereby engendering an unfavourable reaction."

(Hansen \& Philo, 2007, p.496) 
Hansen's participants are acutely aware of how their 'difference' is perceived and how their inclusion is only ever 'partial' as environmental adjustments supposedly designed to facilitate equality, really only "appears as an add-on or an afterthought rather than a natural or automatic part of the process" (Hansen \& Philo, 2007, p.500). In attempting to combat this, Hansen and Philo ask for participatory practices to be taken up, as "Disabled people themselves can (and should) be consulted for fresh perspectives on how to 'map' this through spatialised bodily terrain" (Hansen \& Philo, 2007, p.501). For people with learning disabilities a general lack of public understanding of their hidden impairments and behavioural 'differences' (with regard to the non-disabled, and sometimes other disabled people) has resulted in many being forced to retreat further down the path of segregation. Therefore typifying what Hansen and Philo have deemed the "systematic 'removal' of disabled people (and facilities serving them) from mainstream spaces of living, working and playing” (Hansen \& Philo, 2007, p.495). In seeking security in environments, where they will not face confrontation, rejection and exclusion, people with learning disabilities are removed from the daily life of our public spaces.

Architecture and design professions further enhance people with learning disabilities exclusion as citizens, with little or no evidence of inclusive, participatory practice. In Imrie and Hall's survey of disabled people and/or the organisations that architects consult with, people with learning disabilities represented the least consulted group behind; access groups, the physical/mobility impaired, vision impaired and hardof-hearing (Imrie and Hall, 2001, p.103). Without a social change and accessible communication methods at their disposal, the community and professionals will continue to forget, alienate and exclude people with learning disabilities in favour of the more visible, vocal members of the disability community.

In order to reverse the environmental and social deprivation people with learning disabilities experience, disability researchers working with people with learning disabilities have called for the 'remaking of the public and private spaces within which participants in this research [people with learning disabilities] live their lives - home, street, work and care - into spaces where they could satisfy their material needs (through benefits and/or work), participate in politics and decision-making, and achieve socio- 
spatial inclusion (Gleeson, 1999, p.150), crucially all on their terms (Hall, 2004, p.304). Possible solutions to the creation of inclusive environments are now discussed.

\subsubsection{Development of social design strategies}

The successful design of an environment results in a place where people are able to use the environment to its full effect, and gain pleasure from that use. Designers must respond to the diversity of needs, and ways of being, within the user population in order for maximum inclusivity to be achieved. As with the language which surrounds disability terminology, debates and approaches to design philosophy have become highly political and contested.

Research in the USA is centred on the concept of universal design. The term universal design, was conceived by the architect and designer Ron Mace (1985) who defined the approach as follows 'universal design is an approach to design that incorporates products as well as building features which, to the greatest extent possible, can be used by everyone' (Ostroff, 2001, 1.5 citing Mace, 1988). One of the key aims of universal design is social inclusion. The USA approach to universal design may be perceived as a relatively recent and novel idea, which has received great academic interest over the last two decades and has the potential for large technological and academic investment and development. However, in other cultures such as India, academics recognise the historic, unlabelled existence of universal design (Balaram, 2001, 5.3). Balaram gives the example of Indian everyday objects such as unstitched, uncut clothing (for example the dhoti and saree) where society has naturally designed for diversity and equality. These garments (without extra cost or elaborate modification) may be worn by everybody, perform multiple tasks, be elegant and affordable to all (Balaram, 2001, 5.4). In Balaram's world-view of universal design, he acknowledges that the segregation and discrimination in society (which universal design aims to obliterate) may not be solved by technological invention alone. Instead a more holistic approach must be considered, taking into account the following: societal attitudes, educating for the future, positive thinking by the user groups, networking and increasing usability range (Balaram, 2001, 5.11). Balaram cites communication methods as a integral tool to the acceptance and success of universal design by saying 'in societies where illiteracy is dominant, oral, 
visual, and other forms of nonverbal communication can be employed effectively' (Balaram, 2001, 5.11). This statement could readily be applied to discussion of design approaches when working with people with learning disabilities. Their community and society is not literacy-dominant and without respect given to the use of alternative communication methods, their social inclusion is partial at best.

Limitations of the American universal design approach have been criticized in the UK on the basis they do little to alter the disabled experience within society: 'given that these attitudes are, at present, broadly discriminatory, there is no reason to suppose that technical adaptations, in and of themselves, will significantly change the lives of disabled people' (Imrie and Hall, 2001, p.17). In other words, no matter how effective the design of physical product, the community in which it is situated, which observes and judges disabled users of the design, remains unresponsive and unchanged. This has led to the rise and support of inclusive design. Inclusive design builds upon the ideology of universal design, but in addition values the design process and participation alongside the completed product. As described by the Disability Rights Commission, this is 'the goal of creating beautiful and functional environments that can be used equally by everyone, irrespective of age, gender or disability, [and] requires that the design process must be constantly expanding to accommodate a diverse range of users, as we develop greater understanding of their requirements, desires and expectations' (DRC, 2003, p.4). Involving and responding to all, this approach does not target disabled people as its audience, but foresees inclusion as an 'equity and quality (of life) issue for everyone' (Imrie and Hall, 2001, p.18).

With a focus on the UK, where this research is situated, it is clear that legislation (the DDA (1995)) has far to go to begin responding to the ideals of inclusive design. The Americans with Disabilities Act is seen as the origin for the UK DDA (Goldsmith, 1997) and both react to mounting public awareness of the inequality for disabled people in employment, provision of goods, facilities and services, and accessibility of buildings. The DDA has been described as 'grievance-led' legislation (Goldsmith, 1997, p.122) and has a somewhat additive approach to accessible design. Under the DDA, disabled people may sue a provider of services if he [or she] does not uphold his [or her] duty to make adjustments under the following conditions: 
(1) Where a provider of services has a practice, policy or procedure which makes it impossible or unreasonably difficult for disabled persons to make use of a service which he provides, or is prepared to provide, to other members of the public, it is his duty to take such steps as it is reasonable, in all the circumstances of the case, for him to have to take in order to change that practice, policy or procedure so that it no longer has that effect.

(2) Where a physical feature (for example, one arising from the design or construction of a building or the approach or access to premises) makes it impossible or unreasonably difficult for disabled persons to make use of such a service, it is the duty of the provider of that service to take such steps as it is reasonable, in all the circumstances of the case, for him to have to take in order to:

(a) remove the feature;

(b) alter it so that it no longer has that effect;

(c) provide a reasonable means of avoiding the feature; or

(d) provide a reasonable alternative method of making the service in question available to disabled persons.

(DDA, 1995, Chapter 50, Section 21)

At this point it must be emphasised that these conditions are as easily applicable to the accessibility of public open spaces as built form. In the run up to the 2004 enforcement of the DDA, and with the fear of costly lawsuits looming, developers and architects set about making 'reasonable adjustments' (DDA, 1995) to existing buildings and seeking innovation for the incorporation of accessible features in new designs. Where the response has been the additive introduction of these elements, inclusive design is far from achieved (i.e. ill-conceived ramps and inaccessible disabled toilets). These are therefore seen as a 'token response to the needs of people with disabilities' (Imrie and Hall, 2001, p.14 citing Steinfeld, 1994, p.3) and ultimately engender further discrimination and separation. The method by which design will become meaningful and inclusive is dependent upon an open and productive participation process, whereby disabled people can freely and equally, communicate their experiences of the environment (built or exterior). 


\subsubsection{Reflection on public participation}

Participation is defined as 'the act of sharing in the formulation of policies and proposals' (Skeffington, 1969). At a UK local planning level, in South Yorkshire (where fieldwork for this research was completed) a historic involvement in public participation exists. The creation of South Yorkshire as a Metropolitan County in 1974 required consensus on a new structure plan that would guide future development in the region. A widespread public participation process was put into place that aimed to 'involve the public from the outset of plan preparation in an open-ended discussion about problems and potentials' (Darke, 1975). The researchers involved in analysis of the project were found to be in favour of the principles of participation, as a means by which information could be dispersed and collected whilst promoting interaction between planning authority and the public (Hampton, 1975). However, they were also aware that a selection process of responses was at work, and that as yet only a small proportion of constituents views were being heard.

Alternative and additional methods of participation, such as those that involve forms of visual communication, are now being employed to draw in views of more underrepresented sections of the community, an example that uses model making techniques is 'Planning for Real' (Gibson, 1981). To involve the public in not only the planning, but also the design process of public spaces requires methods of participation that bridge the gap between professional (design) knowledge and the non-professional's experience, desires, and understanding of a site. What is to be avoided are methods that are "incomprehensible to the user, so the user fails to appreciate the relevance of the information provided" (Page, 1974). If this view of participation has been with us for over thirty years, why do we so regularly find an impassable gulf between what professionals design and what the community desires? In order to answer this, we must turn our attention to the culture of the professionals (be it architects, landscape architects or planners) who are involved in shaping our environments. John Turner's seminal work Housing by People: towards autonomy in building environments (1976), put forward the following view that: 
"Paternalism and filialism... are still very common attitudes in Britain. These are especially evident in the common assumption that the 'ordinary' citizen or 'layman', is utterly dependent upon the 'extraordinary' citizen or the 'professional', who cultivates the mystery of his or her activity in order to increase dependency and professional fees"

(Turner, 1976, p.22)

The idea of elevated professions that separate 'extraordinary' individuals from those around them is strongly supported by John Habraken in his recent text Palladio's Children (2005), which considers the legacy of architecture through the ages. Habraken begins by tracing the chronological development of the 'Architect' and how this has resulted in today's profession. Habraken identifies the following as key players, who have been influential in architecture's evolution: Vitruvius Pollio, who in the first century AD wrote on the discipline of 'Architecture', Leon Battista Alberti who defined the role of 'Architect' as a gentlemanly pursuit whose designs were executed 'by sure and wonderful reason and method" (Habraken, 2005, p.41) and Andrea Palladio. Palladio is seen by Habraken as the historic catalyst who reconfigured the role of the architect. Before Palladio, architectural styles bore reference to their geographical location and historic execution i.e. Grecian or Roman architecture. When Palladio published his 'The Four Books on Architecture' the focus shifted dramatically onto the individual architect, who had the power to create buildings in an individual style that then carried an individual name. Palladio depicted his buildings as isolated monuments devoid of the everyday context and therefore not cluttered by normality. As Habraken pronounces, the undeniable importance of Palladio's work is that:

"It distinguished the designer from the indissoluble unity of environmental form and culture that had until then brought forth buildings and entire urban fields, embodying skills and knowledge. From Palladio on, architecture has been identified with individual architects. Everything else the entirety of the ordinary built field where form, inhabitant and maker are functionally integrated and semantically joined - has remained obscure or self-evident. This has inevitably led to emancipation - and the isolation - of an entire professional culture from the integrated field of form and people"

(Habraken, 2005, p.28) 
Today architects continue this legacy, both through their educational training and practice. However, the goal of creating monumental buildings sits at odds with the reality of the daily work of most architects. More regularly, they are called upon to design the everyday environments and contexts that Palladio chose to ignore. Yet through their training, international networks and professional publications, architects continue a love affair with the individual and their iconic creations. In most everyday streetscapes, the places and structures which we live, work and socialise in are not a series of landmark buildings detached from one another. Most environments are made up of incremental developments that connect to, and overlap, one another (be it on a permanent or transitory basis). Understanding how these have come about, and the lives and needs of the people who will shape them in future is the first step in participatory design practice. However, living with goal of individualism, architects often find it difficult to relinquish the control that has been embedded through their profession's historic development. Recent research into the attitudes of landscape architects towards participation echoed this detachment and doubt:

"When working under pressure landscape architects often fall back upon the familiar and well proven approaches they developed during their professional training and early practice. Study results indicated an uncertainty on the part of the landscape architect about how to use input provided by participants in the design process, which could cause problems when it comes to trying out new aesthetical and practical solutions and ideas."

(Paget, 2008)

Architects, landscape architects, planners and the communities they serve are not the only players in today's design systems. In the case of housing provision Turner revealed through his 'Patterns of decision and control' how in the majority of 'centrally administered or heteronomous housing systems' (Turner, 1976, p.29), such as those that are evident in Britain, are primarily dictated to by regulators or the public sector (governance). This governmental control occurs throughout the planning, construction and management phases, with some input from the suppliers or private sector (developers, architects and builders) during construction, and at the bottom of the 
hierarchy, the users or population maintaining the least level of control, only active during the management or maintenance phase. The detrimental result of this centrally administered approach is clear:

"The difficulties and therefore rarity of the participation of users or even local institutions in the planning, construction and management of public housing programmes, needs no further emphasis. The consequences of this lack of participation provide material for an increasing literature on alienation experienced by modern housing users."

(Turner, 1976, p.42)

This model could be equally true of the way in which architects and landscape architects practice, and how much input the community has into their designs (over and above which control is exerted from the public sector). In order for participation by the community to be effective, Turner sees that systems must be in place to allow a more locally self-governing or autonomous approach to be taken. This would entail giving the community more control over planning, construction and management, with the skills of the professionals utilised more responsively during the construction phase, and government facilitating the community through guidance and support. For participation in control and decision-making like this to occur we must break down not only the hierarchical system that has constrained such an approach but also give due attention to the communication barriers (as previously discussed) that separate and divide one profession from another and one community from it's local authority. Habraken recognises the existence and reliance on jargon within the architectural profession and is keen to erode it through:

"A common professional language to research and report on environment in terms of architecture need not eliminate poetic expression in favor of technical jargon, but it would establish separate more general terms of reference with which to build knowledge" (Habraken, 2005, p.151) 
Likewise in this study, the researcher is keen to break down the communication barriers that have separated the learning disability community from the professionals and policy makers that, and added to the imbalance of control.

\subsection{Conclusion}

In this literature review, the researcher aimed to outline the importance of the overlap in academic disciplines between which the research sits. Section 2.1 identifies the hidden social group (people with learning disabilities) and their experience of exclusion. These are the people who have driven the research. The social model of disability provides an approach to understanding their current disablement, however the means by which it may be reversed is heavily reliant upon the range of communication methods explored in section 2.2. In the final section, 2.3, the researcher focuses upon altering the context of one of the most disabling barriers for people with learning disabilities, the experience of environment. The goal of inclusive design is discussed and the need for attitudinal and experiential barriers to be addressed, before structural construction becomes a solution. In researching the participation of people with learning disabilities in the experience of public open space, the researcher works for a future in which "rather than expecting conformity, [we] now strive to accept diversity in needs, attitudes and expression, and therefore in provision for society" (Ward Thompson, 2002). 


\section{Chapter 3}

\section{Methodological Approaches in Analysis}

\subsection{Introduction}

This chapter sits as an intermediary between the literature background of Chapter 2 and the immersion into practical fieldwork during Chapter 4. In Chapter 2, section 2.2, the researcher identified through literature review a number of key qualitative methodologies, which would be tested during the course of the research fieldwork. These methodologies included: photo-elicitation, participant drawings, self-directed photography and semi-structured interviews. In this chapter, Methodological Approaches in Analysis, the researcher introduces the reader to the qualitative theoretical approach that has been taken to the analysis. Firstly, awareness is drawn to the subjective implication of the personal position of the non-disabled researcher, when undertaking a research project driven by the experiences of disabled people. Within this context the researcher explores the merits of adopting a qualitative research approach, with a focus upon inclusive and participatory disability research practices. Having reached this ethical study standpoint, the researcher steps back from the detail to review the three qualitative methodologies that will ultimately guide the approach to data collection and analysis. These philosophies or 'The Big Three' are phenomenology, grounded theory and participatory action research. Finally a new combination approach is evolved, to be known by the acronym DIDEC, which harvests elements from each of The Big Three (but greatest reliance upon grounded theory) in order to produce a methodology capable of in depth and responsive qualitative analysis.

\subsection{Non-disabled researcher in a disabled world}

Research in recent years by the Department of Health, UK, has identified "the growing importance of the views and experiences of people with ID's [intellectual/learning disabilities] and informal carers within the research arena" (Ramcharan \& Grant, 2001, p.348). Nevertheless, the initial research decision to work with people with learning disabilities throws up many questions as to how, as a non-learning-disabled researcher, one might accurately interpret and represent the experiences of the participants. This debate was recently vocalised amongst disability studies researchers at the 2006 UK 
conference of the Disability Studies Association. Many disabled researchers fighting for visibility, in the predominantly non-disabled academic arena, voiced their concerns with regard to non-disabled researchers representing the views and issues of the disability community without experience of what it is like to live as a disabled person.

In this research study, although the researcher does not have a learning disability, this did not negate the right of the researcher to be involved in progressing the understanding and inclusion of people with learning disabilities. Without inclusion of disabled and non-disabled researchers in the field, disability studies is in danger of becoming a biased discipline, one that is forever internally directed, and excludes the rest of society to its own detriment, and that of all other humans. What is needed is "partnership and alliance between disabled people and non-disabled people and their organisations" (Shakespeare, 2006, p.197). Claire Tregaskis eloquently echoes this view when she says the following "the development of situationally-appropriate alliances with non-disabled people can represent a pragmatic approach to achieving change more rapidly across a wider range of social settings than might be achieved by disabled people working alone" (Tregaskis, 2004, p.602). However, as a non-disabled individual, the researcher understands that it would be incorrect to make assumptions as to how one's own life experiences (and specific to this research, those of public open space) might be similar, and therefore relevant and applicable, to the experiences of people with learning disabilities. Thus, in order for the findings to have credibility, the methodological approach taken was one that enabled greater depth of individualised information to be revealed. The research standpoint was achieved through a qualitative not quantitative methodology that valued the unique worldview of a small number of participants from different learning disability communities.

\subsubsection{Qualitative research: a matter of people not percentages}

Having worked at a further education college for people with learning disabilities, the researcher observed how individualised communication methods (particularly for students with little or no verbal communication) were not immediately established but developed over a period of months and sometimes years. In research, as well as practice, this understanding of the importance of relationship longevity that hones communication techniques (between individuals and their carers or participants and the researcher) is well documented (Richardson \& Ritchie, 1989; Ramcharan \& Grant, 2001, p.357). 
Research into the open space experience of people with learning disabilities, in arenas such as landscape and social and cultural geography, comprises a small, and somewhat marginalised, literature field (Park et al., 1998; Butler and Parr, 1999; Gleeson, 1999; Hall, 1999; Hall, 2004). Without a tried and tested methodological approach in place, the application of quantitative research techniques, that do not allow adequate time for experiential dialogue development, from which more universal themes are distilled, are prone to fall foul to exclusionary practice and generalisation of findings. Indeed, as Ramcharan \& Grant (2001) articulated in their review of participant experience in learning disability research and literature, many researchers gloss over involvement and response from the severely or profoundly learning disabled population. Approaches such as these are understandable due to the pressures of time and financial constraints. As larger scale studies they are important beacons for policy and practice, guiding future development through current substantive results. However, to reiterate, without an initial qualitative exploration, quantitative research has little insight into the subtle nature of the research question. Vice-a-versa, without quantitative research, qualitative research can only allow us to understand what should be asked, not what all the answers are. Within the learning disability research arena there appears to be a bias towards more qualitative studies that demonstrate how, "the knowledge base is now strong on the experiential side, but because of the typically small samples involved, the evidence base cannot support the generalizable findings necessary for long-term planning on its own" (Ramcharan \& Grant 2001, p.356). Amongst established disability research domains in health, sociology and education, this call for expansion of quantitative study may ring true. However within the fields of social and cultural geography, architecture and landscape architecture an understanding of disability as a whole is only now forming, with learning disability issues (to all intensive purposes) absent or invisible. A bottom-up attitude is needed. Therefore the research approach adopted was one of observation, evolution and interaction with the participants; working over an extended period of time, with the goal of understanding how the minutiae might affect the whole. This is qualitative research, the grasping for threads that weave a net to capture future findings. This study's ethos towards qualitative research can be heard in the echo of the words of Jan Walmsley's and Kelley Johnson's: 
"qualitative research is multi-method in focus, involving an interpretive, naturalistic approach to its subject matter. This means that qualitative researchers study things in their natural settings, attempting to make sense of, or interpret phenomena in terms of the meanings people bring to them. Qualitative research involves the studied use and collection of a variety of empirical materials - case study, personal experience, introspective, life story, interview, observational, historical, interactional, and visual texts - that describe routine and problematic moments and meanings in individual's lives".

(Walmsley and Johnson, 2003, p.25 - 6 citing Denzin and Lincoln, 1998, p.3)

Having discussed how the research is embedded in qualitative practice, attention now focuses upon approaches to people with learning disabilities involvement and true participation, the goal of inclusive research.

\subsubsection{Inclusive and participatory disability research}

Inclusive research is defined as, "research in which people with learning disabilities are active participants, not only as subjects but also as initiators, doers, writers and disseminators of research" (Walmsley and Johnson, 2003, p.9). Advice in developing an inclusive research agenda focuses upon the following aims, "a research question owned by disabled people, furthers the interests of disabled people, it is collaborative - disabled people involved in the doing of the work, some control exercised by disabled people over process and outcomes, question, reports and outcomes must be accessible to people with learning disabilities" (Walmsley and Johnson, 2003, p.95). In this research, the aforementioned criteria provided a framework and checklist for the researcher to ensure trustworthiness (term used by qualitative researchers to describe the degree to which the product of the research reflects the experience of the participants) (Ely et al., 1991). The mantra 'Nothing about us without us' is apt in reflecting the researcher and participants' dedication to total inclusion of the participants' ideas and experiences throughout the research process. This goes hand-in-hand with the researcher's academic and professional experience, to drive the project and ensure scholastic credibility.

The importance of people with learning disabilities active participation in research should not be sidelined or underestimated. Ramcharan and Grant (2001) have explored the research experiences of people with learning disabilities, and identified how past and current published methodologies perpetuate the divide between research, policy and practice. "Contemporary policy recognises that people with learning disabilities are 
'almost all, including the most severely disabled, [are] capable of making choices and expressing their views and preferences" (Ramcharan and Grant, 2001, p.349 citing Department of Health, 2001, paragraph 4.1, p. 44). However, the inclusion of people with learning disabilities within participatory research processes (which currently takes a number of forms) highlights the issue that some forms of participation are more obviously emancipatory than others. People with learning disabilities have aided, "generation of research ideas, acted as research respondents, as informants and more recently, aided the development of first-hand life accounts, life histories and the growing body of user literature" (Ramcharan and Grant, 2001, p.350). Participatory research is seen to comprise three founding blocks: collective identification of the problem or issue; collective analysis; and collective action (Cocks and Cockram, 1995; Ramcharan and Grant, 2001). Although an ideal approach to aim towards, previous participatory research studies have shown that "the direction of, and total involvement throughout all stages by people with learning disabilities is not always straightforward or without issue" (Ramcharan and Grant, 2001, p.355 citing Minkes et al., 1995; Stalker, 1998).

Emancipatory research is seen to be a step further towards the total control of research by disabled people. This requires that "disabled people exert control over both social and material relations of research production and thus transforms traditional power structures" (Zarb, 1997, Northway, 2000). For the novice disability researcher, there remains an element of confusion when deciding which research approach, emancipatory or participatory, is more appropriate to align oneself with. Much of this has to do with the interchangeable nature of these two terms in literature (Stalker, 1998; Gilbert, 2004). Nevertheless, the ongoing debate surrounding whether it be emancipatory (Oliver, 1996) or participatory (Zarb, 1997) research that provides the more empowering approach for people with learning disabilities, appears immaterial if the objective is one of: honest inclusion; development of lives; and the dissemination of experiences by people with learning disabilities. As one researcher in the area of disability studies stated "of importance is how the process of participation in research is achieved" (Gilbert, 2004, p.301).

Within the design of this research project, the researcher established the project (choice of study centres, arena of study and identification of research team), set up a programme of fieldwork and completed the qualitative analysis of results. The participants drove the evolution of the methodology by way of the fieldwork programme. Their experiences, photographs and artwork provided the data for analysis and format of 
public, community, dissemination of research. The research aims, questions and objectives were evolved through the longitudinal collaboration between the researcher and participants. This method of participatory research ensured the participants, the key stakeholders, had access to the majority of the project process, reflecting the three cornerstones of the participatory research paradigm. Now discussed are the three overarching theoretical umbrellas, phenomenology, grounded theory and participatory action research, that this research emerges out from under with a new combination approach to analysis, DIDEC.

\subsection{The Big Three}

Phenomenology, grounded theory and participatory action research (in no particular order of importance), are the three methodological approaches that underpin the research. When utilised by qualitative researchers they reveal the people and their perceptions behind the academic questions. When employed within an inclusive research context, they awake understanding and are capable of effecting change for underrepresented people. They are tools able to contribute far more than a celebration of impotent empathy or in the worst instance, disguised sympathy. The three qualitative methodological approaches of the study are united to a greater and lesser degree by these statements. The research is not restricted by a slavish commitment to any one methodology over and above another, the merits of each are appreciated and utilised where appropriate. Whilst no one methodology corresponds exactly with the approach and analysis taken, the harvesting of elements from each creates a highly participant-responsive research project, through which results of great insight are garnered. Consideration is now given to how these three methodologies combine and overlap to produce a commitment to understanding and disseminating the voices of the learning disability participants within the research context.

\subsubsection{Phenomenology}

"Phenomenology is the study of structures of consciousness as experienced from the first-person point of view. The central structure of an experience is its intentionality, its being directed toward something, as it is an experience of or about some object. An experience is directed toward an object by virtue of its content or meaning (which represents the object) together with appropriate enabling conditions."

(Smith, 2005) 
Phenomenology is western philosophical movement, which although implicit in many ancient eastern (and western) philosophies has only relatively recently been identified in it's own right. It came to prominence in the early $20^{\text {th }}$ century through the works of philosophers Edmound Husserl, G.W.F. Hegel, Martin Heidegger (Husserl's former research assistant) to then be developed by others such as Jean-Paul Sartre and Maurice Merleau-Ponty. When Husserl, who is seen as the founding father of phenomenology, published his magnus opus, Logical Investigations (1900-01), he converged two separate lines of thought, psychological theory and logical or semantic theory into a new distinct discipline, phenomenology. Husserl developed the idea of phenomenology as being "the science of the essence of consciousness" (Husserl, 1913). This means, "in this discipline we study different forms of experience just as we experience them, from the perspective of the subject living through or performing them" (Smith, 2005). In philosophical concurrence with this last statement, the researcher chose to adopt a phenomenological approach to understanding the public open space experiences of the participants from the view of their individual and unique perspective on the world.

Phenomenological studies are interested in understanding how: "reality is comprehended through embodied experience. Through close examination of individual experiences, phenomenological analysts seek to capture the meaning and common features, or essences, of an experience or event” (Starks \& Brown Trinidad, 2007, p.1374). This study displays characteristics of phenomenological research as the researcher is interested in discovering, on an individual participant level, how, if, when and why, people with learning disabilities share response to public open space experience. However, operational disparities exist. A larger sample size (18 participants) compared with that of standard phenomenological studies (1 to 10 participants) was involved. In addition, during traditional phenomenological studies data collection involves the researcher observing, "how participants live in their environment through space and time" (Starks \& Brown Trinidad, 2007, p.1375). This study diverges from this conventional phenomenological approach as the researcher introduced the participants to new environments and experiences and observed their reaction to these.

\subsubsection{Grounded theory}

In grounded theory the researcher is said to aim: "to develop an explanatory theory of basic social processes, studied in the environments in which they take place (Starks and 
Brown Trinidad, 2007, p.1374, quoting Glaser \& Strauss, 1967). Within the diversity of approaches to qualitative research, grounded theory provides a methodology by which a picture of a phenomenon under study can be revealed and action stimulated. Glaser and Strauss developed grounded theory with the original aim that "generation of theory through comparative analysis both subsumes and assumes verification and accurate description but only to the extent that the latter are in the services of generation" (Glaser and Strauss, 1967, p.28). Later however, divergences in approach appeared between the works of the two founders. Glaser maintained a view more identifiable with the original methodology, whereby all data are important, and therefore ideas generated must be verified by all data and categories are constantly refitted (Heath and Cowley, 2004 citing Glaser, 1978). Strauss meanwhile, veered away from the original methodology, with a starting point of self and literature, moving towards formulation of hypotheses that might alter or be omitted if "their importance fails to materialise in the data" (Heath and Cowley, 2004, p.144). In Heath and Cowley's comparative review of Glaser and Strauss, they conclude by stressing that "qualitative analysis is a cognitive process and that each individual has a different cognitive style" (Heath and Cowley, 2004, p.149). Strauss and Corbin describe their overall grounded theory approach as follows "the researcher does not begin a project with a preconceived theory in mind. Rather the researcher begins with an area of study and allows the theory to emerge from the data" (Strauss and Corbin, 1998, p.12).

This study draws upon the theoretical foundations of grounded theory in a number of ways. It "involves recruiting participants with differing experiences of the phenomenon so as to explore multiple dimensions of the social processes under study" (Starks \& Brown Trinidad, 2007, p.1375), and in addition focuses on a sample size of 18 participants, within the typical range 10 to 60 persons for grounded theory studies (Starks \& Brown Trinidad, 2007). However, it is naive to say that this is research that sits completely within the remit of grounded theory. For example, the number of participants at each study centre remained relatively fixed for the length of the fieldwork. This was as a result of organisational, time, resource and participant interest constraints. In particular, at SC1 (the Day Service comparative study centre, Chapter 6) participant numbers were restricted initially by health and safety requirements (the acceptable ratio of group members to volunteers and staff), and subsequently by the number of Day Service members who showed interest in the project and wished to volunteer. At SC2 (the further education study centre, Chapter 6) the primary restriction was that only students taking a 
certain college module (the Land and Environment BTEC) were offered the project by the SC2 academic staff.

It is said that within grounded theory "the researcher continues to add individuals until she reaches theoretical saturation" (Starks \& Brown Trinidad, 2007, p.1375). As shown this was not the case for this research study; therefore in this respect it also differs from traditional grounded theory. However, similarity to the grounded theory is highlighted with the comment that "grounded theory observation allows the researcher to see how social processes are constructed and constrained by the physical and social environments in which they are practiced" (Starks \& Brown Trinidad, 2007, p.1375). In this study, observation was made of how participants reacted to new open space experiences, with the visual communication toolkit employed to elicit the social factors that constructed and constrained their level of environmental participation. During data collection, both projects of a phenomenological or grounded theory nature are linked by a strong reliance upon the method of semi-structured interview (Starks \& Brown Trinidad, 2007), a key methodological component of the visual communication toolkit utilised by the research. In both we find the semi-structured interview to be the tool to "elicit the participant's story" (Starks \& Brown Trinidad, 2007, p.1372). However, the research deviates from reliance upon mere observation or interview, instead including a diverse palette of communication methods with which to paint a far more detailed and rich participant portrait.

\subsubsection{Participatory action research}

Participatory action research (PAR) makes a true commitment to the inclusion and representation of the views of those who are traditionally seen more as subjects of the research design, thus elevating their importance and level of control within the study. It has been described as: "a collaborative approach in which those typically 'studied' are involved as decision-makers and co-researchers in some or all stages of the research" (Pain, 2004; Torre \& Fine, 2006; Cahill, 2007, p.268). The fundamental principles of PAR are highly evident in this research design, which is led by an "understanding that people - especially those who have experienced historic oppression - hold deep knowledge about their lives and experiences, and should help shape the questions, [and] frame the interpretations' of research" (Cahill, 2007, p.269 - 9 quoting, Torre \& Fine, 2006, p.458). 


\subsection{DIDEC analysis: a combination approach}

Whilst it has been shown that the study was not an exercise in purity of research commitment to grounded theory (Strauss and Corbin, 1998) alone, or by the same token action research or phenomenology, certain underlying principles and methodological techniques from grounded theory proved most constructive in providing a basic structure for coding results during data analysis. From these theoretical foundations the researcher evolved a new five-stage analysis programme. The researcher named this analysis programme DIDEC. DIDEC is an acronym, with the analysis consisting of the following components:

1. Data spreadsheet

2. Individual transcript memos

3. Diagramming

4. Elicitation of key themes and central premise

5. Comparative analysis.

The five components of DIDEC analysis and their functional purpose are now described.

\subsubsection{Data spreadsheet}

The researcher began with an initial reading of interview transcripts, photographs and drawings to elucidate key points. These key points (or subjects) such as people, places, emotions, objects etc., were highlighted in a number of ways:

- Through identification of subjects repeatedly or selectively photographed by participants (visual documentation).

- Through identification of subjects repeatedly or selectively illustrated (through artwork) by the participants (visual documentation).

- Through identification of subjects repeatedly or selectively discussed by participants during interviews (written documentation).

- Through identification of subjects repeatedly or selectively discussed by participants during the drawing workshops (written documentation).

- Through identification of subjects repeatedly or selectively discussed by participants during informal conversation (written documentation). 
- Through identification of repeated or selective participant-environment interactions, photographed by the researcher (observed documentation).

Identification of these key points resulted in the production of a data spreadsheet, which recorded these observations alongside technical information (interview numbers, identities (study centres, participants, staff), participant's pseudonym, sex and age, site numbers etc.). This was the initial analysis ${ }^{1}$.

\subsubsection{Individual transcript memos}

Utilising the initial analysis of the data spreadsheet, individual interview transcripts were then studied in detail, and linked to relevant participant's visual information. This generated numerous 'codes' that highlighted significant information: words, phrases, behaviour, photographic subjects, and repetition of drawn elements. The grounded theory technique of memos or "the researcher's record of analysis, thoughts, interpretations, questions, and directions for further data collection" (Strauss \& Corbin, 1998, p.110), enabled further exploration of these codes ${ }^{2}$. This process was facilitated by employment of first and secondary sources: photographs, participant artwork, re-examination of literature, personal experience, and participant - researcher interactions. As relationships between codes emerged, these were grouped into larger categories (focussing on shared experience amongst participants).

These categories (or emerging and ongoing themes, as described in fieldwork Chapters 4 and 6) were produced throughout the data collection process from the initial pilot study site visits (2004) through to the final site visits (2006). Two examples of memo transcripts (Tables 3.2 - 3.3), the first from an interview with an SC1 participant the second from an interview at SC2 are now shown. The memos contain a number of technical features, which are explained in Table 3.1 over the page:

\footnotetext{
${ }^{1}$ Appendices, Chapter 3 Methodological Approaches, Data spreadsheet.

${ }^{2}$ Appendices, Chapter 3 Methodological Approaches, Data analysis Part 1 and 2.
} 
Table 3.1

Key to technical information in interview transcript memos

\begin{tabular}{cc}
\hline Code in interview transcript & Code explanation. \\
\hline IN & Interview number \\
\hline ID/Q & Interview date/questionnaire date \\
\hline PN/StN & Participant/staff number \\
\hline SN/PR & Site number/project review \\
\hline$[\mathbf{X}]$ & Labels/codes \\
\hline$X$ & Categories/subcategories \\
\hline$(X)$ & Properties/dimensions \\
\hline
\end{tabular}

Table 3.2

\section{Memo example (SC1)}

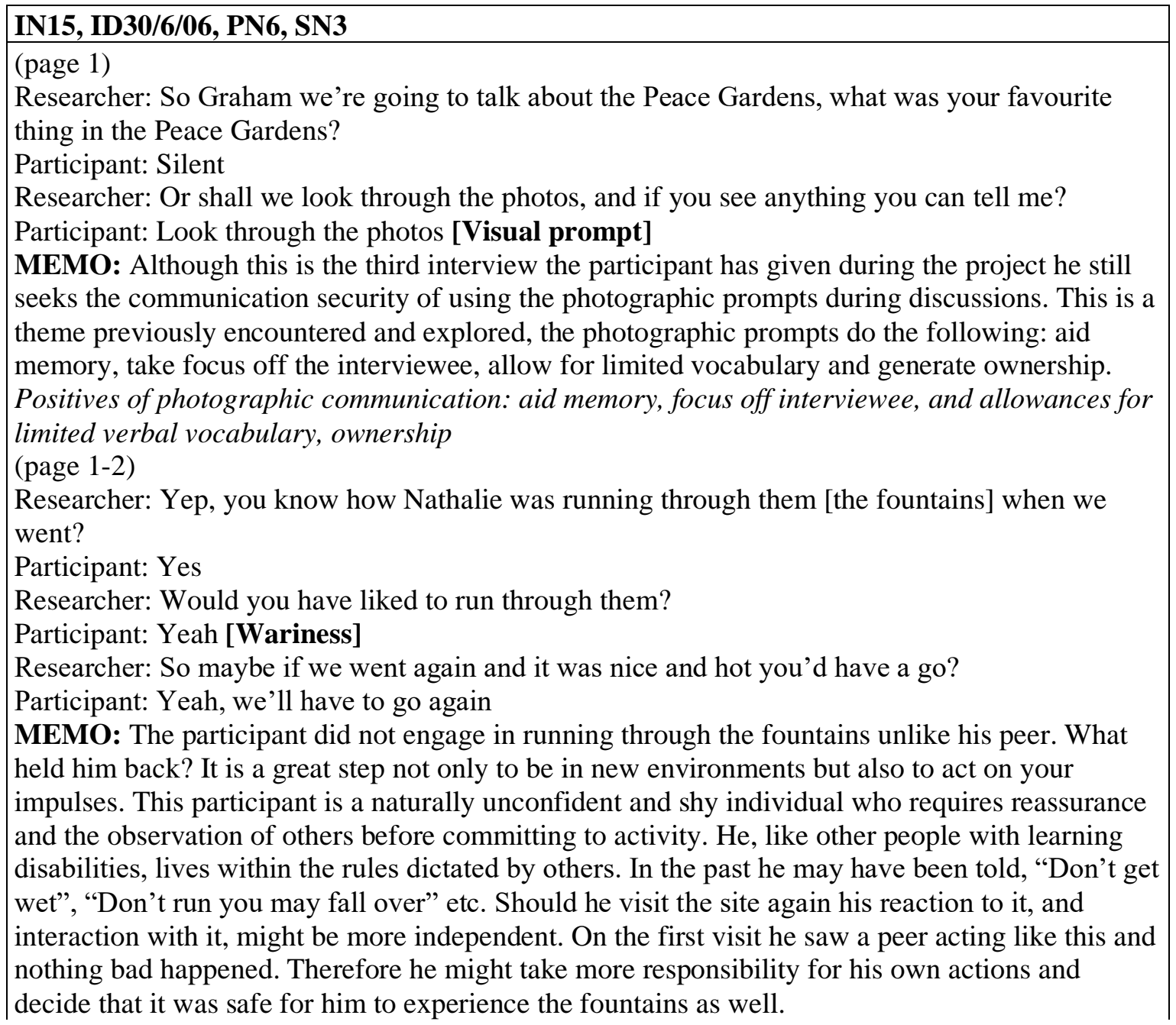


Past environmental experiences

Actions of peers

The rules of others

(page 2)

Repetition of question, as answer.

(page 2)

Researcher: Ok, and the Town hall, and there's everyone having their cup of tea, and there they

are again, so did you read any of this writing that's around the Peace Gardens Graham?

Participant: Yeah, who's that gentleman there? [Limited life experience]

MEMO: With a set daily routine, the appearance of others within it and their reasons for being there are of great interest. The activities of others though seemingly mundane may be very different from those experienced by the participant i.e. going to work, reading a paper, meeting a friend or partner. People with learning disabilities do not often have the independence to make these choices for themselves.

Independent life choices

(page 3)

Researcher: What are the ones at home that you've got? [Talking about wind vanes in the Peace

Gardens]

Participant: Windmills

Researcher: And what colours are they?

Participant: All different colours, that one me cousin bought me it's all red. When the sun shines on it, it leaves a pattern on the fence, it makes a pattern when it's going round [Ephemeral memory] [Pattern]

Researcher: Oh that's brilliant, so have you got these all in your back garden?

Participant: Yes

Researcher: So does it make patterns when it's sunny, or when it's cloudy?

Participant: Sunny [Influence of weather]

Researcher: And what else do you like about the windmills?

Participant: The way they move, the way they go fast and then slow down [Movement]

Researcher: What makes them go faster?

Participant: The wind

MEMO: This is a rare passage of dialogue amongst all the research interviews. The participant offers up many details about his home life and how an element of environmental experience has enriched it. His association of objects on site with those in the familiar domestic environment is confidently and intricately described. This is a very personal memory and therefore it is unlikely to be shared by many others. It is something the participant has control and knowledge of.

Environmental enrichment (ephemeral, physical, social)

(page 4)

Researcher: And what about this, what do you think of pigeons, do you like them or not?

Participant: Yeah. Me Auntie don't like 'em [Family influence]

Researcher: Doesn't she, why not?

Participant: She just doesn't, she says "I don't like 'em flying around"

Researcher: Yeah, I'm not too keen when your walking down the street and they suddenly fly up in your face, I don't like that

Participant: A man who used to go in town [Personal narrative]

Researcher: Yeah

Participant: He used to have them all over his body, all over his head [Personal experience]

[Human interest] [Observation]

Researcher: Really!

Participant: Yeah, he used to be feeding them, and he used to have them all his face

Researcher: All over his head!

Participant: Yeah, and all on his legs

Researcher: Oh I don't think I'd like that

Participant: You ask me auntie when you see her [Dependency]

Researcher: I will do, yeah 
Participant: I've not seen him for a bit, so I wonder if he's in a home [Life experience]

Researcher: Was he an old man or a young man

Participant: I think he were like, like a tramp [Social awareness]

Researcher: Oh yeah, he was probably just feeding them bread crumbs and things

Participant: And he, it says on this sign "Do not feed the birds" why? I wonder why they put that on the sign? [Rules]

Researcher: I think it's because, like your Auntie says you know, some people don't like the pigeons flying about when they're walking around

Participant: When we go to Morrison's they've got a sign up saying "Please do not feed the birds", 'cos when you feed one all the others come. How can all the others, tell if anybody's feeding one?

MEMO: This is a second rare example of participant driven dialogue. The photographic appearance of a pigeon generates an in-depth memory: an auntie's hatred of birds and a tramp covered in them. This was an important personal experience for the participant, he had one reaction to the situation and his auntie had another. He remembers clearly what he thought and what he said. This might be because this interaction in the environment had happened a number of times. It became familiar however the actions of the 'tramp' were alien to him. He would not be allowed to put bread out to encourage birds to climb on him. The memory stimulates other associated memories of place (being at Morrison's and reading the signs). Therefore this memory has important linking qualities.

Linked memories: stimuli (animals, people, buildings, colours, weather, signage etc.)

(page 5)

Researcher: Do you ever come into town with your auntie and go to the Peace Gardens?

Participant: No

Researcher: Where do you go, do you just go to Castle Market?

Participant: Castle Market. We meet our cousins in town, they come down, me cousin weren't down 'til today, she were painting me cousin's bedroom [Routine patterns]

MEMO: Much of the participant's life is governed by routine, he does not have the independence to often stray from this. When challenged about his routine patterns, with something different, he turns the conversation into familiar, personal experiences (where he is confident).

Table 3.3

Memo example (SC2)

\section{IN40, ID13/6/06, PN15, SN9}

(page 1)

Researcher: So which did you prefer Warren the coast or Alnwick Gardens?

Participant: Alnwick Gardens [Preference for formal landscape]

Researcher: What was the best thing about Alnwick Gardens?

Participant: Just because you can see to those waterfalls [Waterfalls] [in vivo code]

MEMO: The participant's preference for Alnwick Gardens to Newton-by-the-sea because of the waterfalls is an interesting one. In interviews at the Day Service Centre regarding another site with water features the participants had been similarly attracted and animated. Why are water features so popular? In observing the participants, one explanation that presents itself is that water allows for contact, hence ownership and understanding of the element. In it's properties it is clear (clean) and does not stain or damage. When controlled (as in water features such as fountains) it is relatively safe and if an individual does get wet the effect is not long lasting. It seems therefore that water is a very valuable element of environmental experience.

Water: attraction and properties (clean, movement, control)

(page 2)

Researcher: There's you and Karl, there's the group. So what's good about the boats? 
Participant: I'm just thinking...I dunno

Researcher: What would you do if you had a boat?

Participant: Oh let me think, I'd go all the way, a long way [Dissatisfaction with current situation]

Researcher: Where would you go to?

Participant: I don't know

Researcher: Would you go to America or Australia?

Participant: Yeah! Maybes America, because I'd like to go to America because you can

see...because it'd be really good

Researcher: What's good about America?

Participant: Just that you can like see really cool places [Life experience]

MEMO: The participant enjoyed the boats at the beach not due to anything physically experienced but rather for what they symbolised, independence, freedom and an escape for current constraints.

Environments of social inclusion

(page 2)

Participant: Maybe go visit some Goths over there

Researcher: So do you think you're a Goth then Warren?

Participant: Yeah [Social inclusion] [Peer identification]

Researcher: So you'd like to hang out with other Goths?

Participant: Yeah

MEMO: The participant longs for integration and has great need for association with those he perceives similar to himself in society. His current (familiar) life environments do not allow for this integration, so he can only dream that unfamiliar environments would provide this freedom. (page 2)

Researcher: Not with me, no just these photographs. So you said to me when we first got here that you didn't want to go on the sand, why didn't you want to go on the sand?

Participant: Well I sort of changed my mind [Alteration by experience]

Researcher: You changed your mind, so it was alright when you got there?

Participant: Yeah

MEMO: The participant's opinion of environment has been clearly changed by actual experience. In this way it is the phenomenon LIMITED ENVIRONMENTAL EXPERIENCE that again appears, uniting understanding behind participant response.

\section{LIMITED ENVIRONMENTAL EXPERIENCE}

(page 2)

Participant: Well anyways so it was a bit draughty yesterday wasn't it? [Weather]

MEMO: Importance of weather.

\subsubsection{Diagramming}

With the aid of associated photographs and artwork, memos for all study interviews were produced. Following this, the researcher found it useful (at a theoretical level) to arrange the exposed memo codes and categories in diagrammatic form. By way of this process of qualitative analysis further connections were revealed, and a smaller number of themes of greater importance discovered. Visual records of these six thematic diagrams with further explanation of each key theme may be found in: Chapter 7, Toolkit and Findings, 7.3.7

Diagramming the six key themes. 


\subsubsection{Elicitation of key themes and central premise}

In grounded theory a core category emerges through the process of selective coding (Strauss \& Corbin, 1998), capable of explaining the phenomenon under study. In this way the research analysis was also consistent with the principles of grounded theory. The identification of six key themes made visible a further cyclical relationship between the themes. Emergent from this cycle was the central research premise. Identification of this central premise was elucidated from connections at the level of individual codes and categories between the six key themes. Detection of a central premise is important as it has the theoretical capability of enlightening the research audience to a situation of more universal significance, beyond the range and reactionary behaviour of this study's two participant groups.

\subsubsection{Comparative analysis}

The credibility of this DIDEC analysis was verified through comparative review (Elliott et al., 1999, p.228; Beart et al., 2004, p.94). The researcher presented the data and findings to an academic landscape architect and a learning disability professional. The insight provided by these two disciplines (between which this research sits) resulted in the redefinition of one key theme (from social exclusion to social experience). As a result of financial and time constraints, formal participant feedback was only completed at the Day Service Centre. The researcher orchestrated a group discussion whereby each theme was illustrated through the presentation of participant photographs and recollection of interviews. The participants were in agreement as to the importance of the themes.

\subsection{Summary}

DIDEC, the methodological approach to analysis employed by this research is heavily embedded in qualitative theory and practice. By taking the attitude that if we are to say anything of consequence about a population (people with learning disabilities) who have, for centuries, been silenced, spoken for and misrepresented, we must do more than listen, we must understand and facilitate their experiences. Our interpretation of what we believe these experiences might be, through literature and observation, are no longer enough. Actively involving people with learning disabilities in the research process from inception to completion and dissemination should not be a footnote or an add on to pass ethical review, it should be an instinct research approach in order to obtain results that are 
trustworthy and meaningful. The methodological analysis of results should be thorough and in depth. By establishing a new process of investigation, DIDEC, which utilises elements from such respected qualitative theories such as phenomenology, grounded theory and participatory action research, it is hoped that the findings generated truly reflect the experiences of the participants and have critical worth in explaining the wider implications of this research.

In Chapter 4, we move forward into the practical application of the research. We explore making contact with potential participants (through the assistance of a local support agency), setting up a pilot study programme, trialling various communication methodologies, experiencing public open space site visits, the influence and views of support staff and the evolution of a participation communication toolkit. 


\section{Chapter 4}

\section{The Pilot Study}

"Inclusive research is much more than the degree to which it is initiated by the people concerned. Where or not the research is initiated or undertaken by people with learning disabilities, there should be a particular commitment by the researcher to consider carefully why it is being undertaken in the way that it is, and how the research may involve and be of use to people with learning disabilities. They need to ask the question whether this does matter to people with learning disabilities".

(Walmsley and Johnson, 2003, p.145)

\subsection{Introduction}

\subsubsection{The setting of a stage and writing of a script}

The fieldwork of this research is divided into two units: the pilot study explored in this chapter, and the main study, considered in Chapter 6. The researcher began this work laden with preconceptions and an individual's subjective viewpoint. To remove these where possible, the researcher immersed herself in the world of the participants, first as a volunteer and later as a supporter worker. Over time, the researcher was able to build strong relationships with the learning disability community and become accepted as an equal member. The period of time that, for sake of clarity, is categorised as the pilot study, served a number of distinct and essential purposes before the main studies could commence. In the case of the South Yorkshire study, to cite a clear division between stages of pilot and main fieldwork is a somewhat artificial claim. There was no break in contact with the participants and weekly sessions continued throughout. Nevertheless, a number of specific aims and associated research outputs may be identified, which could only be achieved through completion of the pilot study.

First of these outputs, was evolution of appropriate visual communication methodologies when working with people with learning disabilities. Although certain qualitative methodologies (such as photo-elicitation, participant drawings and semistructured interviews) were identified through the literature review, tailoring the individual components in response to participant requirements (personal preferences, social behaviour, physical impairments and communication needs) required an extensive period of fine-tuning. In trialling these methodologies, a natural sequence for their use in 
the toolkit emerged. Employment of one methodology led to the organic development and use of the next. The pilot study also served a secondary purpose of identifying the variety of data generated through these different methodologies. Some data exposed valuable insight into an individual's visual communication preferences and public open space experience. Other methodologies elicited information with broader implications for people with learning disabilities. Production of data that revealed a range of experiences and preferences, from the personal to the more universal, furnished the researcher's analysis with a focussed humanity, whilst producing results applicable to the wider life of the learning disability community.

The second aim of the pilot study was to make contact with the local learning disability community. Great criticism has been levelled at medical and positivist research, which objectifies people with learning disabilities (Walmsley \& Johnson, 2003). A personal belief in participatory research practice ensured avoidance of objectifying approaches. This was achieved through immersing oneself in the daily lives of the participants and their community. In taking a transparent attitude to the research aims, issues of unethical treatment are minimised.

The final aim of the pilot study was researcher familiarisation with learning disabled participants. The researcher was a relative novice within the field and therefore made no prior assumptions as to whether her research would: a) appeal to, b) be relevant to, and c) be accepted by the participants and their supporters. The development of the research was directed through collaborative study. Therefore, if the learning disability community rejected the researcher, and her area of study was deemed irrelevant to participants' lives, the purpose of the study would be void. The pilot study gave the researcher and the participants the opportunity to explore communication needs, and individual personalities together, and develop trust in one another. With time allocated within the fieldwork schedule to develop this process, the participants' were given the space to get to know the researcher, her research motivations, aspirations and limitations.

The pilot study aims had the potential to provide a solid grounding for data collection during the main comparative studies through production of the following research components: research question, aims and objectives, a toolkit for use in the main study and development of researcher understanding of the worldview of people with learning disabilities. The researcher began this study with the hypothesis that this research would enable landscape architects and other designers to accomplish the following: utilise the developed methodology to meet the needs of people with learning 
disabilities throughout the design process, and highlight physical and sensory landscape elements that should be included in design; and to make public open spaces accessible to people with learning disabilities. However, as work in the pilot study progressed it became clear that these were not the key issues for the participants. Without completion of a pilot study, the researcher would have been blind, or at the very least unprepared, for what the main study findings would show. In addition, any claims as to abiding by a participatory, inclusive approach would be misleading and ultimately invalid.

The pilot study also generated a fully employable toolkit for use at the commencement of the main comparative studies. The researcher was able to brief participants and supporters involved in the main studies on precisely why and how the toolkit had been evolved. The researcher was able to demonstrate its capabilities when used by other people with learning disabilities and provide a first hand account of experience and endorsement from the Day Service centre where it was piloted. The creation of the pilot study is now discussed.

\subsection{Context and scene setting: literature made life}

\subsubsection{The move away from professionalism into partnership}

Landscape architects have a professional responsibility for the design of the environments that surround us all. This requires that they utilise knowledge they have gained throughout their education to the benefit of the wider community. In training they are taught how to communicate their ideas using profession specific tools such as computer aided design (CAD), aerial plans, sections, 3D images, axonometrics and isometrics. Alongside these and other tools, landscape architects are schooled in a multitude of disciplines from ecological and sustainable design, to historic conservation and public planning whilst also conducting scoping exercises and designing environments from minute high specification detail to urban scale master plans. The ability to utilise these tools and knowledge sets landscape architects apart from the general public and denotes them as professionals in their chosen field. In communicating to other professionals such as architects, surveyors and planners, these tools create a language that may be both precise and technical, but also expressive and inspirational. Such tools are normally used within the constraints of the standard survey-analysis-design (SAD) process (developed by Geddes, 1915). Visionary at the time, SAD is criticised today due to professionals" "unimaginative interpretation" (Thwaites \& Simkins, 2007, p.9) that has 
led to "techno-scientific functionalism and its supposed de-humanising consequence" (Thwaites \& Simkins, 2007, p.8 citing Turner, 1996).

Design participation is often heralded as a means to avoid these difficulties. However, the participation of the general public in the professional design process can sometimes be of frustration to both parties. Whilst professional knowledge regarding design specification and construction requirements are a necessary component of successful participatory projects what is now beginning to be acknowledged is that, "Today, wherever we work, architects have no informed attitude toward the local" (Habraken, 2005, p.169). If viewed as a situational sandwich, with the professionals acting as the top slice of bread and the community the bottom slice, the sandwich filling that holds the two slices together and creates a holistic, responsive design, is often missing. Potentially this 'filling' might include methods of communication that enable the release and relay of information from the 'bottom up', which would then be utilised by professionals to create meaningful designs and forms. Currently this is not the case, and as Habraken reiterates architecture (and similarly landscape architecture) has become increasingly distanced from local reality, with member values more grounded in its "highly networked international professional culture" (Habraken, 2005, p.169). Within this context, the issue of language again rears its head. If professionals are content to rely upon architectural jargon, which itself has the capability to alienate one professional from another due to a reliance upon inaccessible "phenomenology, personal meaning and poetic experience" (Habraken, 2005, p.151), what hope is there for the 'lay' participant? The 'top-down' approach of centrally administered systems, as described by Turner (1976, p.29), is maintained and participation is only ever, at best, partial.

In this climate of professional dominance and local submission, the final product of participatory collaborations may more realistically, be an interpretation by the landscape architect of what they believe the public would want. At worst, a final design is produced based on the landscape architect's personal preferences and desires for the site, with a footnote flagging up public consultation as part of the design process. The cities of today are diverse communities, comprising young and old, male and female, disabled and non-disabled, all who have unique personalities, needs and preferences. The design professional's ability to create landscapes in which people may live happily, work, socialise and relax relies upon their ability to release information about what these environments mean and could mean to every individual. Currently, many professional design tools do not adequately allow landscape architects to create such a dialogue with 
their communities. Without being versed in the language of such tools, members of the community are put at an immediate disadvantage. For those, such as people with learning disabilities, who have restricted verbal and written communication, the opportunity to participate in the design debate is beyond their grasp at present. Having never been consulted or involved in decision-making, the landscape-specific knowledge that people with learning disabilities possess lies dormant and concealed from general view. Without their contribution to the ongoing design debate, let alone the society in which it works, landscape architecture can never claim to be inclusive.

Development of the research approach as described in this thesis has been a very personal evolution. Training as a landscape architect through a Dual Honours degree (Landscape and Planning) and Diploma in Landscape Architecture opened up more avenues for question than answers. Previous experience working with people with learning disabilities (at a learning disability further education college during a Gap Year before university) identified one group in society who were rarely, if ever, involved. These citizens were invisible to the rest of society, supported by health and social services, but impotent to make decisions affecting their environment or that of others. The pilot study begins the researcher's own journey away from a view restricted by professionalism towards a future of participation.

\subsubsection{Studies into recruitment of learning disability participants}

Previous studies with people with learning disabilities have encountered severe problems in identifying and recruiting participants (Siegel \& Ellis, 1985; Lee, 1993; Lennox et al., 2005). Although there has been little in the way of published advice in addressing these issues, two studies, decades apart, have sought to explain why difficulties arise (Siegel \& Ellis, 1985; Lennox et al. 2005). In 1985, the main barriers to participation by people with learning disabilities were obtaining of consent and organisational policies and procedures (Siegel \& Ellis, 1985). With procedure restricting access to study group status, a dependence on the willingness of support organisations to cooperate and an attitude of anti-intellectualism (Lennox et al., 2005) and researcher distrust, recruitment conditions were frustrating. Twenty years later Lennox et al. set out to record the difficulties encountered today. Their study focussed on recruitment of people with learning disabilities for the Advocacy and Health Project (A\&H) in Queensland, Australia. The first barriers identified were, "the complexities and burdens of care faced by family members, and the 'burn-out' and suspicion towards research felt by workers in 
the sector" (Lennox et al., 2005). Another important barrier was the effect the size of support organisation involved had. Large organisations were clogged with numerous management tiers, each having to agree on the participant's involvement. In small organisations, heavy workloads carried by few individuals left little time for debate and consensus, with stakeholders on anything but day to day issues. Other important issues included accessibility barriers (whether registers of people with learning disabilities existed and could be accessed) and again the gaining of consent.

These two studies illustrate how, in twenty years, the barriers to research with people with learning disabilities have remained relatively unchanged. Lennox and colleagues suggest that there is no complete solution instead they outline a set of recommendations. Key to this research were the following:

- The provision of more direct access to participants would reduce recruitment time and provide a more participatory consent process for subjects;

- Allowance should be made for the recruitment phases for 'sensitive' populations should be longer than other populations and matched by appropriate research funding;

- Researchers must be aware that distinct service languages exist and should be used to prevent antagonism;

- Researchers must be prepared to make home visits and visits after-hours to allow for time constraints of the participants and carers.

- Clear descriptions of eligibility, purpose and benefits of research are helpful.

(Lennox et al., 2005, p.304)

The considerations here described were of foremost importance as the researcher began a stage of practical involvement with the local learning disability community, culminating in the pilot study.

\subsubsection{The choice of a pilot study base and participants'}

Awareness of suitable research approaches when working with vulnerable individuals, ensured project commitment to a highly sensitive participant recruitment approach. To be avoided were circumstances where participants found themselves in unfamiliar or threatening surroundings, participating in activities they were not agreeable to, away from their daily routines. With this consideration, a local branch of the British learning disability charity Mencap was approached. Mencap provide both national learning 
disability advice and local, personal support and activities through Day Services. In the past, Day Services have been seen as providing, "much needed respite for families, but they have made a limited contribution to promoting social inclusion or independence for people with learning disabilities" (Department of Health, 2001, p.76). In the White Paper Valuing People (2001) the Department of Health outlined a number of objectives with regard to future provision of resources and activities by Day Services. These were to, "support people in developing their capacity to do what they want; help people develop social skills and the capacity to form friendships and relationships with a wider range of people; enable people to develop skills and enhance their employability; and help communities welcome people with learning disabilities" (Department of Health, 2001, p.77, 7.24). In order to comply with these objectives, Day Services must concentrate on providing individualised and flexible services (Department of Health, 2001). Competence in fulfilling this is dependent upon the range and suitability of communication methods employed by staff. With communication at the heart of many self-advocacy and social inclusion issues for people with learning disabilities, a strong academic argument has developed for creating methodologies that target current communication shortfalls:

"Since the ability to communicate using a commonly understood language is fundamental to the way in which all human beings function in society, it follows that those who are unable to do it are automatically excluded from that society. There is no simple, universal solution and any attempts to remedy the situation involve society broadening its view of acceptable ways of communicating and being prepared to learn those ways too".

(Jones, 2000, p. 20)

Work by Cambridge and Forrester-Jones of the Tizard Centre, during a longitudinal study into individualised communication ${ }^{1}$ with people with learning disabilities, supported this view concluding, "All methods for consulting with and involving people with intellectual disability should be based on the imperative to extend participation through inclusive approaches to communication" (Cambridge \& Forrester-Jones, 2003, p.20). The research partnership with participants at the Mencap Day Services centre aimed to facilitate increased communication between people with learning disabilities

\footnotetext{
${ }^{1}$ Individualised communication is an approach developed by Somerset Total Communication (STC) in collaboration with local speech and language therapists and researchers from the Tizard Centre. It 'utilise[s] established individual vocabularies through a range of signs, graphic symbols and photographs to supplement spoken English' (Cambridge \& Forrester-Jones, 2003).
} 
and other members of the community (landscape professionals and lay people) whilst providing new skills in both familiar and new environments (site visits to public open spaces). In turn, these aims aligned with the afore-mentioned Valuing People objectives. Therefore in approaching the Day Service centre to participate in this collaborative project, staff at the centre were able to envisage not only personal benefits for their members, but a strengthening and improvement of their service if they became involved. This symbiotic relationship between the centre in which the research was conducted and the research itself produced a wide range of benefits:

- Immediate access to potential participants.

- Trust and support for the project from parents and carers (participants' families were made aware of the project and updated on its progress by letters sent out from the Day Service Centre by the Day Service Coordinator).

- Supportive backing from a respected learning disability service when corresponding with other learning disability professionals in the local area.

- Credibility in the research process.

- Necessary evolution of the research methodology. The progression of the methodology ran parallel to the experiences of participants', developing over a period of years.

- Ease in obtaining consent.

\subsubsection{Becoming part of the community}

Introduced to Day Service members as a volunteer in December 2003 assisting with weekly Thursday activities, the researcher was placed with an existing group which comprised ten people with learning disabilities of mixed ability, sex and age and one Day Service Support Worker. Whilst establishing a place within the group, the researcher had the time to observe and become acquainted with individuals, and learn of the group's existing level of knowledge with regards horticulture and the environment. At the time, a Park Ranger from the local City Council assisted the group. The Park Ranger's involvement concentrated upon practical work in the onsite garden, such as the erection of bird boxes, a compost heap and planting of herbaceous species within the borders of the garden. Throughout the spring and summer months of 2004, the researcher worked alongside the group, assisting in the planting and harvesting of vegetables and flowers and taking photographs of the group to record their progress (4.1). The Park Ranger 
completed work with the group at the end of August 2004, and in September the group took on a new direction becoming a focused research team.

\section{1}

\section{Gordon $^{2}$ stringing up tomatoes in the garden}

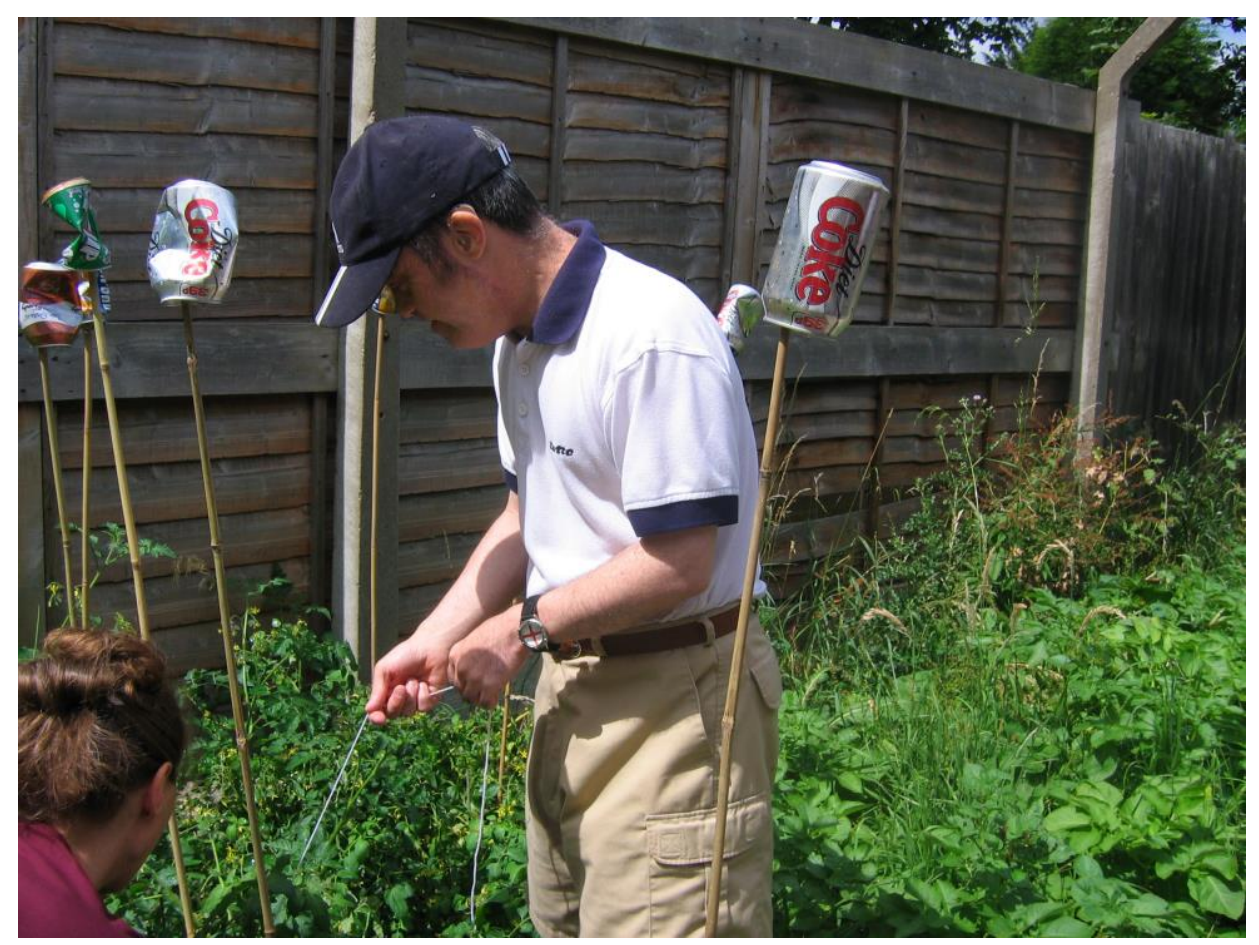

\subsubsection{Summary}

Just as Lennox and colleagues had found, the researcher discovered that working within and alongside a support organisation greatly simplified issues of access to potential participants. Mencap Day Services created a neutral environment in which the research project was incorporated into the weekly timetable of activities, thus minimising disruption to participants' routine. Whilst working with Day Services the role of researcher blurred into that of volunteer and later support worker. This involved becoming part of an established team, creating a level of trust with potential participants and being assimilated into the weekly routine of Day Service activities and familiar faces. When supposed participatory exercises fail, a general criticism is that the instigators of the exercise arrive, listen, promise big things, and then quickly leave, never to be seen

\footnotetext{
${ }^{2}$ Gordon is a pseudonym used to protect the participant's identity.
} 
again. This may be disappointing if you are an independent member of the community, but is demoralising and devastating if you are a dependent, vulnerable individual such as a person with learning disabilities (Clements, Rapley, \& Cummins, 1999; Balandin, 2003). From the outset the research study was designed as longitudinal (see Chapter 1 , Introduction). Acceptance of the researcher by participants as an equal in their world, someone who they could trust and develop open dialogue with could only be achieved through a consistent, long-term commitment. Participants were involved from methodology conception to dissemination design. This participatory research approach, which from the outset involved managing a dual-role, heavy investment of time and personal commitment by the researcher, was inevitably all consuming, "participatory research will always be more than just including people as, by its very nature, the process of involvement compels the researcher to become part of their lives too" (Booth, 1998, p.133). However, the overwhelming benefit of this approach to participatory research is that, "the research may thus afford participants a valued status and provide the opportunity for development of relationships" (Northway, 2000, p.30). 


\subsection{Our Parks and Gardens}

\subsubsection{Evolution of the research methodology through participant action, and researcher reaction}

The term pilot is often used to describe a preliminary investigation which trials methodological techniques in a small study before applying them to a more in-depth or alternatively large-scale project. The Our Parks and Gardens project at Sheffield Mencap was originally intended as a pilot for the main study which would look at results from groups of 12 or more people with learning disabilities participants across the United Kingdom. However, as the pilot continued it became clear that it fulfilled not only the role of testing the methodology (before it could be applied to other situations) but also allowed for continual methodological development throughout the length of the research study. Working alongside the learning disabled participants for a number of years instead of the more usual number of weeks or months (that might normally be expected in a pilot) produced a notable evolution in not only researcher behaviour but also that of the participants. From project introduction to more recent dissemination, the participants grew in confidence and ability to communicate through visual, verbal and physical means. In observing this unplanned dimension, the researcher watched as a new branch of communication unfurled, whereby the learning disabled participants themselves became advocates to their peers, families, support workers, and in some cases complete strangers, regarding the way we experience our environments and how this differs from individual to individual. The introduction, evolution and ongoing development of the Our Parks and Gardens project are now discussed.

\subsubsection{Research introductions and the idea of park}

The researcher approached the project fieldwork with no expectations as to how the participants would react to: the project, its components, different landscape elements, different landscape experiences, and the importance of each. Instead the pilot study was driven by the aim of developing a workable methodology that could be implemented in any situation of landscape architecture, thereby leaving no room for debate as to why people with learning disabilities could not be included in the participatory planning and design process.

The initial presentation of the research project to members and staff at Sheffield Mencap commenced on the $10^{\text {th }}$ September 2004. The project was introduced as Our 
Parks and Gardens. In the morning all members of Day Services (twenty-one people with learning disabilities of mixed ages, genders and ethnicities) and staff watched a PowerPoint presentation $^{3}$ given by the researcher. The presentation used plain English supplemented by photographs and drawings to illustrate: the project aims, possible site visits that might occur, and the use of participant produced photographs and artwork. Following the presentation, the Day Service members (assisted by support staff) formed groups to discuss and produce drawings in answer to the following questions:

- What do we like in parks and gardens?

- What do we not like?

- What is missing?

- What could make parks and gardens better?

The groups were given approximately thirty minutes in which to complete their drawings. Members of each group then presented their sheets to the rest of the people in the room (4.2). The drawings produced by the groups gave clear answers to the four questions regarding their current perceptions of parks and what their ideal park would contain (Table 4.1).

During the afternoon the groups disbanded. Day Service members were asked to produce individual pieces of artwork depicting their own personal views of parks (4.3). Whilst all members had been confident working in groups, some were less so when asked to work individually. Copying of ideas and art design was noticeable amongst a number of females in the group. However support staff commented that this was a problem experienced in other Day Service activities, and could be avoided in the Our Parks and Gardens project through participant selection that divided existing cliques. As expected the individual members artwork reflected many of the same ideas expressed in the group drawings. Day Service members drawn responses to the idea of a perfect park included: flying saucer with aliens, flowers (tulips, daisies and daffodils in Autumn), ducks in the pond, squirrels and benches in Norfolk Park, a golf course, summertime in the Peace Gardens, oak trees in the park with Autumn leaves and a greenhouse $(4.4,4.5)$.

\footnotetext{
${ }_{3}^{3}$ Appendices, Chapter 4 Pilot Study, Our Parks and Gardens.
} 
4.2

Day Service group presentation at research introduction day

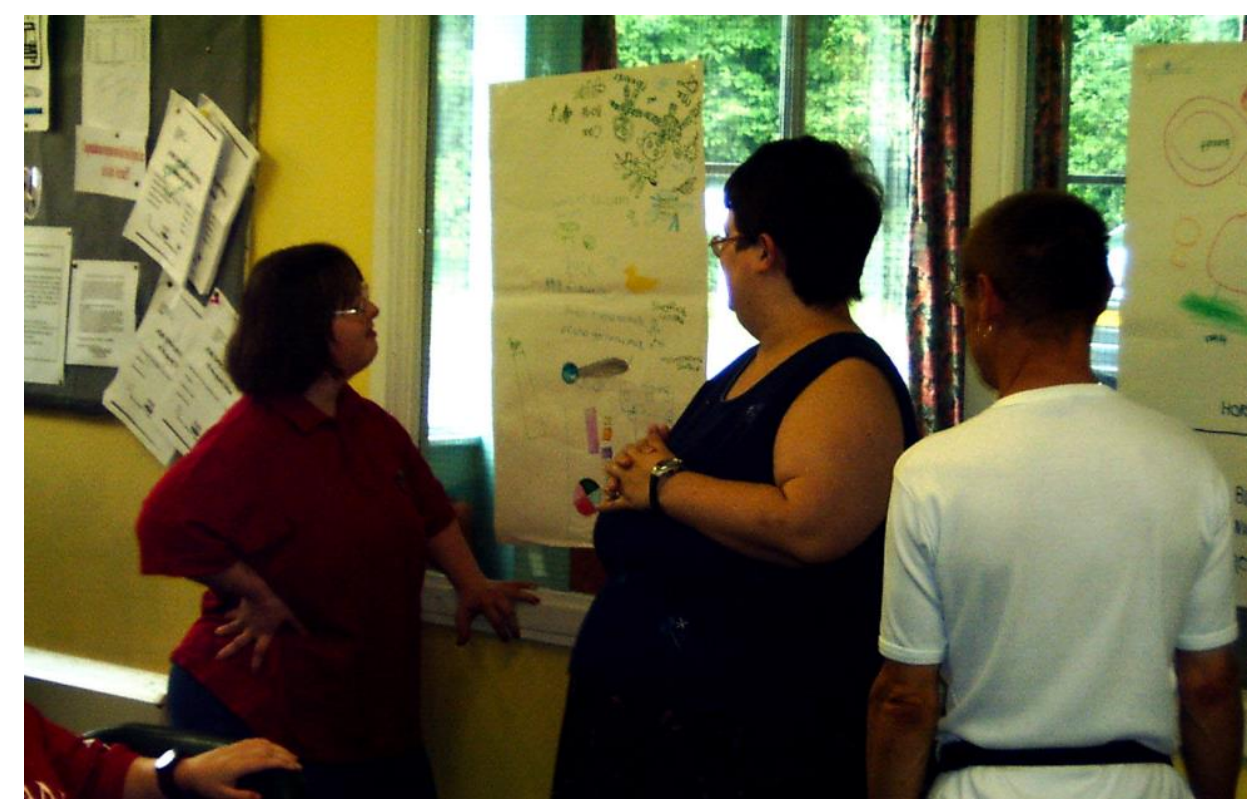

\section{3}

Individual work on park drawing in the art room

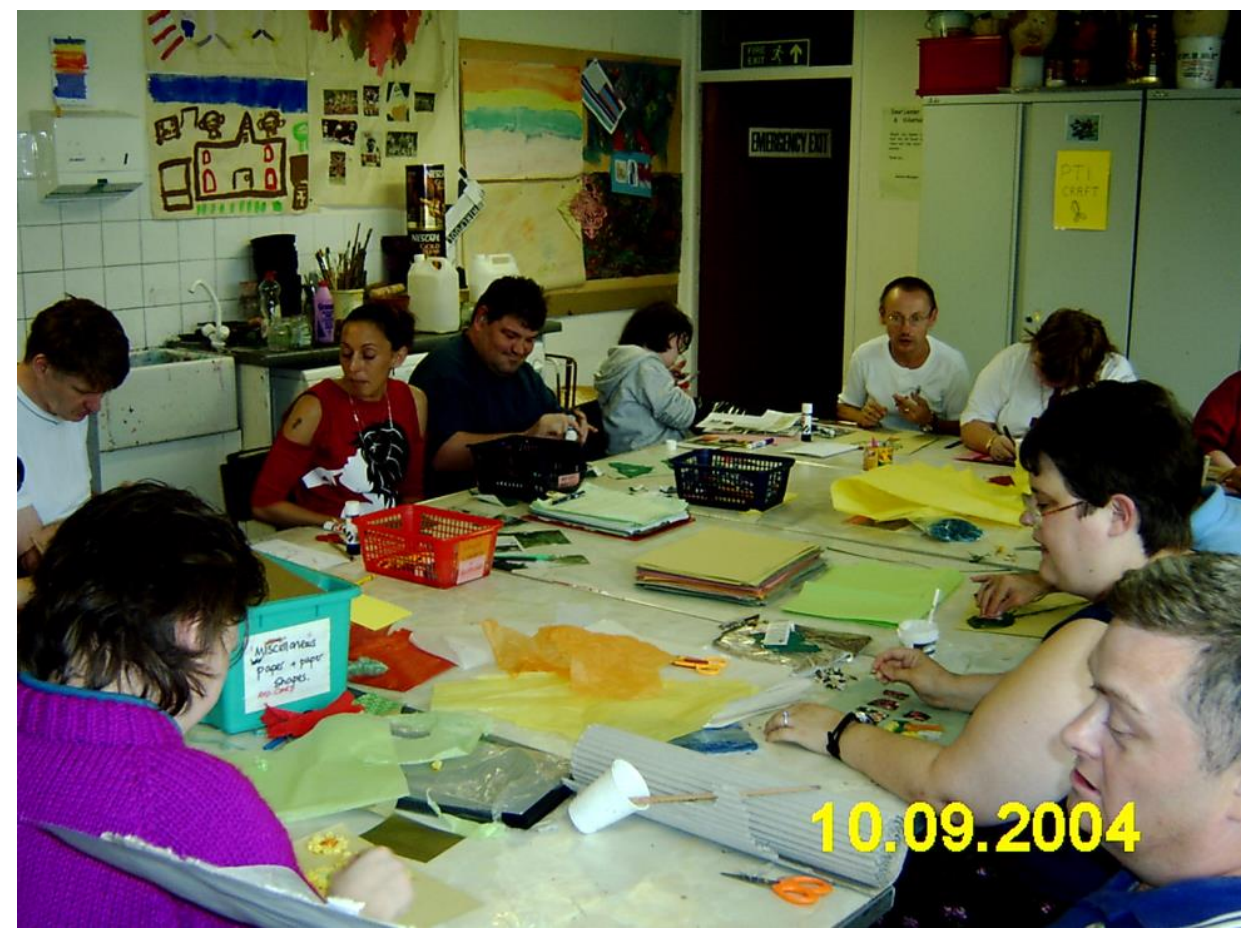


Noticeable in both the morning group workshops and afternoon individual drawings was the positive view with which people with learning disabilities regarded parks. The things they liked about existing parks far outweigh the negatives, and in addition, they thought creatively and constructively, easily envisioning what the perfect park would mean to them, rather than identifying with what was missing.

Table 4.1

Day Service members' drawn responses to questions regarding park use

\begin{tabular}{|c|c|c|c|}
\hline $\begin{array}{l}\text { What do we like in } \\
\text { parks and gardens? }\end{array}$ & $\begin{array}{l}\text { What do we not } \\
\text { like? }\end{array}$ & $\begin{array}{l}\text { What is } \\
\text { missing? }\end{array}$ & $\begin{array}{l}\text { What could make parks } \\
\text { and gardens better? }\end{array}$ \\
\hline Café: cakes, coffee, tea, & Hate & & Kites \\
\hline pop & Dog mess & & People \\
\hline Shops, toilet & Dogs running & & Butterflies \\
\hline Games: balls, golf, & Motorbikes & & Tearooms \\
\hline football, bowling green, & & & Castle \\
\hline cricket, rounders & & & Beach \\
\hline Spending time with: & & & Animals (chicken, sheep) \\
\hline friends, Dad, children & & & Bakery shop \\
\hline Slide, swings, & & & Gift shops \\
\hline roundabout, seesaw & & & BBQ \\
\hline Blue sky & & & Sheffield United \\
\hline Greenhouse, gardens, & & & Horses \\
\hline flowers, trees, grass, nests & & & Donkeys \\
\hline Squirrel & & & Bowling \\
\hline Summer fairs & & & Biscuit \\
\hline Walking & & & Pond \\
\hline Car boot sales & & & Ducks \\
\hline Picnic & & & Boats \\
\hline Fireworks on Bonfire & & & Garden centre \\
\hline night (Guy Faulks) & & & Apple trees \\
\hline Going on the minibus & & & Berry trees \\
\hline
\end{tabular}


4.4

Individual drawing: "A park is golf course" (description by participant)

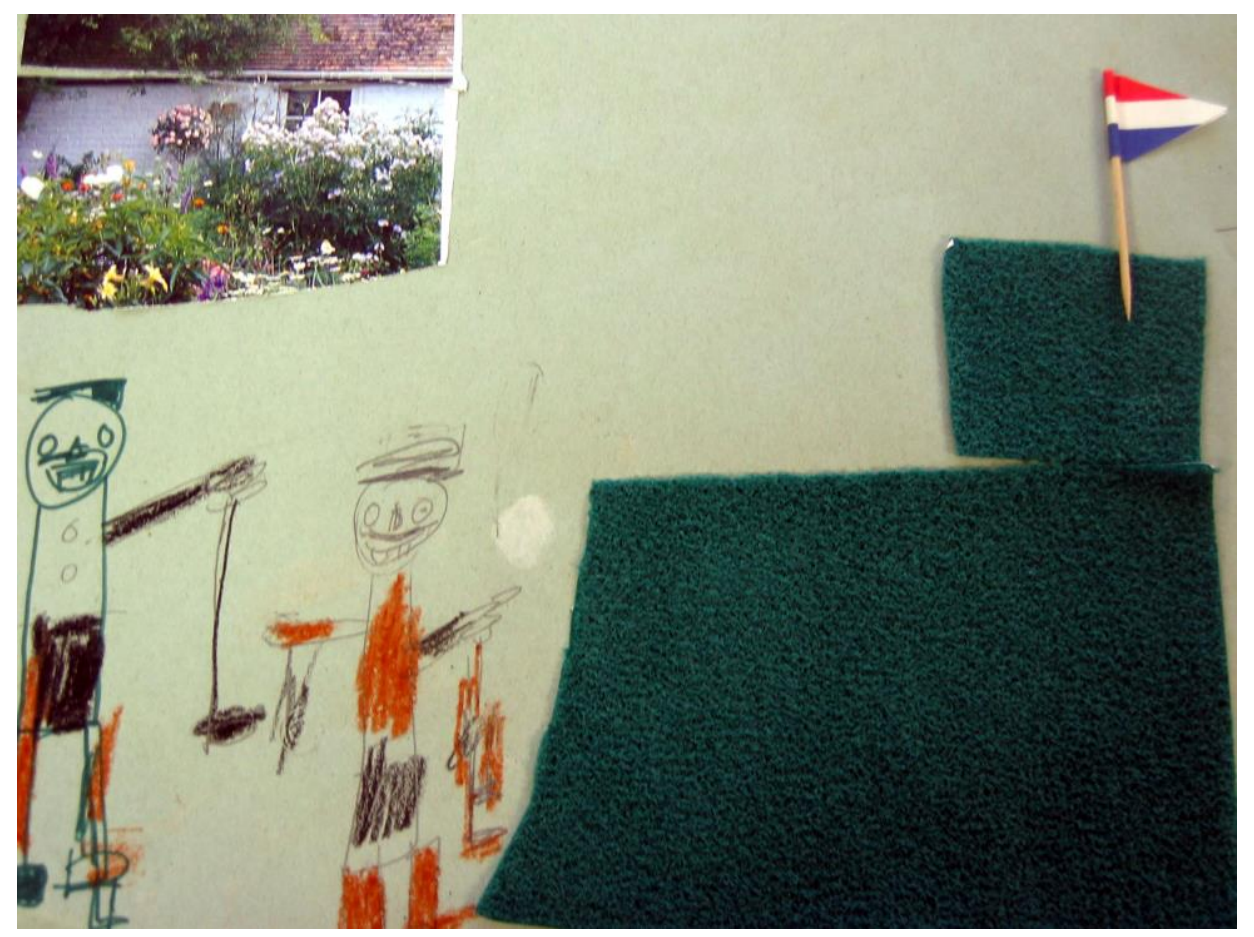

4.5

Individual drawing: "This is a squirrel and the bench in the North Lodge park" (description by participant)

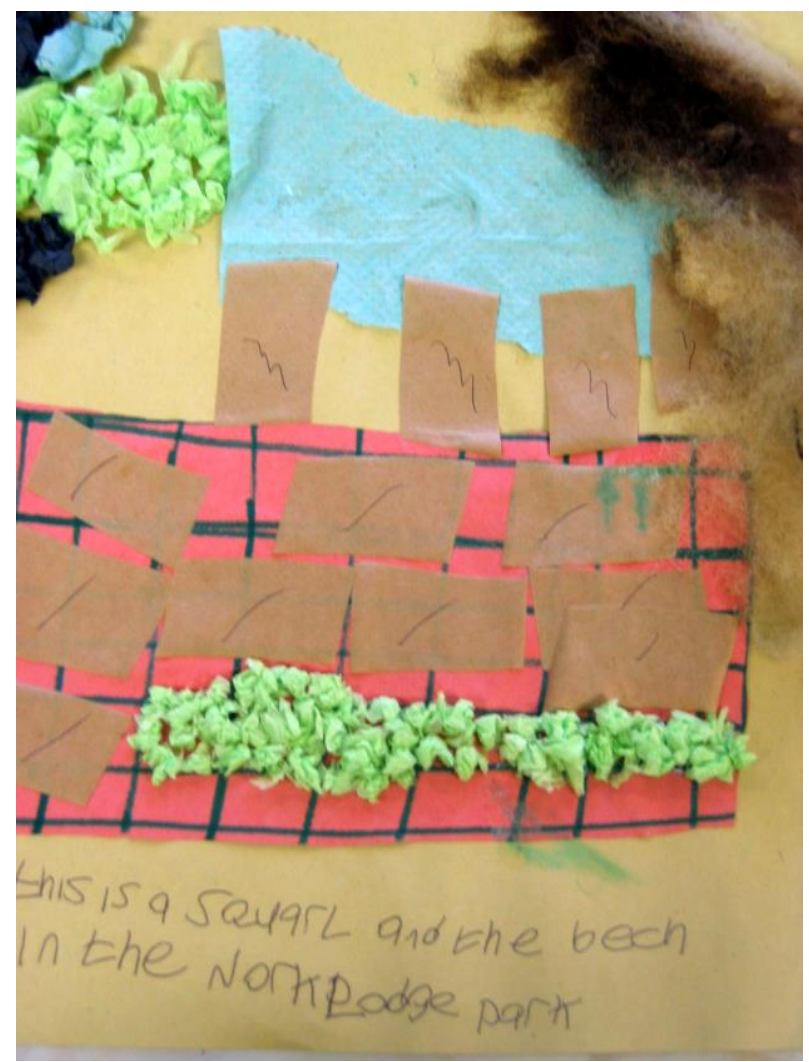


A key aim of the introduction day was to enable all Day Service members the opportunity to experience the kind of subject matter that would be discussed during the project, and the chance to participate in a drawing workshop. As a result of this, members volunteered to become involved in the research project and an initial participant group was formed. Day Service members were free to move between activity groups, therefore if they became dissatisfied with the Our Parks and Gardens project and wished to try out a different activity (such as working in the healthy eating café or the card making group), they were encouraged to do so. Conversely, if other Day Service members wished to become a member of the Our Parks and Gardens project they joined with the benefit of having already been introduced to the project background. The project group consisted of ten learning disability participants of mixed ages, gender and abilities (see Table 4.2), the lead researcher, and a member of Day Services support staff. Mencap volunteers would assist the project on a more infrequent basis, for example when on a site visit, where for legal reasons the ratio of staff/volunteers to members needed to be increased.

Table 4.2

Pilot Study participant details

\begin{tabular}{ccc}
\hline Participant pseudonym & Participant gender & Participant age (in 2004) \\
\hline Claire & Female & 57 \\
Sarah & Female & Early 30's \\
Mary & Female & 63 \\
Tracy & Female & 33 \\
Penny & Female & Mid 40's \\
Gordon & Male & 43 \\
Graham & Male & 48 \\
Peter & Male & 43 \\
Brian & Male & 44 \\
Tom & Male & 42 \\
\hline
\end{tabular}

\subsubsection{The first landscape}

During the introduction day it was decided that the first landscape site visit would be to Sheffield Botanical Gardens was decided. This site was highly suitable for a number of reasons as an introduction to parks: 
- It was easily accessible by minibus from the Mencap Day Services centre.

- There were disabled parking spaces directly outside the park entrance.

- The landform of the site would not present any difficulties for participants unsure of their physical capabilities. The park is gently sloping with an established path network compatible for wheelchairs.

- There were toilet facilities.

- There was a planted glasshouse that would provide indoor shelter and interest if the weather discouraged some participants from exploring the outdoor environment.

- Entrance to the park was free.

The visit to Sheffield Botanical Gardens took place on $17^{\text {th }}$ September 2004. The previous week a letter had been sent to all participant guardian/supporters with a number of aims. It introduced the project, gave details of the trip, what participants would be required to bring (i.e. warm clothing, sensible footware and a packed lunch) and enquired if the participants' supporters would give their informed consent for the researcher to use photographs taken of the participants in her work and presentations. Informed consent from the participants' supporters was unanimous. The notification of participants and their supporters of project progress, methodology additions and alterations became key to establishing project trust and support. The researcher had assumed that participant guardians would be naturally cautious regarding vulnerable people in their custody being involved in a research project with someone they had never met. However, adopting an approach of ongoing communication, culminating in opportunities to share in the project (exhibitions, open days and invitations to accompany the group on site visits) meant this difficulty never arose.

\subsubsection{Camera conduct}

Whilst out on site in Sheffield Botanical Gardens the group made use of two digital cameras. Digital photography has many practical advantages over traditional photography and other visual research methods: being cheap to produce; easy to duplicate; and easy to share with others (electronically by Internet and email) (Danielsson \& Svensk, 2001; Danielsson et al., 2006). Studies completed by Dannielsson and colleagues working with digital photographs and participants with learning disabilities have produced interesting insights into person-environment recognition and relationships. They conclude that 
"pictures of the test person himself or herself in familiar environments were easier to recognise than in unfamiliar environments, whereas the opposite was found for pictures of other familiar persons. No interaction effects of degree of ID [intellectual disability] were found" (Danielsson et al., 2006, p.127). During the Botanical Gardens site visit photographs were taken in the following situations and on the following grounds:

- By the researcher/staff member to capture the participants interacting with the landscape.

- By the researcher/staff member at a participants' request to capture elements of interest for the participant.

- By the participant aided by the researcher/staff member to capture elements of interest.

- By the participant unaided to capture personal interest.

The act of self-directed photography was extremely successful with participants in generating interest in the Botanical Gardens. Through the use of digital cameras, the image could immediately be viewed and evaluated, with the participants becoming highly selective in capturing their own personal view of the park $(4.6,4.7)$. Elements of the park that were repeatedly photographed developed along a number of general themes (which seemed consistently important within the group). These themes and their importance to male and female participants in the group are shown in Table 4.3. A smaller number of more unique observations appeared in photographs that reflected the individual participant's personality and taste. These observations, and the gender of the participant who made them, are shown in Table 4.4. During the day the participants were encouraged to take bark rubbings from trees, and collect objects such as park information leaflets and fallen flora to take back with them to the Day Service centre. The aim of this was to further provoke memories of the landscape, alongside the photographs, that could be useful as prompts in the drawing workshops. This enabled them to retain an idea of textures that could be explored through art back at the centre.

On return to the Day Service centre all participants were enthusiastic about their experiences in the park. However some of the older female members were exhausted by the amount of physical activity. Whilst on site it had been noted that they had required more frequent breaks than other participants. At points this had been difficult because seating had not always been available. On these occasions the staff member and researcher had to compromise the active behaviour of other participants in order to accommodate rest periods for the less active members of the group. 


\section{6}

Botanical Gardens: Peter ${ }^{4}$ is the bear

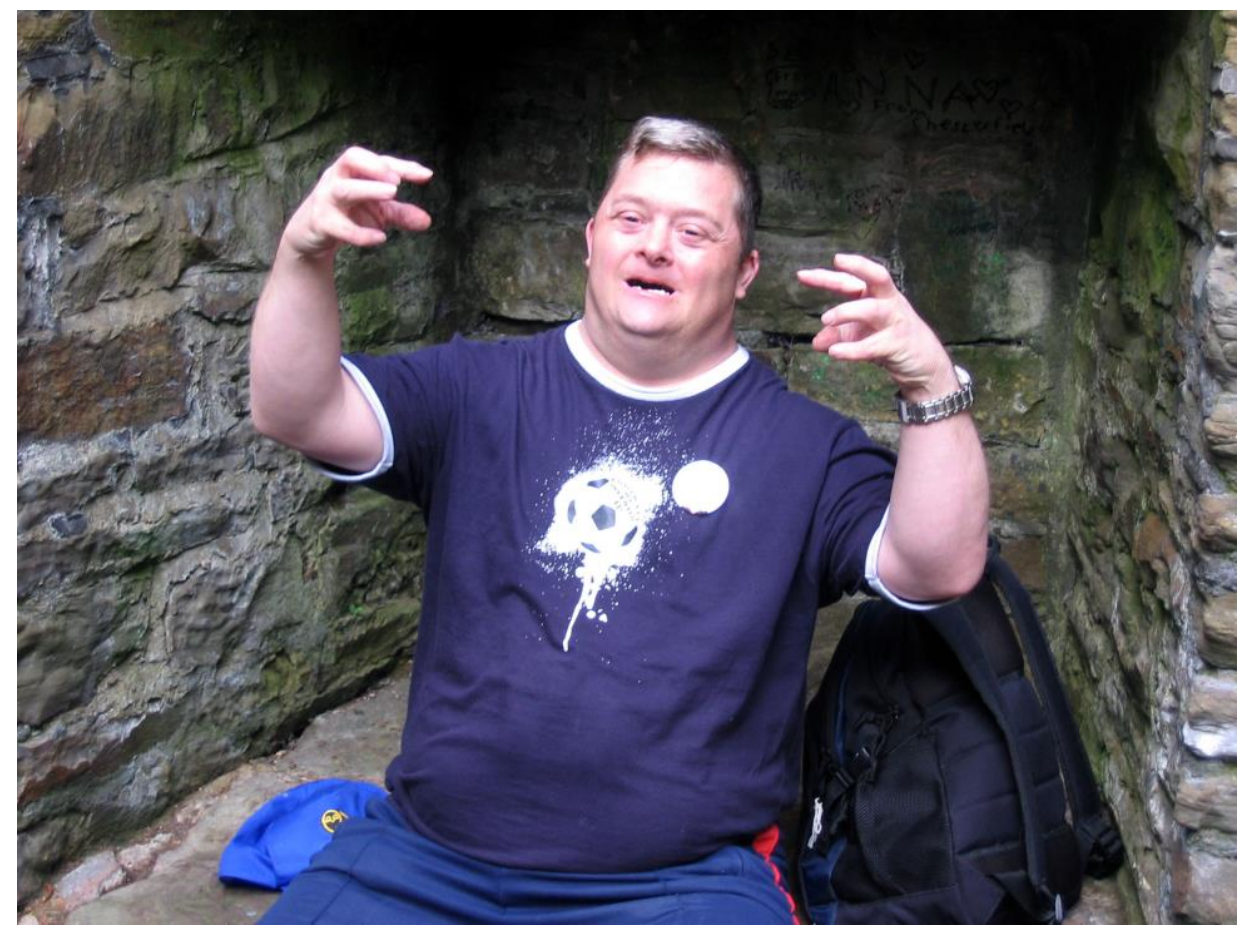

4.7

Botanical Gardens: Penny and Claire eating lunch ${ }^{5}$

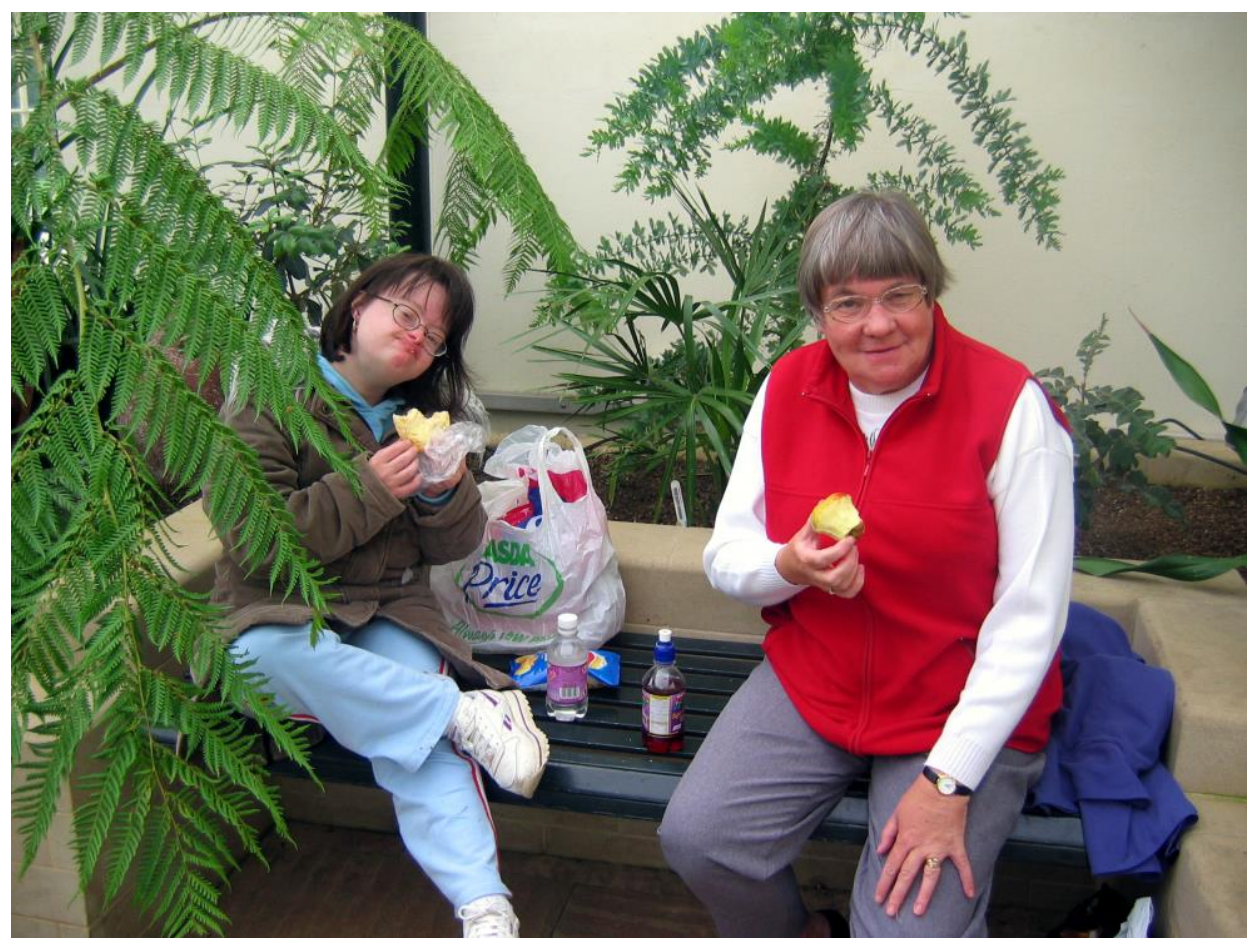

${ }^{4}$ Peter is a pseudonym

${ }^{5}$ Penny and Claire are pseudonyms 
This observation led the researcher to the conclusion that one element essential to the enjoyment and use of parks by people with learning disabilities is the adequate provision of seating (which must be frequent and adaptable for different body types).

Table 4.3

Recurrent photographic themes documented by participants during site visit to Botanical Gardens

\begin{tabular}{|c|c|c|c|}
\hline Theme & Specific example & Male & Female \\
\hline $\begin{array}{l}\text { Formal } \\
\text { planting beds }\end{array}$ & $\begin{array}{l}\text { Annual beds planted either } \\
\text { side of the main pathway }\end{array}$ & Yes & Yes \\
\hline Ornate planters & Urn & Yes & No \\
\hline Autumn foliage & $\begin{array}{l}\text { Robinia pseudoacacia } \\
\text { (False acacia) }\end{array}$ & Yes & Yes \\
\hline $\begin{array}{l}\text { Brightly } \\
\text { coloured } \\
\text { flowers }\end{array}$ & $\begin{array}{l}\text { Hydrangeaceae marophylla } \\
\text { 'Blue Wave' (Hydrangea } \\
\text { 'Blue Wave') }\end{array}$ & No & Yes \\
\hline Wildlife & Grey squirrel & Yes & Yes \\
\hline $\begin{array}{l}\text { Architecture } \\
\text { involved in } \\
\text { narrative }\end{array}$ & The 'Bear Pit' & Yes & No \\
\hline $\begin{array}{l}\text { Park staff and } \\
\text { park } \\
\text { maintenance } \\
\text { equipment }\end{array}$ & $\begin{array}{l}\text { Male park staff member } \\
\text { with truck, working on path } \\
\text { maintenance }\end{array}$ & Yes & Yes \\
\hline $\begin{array}{l}\text { Tropical } \\
\text { planting }\end{array}$ & $\begin{array}{l}\text { Musa basjoo, syn. } M . \\
\text { japonica (Japanese banana) }\end{array}$ & Yes & Yes \\
\hline $\begin{array}{l}\text { Brightly } \\
\text { coloured } \\
\text { berries }\end{array}$ & $\begin{array}{l}\text { Sorbus aucuparia } \\
\text { (Mountain ash, Rowan) }\end{array}$ & Yes & Yes \\
\hline $\begin{array}{l}\text { Places to eat } \\
\text { lunch }\end{array}$ & $\begin{array}{l}\text { Indoor benches amongst the } \\
\text { planting in the Botanical } \\
\text { glasshouses }\end{array}$ & Yes & Yes \\
\hline
\end{tabular}


Table 4.4

Personal photographic themes documented by participants during site visit to Botanical Gardens

\begin{tabular}{lll}
\hline Personal observations & Male participant & Female participant \\
\hline Mosaic artwork & No & Yes \\
\hline Park clock & Yes & No \\
\hline Wind vane & Yes & No \\
\hline Other people in the park & Yes & Yes \\
\hline
\end{tabular}

\subsubsection{Drawing and painting}

In the week following the site visit, the group participated in a one day drawing workshop. The workshop utilised photographs taken on site to inspire artwork and provoke memory and discussion surrounding their experiences in the park. Participants were free to use a range of art media including: coloured pencils, felt pens, collage materials (tissue paper, wool, silk leaves and flowers, felt, magazines, print outs of photographs taken on site), acrylic and poster paints. These media, which were inexpensive to purchase, formed part of the Day Services existing art supply (4.8).

\section{8}

Participant drawing of Botanical Gardens: People walking in the park through the flowerbeds

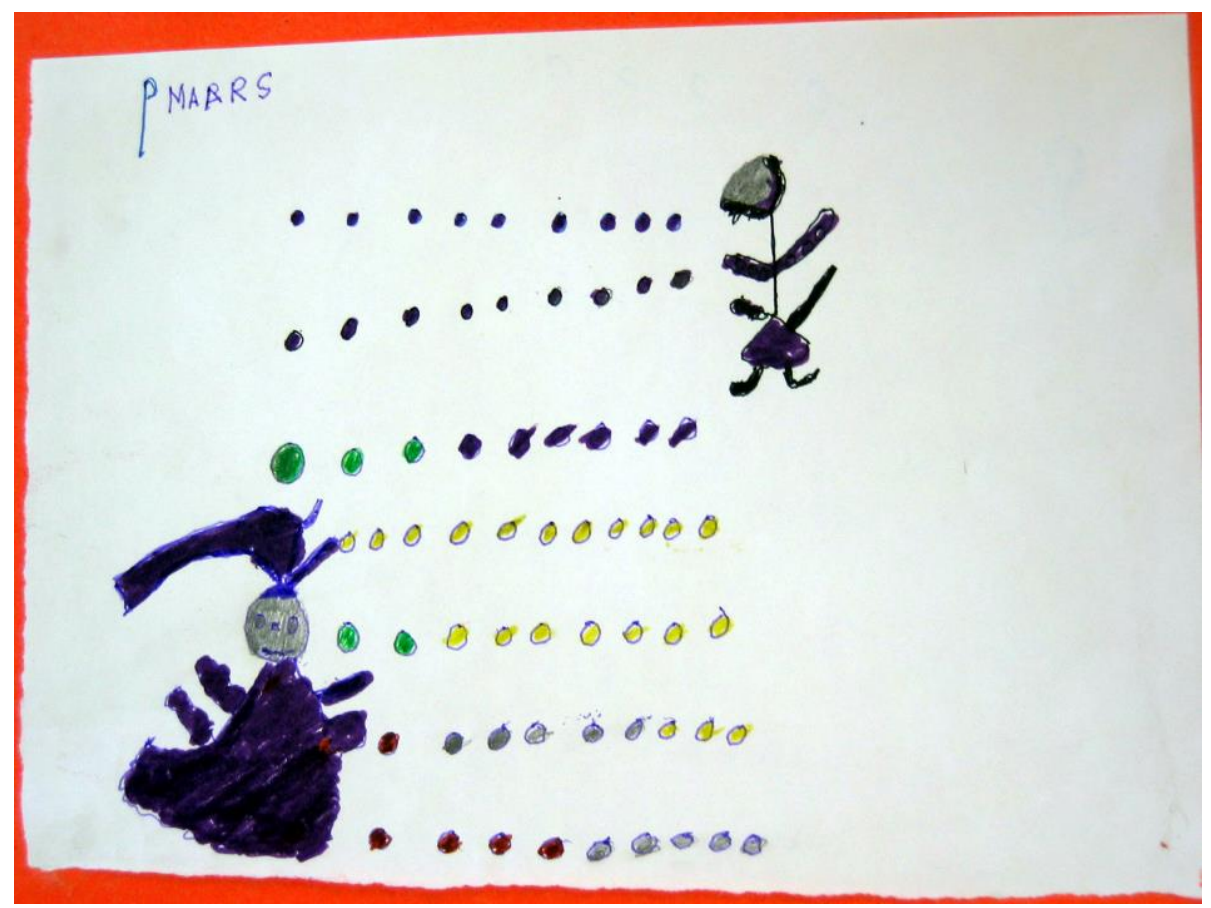


The participants placed all artwork they had produced into their individual project books. This served a number of purposes:

- Ensured complete and progressive documentation of individual participants' experiential journey through the project.

- Facilitated participant ownership of the project.

- Encouraged participant pride in their work (achieved through the physical nature of each book belonging to one individual alone).

- Substantiated the worth of each participant's work for consideration in its own right (not only as part of the larger project group).

- Promoted participant commitment to the project.

During the drawing workshop the researcher conversed with individual participants as to the content and impetus of the artwork they had created. From review of these discussions, participant photographs and their artwork, a number of themes emerged as important in shaping the quality of the participants' experience of the Botanical Gardens (Table 4.5). As can be seen in Table 4.5, justification of theme importance has been identified by gender. Further analysis, revealed that the most obvious differences occurred between the responses of opposite genders, whilst the most obvious similarities occurred between members of the same gender.

Table 4.5

Emerging environmental themes from participant drawings

\begin{tabular}{lll}
\hline Theme & $\begin{array}{l}\text { Reason for importance to } \\
\text { male participants }\end{array}$ & $\begin{array}{l}\text { Reason for importance to } \\
\text { female participants }\end{array}$ \\
\hline Autumn foliage & $\begin{array}{l}\text { Visually attractive and } \\
\text { prompted questions of why } \\
\text { leaves change colour. }\end{array}$ & $\begin{array}{l}\text { Form and colour were visually } \\
\text { attractive. }\end{array}$ \\
\hline Brightly & Visually striking. & Enjoyed colour, texture, pattern and \\
coloured flowers & & $\begin{array}{l}\text { form. Prompted discussion of flowers } \\
\text { grown at home with parents and }\end{array}$ \\
& & carers. \\
\hline Wildlife & Interesting, unexpected & Interesting, unexpected unpredictable. \\
\hline
\end{tabular}




\begin{tabular}{|c|c|c|}
\hline & unpredictable. & \\
\hline $\begin{array}{l}\text { Architecture } \\
\text { involved in } \\
\text { narrative }\end{array}$ & $\begin{array}{l}\text { The story of the 'Bear Pit' } \\
\text { influenced re-enactments of a } \\
\text { performing beast and a } \\
\text { terrified audience. The wind } \\
\text { vane's had a clean lined } \\
\text { appearance with interesting } \\
\text { construction and working } \\
\text { parts (one participant built a } \\
\text { working model of the } \\
\text { structure in a later workshop). }\end{array}$ & $\begin{array}{l}\text { Did not appear in the art or } \\
\text { discussions of female participants. }\end{array}$ \\
\hline $\begin{array}{l}\text { Plants/trees that } \\
\text { could bear edible } \\
\text { fruit }\end{array}$ & $\begin{array}{l}\text { Had never seen a banana tree } \\
\text { before, did not know bananas } \\
\text { grew on trees. Prompted } \\
\text { discussions of other fruit } \\
\text { bearing trees. }\end{array}$ & $\begin{array}{l}\text { Had experience of native fruit trees in } \\
\text { their home gardens, and enjoyed the } \\
\text { form and colour of leaves and fruit. }\end{array}$ \\
\hline $\begin{array}{l}\text { Other people in } \\
\text { the park }\end{array}$ & $\begin{array}{l}\text { Interest in the work of park } \\
\text { staff and why parks required } \\
\text { maintenance. }\end{array}$ & $\begin{array}{l}\text { Provided opportunities of contact } \\
\text { with 'new' people, the chance to chat } \\
\text { and introduce themselves. }\end{array}$ \\
\hline Glasshouse & $\begin{array}{l}\text { Although popular with all } \\
\text { men, this was of great } \\
\text { importance to one male } \\
\text { participant in particular. He } \\
\text { had grown tomatoes in a } \\
\text { greenhouse at home with his } \\
\text { father who had recently } \\
\text { passed away. }\end{array}$ & $\begin{array}{l}\text { Did not appear in the art or } \\
\text { discussions of female participants. }\end{array}$ \\
\hline
\end{tabular}

\subsubsection{Summary}

The developing methodology now had three components; site visit, photographs and art workshops. The methodology allowed the development and exploration of park experiences, but lacked a thorough approach to analysis that could extract a deeper level of detail. Semi-structured interviews are one method by which qualitative researchers achieve access to this level of detail. The semi-structured interview was introduced to the 
participants with learning disabilities in the context of the next project phase, a visit to Sheffield's Millennium Galleries.

\subsection{Exploring art and interview}

\subsubsection{A discussion of sculptures and statues}

The approach taken during this research project was one of evolution. At the completion of each stage the researcher reviewed the data collected and methodological techniques employed. Analysis of these, revealed further methodological elements that should be explored. The element explored in this section is the level of communication gained through using semi-structured interviews with people with learning disabilities, and necessity of subsequent modifications.

During their exploration of the environment at Sheffield Botanical Gardens, a number of the female participants remarked upon the appearance of a detailed mosaic in one of the glasshouses (which one female participant repeatedly photographed). Their interest remained sustained upon their return to the Day Service centre. In response to this the group held an open discussion where participants expressed interest in producing alternate forms of art including mosaic and sculpture. To enable the group to experience a range of three-dimensional artwork (that might inspire their own pieces) a visit to 'Tate Sculpture: The Human Figure in British Art from Moore to Gormley' at the Millennium Galleries in Sheffield was planned.

The site visit to the Millennium Galleries provided an opportunity to explore the participants' photographic, drawn and impulsive responses through the means of a semistructured interview. Few of the participants had attended interviews before and therefore the interview content and purpose was explained in depth. The focus of the interviews was the group's gallery site visit. Interviews were conducted using photographs participants' had taken on the day as visual prompts to promote conversation. This technique, known as photo-elicitation, involves using photographs to invoke comments, memory and discussion in the course of a semi-structured interview (Banks, 2001). The merits of using photographs within the interview context have been strongly supported in recent publications by visual researchers such as Gemma Orobig Canal (see Chapter 2 Literature Review, section 2.2). 


\subsubsection{Researcher and participant preparation}

The interview schedule originally contained seven short, simply worded questions ${ }^{6}$. Direction on wording, was taken from Mencap's (2000) Am I making myself clear? (the charity's guidance document for accessible writing). The language used in the questions was carefully considered to ensure it was not ambiguous, overly complicated or directional. The aim of this approach was to avoid the participants' attempting to guess answers the researcher would approve of, and instead answer truthfully and impulsively. It was intended that the interview might last approximately thirty minutes with questions designed to be open in nature, in order that other discussion might arise. The interview questions aimed to draw the participant through the experience of being in the gallery into anticipation of their experience of the next site (the Yorkshire Sculpture Park). When considering what this experience of the Yorkshire Sculpture Park might be (in addition to the use of photographs of the Millennium Galleries) the participants were invited to consult drawings they had produced and assembled in their participant books. It was hoped this would provide a useful, additional, visual prompt, as many of the participants had low oral or written communication skills.

The interviews were originally scheduled for the week following the visit to the Millennium Galleries (to keep the experience fresh in the minds of the participants). However due to the departure of a member of Day Service staff and subsequent leaving party, a fortnight passed between the visit itself and the interviews. The interviews took place in the empty General Office at Sheffield Mencap Day Service centre. The group normally meets in the Art Room at the centre, however it was decided to perform the interview in a professional manner to respect the seriousness with which they treated the occasion. Subsequently, the chosen room was one participants associated with official business, within the centre (to provide a sense of security) but removed from the distractions and everyday activities of the group. The participants were informed in the morning the time at which (in the afternoon), their individual interviews would take place. They met as a group in the Art Room after lunch and then proceeded to the General Office at their allotted time. Without the continued assistance and backing of the support worker on the project it would have been impossible to carry out the interviews in this fashion, and keep the rest of the group occupied continuing with the scheduled activity.

\footnotetext{
${ }^{6}$ Appendices, Chapter 4 Pilot Study, SSI format.
} 


\subsubsection{Power relations}

The researcher anticipated a certain power imbalance during the interviews that would place her in the position of authority and control. As creator of the interview questions, she also had knowledge of the format that the interview would take. In addition, although the participants were aware prior to the interview of the topic that would be discussed, it was decided not to make the interview questions available to them. It was predicted that the participants would have been highly unlikely to read them (as most had relativity low literacy skills) and if they had had assistance answers might not have been as instinctive or truthful. The researcher was also aware of the immediate social imbalance. The participants had not been in a formal interview situation before (although showed great willingness to participate) and were slightly apprehensive of the behaviour required of them. However, this social imbalance was decreased by a number of factors. These were namely; the age of the researcher (twenty six), the gender of the researcher (female) (Schoenberger, 1992 in Cochrane 1998, p.2125), the researcher's appearance (non threatening and casually dressed) and of greatest importance, the participants familiarity with the researcher. It was therefore easier to obtain permission from the participants (and their supporters) to conduct the interviews. Most importantly, when working with this group of individuals it would have been morally and socially wrong to take advantage of their vulnerable status to carry out the interviews without fully involving them in the research project.

Taking these issues into consideration, the researcher expected to take the leading role in the discussion, prompting the participants using the visual cues (photographs and drawings) into further conversation beyond the prescribed question format.

\subsubsection{A brief discussion of the ethics surrounding participant anonymity in research}

Before commencing with an account of the interview process and outcomes, the researcher draws the reader's attention to the issue of participant anonymity within this research. The importance of this issue has been alluded to earlier in this chapter, when the researcher discussed ethical methods for obtaining informed consent. However, the issue becomes reality at the commencement of the practical interviews. When working with vulnerable people, such as those with learning disabilities, it is fundamental that certain precautions are taken into account to protect the participants from public identification which might place them in situations of danger, or allow others to take advantage of their 
vulnerable nature. In taking a humanistic approach to the research it became impossible to diminish the individuals who participated to a number or code. Their personal accounts and work deserve to be accredited to them. As a result the researcher decided to assign a pseudonym to each participant. This therefore protected the individual from public identification, whilst allowing the reader to empathise with a personal story, rather than reducing each participant's experience to that of a generic code. These pseudonyms are used when referencing written or spoken quotes, photographs and artwork.

\subsubsection{The interview process}

The interviews were recorded using a mini-disk player and flat microphone placed in full view of the participant. At the beginning of each interview it was explained to the participant that this would be the method of recording. All participants had given their consent to both being interviewed and the interviews recorded. To ensure maximum sound quality of interview recordings on the mini-disk, the interviews were conducted in the General Office. This was chosen as a suitable venue as it was a small, quiet, empty room, away from the Day Centre's main activity spaces. Mencap staff were made aware that the room was in use for the afternoon to avoid unwanted disturbances and interruptions. The room was well known to participants and not an area 'out of bounds' in normal circumstances. This was important to put the participants at ease.

During the interview the researcher intended to take notes in order to supplement the interview transcripts. An interview format sheet was produced that included the seven original questions but with room to write down additional information and observations. This interview sheet was placed in plain view of the participants so as to not conceal any aspect of the interview procedure. Digital photographs taken during the Millennium Galleries site visit were downloaded onto a computer in the interview room. These images were then set up as a slide show on the computer screen in order that both participant and researcher could view the photographs with ease together. The interviews took place consecutively on Friday the $15^{\text {th }}$ April 2005. The first observation made, with regard to expected and actual results, was the length of the interviews themselves. The researcher had estimated interviews would last no longer than thirty minutes. In reality the interviews lasted no more than ten minutes due to a number of factors.

Firstly, within a straightforward interview context the participants exhibited a far reduced level of concentration than had been anticipated. This is clearly demonstrated in 
the transcript of interview with Tracy ${ }^{7}$. Approximately two minutes into the interview the Tracy asks, "and then can I go back in a bit?" This may have been, in part, due to her nervousness about being in an interview situation for the first time. This caused the researcher some concern at the actual time of the interview, i.e. the participant felt extremely uncomfortable with the process, with the researcher beholden for taking up her time. This exposed an unexpected power relationship. The 'vulnerable' participant could control the supposedly 'powerful' researcher; if the participant wished to discontinue the interview the researcher was powerless to do otherwise. This is a situation common to many interviewer-interviewee relations (McDowell, 1992, p.213; Schoenberger, 1991; 1992; Cochrane, 1998, p. 2124), although interestingly it is normally documented in the interviewing of elites, not the seemingly vulnerable. Ultimately, the interview did continue until all topics had been covered and all questions had been asked. In addition, the researcher was subsequently reassured when thirty minutes after the interview had concluded Tracy asked, "and when will we be doing more interviews?"

The second factor, which reduced the duration of the interview, was the length of response participants gave to questions. During Graham's 8 interview, the responses he gave to the majority of the original questions comprised one-word answers, or very short confirmative sentences such as, “yeah”, "hmm” or "I don't know”. For example when asked: "Ok. New question, we'll soon be visiting the Yorkshire Sculpture Park, what do you think you will see there?" Graham's response was, "I don't know". Using the prescribed question format alone this could have been a rather disheartening, and in some ways uninformative interview. Participant response would have been limited to seeking provision of the seemingly correct answer in order to please the interviewer, or alternatively producing no response when confused or bored by the question.

The scope of the responses given by Graham was broadened by the introduction of photographs into the discussion. These created a more level power relationship within the interview, reducing the researcher's control over the shape of the interview's progress and outcome (a concern of researchers such as Cochrane (1998, p. 2123)) when working with less powerful participants. Graham and the researcher focused together on the photographs of the site visit whilst the researcher asked more informal questions and responded encouragingly to Graham's replies, affirming the worth of his observational and experiential responses. This type of discussion replaced much of the original,

\footnotetext{
${ }^{7}$ Tracy is a pseudonym

${ }^{8}$ Graham is a pseudonym.
} 
prescribed-question format. Together, observing the photographs, the participant and researcher were able to start unlocking hidden meanings, decoding the actions in the photographs (Bartram, 2003). An example illustrating this is shown within Graham's transcript, where bridging two questions the researcher says, "That's right, I think they were called 'The King and the Queen'. So lets look at the next one (shows Graham the photograph), this is a photograph of you. Can you remember what you were doing there?" In response Graham says, "Being like a statue" (4.9). Although a short sentence, this begins to reveal far more regarding how Graham interacts with the environment than would be possible through oral questioning alone.

This was also true of the interview with Tracy. Although she appeared far more emotive in her answers (possibly as a result of differences between the two interviewees personalities and genders) her answers were still relatively short. For example when asked, "What was nice about the gallery?" she replied, "All the models were fantastic". It followed that in general Tracy, like Graham, had a similar increase in response level once photographs were introduced into the discussion. This was clearly demonstrated when the researcher asked her to pick out photographs of other sculptures that attracted her attention, to which she immediately responded, "That one that. That was like a 'Rocket Man', yeah I said that". Tracy's response to the photograph also revealed "the complex social processes and significance visual images begin to express, that pure oral dialogue cannot" (Rose, 1996, p.283), i.e. in this case one begins to wonder the origin of the term 'Rocket Man'. 
4.9

\section{Millennium Galleries: Graham "Being like a statue"}

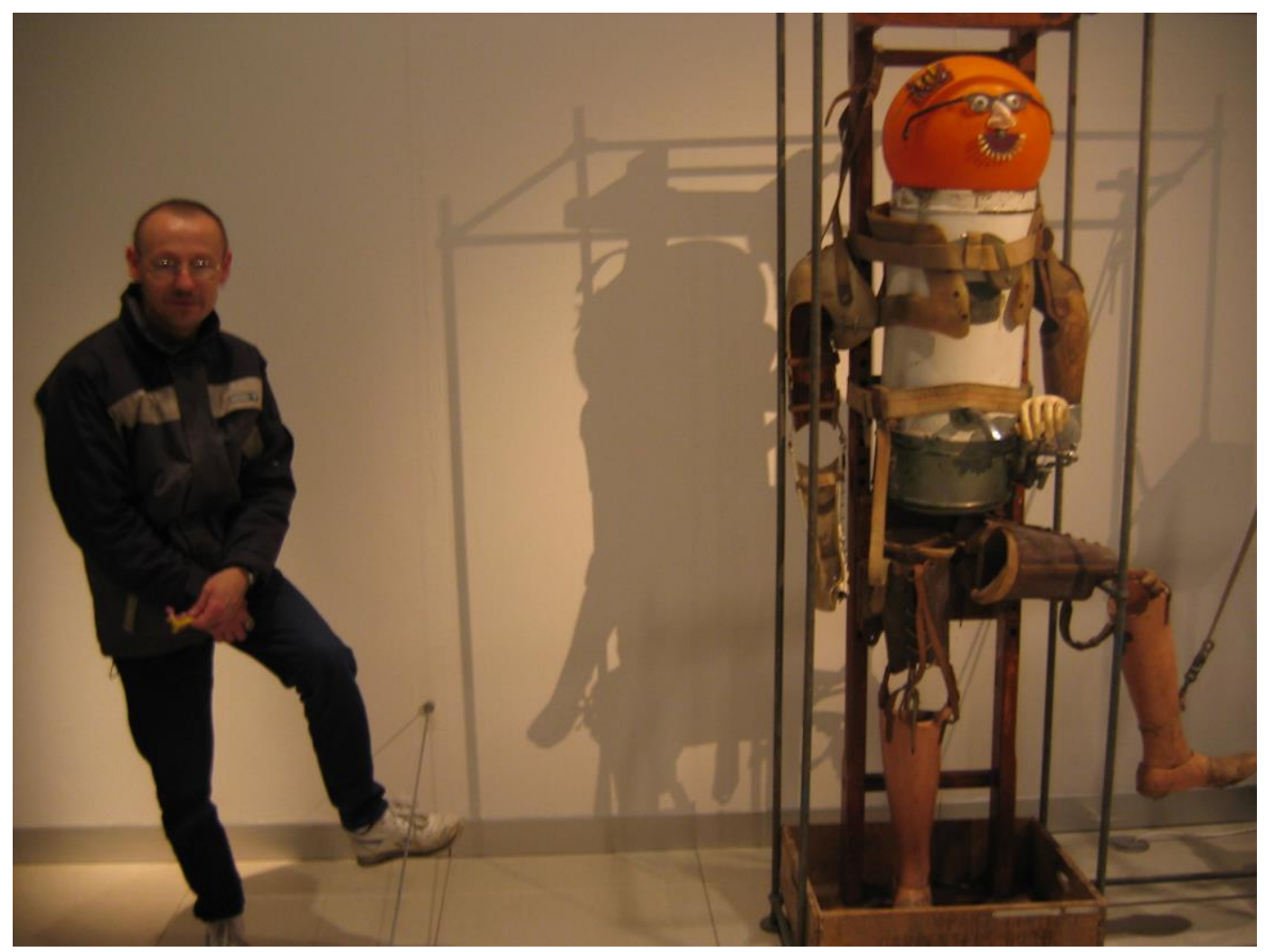

In examining notes written on the interview format sheets subsequent to the interviews, it became obvious how little the researcher had recorded at the time of the interview. This was explained by the researcher's need to hold the attention of the participant throughout the interview e.g. maintaining eye contact and interest whilst moving the computer screen on to the next photograph, with little time to write. On reflection, the researcher realised the benefit having a note-taker present would have been. Someone, who in addition to the researcher, would be able to record the interview's extra (non-verbal) context such as body language, glances, seating positions, mood, background distractions (Kneale, 2001). Like Kneale, at the time the researcher had to rely purely upon memories of the interview to add any observations to the transcripts of the mini-disk recordings.

Towards the end of the interview the researcher moved the focus of the discussion onto the future site visit to the Yorkshire Sculpture Park. During this section of the interview the researcher assessed the worth of the participants own drawings as a source of information and experience applicable to more conceptual situations. The drawings 
worked well within this context, the participants were proud to have produced them and they represented positive elements of what parks could contain. Although sometimes unrealistic in their answers (for example Graham's attraction to banana trees growing outside in Britain) they encouraged discussion and prompted shared memories.

\subsubsection{Summary}

As has been discussed throughout this commentary many ethical issues arose during the establishment and implementation of the described interviews. The interviews were ethically sensitive as participants are members of one of the most vulnerable groups in society. The researcher's approach aimed to be as appropriate as possible through commitment to the following:

- The building up of relationships.

- Receiving informed consent from the participants and their supporters.

- Making aware and available (to both the participants and their supporters) details of the project as it progressed on a weekly basis.

- Carrying out the interviews in a familiar, neutral, non-threatening but respectful setting (to show the value that was attached to their contribution).

- Supplementing of oral questioning with a discussion approach.

- Utilising participant produced visual resources.

In retrospect although the researcher felt happy with the general approach, it was noted that a number of improvements could be made. Firstly, in addition to carrying out individual formal interviews, more informal recorded discussions could be used whilst the group were onsite during trips and in the drawing workshops prior to the interviews. Secondly, the transcripts of discussions could be used in the formal individual interviews to focus on more specific points of interest that deserved greater analysis on a one-to-one basis. People with learning disabilities do not always interact with their peers as other groups might, and tend to communicate on a one-to-one basis, mainly with those supporting them. Therefore, the researcher decided to continue to focus on using a oneto-one approach (be it formal or informal, discussion or interview situation), whilst remaining open to recording and encouraging instances of interactive dialogue between participants. Thirdly, as previously discussed, was involvement of a third party to take notes during interviews. Due to an awareness of the sensitivity needed when working 
with vulnerable people, it was felt the appropriate approach would be to involve an individual already known to the participants, someone with whom they felt comfortable. It was anticipated this method of interviewing would be useful when working with other individuals who might be unconfident or vulnerable in a formal, oral interview context. These could include children, people with dementia, individuals whose first language was not the one in which the interview was conducted, and people from different cultural backgrounds (who might find the manner in which set oral questions were asked to be uncomfortable or even offensive). Fourthly, support staff would complete a questionnaire to incorporate their reactions to the participants' experience of the site visits, the project in entirety (and it methodological elements). To conclude, through evolution of the semistructured interview, the researcher levelled power relations and obtained valuable insight into participant perspectives whilst avoiding reliance upon verbal communication ability. The researcher's approach to interviews continued to evolve over the next two years, fine-tuning the process to tailor the individual's needs. Finally, work during the Millennium Gallery project had resulted in the incorporation of a number of new elements into the developing methodology: photo-elicitation in semi-structured interviews and note-taking by support staff.

\subsection{The Yorkshire Sculpture Park: a coming together of methodological techniques}

\subsubsection{What we will need}

The Yorkshire Sculpture Park (YSP) was the second public open space visited by the researcher and participants, and provided the opportunity to trial the emerging toolkit in a far more structured fashion than previously possible. The following description, analysis of the visit, and the subsequent visual communication workshops, provided the provisional toolkit template taken forward into the main studies.

On announcement the site visit was approaching the participants expressed intrigue and excitement. Most interest came from the notion everyone was going out on a trip in the minibus. For many, this would be their first experience of the site. This drew the researcher's attention to the issue of general lack of exposure amongst the participants to parks and public open spaces in their local area. For example, in providing the participants with background information as to the nature of the site, a number of the 
participants inquired as to whether the sculptures at the YSP would be the same as those they had seen during the visit to the sculpture exhibition at the Millennium Galleries. This previous trip appeared essential as it provided a rare comparison of public space experience (be it interior or exterior) over which the participants had ownership.

On the day of the site visit only one physical preparation was necessary for the comfort of one of the participants, that being a wheelchair. The participant concerned had asked staff that one might be provided, as she felt unable to walk long distances on foot. All other participants and their carers had been briefed to bring suitable clothing, footwear and any medication, which they received daily.

\subsubsection{Informed arrival}

On arrival at the YSP a disabled parking space was easily located close to the entrance of the YSP galleries and cafe. The building immediately drew the group's attention, and questions were raised with regard to presence of a café or shop (identified during previous introductory drawing workshops as being one the most familiar elements, to participants, of parks and open spaces). A group decision was made to enter the YSP galleries before exploring the park. It was hoped this would provide an interesting introduction to the park and the range of sculptures that it held. Entry to the buildings was along a wrought iron walkway bearing the names of all those who had contributed to the park's funding and development (4.10). In subsequent interviews it emerged that although participants remembered the walkway, few had read it and for some it caused considerable distress. Of the six participants interviewed three made a connection with that of the writing on gravestones. One male participant's father had recently passed away, and when confronted with the photograph he responded, "I don't like that one, reminds me of my dad, I'm missing him". 
4.10

Yorkshire Sculpture Park: Peter ${ }^{9}$ on the iron walkway

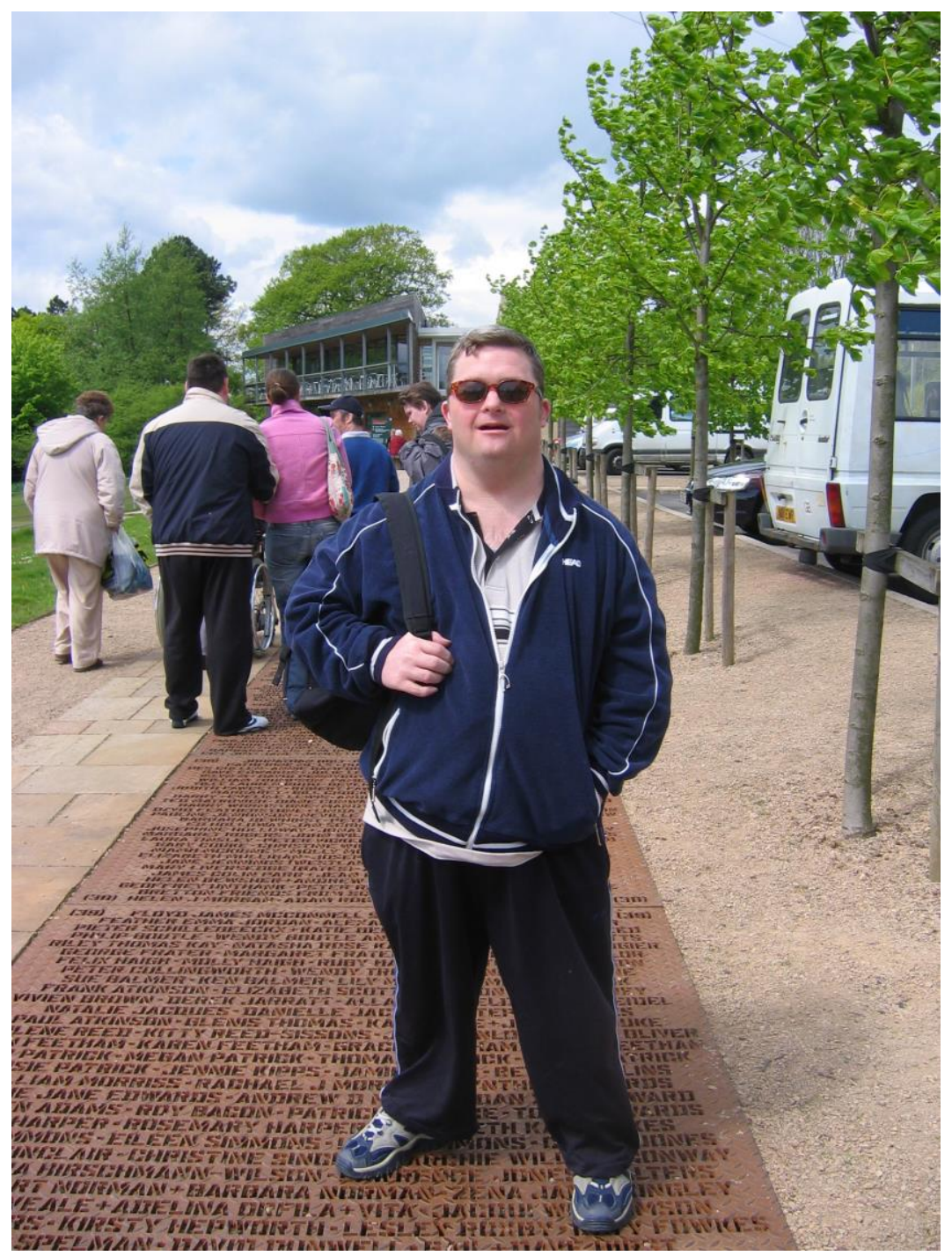

Another participant, who had also made the gravestone connection commented:

“It looks like a grave doesn't it, when you put names of people on” but added, "I liked it really 'cos you could read them". This appreciation of writing was echoed in another female participant's interview. However, although this participant had admired the walkway for its visual impact, she had not made any attempt read the names. This was the first of many examples in the park that illustrated the importance of elements in the landscape was derived from the participants ability to make associations with known factors from their personal home lives and interests, be it family, friends, film, television programmes or routines.

\footnotetext{
${ }^{9}$ Peter is a pseudonym
} 


\subsubsection{Indoor visual communication}

The building itself provoked little reaction from most participants. However one female participant, Tracy, became excited when she discovered a display of pottery, and requested if she might take a number of photographs as a record. During Tracy's interview she responded strongly to these photographs, recalling how, "in the museum ... I liked it, it had nice ornaments in it like them pottery things". Observing her photographs with interest Tracy said, "I liked the shape, how they made it" whilst hand gesturing the making of a dish (4.11), "Yeah I liked that one 'cos it's pottery, 'cos it looks like an ashtray". Another photograph of pottery inspired the remark, "and that one looks like a pair of shoes". These comments represented the peak of interest in the YSP interview for Tracy, a conclusion reinforced by the penultimate interview question, "Which was your favourite sculpture?” to which she replied, “That ornament thing, that pottery...'cos it looks like a shoe". The association she made between the pottery and familiar objects such as shoes and ashtrays gave the participant confidence to elaborate on her thoughts during the interview, which at other points she was unwilling to do, illustrated by her repeated enquiry, "How many more is there?" The simple, clear patterns of the pottery reflected the participant's own style of artwork produced during the drawing workshop post the site visit. The clean nature of the pottery appealed to the participant who in the past had disliked physical contact with things that she perceived as unclean.

Whilst inside the YSP visitor's centre the group watched an introductory video to the park and sculptures they would see later in the day. During interviews back at the Day Service Centre it became clear that although the participants had watched the video eagerly, its format and subject matter had not held their attention. General participant response regarding the video's content appeared vague and disinterested i.e.: "Video about their work...didn't tell anything about the park". Little or no connection was made between the images the participants viewed on screen and the concept of experience of the space. The format of video provided a familiar visual communication method, however it did not allow them to interact with their environment and did not inform their visit. 


\subsection{1}

\section{Yorkshire Sculpture Park: Tracy's photograph of pottery}

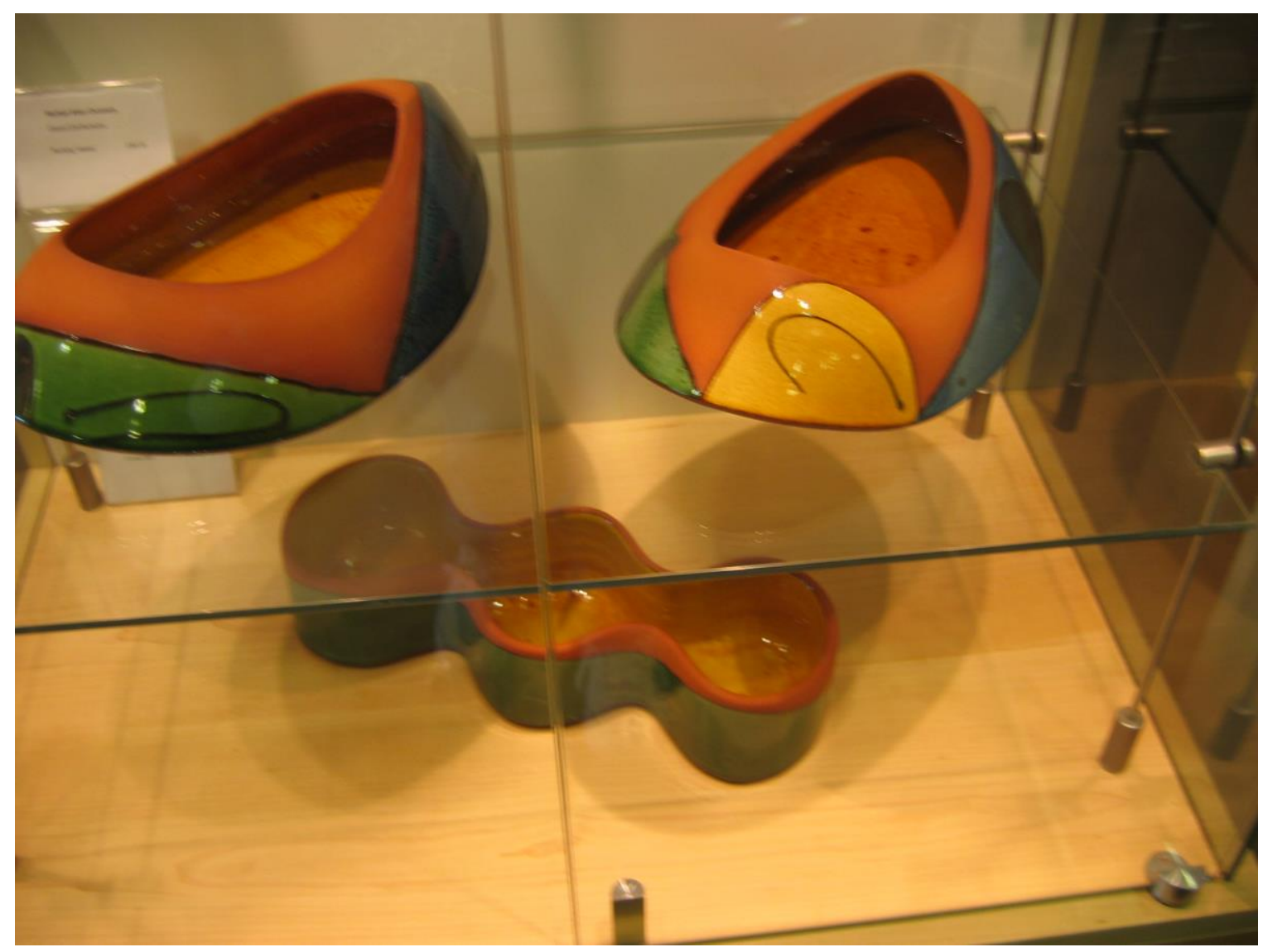

Inside the YSP galleries, as with other exhibitions, the participants were unable to make physical contact with the sculptures on display. This became a frustration and a disappointment to some who had to repress their natural instinct to touch the exhibits in order to fully understand them. Graham remarked, "How come it is you can't touch them inside the gallery and only the ones outside? I wonder why they tell you not to touch them?" As a result of this, the participants' behaviour inside the galleries was subdued. The gallery provided yet another environment that was dictated by rules, enforced by others (YSP enablers) a reflection of the external control participants encountered regularly in their day-to-day lives.

\subsubsection{Going outside}

The group ate lunch outside at the picnic area. When interviewed regarding this decision to eat externally, rather than in the café, all responses were positively in favour bar one. 
Brian commented he would have preferred to eat inside where he could, "watch telly". This again highlighted the overwhelming influence daily routine and familiarity of surroundings plays in the perception of new situations for people with learning disabilities. In everyday life they have limited control over such routine events such as meal times, as they are often living in supported accommodation or with elderly parents who have set routines. For the rest of the participants who responded positively, eating outside generated such comments as, "I like eating outside" and, "'cos you have a picnic don't you outside". The experience was special to them for the precise reason that it was different from their daily routine. When asked if they generally preferred being outside or inside, the answer was unanimously in favour of outside from all participants, with responses such as, "I thought it was lovely, I thought it was nice". When questioned further as to why this was Graham answered, "because there's things to see outside, lots of things to see".

Once in the park, the participants were free to explore the environment utilising a wide range of senses to inform their judgements and comments of the experience. The importance of direct contact with the landscape was reflected in the participant interview response to photographs taken outside. Interview discussions regarding the exterior environment were on the whole more emotive, descriptive, perceptive, and informed compared to those concerned with the interior experience. In interviews this was reflected by reduced participant reliance upon visual prompts to in order to recall memories of the park. For example, one of the first comments made by a participant, prior to viewing his set of photographs, was he remembered, "That big lady, she seemed real". Although relatively abstract compared with other figures, the sculpture was instinctively a woman for him. He had touched her, mimicked her pose and understood her.

\subsubsection{Space and shape}

The landscape in which many of the sculptures were situated was pastoral, one of rolling fields and mature far spaced oaks (4.12). In their interviews the participants were asked to examine the landscape in these photographs and decide whether they enjoyed being in open fields compared with the latter, more wooded, landscapes in the park. The group was split as to whether open landscapes were more preferable to enclosed environments. Some participants enjoyed a diversity of spaces. However, what became evident (through behaviour, photographic records and interview responses) was that the open fields 
provided an environmental opportunity for male participants to use their bodies in way in which they normally felt inhibited or unable to do so otherwise.

4.12

Yorkshire Sculpture Park: participants experiencing sculpture in the landscape

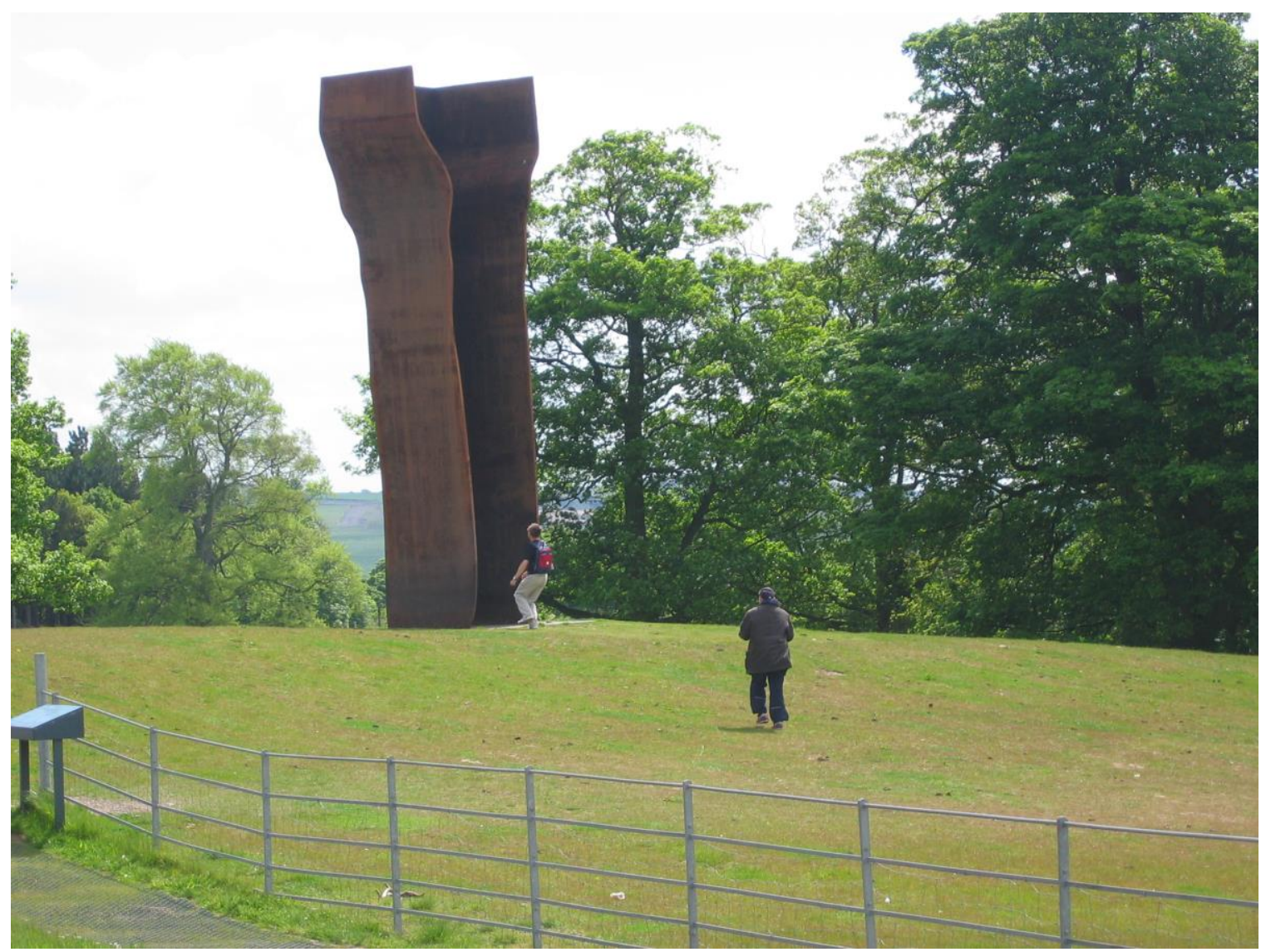

Graham's response to being asked, "What was the best thing about the park?" was to reply, "running about" whilst Peter's favourite photograph was: "that one with Brian messing about. It's good that, hard play, fighting”. To reach far placed sculptures before their peers, the participants ran between them in the open landscape. Their desire was to be the first to climb onto the sculpture, and the first to pose with it for a photograph (4.13). Participants, such as Peter, recalled in their interviews the exertion that this level of activity (not present in their day-to-day lives) had caused them. Peter, "I was out of breath, and that other time I had to sit down 'cos I fell over'. Participants' great sense of achievement was highly evident in their expressions captured by the photographs.

The sculptures in the YSP were all at human scale or larger. This enabled the participants to experience being on top of or inside the art. In turn, this provoked different 
reactions from males and females. All the men were eager to make the sculptures their own through naming and exploring them physically. The women were more reticent. In an interview with Claire ${ }^{10}$, the researcher posed the question, "This next one is everyone inside that sculpture we saw, what do you think about being able to climb through the inside of them? Would you have liked to be able to do that?" Claire made no response. During the day she had chosen to take on the role of note taker, writing down her observations, making active comments but not experiencing physical contact with the sculptures. Another female participant, Tracy, answered, "It's alright being outside [the sculptures] but not inside”, later adding: “yeah, but I didn't go inside, I didn't want to, I stopped outside". The female participants fear of the unknown, prevented them from additional sensory experiences that might have added to their personal understanding of the sculptures.

4.13

Yorkshire Sculpture Park: Brian and Gordon inside the "apple core"11

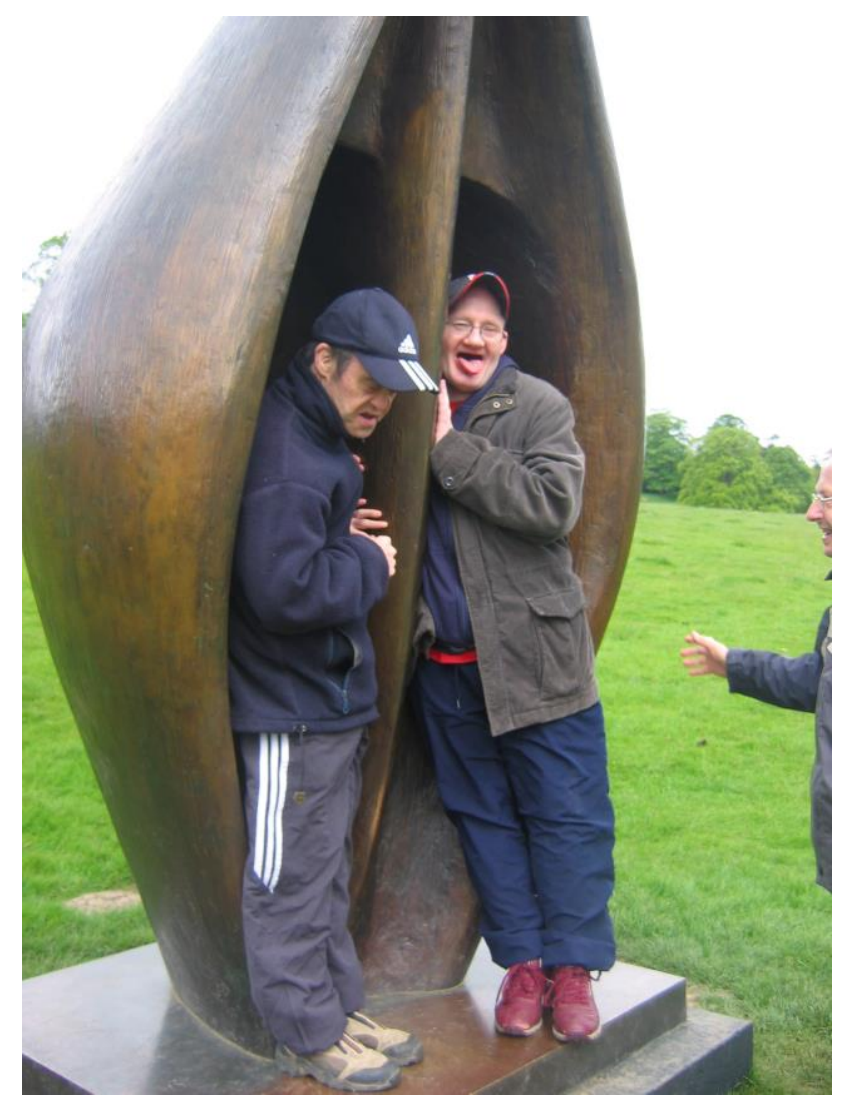

${ }^{10}$ Claire is a pseudonym

${ }^{11}$ Brian and Gordon are pseudonyms 
In the case of Tracy, her highly sensitive observational skills allowed her to understand new experiences in the park through the actions of others. Tracy acknowledged this when in response to the researcher's comment: "This is you standing outside [the sculpture], would there have been any reason for you to go inside?" she replied: "no, just like watching the others" (4.14).

\subsection{4}

Yorkshire Sculpture Park: Tracy waiting outside the sculpture

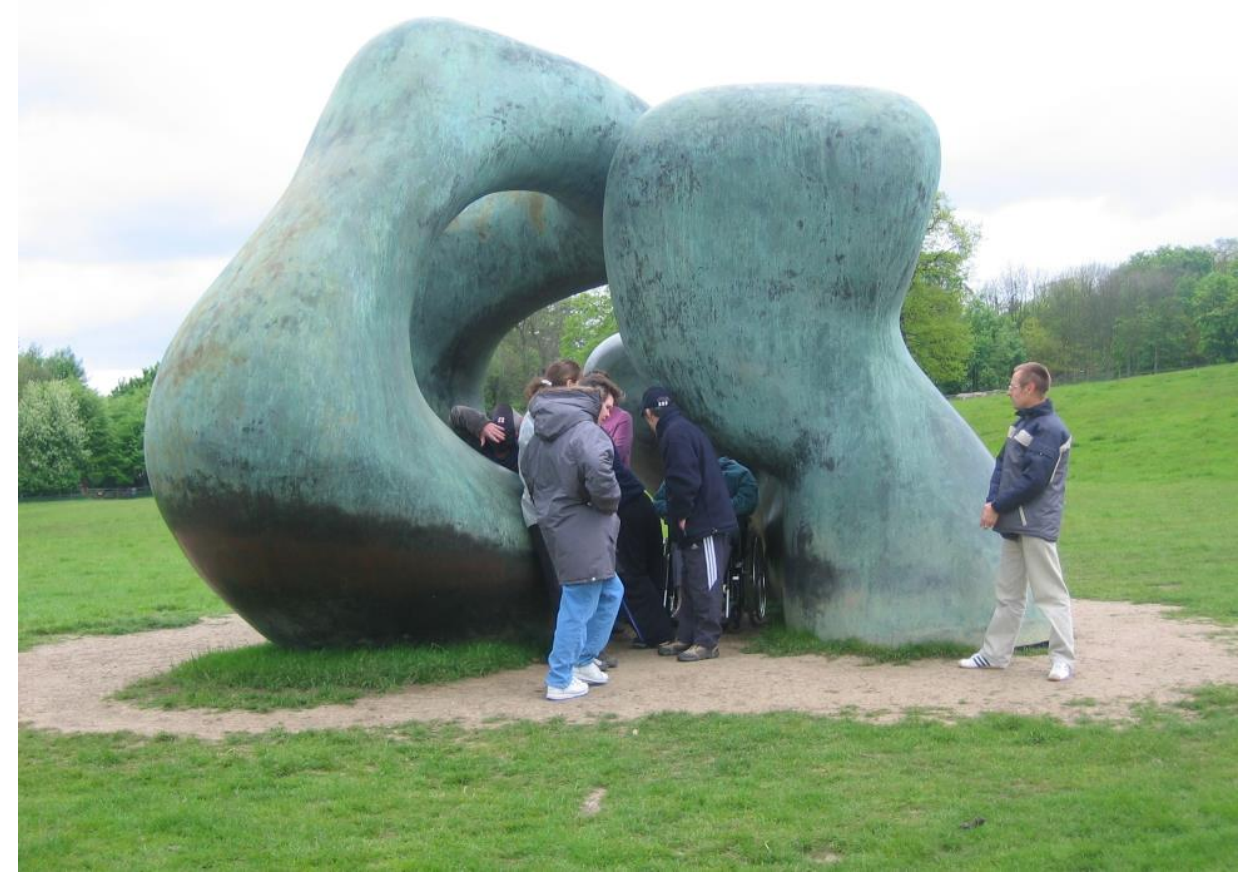

\subsubsection{Stimulation in the landscape}

Generally the participants relied overwhelmingly upon their visual sense to make judgements and evaluations of different elements within the YSP. However, their tactile experience of sculptures and landform produced interesting responses during interviews.

An initial observation from the site visits and interviews was participants were often unaware of the type of material (and it's inherent qualities) sculptures were constructed from. During interview discussions, participants would make connections between the object they visually perceived (determined by familiar references), and the material that this notional form should be constructed from. For example, in describing an iron tube sculpture Claire said, "It looks like one of those chimneys, a proper chimney". When asked what she believed it to have been made from, Claire replied, 
"now that top bit looks like brick". Although the sculpture in question was constructed entirely from metal sheeting, this material is never used in the building of household chimneys and therefore never occurred to the participant.

The issue of the participants' limited understanding of materials and their inherent qualities extended to the landform and it's surfacing. Whilst walking around the YSP, Peter slipped on a stony path and grazed his knee and shin. At the time this caused him only minute distress, for which he was comforted by his peers, and preceded relatively unaffected around the site. During the interview Peter, remembered vividly falling over, "umm I like it [walking in the park]. Not when my leg's sore" and, "I hurt my leg, I slipped down. He's looking at my leg". However, of all participants he was only one of two to distinguish the impact falling upon a hard surface had contributed to his injury. When Peter was asked, "what does it feel like to fall on grass?" he answered that it too would be hard, but that it would have been better to fall on grass than he had done on stones. Without direct, personal experience of falling, the other participants' responses were uninformed and unsure, changing the cause of incident between a rock, tree and, "he went dizzy didn't he?" when the group were running uphill on grass. They were unable to make connections between surface nature and severity of injury.

This may again be explained through a lack of experience. On a day-to-day basis most of the participants' spend their time in safe, indoor environments, or else on prescriptive routes where unknown, or unseen, dangers are minimised by protective families and carers. As a result, the participants were not as naturally inquisitive and daring as they might be. Straying from the known route onto grassed areas, or off into more wild, wooded environments was unfamiliar, and a source of potential danger for some. In contrast, hard surfaced paths were familiar and therefore safe.

Another sensory experience brought into play through sculpture in the YSP was sound. The sound shelter (4.15) played music from different points around the seating area and was enclosed overhead by vine-like vegetation. Although music was the obvious sensory stimulant (and made the shelter different from other sculptures) it remained memorable to all those interviewed for a wide variety of reasons, with only two of the participants recalling having heard music. For these two male participants, music was a powerful element in the landscape but only in conjunction with the physical form of the shelter. When asked: "We went inside here, what did it feel like once you were inside?" Peter replied: "Music". 
4.15

Yorkshire Sculpture Park: the sound shelter

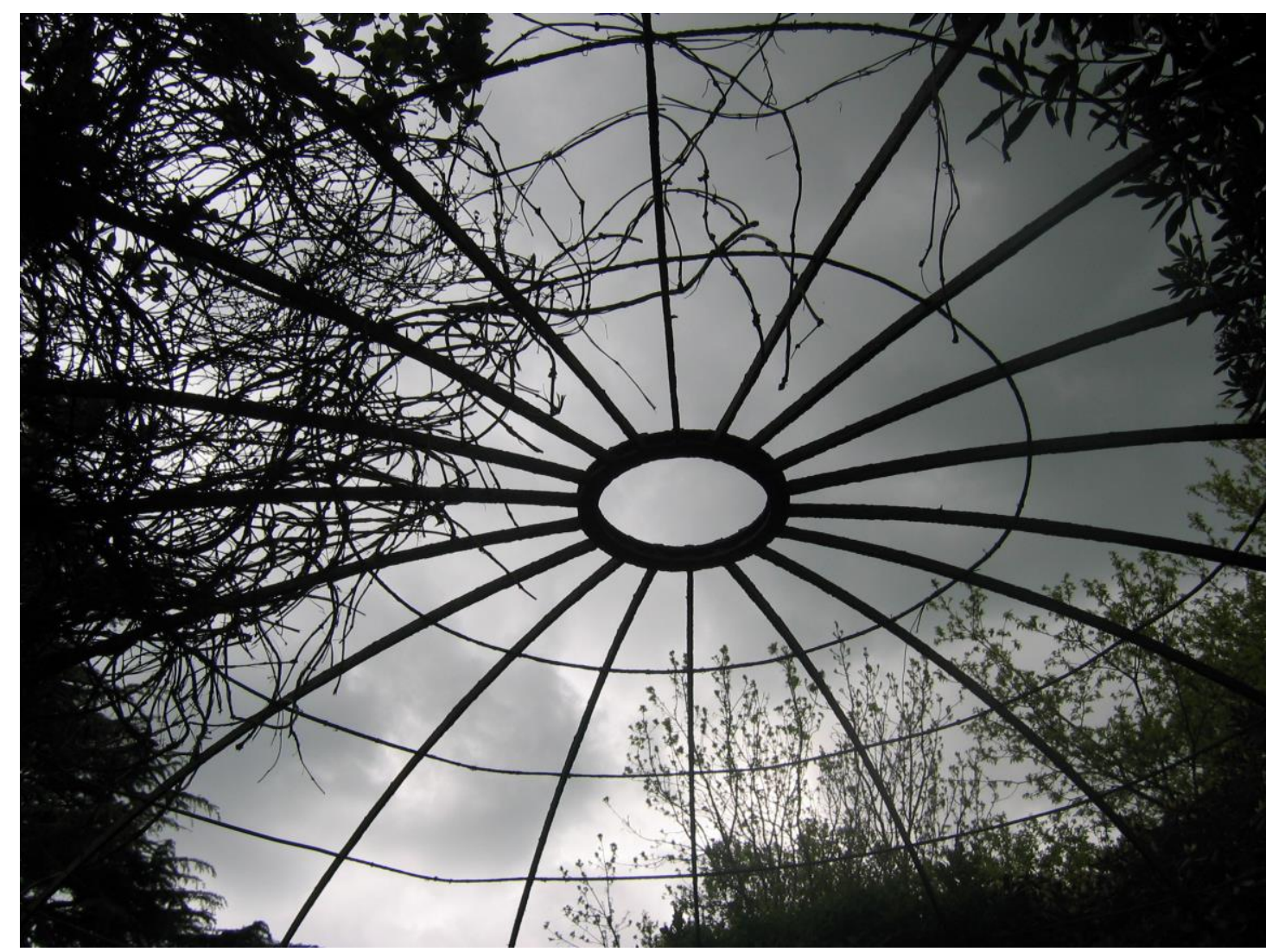

Peter, elaborated on this statement explaining how he had enjoyed listening to the music and it made him feel, "Weird, like aliens were coming down, E.T.”. Peter has a strong imagination imbedded in the wide variety of films and television programmes he watches. In normal conversation he enjoys taking on the roles of various heroes for his own entertainment and that of others. The reference to E.T was one of many film references made during the YSP visit, which allowed him to express his knowledge, and enjoyment, creatively. Graham who had also recalled hearing music was asked during his interview, "In this one [photograph] can you remember where you were sitting?" to which he answered confidently, "Yeah, under that thing where the music were playing, that musical bench". He too enjoyed hearing the music, a feeling of happiness strengthened by the physical form of the shelter where he replied, "I felt like I was undercover".

For other participants, who had not mentioned the sound, it was the shelter's unusual form that struck them. With regard to the sound shelter photographs Claire 
excitedly remarked, “And that looks like glass don’t it, it looks like glass”. Claire had tried, and succeeded to connect the form of the sculpture to that of an object more familiar in her everyday life, the panes of glass in windows. Another participant, Brian, commented on the vines, "Over, over tree", which represented the special element of the shelter for him. Tracy, who had refused to go inside other sculptures, was again unsure of being inside the shelter, although she was obviously intrigued by it and took a series of photographs. Tracy commented, "It look like a tent... yeah I like it, but not too much". Again, she was unwilling to remain inside the shelter for a long period of time, but happy to observe and record the behaviour of other participants.

The sensory impacts of sight, sound and smell came together when experiencing other life on site, namely animals. Although the only noticeable fauna in the YSP were a small group of geese, photographs viewed during interviews, created nervous reactions from some of the participants. Peter said, "No, no I'm not sure about them", "Not ducks, always begging for food...no they're just always begging. When we're on holiday my mam doesn't like them", whilst Tracy commented, “Geese, I'm not too keen on geese... I like them, but I don't like them flying around. Sorry about that". All participants recognised the geese as being a type of bird, though most mistook them for ducks. The participants were unfamiliar with the geese and unable to anticipate their movements, this made them cautious about having any contact with the birds. However, interestingly, when asked if they would like to see other animals in parks, all participants replied enthusiastically in favour. The range of animals they responded with was imaginative; blackbirds, rabbits, elephants, kangaroos (“Skippy roo”), giraffes and donkeys. They were unconcerned as to the suitability of the space or climate for the animals, but were animated when thinking of the most exotic and wonderful animals that they could have contact with.

\subsubsection{Personal perception}

Through self-directed photography, the question of perception of personal safety by the participants and other people with learning disabilities arose. Safety may take on different meanings in different contexts. It is an issue people with learning disabilities face on a regular basis, as support agencies and parents/carers often have to assess the suitability of new situations for people, before the individual experiences them. What arose from the site visits was a question of nature or nurture? People with learning disabilities may be perceived as vulnerable due a number of factors, which the researcher observed firsthand. 
These include: their innate trust in others, their dependency on those around them for support, and their lack of life experience due to limited exposure and integration in the mainstream community. However, the question remains one of morality. Is it right to assume that because people with learning disabilities seem unaware of potential dangers, society should overcompensate through enforced protection and restrictive attitudes in new social or environmental experiences? The researcher believes that as the participants in this research are not children, encouraging a greater awareness of personal responsibility, safety and individual choice must be promoted. A practical example which illustrates the daily dilemma for family and carers regarding the personal safety of people with learning disabilities, occurred during the first public open space site visit to the Botanical Gardens.

During visits to Botanical Gardens and the Millennium Galleries, the participants' enjoyed the opportunity of interacting with the public in new environments. At the Botanical Gardens one female participant separated herself from the rest of the group and engaged in conversation with a number of male members of the public and site staff. These visits gave her the opportunity to meet men (in contrast to her female dominant home environment) and provided great enjoyment for the female participant. In each case, these interactions proved harmless and entertaining. The participant was always in physical reach and hearing range of the group. Once the participant had engaged in conversation with a member of public the group would quickly join her side in support. However, the researcher was aware of the potential danger that might arise due to these approaches by the female participant. The issue of trust plays a significant role in these situations with questions arising as to:

- How much trust do we have in the public not to take advantage of vulnerable people?

- How much trust do we have in people with learning disabilities to accurately evaluate the appropriate nature and behaviour of members of the public in response to their advances?

- Do people with learning disabilities unintentionally display provocative behaviour?

- Is it right to curb the enthusiasm and interest that people with learning disabilities have about the general public?

Parks and public open spaces provide a wonderful arena for human interaction that might not otherwise occur. These interactions (if positive) enrich our lives and lead to greater understanding, tolerance and interest in our communities. For people with 
learning disabilities and their supporters the issue of safety and awareness is a complex one. As one of society's previously invisible groups, people with learning disabilities have suffered from a legacy of misunderstanding. The researcher believes that interactions in places such as parks, between the public and people with learning disabilities are dichotomous in benefit. The public is provided with the opportunity to reverse misconceptions and widen their outlook. In turn people with learning disabilities gain experience in social relations beyond those with carers and parents. They learn appropriate behaviour through actual situations not hypothesised scenarios. The true question, is not how much faith we have in people with learning disabilities to behave within the limits of what society might deem suitable, but whether we trust our communities not to abuse inherent vulnerabilities in people with learning disabilities. Ultimately the answer lies with the public who must begin to appreciate the diversity people with learning disabilities bring to society.

\subsubsection{Emerging experiential themes}

The experiences of the participants, the photographic record generated during the site visit, and the ensuing series of art workshops and individual interviews, together produced a wealth of information about this particular public open space. The personal nature of this information was revealed when the researcher asked the participants to produce an individual canvas that utilised all the resources gathered to depict their own experience of the site $(4.16,4.17)$. In addition, staff members present during the site visit were asked to record their observation of the group's behaviour as they moved around the YSP. This provided a secondary source of experiential data from those who knew the participants well. The researcher then employed a detailed qualitative analysis, or DIDEC, as described in Chapter 3 Methodological Approaches, 3.4. The mass of visual and written data was assimilated, critically analysed and reduced into eight contextually determined and emergent themes. These themes have the capability of influencing the specific landscape experience of the participants at the YSP. 
4.16

Yorkshire Sculpture Park: Claire's canvas

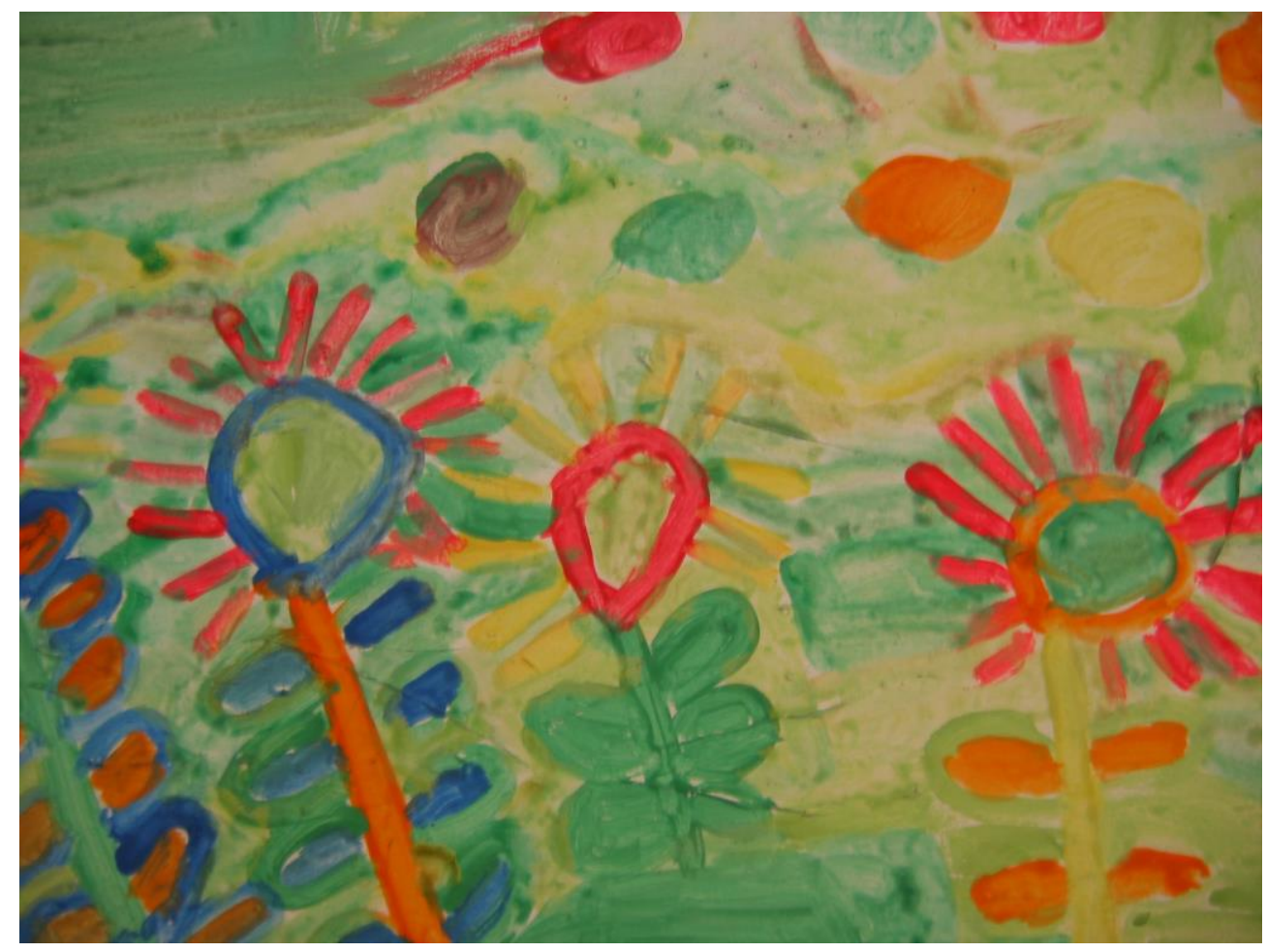

4.17

Yorkshire Sculpture Park: Tracy's canvas

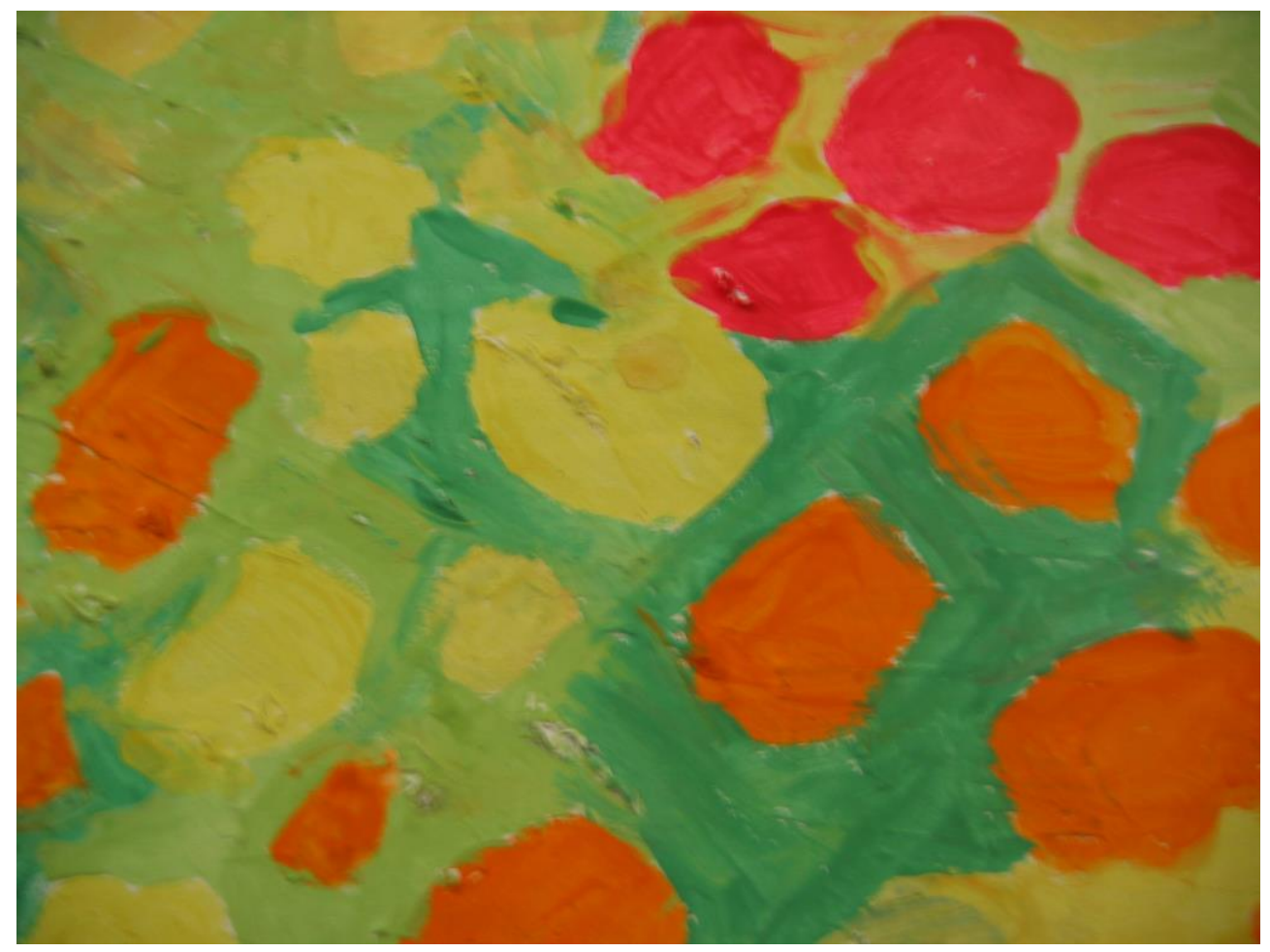


- Art.

This had the immediate effect of supplying a focus for participants in the landscape. The form of the art itself appeared unimportant, as with the rest of the population personal preferences varied i.e. some liked sculpture, some paintings and others pottery. However, texture and personal contact with the art was crucial. Variations in texture from smooth to rough were stimulating, as was the use of varied materials such as stone, wood, metal and plastic. Differences in size and scale were also important. Participants revelled in the personal discovery of small and delicate artwork, pieces on a more human scale created a sense of self-reflection, whilst the large sculptures commanded drama and impact.

\section{- Vegetation.}

Although most participants did not comment directly upon vegetation on site, key variations (such as density), signalled marked changes in participant behaviour. Where the landscape was sparsely vegetated and open in character, participants behaved far more freely running about and exploring. In contrast, areas of the park that were enclosed caused participants to slow down and behave far more cautiously. Like art on site, scale also factored in planting, as did individual species (be it ground cover, herbaceous, shrub or tree) upon overall participant memory of the site. Small species, unless flowering and therefore colourful, attracted far less attention than the far larger mature trees. Most important to the group were lone specimen trees that formed natural focal and meeting points. The participants seemed unconcerned whether vegetation was formally maintained or left to grow wild, unless it affected their ease of movement through the site.

\section{- Safety.}

An important issue covered in some detail earlier in the chapter. Well-designed landscapes can aid awareness of possible dangers and other users etc. Instinctively, the participants favoured areas of the park that were open with good visibility. This had a great effect on their behaviour and willingness to try new situations. The researcher interpreted this as; these were environments in which the participants felt safe. In a safe environment, experiences that might have negative connotations, such 
as falling over and grazing your knee, could be easily recovered from and provided a learning opportunity of what should be avoided in future.

\section{- Access and information.}

The researcher and staff supporting the participants made a number of preparations and inquiries before the day of the trip. However information requirements directly from participants, focused more upon the idea of site experience than physical access. Disabled parking spaces and accessible toilets were the only essential on site facilities required by the group. The participants did not utilise any of the written information at the YSP and the visual map was difficult for many to conceptualise and relate to the landscape they saw before them. For most until they had experienced the site first hand and taken their own photographic record the trip remained a fantasy they were unable to explore.

\section{- Seating.}

There were many comments from participants regarding seating. Both on the day of the site visit, and during individual interviews back at the Day Service Centre. For most, exploring the YSP was an exciting, yet tiring, experience. Unused to such physical exercise, frequent stops and seating became an issue for the group as a whole. Participants talked about wanting choice in seating and seating that would accommodate different body types. Varied location of seating was also discussed, with participants wishing to be able to pause for breath along main routes, have private space away from the paths, and take advantage of views across the open landscape.

\section{- Sensory experience.}

Any landscape is sensory, it has a sound, a sight, a smell, a touch and if one wants, a taste. The YSP stimulated four of these senses in the participants; sight, sound, smell and touch. Sensory stimulation does not always have to be designed, in the manner of the once fashionable sensory garden. It can be incidental, transitory and evolving and ultimately far more personal and memorable. At the YSP sound came from such designed sources as the music installation, and non-designed such as the movements of other users, traffic and rain. Sight and smell may also be purposely or incidentally 
stimulated: views are created but change, bursts of colour in planting surprise the viewer but may be artificial or seasonal, walking across a pile of sheep dung may not be pleasant but creates memory. Touch was brilliantly stimulated at the YSP, through vegetation, surfacing, site furniture and art. In this way, the participants learnt more about the environment than a leaflet or video could ever convey. It is through allowing and encouraging behaviour (utilising all senses) that an appreciation for landscape grows.

\section{- Animals.}

At both the Botanical Gardens and YSP, the presence of animals contributed to a stimulating environmental experience for the participants. The way in which the animals moved, i.e. squirrels furtively bounding about and geese waddling, created an unpredictable dynamic in the landscape. These new individual experiences, inspired associated memories of different public open spaces, where participants had encountered animals whilst out with family members or carers. The physical sites may have been different but a chain of ownership was constructed through the experiential dimension of space.

\section{- Play.}

In the eyes of most, the worth of play is often restricted to children and deemed the possession of the young. However, through exploration of the YSP experience, during visual communication workshops and interviews, it emerged that play was just as important for adults with learning disabilities. It was a release from the restriction of the rules of others, and a creative means by which individuals could express elements of their personalities. Play, or 'fun' as it was described by one of the participants, took many forms: formal, informal, active and observational, to name but a few. Through play the participants experienced freedom, such as making choices to deviate from main routes and running off to explore the park from a personal perspective. The most marked difference that separated how individuals in the group approached and experienced play was between the men and women. Masculine play utilised the environment (and each other) for physical challenge and reward, through activities such as climbing and wrestling. The women were inclined to be far more observational, taking photographs, notes or drawings. Their play came at a distance, 
appreciating the actions of others, and responding verbally to encourage their peers. Positive play at the YSP was a product of not only the physical setting but also the social one. The YSP provided a non-judgemental space, where the behaviour and bodies of the participants were free from public control or negativity.

\subsubsection{Language, verbal and visual}

Research with participants exploring the YSP experience drew attention to the benefits of different elements in the toolkit as well as refining certain approaches. Researcher language during the semi-structured interview was one area that came under scrutiny. It emerged that certain terminology was difficult or meaningless for the participants, this included the words: landscape, woodlands, historic, material, area and open. More useful or meaningful words were: park, trees, old, inside and outside. The approach to questioning also evolved in reaction to participant action. As in earlier interviews regarding the Millennium Galleries, direct questioning did not always produce a response from participants, and more often than not made them feel uncomfortable and unqualified to answer. However, unlike previous interviews the participant showed greater confidence when discussing their opinions of photographs taken on site.

Familiarisation with the process of taking photographs and growing confidence with digital technology resulted in the development of: participant pride, achievement and ownership. A visible sign of this change came as participants' began to express a desire to share personal experiences, artwork, photography and knowledge with others outside the research group. Their confidence in their own ability to communicate their experiences visually now demanded a public arena for dissemination and debate.

\subsubsection{Staff perception}

Observing the close relationship between the pilot study participants and their support staff, the researcher appreciated that the support staff held valuable insight into interactions between participants' prior environmental experiences, their medical history and their social life (with family, at home, amongst friends, and within their community). Therefore at this point in the project the researcher added staff questionnaires to the toolkit methodology. The general topics and questions present in the questionnaire ${ }^{12}$ were generated primarily through exploration of the various dimensions and properties of the

\footnotetext{
${ }^{12}$ Appendices, Chapter 4 Pilot Study, Staff questionnaire
} 
eight experiential themes revealed by qualitative analysis of the YSP site visit. As a result of the questionnaire the support staff's perception of the project and the appropriateness of the communication methodologies employed, could now be included in the developing toolkit. Two support staff assisted the researcher during the 'Our Parks and Gardens' pilot study and their questionnaire responses are summarised in Table 4.6.

From Table 4.6, we can see how the observations of the support staff reflect many of the researcher's intermediate conclusions. Most notably: the effectiveness of photoelicitation as a communication method, the significance of public open spaces as environments released from rules and the importance of physical contact with sculpture and other landscape elements in order to understand the environment. The staff questionnaire also draws attention to the preparatory and organisational role of those accompanying people with learning disabilities on such site or leisure activities. The comprehensive preparation checklist, as described by the second staff member:

- Wheelchair accessibility

- Appropriate transport

- Ratio of staff/volunteers to participants

- Provision of lunches

- Appropriate dress

- Signing in and out of the Day Service Centre

- Maintaining mobile phone contact with Day Centre

- Itinerary information for some members.

These preparations may be time consuming and form a great responsibility for the staff, yet they are essential for the safety of the participants. For older people with learning disabilities, who have grown up within a sheltered or even institutional background, considering these preparations independently and taking personal responsibility for them may not have become part of their daily routine. Therefore, reliance exists upon support workers, personal assistants and family to facilitate their environmental, and other, experiences in this way.

Exposing the participants to a wider range of environmental experiences begins the process of creating new routine behaviour. For example, once a participant has experienced wet weather on a number of occasions they will consider either: not going out in bad weather, or bringing a coat as a necessary precaution. This learning by 
experience is vital to people with learning disabilities that may, through no fault of their own, may have lived experientially restricted lives to date. The risk and preparation involved in changing these circumstances is minimal in comparison to what someone may gain.

Table 4.6

\section{Section 1: Site Visits}

\begin{tabular}{ll}
\hline Topic for discussion & Staff comments \\
& Support staff 1 = regular font \\
& Support staff 2 = italic font
\end{tabular}

Anticipation and
preparation for site
visits
visits
- Members were excited asking, "when was the day of the trip?"

- Members were told weeks in advance as some have difficulties with the concept of time.

- Some members were anxious due to unfamiliarity of place and difference to normal routine.

- Rang sites in advance to check disabled access and facilities were available.

- People were in high spirits looking forward to something different.

- In advance checked: wheelchair accessibility, appropriate transport, ration of staff/volunteers to members, lunches, appropriate dress, signing in and out, mobile phone contact with Day Centre and itinerary information for some members.

\section{Access and information}

- Sufficient facilities were provided on site.

- Pictorial signs would have been useful.

- Maps and signs had no impact, however everyone sat down in front of the television to watch the video -it was familiar and held the group's interest.

- Some paving was uneven and steep, which was difficult for the wheelchair user.

- The group loved collecting leaflets, they responded to the images and enjoyed the fact they could take something away from the day.

- The map was not useful or appropriate as it was difficult for members to read or understand this information format. 
Art and sculpture

- Very positive element in the landscape, sparked imagination, made them explore materials and textures.

- Male members wanted to climb and explore more than the female participants.

- Female members were content to view rather than climb and enjoyed the music.

- Extremely positive, the group responded to the shapes and sculpture trail that allowed them to spot ahead to the next one.

- Male members were a lot more 'hands on, members participants content to watch or become the photographer.

- $\quad$ Form, texture, materials and size all affected the members enjoyment of the sculptures; every sculpture was different and interested the group for different reasons.

- Sculptures could be improved through better access and focus on different senses. 


\begin{tabular}{|c|c|}
\hline Landform & $\begin{array}{l}\text { - The open space seemed to encourage an enthusiasm to run } \\
\text { and spread arms to explore the space around. } \\
\text { - New sense of freedom [when outside] that showed in their } \\
\text { movement and lightness of mood. } \\
\text { - Members enjoyed being outside because they weren't tied to } \\
\text { rules and noise restrictions as they had been in the buildings. } \\
\text { - There were physical barriers - the wheelchair user spent most } \\
\text { of her time in her chair, she chose to sit and look. } \\
\text { - A new shape to explore. } \\
\text { - More signs in pictorial form could improve the site. } \\
\text { - They found it quite freeing, there was plenty of space to run } \\
\text { around, shout loud, explore. } \\
\text { - Inside there are rules that everyone has to adhere to (don't } \\
\text { touch, be quiet) outside there were no restrictions. } \\
\text { They enjoyed being outside when the weather was good. It } \\
\text { did rain at some points, which some members found } \\
\text { - Prustrating. } \\
\text { - to mansical barriers - paved areas, rough ground was difficult } \\
\text { - They enjoyed being in the wooded areas (looked at the } \\
\text { shapes that gnarled old trees made). } \\
\text { - Site could be improved by more obvious routes (using } \\
\text { colours and pictures for guides), simpler maps, more staff } \\
\text { around to support and give guidance. }\end{array}$ \\
\hline Vegetation & $\begin{array}{l}\text { - Some members commented on shapes, structures of } \\
\text { trees/plants. } \\
\text { - } \quad \text { Could be improved with more flowers (smell). } \\
\text { - } \quad \text { Females maybe more interested in flowers than males. }\end{array}$ \\
\hline Safety & $\begin{array}{l}\text { They had to be careful near the stone steps next to the } \\
\text { building. The steps were very wide, so some members were } \\
\text { not near the handrails. } \\
\text { Not sure they are aware of other people's safety (I did a } \\
\text { workshop with another group of learning disability } \\
\text { participants and paired them up into blind/guided walking. } \\
\text { Most seemed not to understand that they had to go slower } \\
\text { and guide the blind person carefully. Most just walked as } \\
\text { normal, not accounting for their blind partner.) } \\
\text { I feel the group are aware of each other's needs and are } \\
\text { willing to help and support each other. }\end{array}$ \\
\hline Seating & $\begin{array}{l}\text { - Could have been more seating in the large open space } \\
\text { (although some of the sculptures doubled up as seating). } \\
\text { - More seating in the form of sculptures } \\
\text { - Seating was not adequate. This is something that I suppose } \\
\text { the park has a problem with aesthetically, more seating } \\
\text { could infringe on the impact of the sculpture. However, the } \\
\text { lack of seating makes it more difficult if someone gets tired } \\
\text { easily and is not able to sit on the grass. } \\
\text { - Occasional benches along the walkways so they could be } \\
\text { easily accessed and wouldn't affect the sculptures. } \\
\text { - Seating was mainly picnic benches, which some members } \\
\text { found difficult to get into. }\end{array}$ \\
\hline
\end{tabular}




\begin{tabular}{|c|c|}
\hline Senses & $\begin{array}{l}\text { - The members enjoyed: the large green fields and liked } \\
\text { touching the large bronze sculptures, they said they were } \\
\text { smooth and cold. } \\
\text { - The members enjoyed: the sound piece, knocking on } \\
\text { sculptures, spotting sculptures to go and explore shapes, } \\
\text { what things reminded people of, climbing on, touching } \\
\text { sculptures, textures and I didn't notice anyone smelling } \\
\text { anything. }\end{array}$ \\
\hline Animals & $\begin{array}{l}\text { - They saw some ducks/geese. Some walked towards them to } \\
\text { get a closer look. } \\
\text { - It was male members' that wanted a closer look at the geese. } \\
\text { - From past experience, I know they like to spot squirrels, but I } \\
\text { can't remember if they saw any at YSP. } \\
\text { - It would have been interesting if there had been some } \\
\text { domesticated animals that they could have seen up close and } \\
\text { maybe touched. } \\
\text { - Important to see the animals in natural surroundings e.g. } \\
\text { cows, goats in a field. } \\
\text { - Some members were keen to spot wildlife e.g. a colourful } \\
\text { bird and a baby rabbit. } \\
\text { - It was female members' who spotted creatures. } \\
\text { - Encounters with animals are enjoyable and important for } \\
\text { everyone. I think it might develop some peoples' interest, and } \\
\text { perhaps inspire some into work they might do in the future. }\end{array}$ \\
\hline Play (activities) & $\begin{array}{l}\text { - } \quad \text { Climbing on sculptures. } \\
\text { - Risks: falling off sculptures. } \\
\text { - They had no physical restrictions to invent their own play. } \\
\text { However, imagination and few past experiences of playing in } \\
\text { open spaces may have been limiting. } \\
\text { - Clambering on sculptures, imagining what things look like } \\
\text { and acting it out e.g. Dr Who and the time machine. } \\
\text { - Risks: climbing around on slippery surfaces and running } \\
\text { through rough grass and uneven ground. } \\
\text { - The members were completely free to invent their own play, } \\
\text { however the staff were keen to let the group see everything so } \\
\text { maybe we moved people on sometimes. } \\
\text { Males more physical, energetic play. Females more } \\
\text { interested in understanding and picture making. }\end{array}$ \\
\hline
\end{tabular}




\begin{tabular}{|c|c|}
\hline \multicolumn{2}{|c|}{ Section 2: Photo-elicitation } \\
\hline $\begin{array}{l}\text { Topic for } \\
\text { discussion }\end{array}$ & Staff comments \\
\hline $\begin{array}{l}\text { Participant } \\
\text { produced } \\
\text { photographs }\end{array}$ & $\begin{array}{l}\text { - More than three members used the digital cameras to } \\
\text { take photographs on site. } \\
\text { - Once they had been shown the actual process of using } \\
\text { the camera, and it was understood, it became } \\
\text { reasonably straightforward for most to use, however } \\
\text { sometimes it was tricky to find the shutter button. } \\
\text { - Photos gave a sense of being in control. A sense of } \\
\text { achievement, when they can immediately see their shot } \\
\text { by scrolling back in the camera. } \\
\text { - I think they enjoyed capturing the moment on film. } \\
\text { - People took photographs of shapes, the group, pottery, } \\
\text { - } \quad \text { The memberures anything that was of interest to the person. } \\
\text { - Photos used as a way of showing what was interesting } \\
\text { but also to take ideas back to Mencap to do in future. } \\
\text { - They enjoyed creating images, posing for them, } \\
\text { exploring imaginative ideas. }\end{array}$ \\
\hline
\end{tabular}

Section 3: Project review to date

Topic for Staff comments

discussion

- Photographs definitely, it jogged people's memories. It would have been difficult to ask questions about a particular place without having pictures to back up the words. 'Which place, time and space?' does not mean anything to someone who doesn't know the time or day. One place may mean another place to their mind without a photo to ground the question.

- The photos give an instant snapshot of what the member is interested in. The paintings and artwork I feel show a deeper, longer lasting impression of their experience at YSP. The paintings also convey a feeling/mood of their experience.

- Other communication methods: Audio recording, maybe a recording of the noises in the park, this might produce other ideas and inspire.

- On the exhibition: I felt they got a tremendous sense of pride and self worth. At Mencap they enjoyed showing friends their work. At the Showroom I remember Peter proud as punch next to his canvas, quite happy to tell anyone who passed that it was his painting.

- Improving the project: Not sure that it can be improved. Possibly soon after the visit have a group discussion about the photos. Possibly make it into a game e.g. glance at all the photos and pick up just one that catches your eye and tell us a little bit about the photo. 


\subsubsection{Summary}

By this stage in the pilot study, the visual communication toolkit neared completion and was fit for trial with new participants and landscapes (4.18). Diagram 4.18 illustrates how the longitudinal nature of the Our Parks and Gardens project had given the researcher the unique opportunity to continually evolve and supplement the toolkit in response to participants' requirements. Through the pilot study the researcher had achieved the aims set: appropriate visual communication methodologies were evolved into a useable toolkit, contact was made with the local learning disability community, and the researcher and participants developed a successful working relationship of understanding and trust. Fieldwork and DIDEC analysis exploring the YSP environment had evolved a set of eight experiential themes with the capability of revealing the contextual and hidden dimension of this public open space for this group of people with learning disabilities.

Identifiable limitations of the pilot study centred on the specific nature of these themes and therefore their restricted application i.e. they were only concerned with one landscape and one small group of participants. However, with the methodology in place, further testing and in-depth analysis during the main studies was seen as the means by which the scope of the pilot study would broaden into identification of universal phenomena. Finally, in response to the actions and requests of the participants, one further element was added to the toolkit and refined the pilot study. The participants wished to make visible their findings and artwork to the wider community and so the research team explored local means for their public dissemination. 


\subsection{8}

\section{Evolving visual communication toolkit.}

Present and highlighted in bold are the developing toolkit elements: introduction day (with a focus on informed consent), site visits, take photographs (photo-elicitation), art (drawing) workshops, participant (semi-structured) interviews, staff questionnaires.

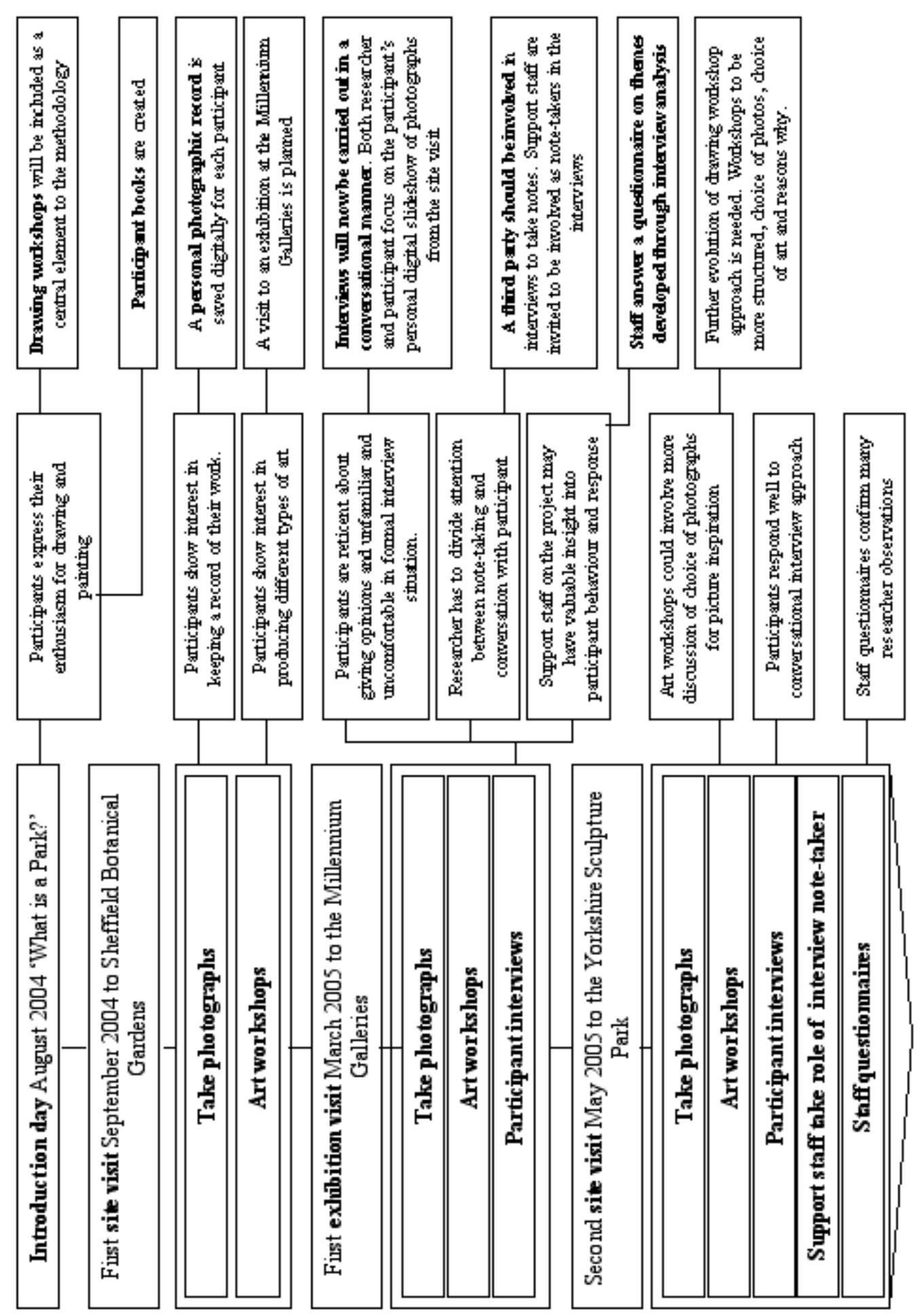




\subsection{Communicating with the community: the importance of dissemination and project ownership}

\subsubsection{Participant self-advocacy}

A foremost advantage of the pilot study was the allowance of time to develop the selfadvocacy of participants regarding their project experiences. A clear definition of self advocacy is provided by People First (1996) who describe self-advocacy as, "speaking and standing up for yourself, standing up for your rights, making choices, being independent and taking responsibility for yourself'. Issues surrounding how people with learning disabilities comprehend the concept of self-advocacy (Simons, 1992; Sutcliffe \& Simons, 1993) and the type of groups involved (Crawley, 1982, 1988, 1990; Browning et al., 1985; Cone, 2000) have been subject to examination since the early 1980's. However, around the turn of the twenty first century other disability researchers have begun to focus attention upon the experiential dimension of being a learning disabled self-advocate (Mitchell, 1997; Goodley, 1997, 1998, 2000; Beart et al., 2004).

In the case of the Our Parks and Gardens project, through the act of participation in site visits, workshops and interviews, individuals gained the confidence to become project advocates. For some this took the form of engaging staff, peers, carers and family members in conversation regarding work they had produced, and activities in which they had partaken. For others, their increased confidence was manifest through verbal and physical displays of pride in their artwork and photography. This was often accompanied by greater proficiency when executing methodological components (i.e. the action of taking photographs and the precise choice of art media to convey landscape experience). Project involvement had resulted in participant change. Participants acquired and developed new skills, and for a few individuals the project facilitated a move towards independence. Some began to question their daily routine and the opportunities to experience new places and social interactions, which were currently limited within it. With this developing awareness they began to become more confident and vocal regarding their right to choose, a living illustration of emancipation.

So far there had been little opportunity to share project developments with the wider community. However, having completed the fieldwork for the pilot study, a natural pause for review and reflection occurred, and from this the need for dissemination. During the pilot study participants had produced a wealth of visual material. In observing the enthusiasm and delight that site visits to the Millennium Galleries had generated it 
was decided to stage exhibitions of participant artwork in Sheffield. These exhibitions provided the public stage from which the project work was viewed, whilst the participants interacted with members of the public. In addition, the involvement of participant peers from the learning disability community was recognised as a means by which further inclusion and insight could be brought to project development. The opportunity to do this arose almost six months post the project exhibitions with a presentation day at the Yorkshire learning disability parliament. The story of these exhibitions and the subsequent Peoples' Parliament (a regional learning disability selfadvocacy assembly) presentation are now discussed and their impacts analysed.

\subsubsection{Exhibitions at the cinema and Day Service centre}

The first group exhibition was held in the light well at the Showroom Cinema, Sheffield, from the $15^{\text {th }}$ to the $22^{\text {nd }}$ June 2005 to coincide with National Learning Disability Week. The site of the exhibition had been chosen with care. Patrons of the cinema, and those frequenting its bar and restaurant, passed through the light well in order to reach their final destination. This provided the opportunity for the exhibition to be viewed by a wide range of people throughout the day and into the evening. Included in the exhibition were: photographs taken whilst out on site in the YSP, painted canvases in response to the YSP, and titles created by the participants to give further insight into individual's experiences. Also included was a poster of background information regarding the project's aims and evolution.

For many Day Service members the visit to the exhibition was their first experience of the cinema. Part of the attraction of holding the exhibition there was the good level of physical accessibility, with both steps with railings and ramp access. However, good access is not only a physical issue it may also be dependent upon social concerns. On the day of the exhibition visit it was noticeable that although most members were excited about the trip some, particularly those who were not project participants, were apprehensive about the experience. Being unfamiliar with the building, how to behave, and what was expected of them, made some members nervous. However, once at the exhibition this nervousness was overcome by curiosity and (for project participants) pride in the experience of seeing their work displayed professionally. Members, who had not participated in the pilot study, were keen to identify their favourite photographs and discuss them with the group (4.19). This interaction incited a further depth of relationship between the project participants and their work. Participants were eager to pick out 
individual photographs and re-enact the situation under which they was taken. It was observed on the day, that some artwork titles chosen by participants prior to exhibition, no longer reflected the significance they now gave to the images.

4.19

\section{Yorkshire Sculpture Park exhibition at the Showroom Cinema}

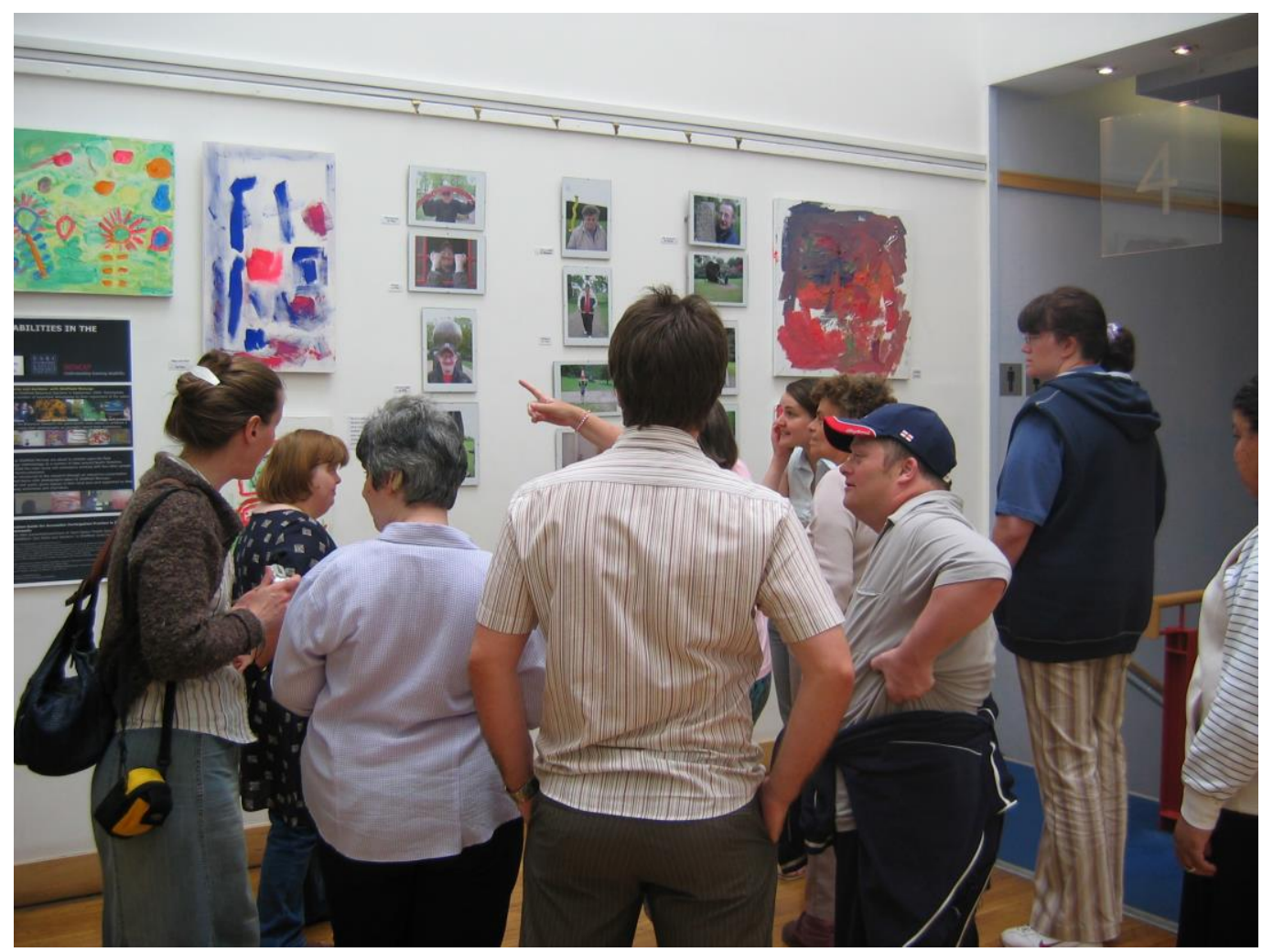

This was an important methodological discovery, as it ensured that future drawing workshops and interviews always followed site visits as promptly as possible, therefore enabling a more accurate participant response to the experience.

The exhibition at the Showroom Cinema was only regarded as a partial success. Positive outcomes included participants viewing their work displayed in a public arena, public access to the project and the enthusiastic respond from cinema staff to the work on display. However, few parents or carers attended the exhibition, the cinema clientele did not represent a true cross section of the Sheffield population and without a visitor feedback book it was difficult to gauge public reaction. In response to these issues a second exhibition was held at the members Day Service centre. The exhibition was held 
on $18^{\text {th }}$ August 2005 at the Open Day for parents and carers. On the day, the participants' supporters appeared greatly impressed by the range of work produced by the group. On the feedback board many wrote positive and encouraging remarks. This boosted participants' self-confidence and allowed them another opportunity to externalise their experiences. The interest generated by the display ensured the exhibition remained on display for the following six months.

In retrospect researcher reflections on both exhibitions recalled the difficulties of creating a dissemination environment of total inclusion i.e. like the cinema, the second exhibition at the Day Service centre attendance was by a distinct audience (people directly related to Mencap members). With a project this specialised the researcher realised it was unrealistic to expect the work would receive wide public exposure. Therefore in order to increase the research profile, the researcher began a process identifying forums for dissemination, which interested target audiences would attend. The learning disability Peoples' Parliament was cited as key in providing a suitable platform from which participants could share experiences and products of their work with members of the wider learning disability community.

\subsubsection{Presentation at the Peoples' Parliament}

The Peoples' Parliament is an advocacy driven monthly gathering of people with learning disabilities, and their supporters, from across the Yorkshire region. Organisation of the event, is overseen by the Sheffield advocacy group Sufa (Speaking Up For Action). The Our Parks and Gardens project approached Sufa in December 2005 with the idea of presenting the research at a future parliament session. On the $19^{\text {th }}$ January 2006 the 'Our Parks and Gardens' project ran the first Parliament to be orchestrated by an external organisation. On the day over 100 people turned up to the Parliament. They came from a wide range of professional backgrounds united by their interest in securing rights, choice and advocacy for people with learning disabilities. Organisations in attendance included: Sheffield Mencap, Crown Hill, St Wilfred's Day Centre, Sufa, Doncaster Advocacy, University of Sheffield academic staff, Sheffield Hallam University students, the Sheffield City Council Social Inclusion Team, Burton Street, The Elms, John Holmes Inclusive Fitness, Dover Street, Oakbrook View, the Development Manager of Sheffield Social Services, and the Mayor and Lady Mayoress of Sheffield.

The morning session comprised a series of visual and verbal presentations by the project participants and researcher. The diverse range of presentation techniques 
employed, were designed to enable involvement from all audience members. The project participants had themselves created: the questions for a quiz, constructed the quiz PowerPoint, and evolved the Garden Drama story in which they acted. Audience participation and feedback was immediate and positive, with a number of male audience members addressing the Parliament mid-session to compliment project participants on their presentation. This external encouragement and praise was highly beneficial to the participants. They gained greater confidence in their weekly project abilities (taking photographs, communicating their ideas through drawings) and their more formal project advocate personas (presenting in front of large audiences).

\subsubsection{Audience opinion}

The afternoon session explored the ideas of the audience regarding their views on public open spaces. The audience was divided into eight groups, each group contained members from a variety of organisations and at least one project participant. The groups were provide with large sheets of paper and marker pens and given thirty minutes in which to answer (through illustration and/or text) the following questions:

- What do you like about parks?

- What don't you like about parks?

- What would you like have in your perfect park?

Spokespeople from each group explained to the rest of the room their drawings (4.20). The groups produced a wide variety of thoughtful, creative answers and everyone listened carefully. After the Parliament, the researcher recorded the content of the drawings produced (images and written words), which revealed the responses shown in Tables 4.7 - 4.9. Many responses reflected initial ideas by the research participants at the Day Service introduction day to the pilot study. Parks were seen as positive places for a range of reasons, from the social, environmental to experiential (Table 4.7). In contrast antisocial behaviour remained the primary factor in discouraging park use by people with learning disabilities. This issue was also apparent in the verbal presentations, with group members passionately describing negative situations they had experienced in parks (Table 4.8). Almost all were a result of people and not place. Responses to the requirements of a perfect park (Table 4.9) included accessible design features, but most importantly described possible means by which people with learning disabilities could 
become socially included in the life of the park and surrounding community. Initiatives suggested included: telephones where you could get in touch with people if you needed, houses for people with learning disabilities at the edge of the park (so you didn't have to rely on others or public transport to get there) and community cafés. The audience that attended the Peoples' Parliament did not want a park expressly designed for them, they wanted a park that was valued, and cared for, where they would be welcomed as equally respected members of the community.

\subsection{0}

Peoples' Parliament: group drawing workshop feedback to the audience

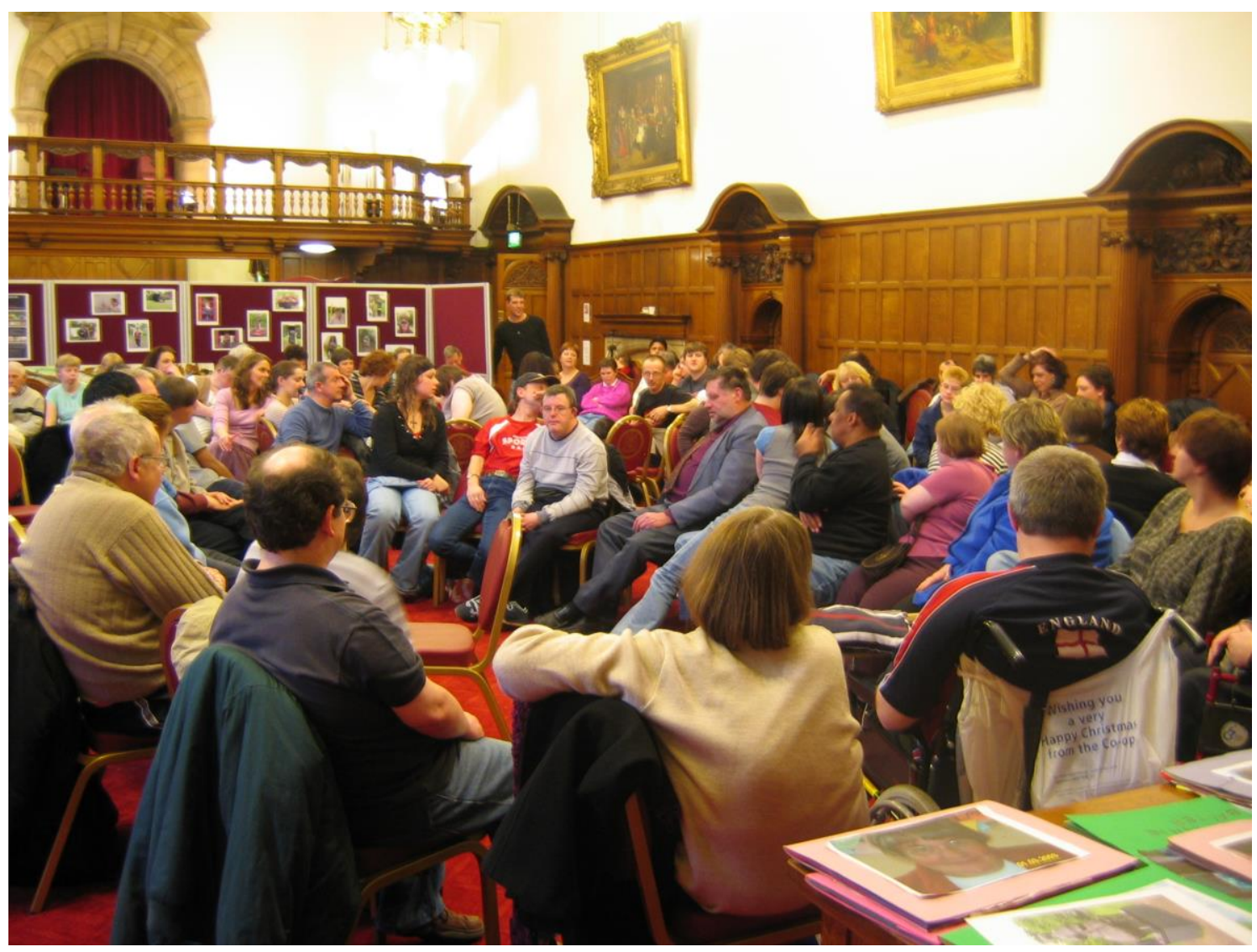

Table 4.7

What do you like about parks? (Peoples' Parliament, January 2006)

\begin{tabular}{lll}
\hline Response & Explanation & Example \\
\hline Walking & & With sister, dog, friends \\
\hline Flowers & Brightly coloured & Tulips \\
\hline Play equipment & & Swings, slides, climbing frames and roundabouts \\
\hline Seeing animals & Birds, squirrels, guinea pigs, sheep, horses, chickens \\
\hline
\end{tabular}




\begin{tabular}{|c|c|c|}
\hline Playing games & & Football, catch, bowls, basketball, rounders, tennis \\
\hline Picnic & & \\
\hline Feeding the birds & & Ducks \\
\hline Trees & & Horse chestnut \\
\hline Cycling & & \\
\hline Sculptures & & \\
\hline Water & & Fountains, lakes and waterfalls \\
\hline Greenhouses & & \\
\hline Ice cream vans & & \\
\hline Historic gardens & & Chatsworth house and gardens \\
\hline Rubber matting & $\begin{array}{l}\text { Doesn't hurt if } \\
\text { you fall over }\end{array}$ & \\
\hline Pavilions & & \\
\hline Good lighting & Feel safe & \\
\hline Café & $\begin{array}{l}\text { Drinking hot } \\
\text { chocolate }\end{array}$ & \\
\hline Park keeper & & \\
\hline
\end{tabular}

Table 4.8

What don't you like about parks? (Peoples' Parliament, January 2006)

\begin{tabular}{lll}
\hline Response & Explanation & Example \\
\hline Chewing gum on the floor & & \\
\hline Dirty toilets & & \\
\hline Grass not cut & & \\
\hline Bad walkways and pavements & & \\
\hline People smoking & No bins & \\
\hline Dog mess & No bins & \\
\hline Rubbish & Graffiti & \\
\hline Vandalism & Not safe at night & People messing about in the water \\
\hline Bullies, bad people, swearing & & Broken, not enough and unsuitable \\
\hline Motorbikes & & \\
\hline Broken swings & Not safe at night & \\
\hline Bad seating &
\end{tabular}


People throwing fireworks Not safe at night

Bad ponds

Dead fish and rubbish dumped in the pond.

Table 4.9

What would you like have in your perfect park? (Peoples' Parliament, January 2006)

\begin{tabular}{|c|c|c|}
\hline Response & Explanation & Example \\
\hline Good accessibility & Parks that are easy to get to & Direct bus routes \\
\hline \multicolumn{3}{|l|}{ Clear paths } \\
\hline Sculptures & & $\begin{array}{l}\text { Flying saucers, cars, } \\
\text { vans }\end{array}$ \\
\hline Telephones in parks & $\begin{array}{l}\text { Places where you can get help } \\
\text { and advice }\end{array}$ & \\
\hline \multicolumn{3}{|l|}{ Tree houses } \\
\hline $\begin{array}{l}\text { Houses for people with learning } \\
\text { disabilities around the edge of } \\
\text { the park }\end{array}$ & $\begin{array}{l}\text { Great views and you can get to } \\
\text { the park easily }\end{array}$ & \\
\hline \multicolumn{3}{|l|}{ Maze } \\
\hline \multicolumn{3}{|l|}{ Jogging path } \\
\hline \multicolumn{3}{|l|}{ Model village } \\
\hline \multicolumn{3}{|l|}{ Library } \\
\hline Walled garden project & $\begin{array}{l}\text { Opportunity for people with } \\
\text { learning disabilities to get } \\
\text { involved }\end{array}$ & \\
\hline \multicolumn{3}{|l|}{ Community café } \\
\hline \multicolumn{3}{|l|}{ Go-carting } \\
\hline Bandstand & Place to hold concerts & \\
\hline \multicolumn{3}{|l|}{ Park clock } \\
\hline \multicolumn{3}{|l|}{$\begin{array}{l}\text { More toilets with facilities for } \\
\text { people with learning disabilities }\end{array}$} \\
\hline \multicolumn{3}{|l|}{ More places to sit down } \\
\hline Clean and tidy parks & & More rubbish bins \\
\hline Good lighting & Feeling safe & \\
\hline
\end{tabular}




\subsubsection{Summary}

The exhibitions and presentation day illustrated how effective visual communication methods were at engaging diverse audiences in the research. It was seen that components of the toolkit could also be used in isolation i.e. the drawing workshop at the Peoples' Parliament, with methods employed creating an arena where all answers were valid and all answers were heard. The method of research dissemination was not owned by the researcher and therefore limited to the echelons of the academic establishment; it was inherently accessible to all, as had been driven by the work of the participants.

\subsection{Conclusion}

The recruitment of people with learning disabilities in participatory research is a sensitive matter and should be handled as such. People with learning disabilities are particularly vulnerable to manipulation and therefore those who are concerned for their wellbeing should be rigorous in assessing the suitability of their potential involvement in projects. In the case of this pilot study, commitment to honest and open communication between the researcher and support agency (Day Service) resulted in the successful establishment of a strong research partnership. The benefits of collaborating with a support agency are many. In the case of this research most valuable were: support agency staff experience and insight into participant behaviour, guardian support and trust for the project (as a result of project backing from the support agency), a channel through which consent was obtained easily and direct access to participants freely given.

Initial estimations of the researcher's personal connection to the day-to-day lives of the participants was far exceeded during the pilot study, which continues to this day. Such involvement with participants and support staff brought much joy and satisfaction to the research process, which the researcher felt would be beneficial to any participatory study approach with social groups. However, abiding by the principles of participatory research must be a personal commitment, with realism that a heavy time investment is required. Researchers must be dedicated to not only running the project for the length of the data collection period, but also allow considerable time to establish the project and relationships, and in the long term create foundations, and a running format, that may be easily adopted, and adapted, by future staff or volunteers. When this is accepted the research becomes innovative, exciting and most importantly participant led. 
Working with participants during the pilot study it became clear that physical and sensory design was not so much the issue, as the lack of environmental experience people with learning disabilities had. By taking a participatory research approach, it became obvious that the researcher's initial perception of people with learning disabilities was very different from the participants' reality. Their experiences honed the research question into something far broader than the field of landscape architecture, that of social inclusion and their lack of it.

A crucial lesson learnt from the pilot study was timescale. From the introduction day to the final exhibition, the pilot study ran for ten months, with an additional nine months working as a volunteer prior to this. From this the researcher ascertained that the main studies would also require longitudinal investment in order to obtain meaningful results. Adopting a longitudinal approach had enabled the researcher to tailor the toolkit to the individual communication requirements of the participants. Resulting from this, was an in depth understanding of the participants personal preferences, their dislikes and abilities. Spending extended time with the participants allowed the researcher to gain insight into their previous environmental and social experiences, which had an oftenpowerful effect upon those present or future experiences. Clearly apparent was the ineffectual and incorrect assumption that a professional (be it landscape architect or otherwise) could enter into any participation or consultation process with people with disabilities over a short-term period and obtain responses or information of any significance.

It was therefore decided that two comparative studies would be most practical to test the evolved toolkit. The first would build upon the pilot study through continued contact with the South Yorkshire participants, whilst the second would bring the toolkit to a new set of people with learning disabilities in the North East. An advantage of this approach was the opportunity to continue refining what had been employed to date, whilst testing the methodology's operational effectiveness (within a limited timescale) at the comparison study site. Other qualitative researchers taking a similar approach have justified the use of only one comparison study as follows, "According to the qualitative paradigm two case studies are sufficient to separate single qualities of a phenomenon from general ones, if they are of comparable character (culture, function, size)" (Buchecker et al., 2003, citing Oevermann, 1991). The story of these comparative case studies is discussed in Chapter 6, whilst in Chapter 5 the researcher reviews the evolving visual communication toolkit generated by the pilot study. 


\section{Chapter 5}

\section{Evolved methodology}

'Which came first, the chicken or the egg?'

\subsection{Introduction: a worthwhile dichotomy}

At this point in the thesis, reviewing what has been achieved, a much overused and maligned cliché is called to mind. There are undoubtedly more intellectual alternatives that could have been eloquently employed. However, these eight words feel apt in voicing a, "metaphor for a circumstance or a condition in which no clear causal or temporal ordering can be determined" (Garner, 2003), and are applied when considering creation of the visual communication toolkit and the hidden voices that may now be heard as a result. These are conjoined research products, and therefore require a dexterous, delicate approach to extricate one from another.

Research may be driven from the outset by a specific question, set by the supervisor, or academic institution, and answered using prescribed techniques. The approach to this research is more individualistic. Through identification of an area of limited understanding, working in partnership with those with lived experience, a unique research question was evolved, and the means by which to answer it. The pilot study (Chapter 4) presented a practical example of the difficulty in determining the order, and influence, of intrinsically linked research goals. Without evolution of a visual communication toolkit (Table 5.1) it would be impossible to gain direct understanding of the public open space experience of people with learning disabilities. Yet, it is through greater understanding of their participation experience that the toolkit evolves to more accurately meet their needs. Now discussed is the 'how to' guide for employment of the seven step toolkit, and a summary of important lessons learnt from the pilot study. 
Table 5.1

\section{Evolved methodology}

\begin{tabular}{|c|c|c|c|c|c|c|c|}
\hline 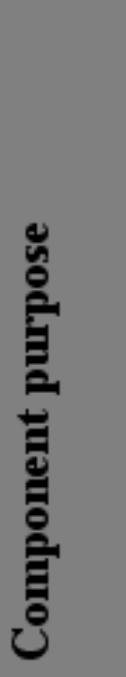 & 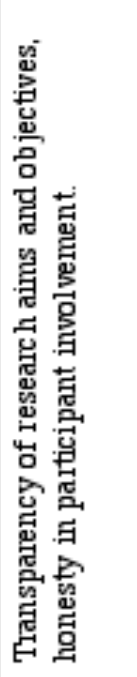 & 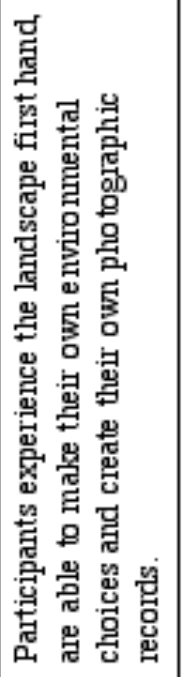 & 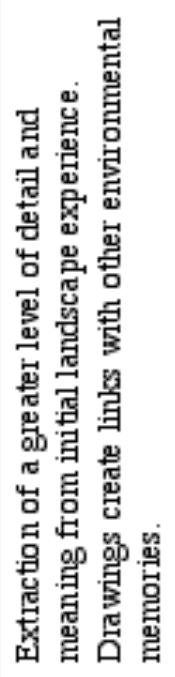 & 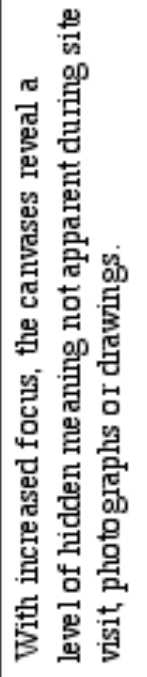 & 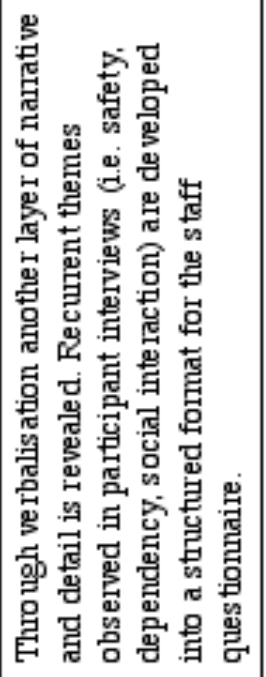 & 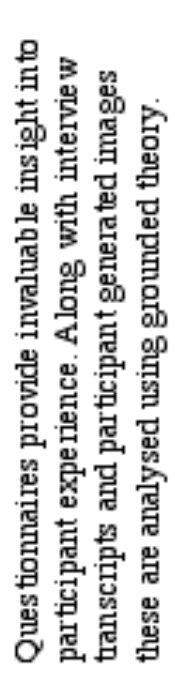 & 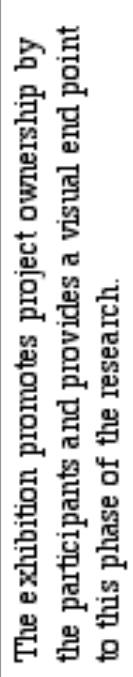 \\
\hline 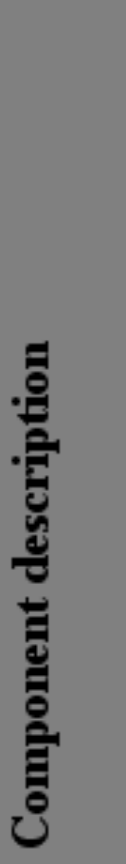 & 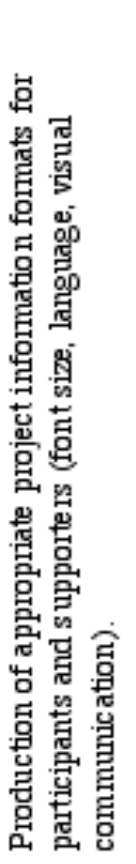 & 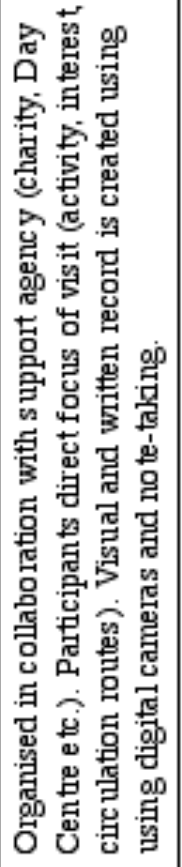 & 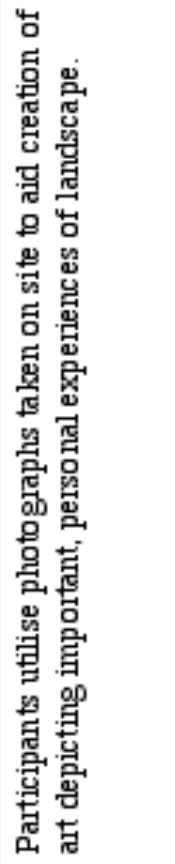 & 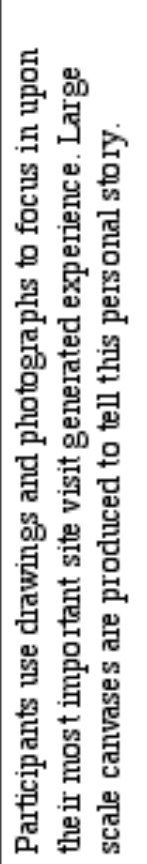 & 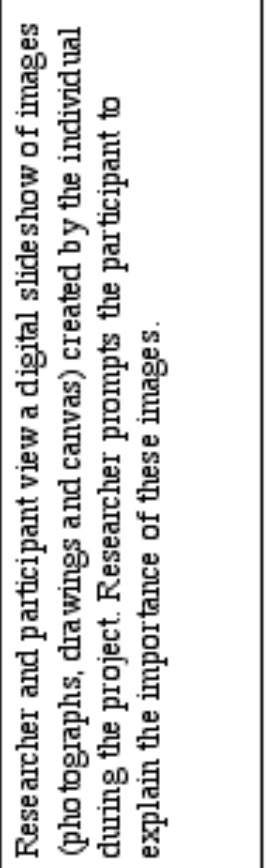 & 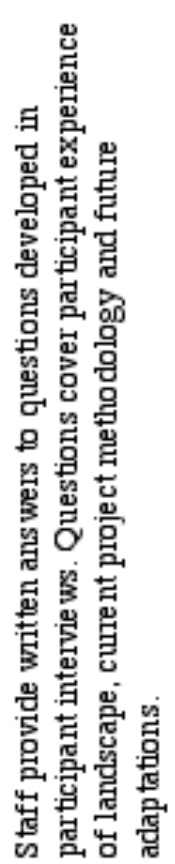 & 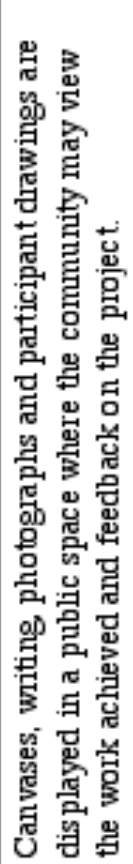 \\
\hline 象 & 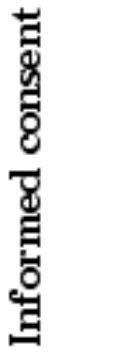 & 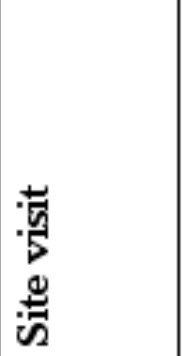 & 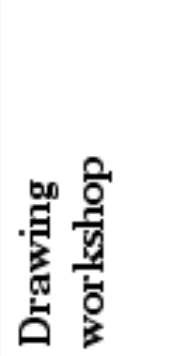 & 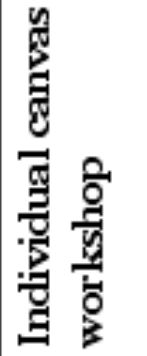 & 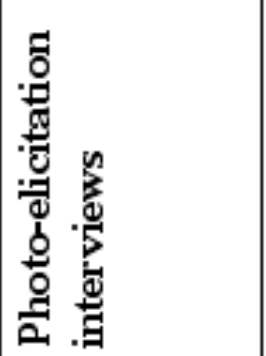 & 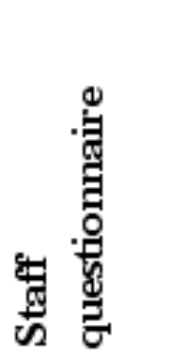 & 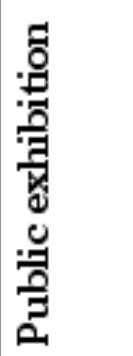 \\
\hline
\end{tabular}




\subsection{A process of parts: the seven step visual communication toolkit}

\subsubsection{Informed consent}

Participant introduction to pilot study fieldwork commenced in 2004, with an informed consent document compiled with the aid of the then Mencap Day Service Co-ordinator.

The consent form was designed to enlighten members and their families, upon all aspects of the research project, enabling them to make an informed decision regarding written consent to an individual's participation. Informed consent is defined as, "where a prospective participant, prior to participating in research: is fully informed about all aspects of the research project, in which s/he is considering participating, that might reasonably be expected to influence his/her willingness to participate. In addition, the researcher should normally explain all other aspects of the research about which the prospective participants enquire" (The University of Sheffield, 2007, p.2). The issue of obtaining informed consent from vulnerable adults is particularly sensitive, with the University of Sheffield giving the following advice, "where a prospective vulnerable adult is unable to give informed consent to participate a 'legal representative' may give assent on his / her behalf" (The University of Sheffield, 2007, p.6).

The research ethics review process was officially formalised at the University of Sheffield in 2005. For any research project involving participants, an ethics application must be put forward for approval by the Ethics Review panel. Prior to commencement of main fieldwork, an informed consent application ${ }^{1}$ was submitted on the $24^{\text {th }}$ January 2006. The application received approval from the Ethics Review panel on $2^{\text {nd }}$ February 2006. The approach and documentation of the informed consent application was specifically adapted in order to be fully accessible to the participants. Key factors in creating this ethically sound consent form were:

- Production of alternative information formats: for potential participants, and carers/ support staff.

- Participants' information sheet to use: large clear font, plain English, visual illustrations, examples from the pilot study.

\footnotetext{
${ }^{1}$ Appendices, Chapter 4 Evolved methodology, Informed consent
} 
- The endorsed support of collaborating centres (Day Service and Further Education College).

\subsubsection{Site visit}

Once informed consent had been given, research moved on to the practical stage. The choice of public open spaces to be explored through site visits, was decided upon as a result of two key factors: those which could be easily accessed within the given time frame of the Day Services day and those which provided a variety of landscape experiences (from the formal and managed to the informal and wild). During each site visit, the researcher, a support worker and volunteers accompanied participants.

General preparations varied little across site visits, or from those one would expect of any social group outing. However, the thoroughness with which staff and volunteers carried out these preparations was crucial to the smooth running of the day, and the level of enjoyment the participants gained from the experience. Preparations made were as follows:

- Transport was booked.

- An outline of the day (with expected arrival and departure times) was provided.

- Weather conditions were checked.

- Advice on suitable outdoor clothing and footwear was given.

- Participants were requested to bring packed lunches.

- Reminders to bring any daily medication were supplied.

- Participants who required wheelchairs were asked to bring these from home (or were provided with a Day Services wheelchair).

- Information regarding physical access was obtained and distributed accordingly.

The only notable difference in this participant group preparation, from more independent participant outings, was the allocation of welfare responsibility for specific participants by staff and volunteers. Leaflets, photographs, and the Internet provided a range of visual information sources for participants who wished to know more about the site prior to the actual visit. Group discussions were also held, to reassure those who had 
concerns and answer questions. At this juncture it was established that during discussions, participants were notably less hesitant, and more verbally forthcoming, if visual information sources were made accessible as prompts.

Whilst on site, facilities such as toilets, cafés and places to buy souvenirs provided a great draw and distraction for participants from exploring the landscape. The allure of such facilities was (relatively) successfully avoided through: prior provision of participant lunches, making use of the Day Service Centre lavatory facilities before commencement of the trip, and discouragement of the need for excess spending money. Familiar facilities offered a reassuring crutch for participants experiencing new environments. However, when they were not automatically available, few (with the proper preparations) missed them.

Experiences of site visits were, for the main, recorded through digital photography with the use of two cameras: one belonging to the researcher, the other to the Day Service Centre. However, latterly some participants chose to bring along their own cameras (the majority of which were disposable). This was encouraged, as it was perceived as a positive action whereby participants' began to take ownership, demonstrated increased interest, and personal control over the experience. Recapitulation of the following approaches to photographic activity on site (originally addressed in Chapter 4) is necessary in providing a guide to this toolkit component's employment. Therefore, whilst on site digital cameras were used in the following ways:

- By the researcher/staff member to record the participants interacting with the landscape.

- By the researcher/staff member at a participants' request to record elements of interest for the participant.

- By the participant aided by the researcher/staff member to record elements of interest.

- By the participant unaided to record personal interest.

In addition to photographic records participants collected visual mementos. These included: information leaflets, flora (leaves, berries), and bark rubbings. Where possible 
the researcher, staff and volunteers recorded through note taking: their observations of the day, participant behaviour, and environmental and social interactions. At some sites this was unfeasible due to:

- The individual needs of participants.

- Participant to staff/volunteer ratios.

- The site environs i.e. large scale sites often required greater safety observation, and therefore provided less opportunity to make time for note taking.

However, at sites where no notes were taken, the researcher's impression of participant experience was not diluted, due to the wide range of visual information generated.

\subsubsection{Drawing workshop}

Following each site visit, participants began a series of drawing workshops in which they chose photographs that held specific meaning, to use as visual prompts for artwork illustrating individual experiences on site. Participants were encouraged to experiment with different media. This enabled participants to independently discover which materials and techniques provided the most appropriate, and natural, visual language through which they would communicate their ideas. Examples of media and techniques explored by participants included: collage, pencil drawing, stencilling, and painting with acrylics and poster paints. A number of participants chose to supplement their visual imagery with written word, sometimes by hand, but more frequently by computer. The research budget allocated to cover material costs was relatively small; therefore there was a general reliance upon existing Day Service art materials and those on regular re-order. However, this did not appear to hamper the originality or diversity of the artwork produced by participants.

Individual participant artwork was kept in individual project books. These books became incredibly precious to the participants. They charted their process, demonstrated their artistic prowess, recorded their experiences and provided an eloquent means of communication to those outside the project looking in. 


\subsubsection{Individual canvas workshop}

To increase focus and encourage project ownership, each participant constructed, designed and executed a painting in the individual canvas workshop. These depicted a landscape, real or imagined, that held most resonance for them. Participants used a combination of sketches and photographs from their individual project books to produce landscape paintings. These demonstrated a range of themes such as: their aspirations for employment, social inclusion, memories of family, happiness in leisure time and personal association with landscape experience. In image $5.1 \mathrm{Tom}^{2}$ constructs the wooden frame for his individual canvas. Completion of individual canvases signalled the end of the visual data generation phase for the participants. With this data in place, interviews were now conducted to explore and review the site experience of participants.

\section{1}

\section{Tom sawing wood (from which he constructed the frame for his canvas)}

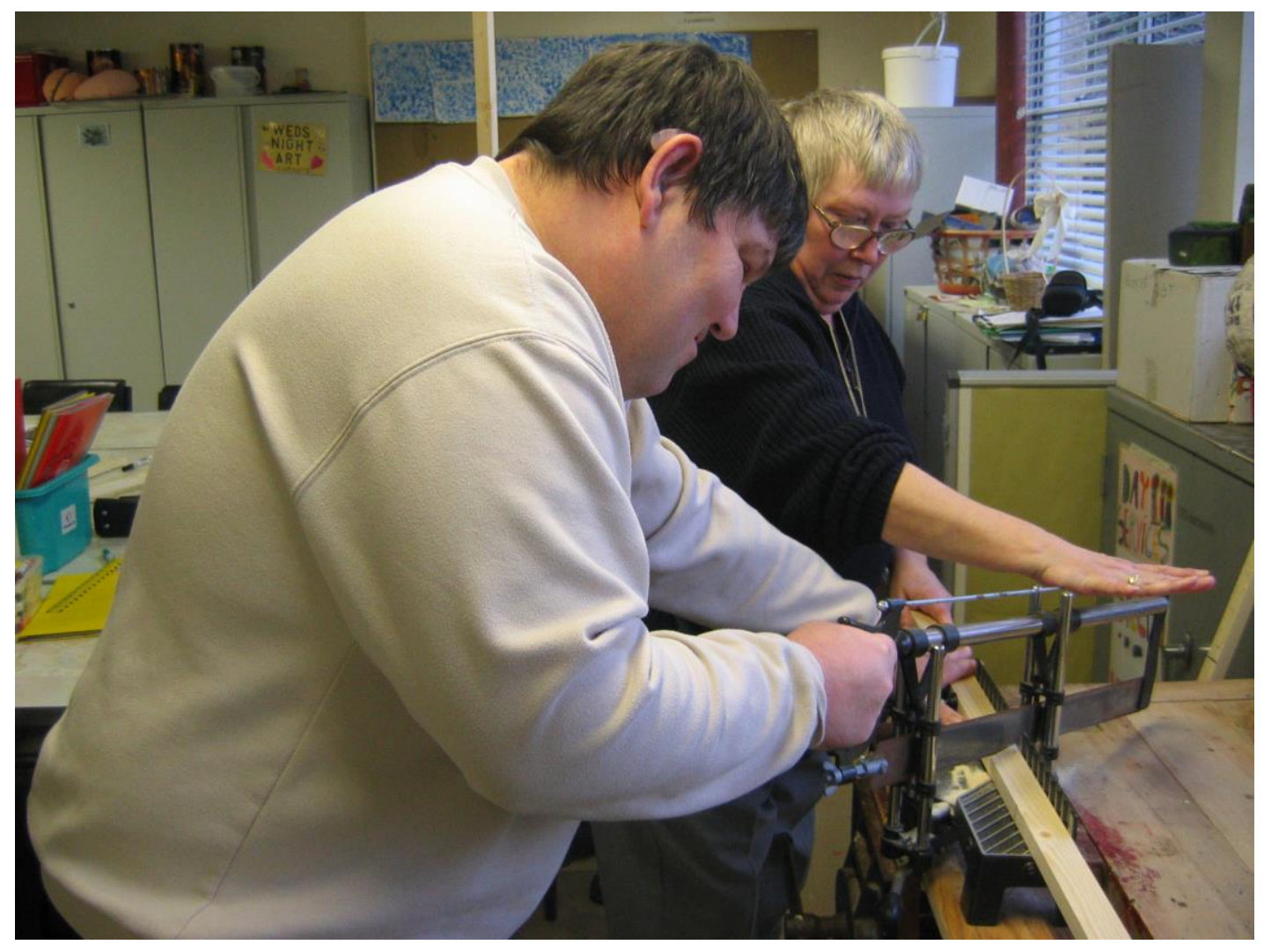

\footnotetext{
${ }^{2}$ Tom is a pseudonym used to protect the participant's identity.
} 


\subsubsection{Photo-elicitation interviews}

Photo-elicitation interviews were most effective when conducted swiftly after the site visit or exhibition, which they sought to discuss. If a long period of time was left between the event and its interview reflection, participants became vague regarding what they had experienced. During interviews, the researcher and participant sat in front of a computer watching a digital slideshow of photographs taken on site. In addition to viewing and discussing photographic images, participants were asked to elaborate on work produced in their record books and, in later stages of the project, their individual canvases. Interviews were recorded and transcribed (with the participant's consent) and further themes relevant to this particular participant group elicited. These themes were useful in shaping the direction of future interviews. They explored not only the visible experience, but in addition, the hidden participant perceptions that hinted at more universally important subjects, common to a wider spectrum of the learning disability community.

\subsubsection{Staff questionnaire}

Staff questionnaires provided information on three key aspects of the research project:

\section{- Participant backgrounds}

People with learning disabilities are often dependent (to varying degrees) on social service support staff, developing relationships that may last a lifetime. Support staff are familiar with participants in both residential, and edification, capacities and therefore their views should be taken into account. They have valuable insight into interactions between factors such as: participants' environmental experiences to date, their medical history, and their social life (with family, at home, amongst friends and peers, and within the local community). Obtaining an overview of this is essential in unpicking how such elements overlap to shape a participant's current viewpoint, and their participation in environmental experiences.

\section{- Toolkit methodology reflections}

The questionnaires gave support staff the opportunity to reflect upon the methodological successes, and limitations, of the visual communication toolkit. They were asked to suggest if any other methodologies might be appropriate for inclusion. 


\section{- Working research partnership}

The successful establishment of a longitudinal, ethnographically driven research project of this kind, is highly reliant upon the creation of a smoothly, functioning, partnership with the organisation support staff. Therefore, the questionnaire sought to develop means by which the project could be carried out with maximum ease from a support staff perspective.

\subsubsection{Public exhibition}

Creating a clear outcome for participants, knowledge transfer, project transparency and inclusive dissemination were also objectives of this longitudinal pilot study. Through collaboration with the Day Service Centre, dissemination was not restricted to the academic arena but included the general public, policy makers and learning disability community. Participants orchestrated a visual communication seminar day at the Peoples' Parliament (Yorkshire monthly meeting of people with learning disabilities, their support agencies, academics, policy makers and those working in practice). In addition, an art exhibition was held at a cinema in South Yorkshire, which was key in providing project closure for participants. In ensuring respectful, professional dissemination and exhibition of work, the production of visual work was taken seriously with pride, by all participants. Feedback from the public who viewed the work, and the organisation who exhibited it, was wholly positive, with the opportunity to use the space to stage future projects.

\subsection{Lessons learnt in preparation for the main study}

\subsubsection{Time allowance}

The foremost consideration in undertaking fieldwork of this kind was ensuring adequate time for completion. The fieldwork period comprised three distinct phases: introduction, implementation, and dissemination. In turn, each phase was broken down into a number of smaller tasks:

- The introduction phase comprised: identification of a suitable service with which to collaborate, establishing contact with the service, becoming known to potential participants, staff and volunteers, familiarising the service with the project aims, 
objectives and programme, and obtaining consent for involvement. The project only began when a suitable break occurred in the activity programme of the Day Service Centre.

- Implementation of the project occurred by means of the seven-step visual communication toolkit. Employment of each tool, at each stage was dependent upon a variety of factors, from the weather (site visits) to art materials in stock (drawing workshops) to social engagements (interviews).

- Dissemination of the project occurred through a number of channels: academic, practice, and direct to the learning disability community. A breadth of verbal communication techniques was therefore employed (from plain English to the more arcane and academic); which ensured research findings were always represented in a manner that was audience appropriate. In all presentations, the common denominator was a high reliance upon visual imagery, reflecting its strength during research fieldwork. Further advance planning was required as public arenas for exhibition were often booked far into the future, and appropriate dates infrequent (i.e. the art exhibition was arranged to tie in with the annual National Learning Disability Week, and the Peoples' Parliament only occurred monthly).

\subsubsection{Flexible, individualised communication}

Although the aim of toolkit was to provide a complete means with which to enable participants to communicate hidden information regarding public space experiences, it is important to note that its employment with individuals' was not identical. With no one precise template for use, the toolkit was developed to be participant responsive. For example: for some participants, who were relatively confident in their written and verbal communication, the semi-structured interviews were key in communicating their ideas, with the visual images acting in supporting role as prompts. For others, with little to no verbal language (who did not take part in the interviews), their site visit experiences, captured by digital camera, elicited far stronger meaning when explored during the drawing workshops. The visual communication toolkit provides a ranges of methodologies, or tools, which when used in conjunction with one another, but not necessarily all together, have the ability to build a strong experiential understanding of 
public open spaces for people with learning disabilities. The skill of this toolkit's employment is in tailoring the tools to suit the individual's needs.

\subsubsection{The important role of the support agency}

The researcher cannot overstate the crucial role of the support agency in facilitating this project. Without the committed involvement of the Day Service Centre, it's staff, volunteers, and material resources (which were all placed at the researcher's disposal) the project would have been impossible. The only advice required here, is to understand that as a researcher working with such communities, you are a privileged visitor in the lives of others and should treat the situation, organisation and staff with the respect they deserve. They may well become your most valued research allies.

\subsubsection{Participant-researcher relations}

The pilot study aimed to ease the process of the participants' familiarisation with the researcher, and immersion of the researcher into their lives. In this respect it was entirely successful. However, this in itself presented a new ethical dilemma; resolution of the issue of when, and how, to end the research project.

Much time had been invested in building relationships with participants, staff and volunteers; therefore the breaking of these bonds (though necessary) was fraught with emotional attachments. In deciding to extend the fieldwork timetable (from a stand alone pilot study into longitudinal main study) awareness developed that increased participant familiarity with the researcher might create future complications. Primarily intensifying feelings of abandonment once the project ended. Research studies indicate that this is an area of concern when completing participatory research with people with learning disabilities, that may in part be attributed, "to the fact that many may have very limited social networks" (Northway, 2000, p.30 citing Booth, 1998; Goodley, 1999). The benefits of participating in research of this kind i.e. involvement in a project with others with shared interests, developing one-to-one relationship and becoming part of network or team (Northway, 2000) may be short term, lasting only for the length of the project. Therefore, on project completion, "there is obviously the potential for this stage of the research to have a very negative impact on the people involved" (Northway, 2000, p.31). 
Both Stalker (1998) and Northway (2000) are quick to comment that not all participants with learning disabilities will develop such an attachment to the project and researcher, just as not all researchers will experience difficulty in concluding the research.

In the context of this project, individual participants did develop close relationships with the researcher. However, these were not abandoned as the researcher was already committed (beyond the remit of the research) to involvement with participants as part of the wider learning disability community, through social activities such as the creation of a learning disability friendly nightclub. Therefore, the anticipated end of the project did not signal the end of personal contact. Crucially a clear role distinction and division was made: attendance of the Day Service Centre was always as a researcher, involvement in outside activities with the learning disability community was always as a collaborator and friend.

\subsection{Summary}

Having summarised the provisional visual communication toolkit, its methodologies for use, and limitations, we now move forward into trial of this toolkit under comparative study conditions in the North East and Yorkshire. The employability of the toolkit emerges as not only restricted to the fields of landscape and urban design, but in any situation where people with learning disabilities wish to participate in a decision making process, communicating on an equal level with others. This is their right; it is the wider world that must be taught to listen. 


\section{Chapter 6}

\section{The Main Studies}

\subsection{Introduction}

\subsubsection{The shock of the relatively new}

Longitudinal studies, such as the one experienced by the researcher working with Day Service members in South Yorkshire, create a security net that is supportive yet difficult to disentangle oneself from. Familiarity with participants, locations, organisations and routines, brings many benefits to the quality and profound nature of the research produced. However, it is the act of leaping without a net into the unknown, accompanied only by the experience you have gained, that the true payoff of months or years of practice may be discovered. Just as a trapeze artist or gymnast will continuing to finetune individual movements and skills, the research approach to the main fieldwork period maintained in parallel; the means to refine individual methodological toolkit components (at the Day Service Centre) whilst extending the scope of the research with a new study centre and participants.

Many valuable lessons had been learnt in the context of the pilot study, with one of the foremost being how presentation of the participants transcribed verbal data (their photo-elicitation interviews) might be misinterpreted if read in isolation as not demonstrating the level of meaning described here in the thesis. However, the researcher makes the clear assertion that it is through use of the visual communication toolkit, employed in a longitudinal context, that solitary words and phrases are enriched and untangled. The transcribed verbal communication of the semi-structured interviews, in itself does not do justice to the individual's experience; development of researcherparticipant understanding is only achieved once all stages of the toolkit are completed.

Research completed during the pilot study at the Day Service Centre resulted in the evolution of a seven-step visual communication toolkit. The toolkit was revealed to be effective in the generation of landscape experience information with this specific participant group. However, it had yet to be tested with people with learning disabilities who had not been party to its development. In response to this, a second study centre was 
identified and approached, who subsequently agreed to be involved. As in the case of the original pilot study centre, the second comparative study centre was chosen as a result of the researcher's previous, personal involvement with the learning disability support organisation. At the Day Service Centre (hereafter referred to as Study Centre 1 (SC1)), researcher participation in the organisation was first as a volunteer and later as a support worker. At the second study centre, a Mencap further education college in the North East of England (hereafter referred to as Study Centre 2 (SC2)), the researcher was previously employed as an assistant tutor with responsibility for student welfare in both a residential and edification capacity. Existing familiarity with both organisations facilitated collaboration and promoted trusting research relationships. By continuation of fieldwork at $\mathrm{SC} 1$, in conjunction with commencement of new fieldwork at SC2, a situation of comparative study was established.

\subsubsection{Study centre similarities and differences}

There are a number of significant similarities and differences between the two study centres that had the potential to effect research outcomes.

The first variation experienced was in participant familiarity with the visual communication toolkit between the two study centres. Participants at SC1 had developed the toolkit with the researcher over a period of approximately 18 months. They had therefore gained understanding of the different toolkit components, and ease in their execution i.e. taking digital photographs out on site or participating in individual semi structured interviews. For students participating at SC2, this was their first exposure to the toolkit; consequently it was unknown how they would react to the research project.

The second issue was that of participant acquaintance with the researcher. Again, having developed relationships with participants over a longitudinal period at SC1, the researcher was relatively assured in their cooperation during the comparative fieldwork period. However, having had no experience of the students at SC2, it was impossible to predict if similar beneficial relationships could also be developed there.

Thirdly, there were differences in project role and execution within the context of the two support organisations. Whilst conducting research at $\mathrm{SC} 1$, the project had always been supported by a female member of staff and a number of volunteers, most of who 
were also female. At SC2, a male Estates Department tutor provided support for the project, with occasional additional support from assistant tutors. At SC1, the research project was offered to members as an option in the learning disability service's activity portfolio. Participants were provided with the opportunity to explore local public spaces, and develop communication means to extend their self-advocacy regarding environmental experience. At SC2, the research project was embedded within the existing curriculum, as a means to support students within the course of a taught module. The research project was incorporated into the college curriculum as part of fieldwork for the 'Investigating Land and Environment' BTEC qualification. Students undertaking the module, at Entry Levels 1 and 2, were required to fulfill a number of outcomes on completion of the course. It was agreed with the BTEC tutor and the college, that the visual communication toolkit would be employed during the fourteen-week Spring/Summer term of 2006 to discover if it could provide a suitable education methodology to achieve these outcomes.

At 'Investigating Land and Environment' BTEC Entry Level 1. required student outcomes were:

1. Recognise different aspects of land/environment use in the local area

2. Collect information on the provision of amenities in the local area

3. Identity the main attractions/land use in the locality

(Edexcel, 2004)

At 'Investigating Land and Environment' BTEC Entry Level 2, required student outcomes were:

1. Identify different aspects of land/environment use in the local area

2. Provide clear information about the main attractions/land use in the locality

3. Show an awareness of the advantages and disadvantages of developments in the landscape

(Edexcel, 2004) 
Significant differences between the two study centres were also identified at the level of the participant groups. At SC1, the research group comprised on average ten participants, although this number fluctuated slightly as members were free to move between activity groups in order to try new projects. This was a diverse group, of mixed gender, white British in nationality, aged between 29 and 63, with a range of physical abilities (from two wheelchair users to the physically able) and various communication needs (from those with little or no verbal or written language to the very able). At SC2, the project operated with a constant set of five participating students, all male, one British Asian and four white British aged 18 to 21, with a small range of communication needs and no physical impairments. Similarities in factors such as age, social background, communication ability and gender, identified the students at SC2, as a more unified demographic group than SC1 participants. Therefore, research fieldwork at SC2, explored an even more focused, and even less understood social research angle, that of the public open space experience by young men with learning disabilities.

The final difference in the research approach at the two study centres, was the length of fieldwork involvement. At SC1 the researcher was committed to the participants on a weekly basis over a number of years. At SC2, fieldwork was limited to the length of the taught BTEC module (14 weeks). Therefore, research at SC2 created an opportunity to test the timescale viability of the visual communication toolkit, gauging its operation suitability during participatory landscape planning and design processes. Having identified and described the similarities and differences of the two study centres, a set of aims and objectives emerged for research at each (see Tables 6.1 - 6.2). 


\subsubsection{SC1 and SC2 aims and objectives}

Table 6.1

\section{SC1}

Aims

1. To refine methodological components of the visual communication toolkit.

2. To gain a greater depth of knowledge about individual participants' open space experiences.

3. To develop participants appreciation and understanding of public open space.

Objectives 1. Repeat employment of the toolkit.

2. Respond to the comments and experiences of participants to best facilitate toolkit refinement.

3. Select two different types of public space not previously encountered during the project.

Table 6.2

\section{SC2}

Aims

1. To discover what affects participation in the experience of public open space by young men with learning disabilities.

2. To test the use of the visual communication toolkit within a limited time frame.

3. To test the toolkit's viability for producing relevant environmental information within the course of a taught module.

4. To develop participants appreciation and understanding of public open space.

Objectives

1. Complete all seven stages of the toolkit within a fourteen-week period.

2. Study a range of different public spaces and landscape types.

3. Repeat employment of the toolkit.

4. Respond to the comments and experiences of participants to best facilitate toolkit refinement. 


\subsection{A tale of two studies: part 1}

\subsubsection{SC1 Project arrangement}

The Parks and Gardens project was now fully established as a weekly activity in SC1's service portfolio. Staffing changes at SC1 and the arrival of a new support worker to assist the project brought a new historic perspective to the group's research on public open spaces. The relationship between the researcher and the support staff was integral to the project's success. Embracing the diversity of staff approaches to the project ensured their cooperation and interest. Without this flexibility, it would have been unlikely that the project would have achieved such a level of establishment and respect within the organization.

To maintain maximum continuity when re-testing the visual communication toolkit components, it was agreed that participants joining the project at this point in time would be encouraged to continue involvement until completion of the research, after study of the two public open spaces and public exhibition of participant work. On this understanding eight SC1 members agreed to participate. Five out of these eight participants had been previously involved in the pilot study. Of these eight participants, four were male and four were female. Three participants had little to no spoken language and were therefore absent from verbal interviews. However, these participants were included in every other stage of the methodological process.

During the pilot study, participants had experienced a formal botanical garden and a more informal, rural landscape at the Yorkshire Sculpture Park. With the assistance of the support worker and discussion with participants, a variety of local parks and public open spaces were identified as being of future interest. Most popular amongst the participants was a space recently developed in the city centre (The Peace Gardens). This space lies adjacent to the historic town hall. Participants were relatively familiar with this building and the surrounding space, as a result of attending the monthly learning disability parliament hosted there. In contrast, the support worker suggested the second site of study might be a historic graveyard (The General Cemetery), which lay at a distance from the city centre, and was relatively unknown to participants. Of the three participants who had most recently joined to the project, one male participant was particularly interested in churches and funerals. Therefore, the site captured his personal 
interest, providing him an exciting introduction to exploring public space experience. The story of the group's visit to these two sites, and the participant experiences they elicited are now discussed.

\subsubsection{The urban green space experience}

The Peace Gardens are situated at the heart of Sheffield City Centre. Physical access to the site was relatively simple; as a suitable public tram stop lies five minutes walk away. The site visit took place on the $17^{\text {th }}$ February 2006. During the pilot study at SC1, outdoor site visits had occurred during the summer and early autumn months, when it was perceived weather conditions would be naturally more favourable (warmer and drier) to participant experience. By staging site visits during late winter and early spring the opportunity arose to test what effect weather conditions had upon the participants' enjoyment of environmental experience.

Preparations for the site visit focused upon ensuring participants were provided with suitable clothing and footwear to guard against the colder weather. Most participants, bar one, had no physical impairments. Nathalie ${ }^{1}$, a new project participant, was unsteady walking long distances therefore she brought her wheelchair. Participants were advised to bring packed lunches and minimal spending money. Past experience had proved the immediate allure of shopping and immediate reward of purchase was an overpowering distraction to individuals. The process of gaining personal reward from participation in the landscape was relatively unfamiliar when compared with the incentive of the shopping experience (which was embedded in the daily life experience). In order for individuals to relearn the returns different landscapes could provide them such diversions were avoided where possible.

As with previous site visits, the participants' environmental experience was recorded primarily through digital photography. Participants, the researcher, support staff and volunteers all engaged in this act. In addition, the support staff member provided participants with brass rubbing materials, to capture firsthand images of the carvings and surface textures within the site. On return from the site visit, the project followed the

\footnotetext{
${ }^{1}$ Nathalie is a pseudonym
} 
seven-stage visual communication toolkit, with one amendment. After the initial drawing workshops were conducted, art produced by the participants was held in their project books not utilized immediately in the creation of individual canvases. It had been decided to carry out the final two site visits (to the Peace Gardens and General Cemetery) in quick succession, therefore providing participants with the opportunity to reflect upon which landscape experience they preferred. The landscape experience of their choice, and the artwork that they produced to support it, would be taken forward into design of their individual canvas for the final project exhibition. After the drawing workshops, participants engaged in photo-elicitation interviews as delineated by the toolkit. The support staff member completed a project questionnaire, and after the cemetery site visit canvas preparation for the exhibition began. Environmental and experiential themes, specific to the participants' Peace Gardens site visit, were revealed through use of the visual communication toolkit and further analysed through use of the DIDEC programme (see Chapter 3). These themes are now discussed in detail.

\section{- Peer photography}

Whilst on site at the Peace Gardens, photo novella, where participants controlled the cameras in order to discuss the environment as they saw it, proved particularly popular and became a powerful tool of empowerment (Wang and Burris, 1994; Hurworth, 2003). Over the longitudinal course of the project, participants had developed great confidence when operating the digital cameras. As a result of this, they became increasingly selective over the scenes and objects that interested them and they wished to capture. There was, however, one photographic subject that united the participants, each other. This focus on friends and other participants was previously apparent in the photographs taken during the pilot study (see Chapter 4). As in the study by Aitken and Wingate (1993) the participants repeatedly chose to take photographs of their peers (Images 6.1 and 6.2). Participant peer photography ranged in design from the highly posed, to snapshot documentation, to euphoric action shots. Even if participants did not engage in all forms of environmental interaction, they had the photographic record to prove they had experienced it (albeit observationally). Amongst peer photographs those with multiple 
participants held particular resonance. When $\mathrm{Carol}^{2}$ was asked during her Peace Garden interview, "What did you like about the day?" she replied, "The group photograph". If more than one participant appeared in the photograph, the group identity was strengthened and they were united in their ownership of the experience (Image 6.3).

\section{- False memory}

Whilst on site certain subjects held the participants attention, however in subsequent interviews their memory of them became clouded. Actual events were sometimes replaced by seemingly more possible, familiar experiences. This is illustrated by the following exchange, when the researcher asked, "And why would people go to the Peace Gardens?" the participant Nathalie replied, “To go to the café". As no café exists on site, and the participants had all provided their own packed lunches, the researcher tried to explore this answer further by asking, "Is there a café there?" to which Nathalie answered, "Yes". As with shopping facilities the allure of places to buy food was strongly embedded in the participant's mind.

\section{1}

\section{Carol photographed by another participant in the Peace Gardens}

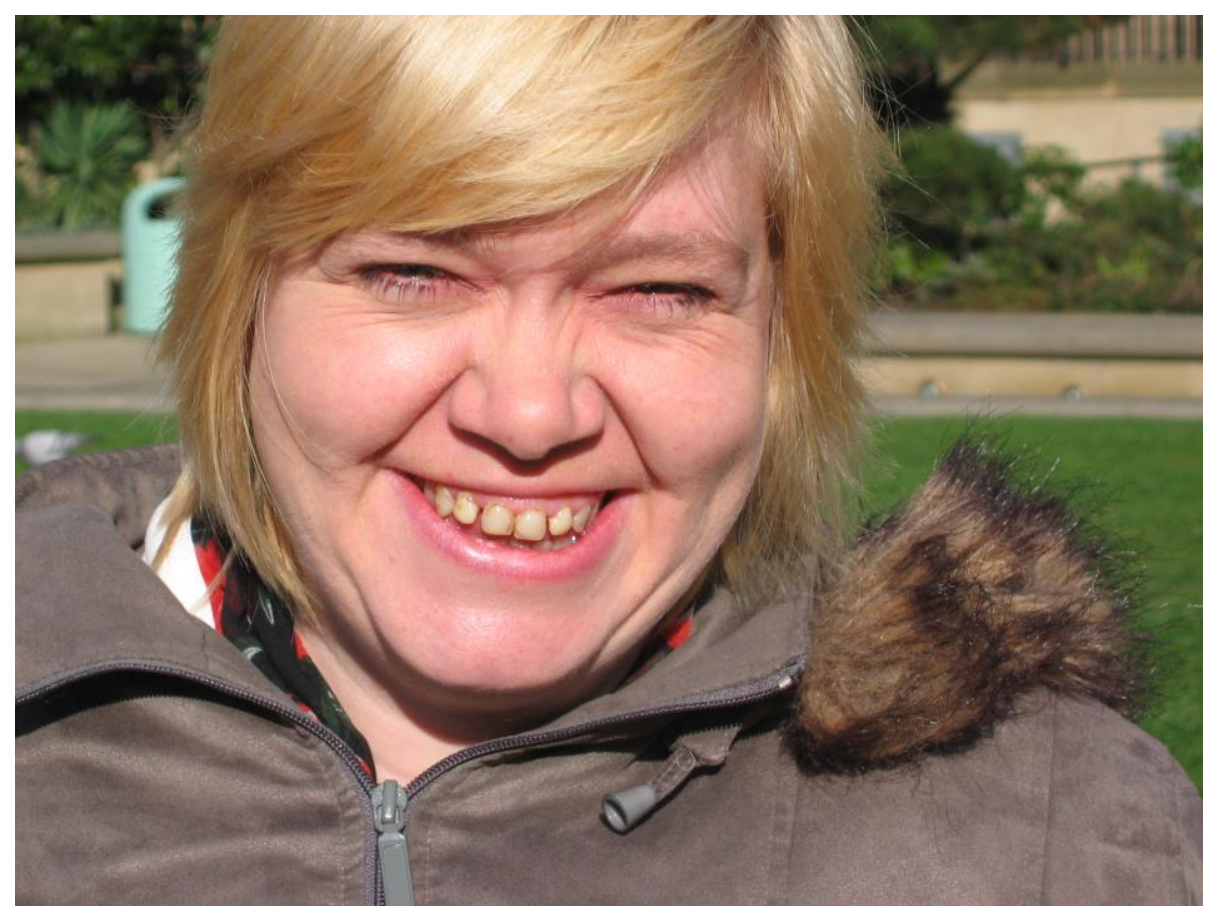

\footnotetext{
${ }^{2}$ Carol is a pseudonym
} 
6.2

Mary ${ }^{3}$ photographed by another participant in the Peace Gardens

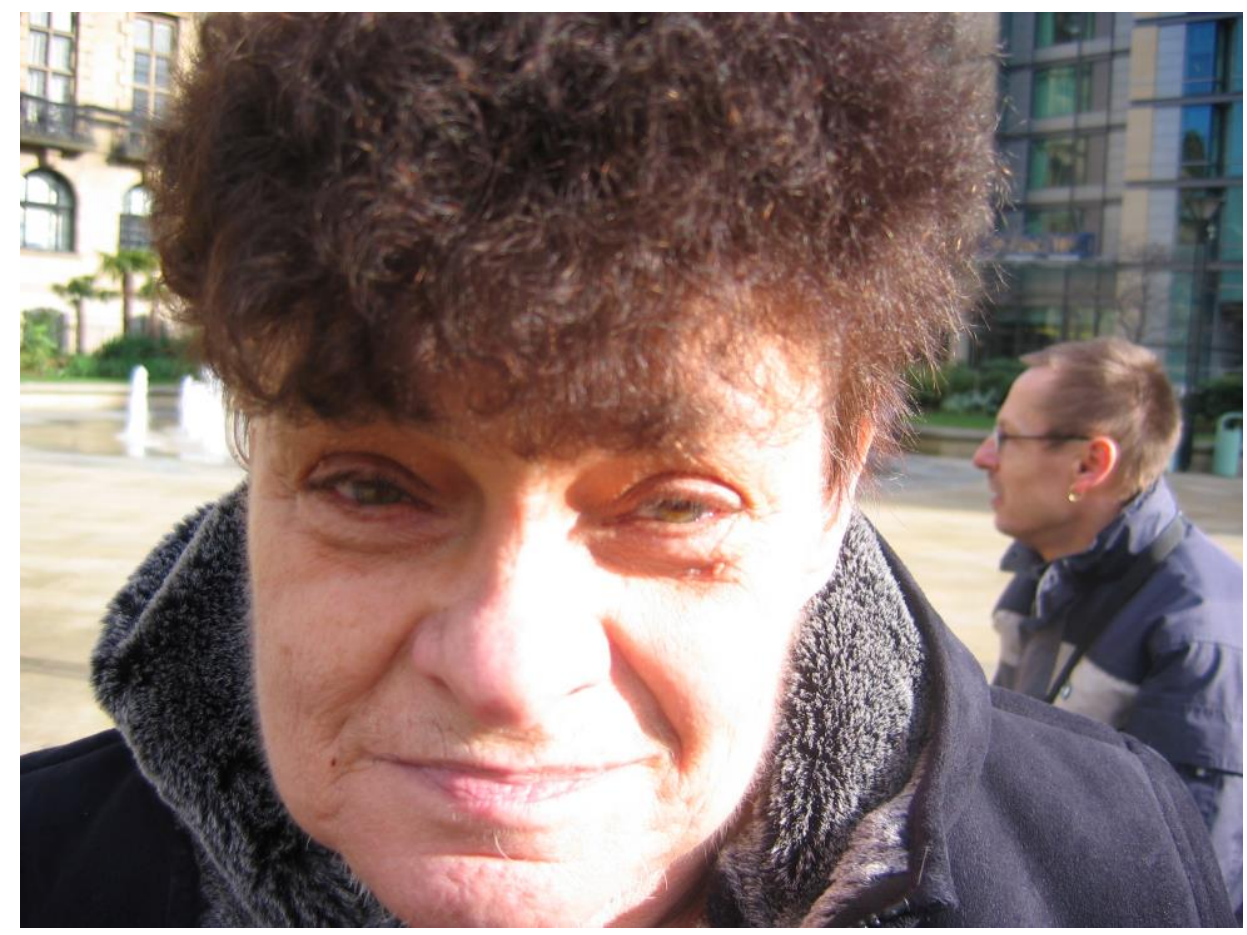

6.3

Tea break at the Peace Gardens photographed by Carol

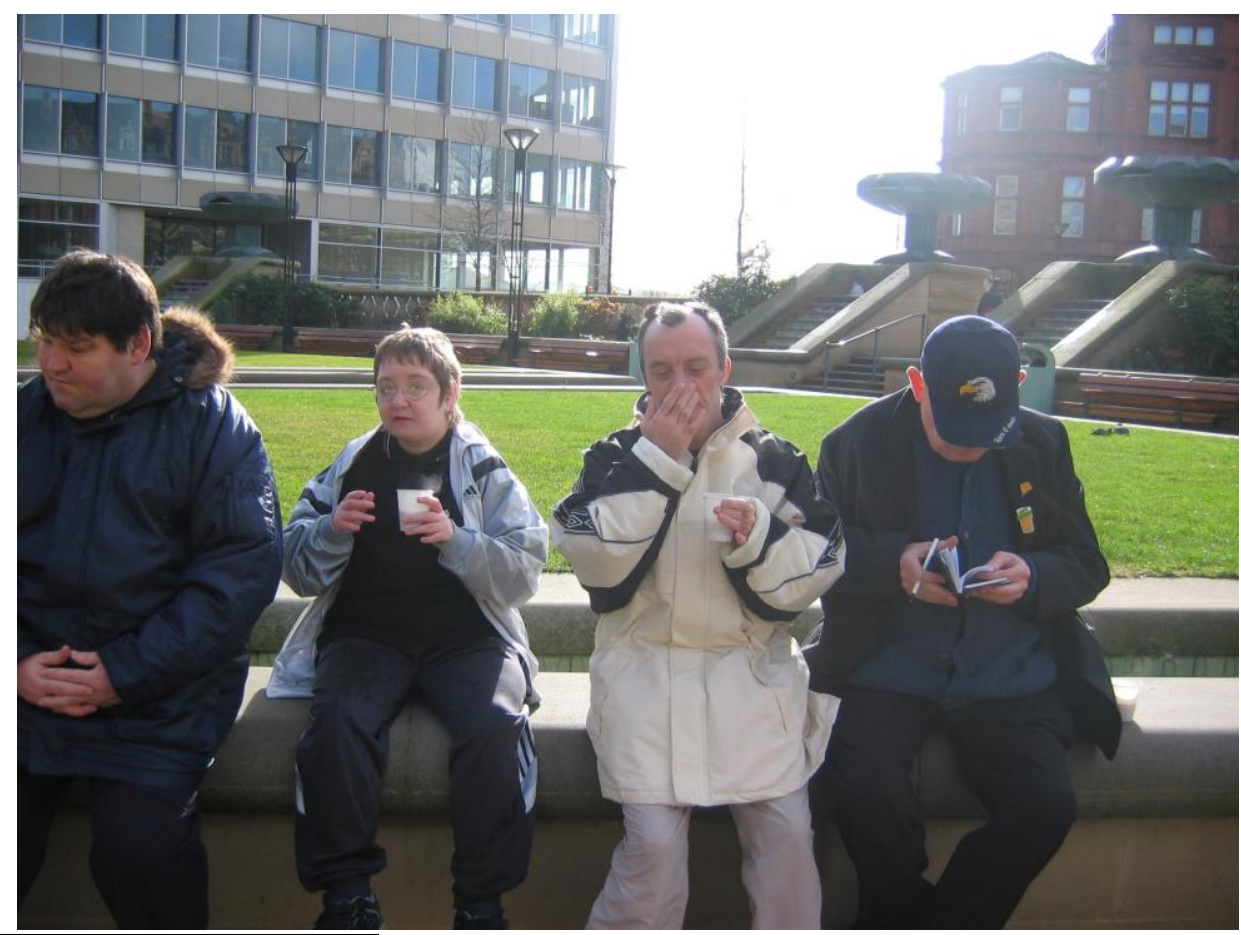

${ }^{3}$ Mary is a pseudonym 


\section{4}

\section{Nathalie running through the water fountains}

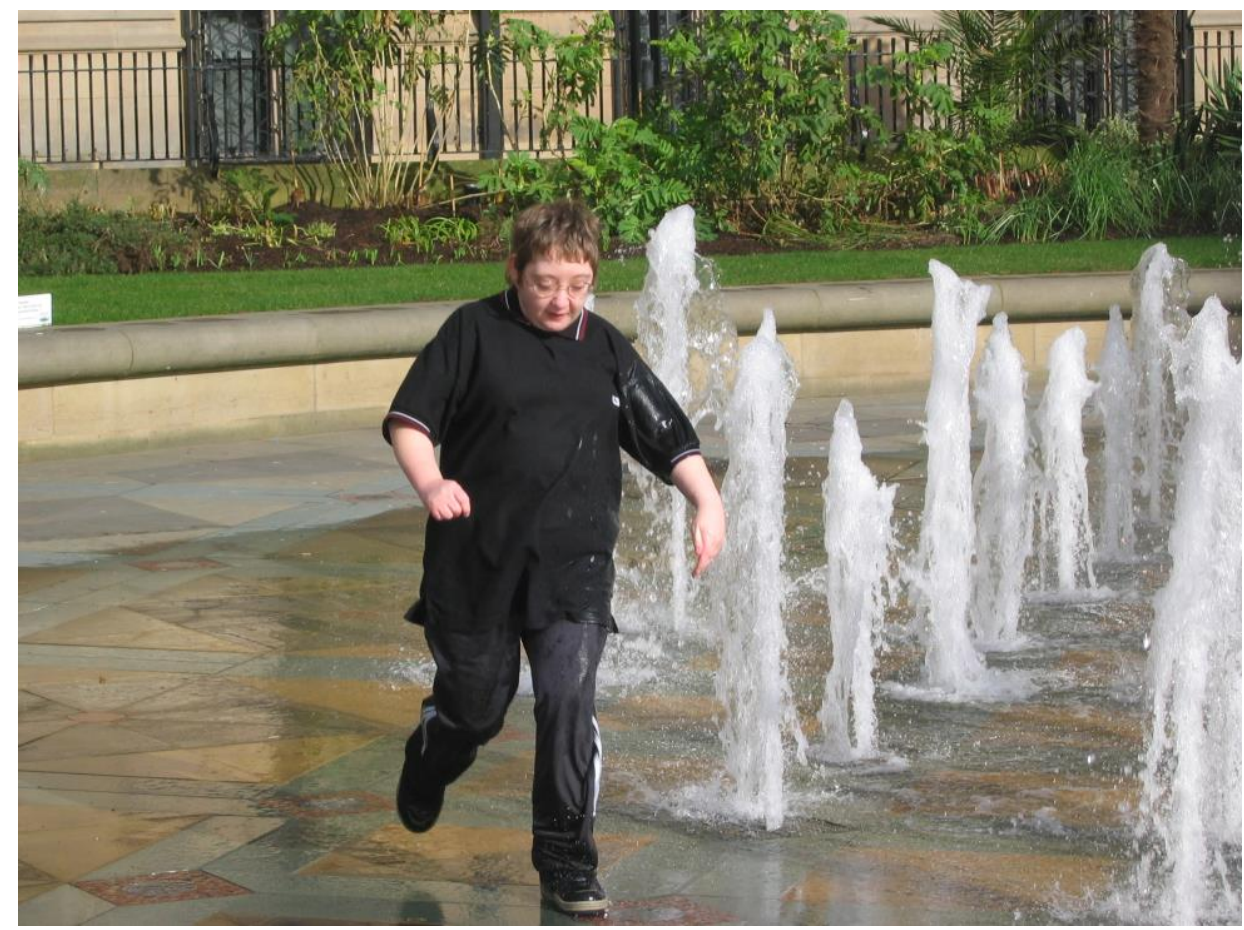

Through her responses we can see how Nathalie, recalled an experience that although missing from the site visit, remained the habitual focus of many of her days out with family, friends or peer group. Photographs taken of Nathalie by other participants, the researcher, support staff and volunteers, reflected a very different and real reason why she had enjoyed the Peace Gardens and would recommend it to others, the interaction with water.

\section{- Physical reaction to water action}

Nathalie was the only participant in the group to require a wheelchair to aid physical mobility onsite. In this respect her physical impairment gave her prominence and priority with staff amongst her peers, which was reflected through the personal importance she placed upon her wheelchair. When asked at the commencement of her interview following the site visit, "And what was the best thing about it [the Peace Gardens] for you?" she replied, "Pushing my wheelchair". However, in reality 'pushing her wheelchair' formed only a very small proportion of her physical activity on site. Most of 
which was concentrated on interaction with the water fountains (Image 6.4). Whilst other group members clearly recalled Nathalie's participation in this experience, it was her direct engagement with the water that gave Nathalie ownership over the event. When experienced first-hand, the water was exciting and enjoyable. Researcher, "What did it feel like running through those fountains?" Nathalie, "Good". Through the secondary act of observation, other participants were able to safely assess the outcomes of interacting with water (i.e. getting wet, feeling invigorated, testing physical fitness) before they embarked upon a similar course of action. This provided the opportunity for individuals to gain personal confidence in environmental behaviour without endangering oneself through physical and social risk.

Towards the close of her Peace Gardens interview, Nathalie was asked again to reflect upon her use of her wheelchair during the site visit. This time, when asked, "When did you use it [the wheelchair]?" she replied, "On the way back". For Nathalie, the act of photo-elicitation during interviews provided her with an accurate visual record of activity onsite, and a true memory of events (i.e. running through the fountains). Without photoelicitation, Nathalie and other participants were quick to rely upon false memories generated through the familiarity of everyday routine (i.e. a site visit spent sitting in or pushing a wheelchair).

\section{- Safety in the city}

Participant awareness of safety in public spaces (both physical and social) was an issue revealed during the pilot study. Unlike other sites previously visited by the SC1 participants, the Peace Gardens are situated in an urban location and are therefore subject to security surveillance, a feature now common to most city centres. Of all participants interviewed only one, Steven ${ }^{4}$ who had recently joined the project, verbalised an awareness of this precaution. When asked, "So why would people go to the Peace Gardens?” he replied, “To have a look round, 'cos it's quiet in there. There's a camera up there, look". In his drawing attention to the close circuit television system (CCTV), the researcher enquired further as to his knowledge of these, and the following exchange occurred:

\footnotetext{
${ }^{4}$ Steven is a pseudonym
} 
Researcher: "Oh yeah, what are those cameras doing?"

Steven: "They're the security cameras"

Researcher: Why do they need them?"

Steven: To keep an eye on this lot down here, in case any trouble starts"

This was the first instance within the project where a participant had displayed a direct, unprompted awareness of the social dangers that might be experienced when visiting public spaces. In addition Steven was also well informed as to methods employed by the local authority to endeavor to ensure social safety. These features of the urban landscape may be relatively visually unobtrusive, however they represent a dramatic change in public trust about how we treat our urban environments, and each other when we spend time within them.

\section{- Experiences past, personal and new}

Socialising with peers, and on occasion the general public, in new or relatively unfamiliar environments like the Peace Gardens, triggered some participants to reflect upon previous social encounters they had experienced in the urban landscape. The following extract is from an interview with Graham $^{5}$, whose responses were initiated by a photograph of a pigeon taken at the Peace Gardens by another member:

Researcher: "And what about this, what do you think of pigeons, do you like them or not?"

Graham: "Yeah. Me Auntie don't like 'em"

Researcher: "Doesn't she? Why not?"

Graham: "She just doesn't, she says: "I don't like 'em flying around"”

Researcher: "Yeah, I'm not too keen when your walking down the street and they suddenly fly up in your face. I don't like that"

Graham: "A man who used to go in town..."

Researcher: "Yeah..."

Graham: "He used to have them all over his body, all over his head"

Researcher: "Really!"

Graham: "Yeah, he used to be feeding them, and he used to have them all his face"

Researcher: "All over his head?"

Graham: "Yeah, and all on his legs"

Researcher: "Oh, I don't think I'd like that"

Graham: "You ask me Auntie when you see her"

Researcher: "I will do, yeah"

Graham: "I've not seen him for a bit, so I wonder if he's in a home"

${ }^{5}$ Graham is a pseudonym 
Researcher: "Was he an old man or a young man?"

Graham: "I think he were like, like a tramp."

What is most surprising regarding this exchange is the Graham's acute awareness of the social situation of those with whom he came into contact. The 'tramp', as he most accurately identifies the man, was not someone with whom he had direct contact, or knew through association. However, through sharing the same public space, Graham was able to observe him and his behaviour in a non-judgmental fashion. This encounter, though not personal or participatory, added a level of richness to the street life that Graham experienced, and left him wondering when next he might come into contact with such an occurrence. Although unrelated to the specific physical design of the site, it appears that by merely being outside, where Graham was able to observe the man at a distance (and not inside where he might be forced into a situation of direct contact) he gained a certain confidence and security in ways of social behaviour.

Popular urban open spaces provide the opportunity for the great richness of the general public delta to be experienced. People flow more slowly through these spaces than other channels such as streets, and a vast diversity of humanity mixes, ebbs, settles and flows on within the course of a day. This was what Graham describes in his encounter. When people with learning disabilities use these spaces, they like others enrich them and add interest. Whether encounters are positive and active, or merely positive and observational, those leaving the site depart with a greater social experience than when they arrived.

\section{- Landscape narrative}

Informal discussions and post Peace Gardens interviews often focused upon the relationship participants drew between experiences in the home environment and new situations they had encountered during the site visit. This process of fluid landscape and object interpretation allowed them to make the unfamiliar, understandable. This was overwhelmingly the case for one participant in particular, Graham. At home the objects that Graham valued the most were series of plastic windmills, set up in his back garden so he could view them daily from his kitchen window. Whilst visiting the Peace Gardens he discovered an object that visually reflected these windmills. Therefore, this became 
the focus of his onsite experience (Image 6.5). The interview discussion where this object's importance was revealed is shown below:

Researcher: "Ok, now I think this was your favourite thing"

Graham: "Yeah"

Researcher: "Because this is what you were making your model out of. Tell me about this, because you've got some at home haven't you?"

Graham: "Yeah"

Researcher: "What are the ones at home that you've got?"

Graham: "Windmills"

Researcher: "And what colours are they?"

Graham: "All different colours, that one me cousin bought me it's all red. When the sun shines on it, it leaves a pattern on the fence. It makes a pattern when it's going round"

Researcher: "Oh that's brilliant, so have you got these all in your back garden?"

Graham: "Yes"

Researcher: "So does it make patterns when it's sunny, or when it's cloudy?"

Graham: "Sunny"

Researcher: "And what else do you like about the windmills?"

Graham: "The way they move, the way they go fast and then slow down"

Researcher: "What makes them go faster?"

Graham: "The wind"

Researcher: "So when you made... because we started making a little one... would you like to make a bigger one?"

Graham: "Yeah"

Researcher: "And would you have it in your back garden or put it here?"

Graham: "Have it in our back garden."

Graham was so affected by the giant 'windmill' he saw at the Peace Gardens that he chose to try and recreate a working scale model. In his interview, Graham describes the ephemeral qualities of these windmills. Ever changing, and unpredictable, environmental qualities such as light, colour and wind greatly contribute to our experiences of outdoor environments. This was the essence of what Graham appreciated in his windmills at home, that they would be different, yet familiar, every day. In attempting to recapture this experience, through replication of the windmill at the Peace Gardens, he exposed a complex landscape narrative. Landscapes we have knowledge of and ownership over (such as our gardens at home) are rich sources of information and understanding, aiding us in our quest to decipher what we see in the wider world around us. The richer and more diverse our home (and to a varying degree neighbourhood) environment, the more equipped we are to interpret new landscapes and places. For people with learning disabilities, if their home and neighbourhood experiences are 
limited, new environmental encounters may often be daunting and confusing. Graham's experience illustrates how, by holding on to the familiar, and using it as a tool to interpret the unknown, greater ownership and ease in the landscape is achieved.

\section{5}

\section{Graham's Peace Gardens windmill}

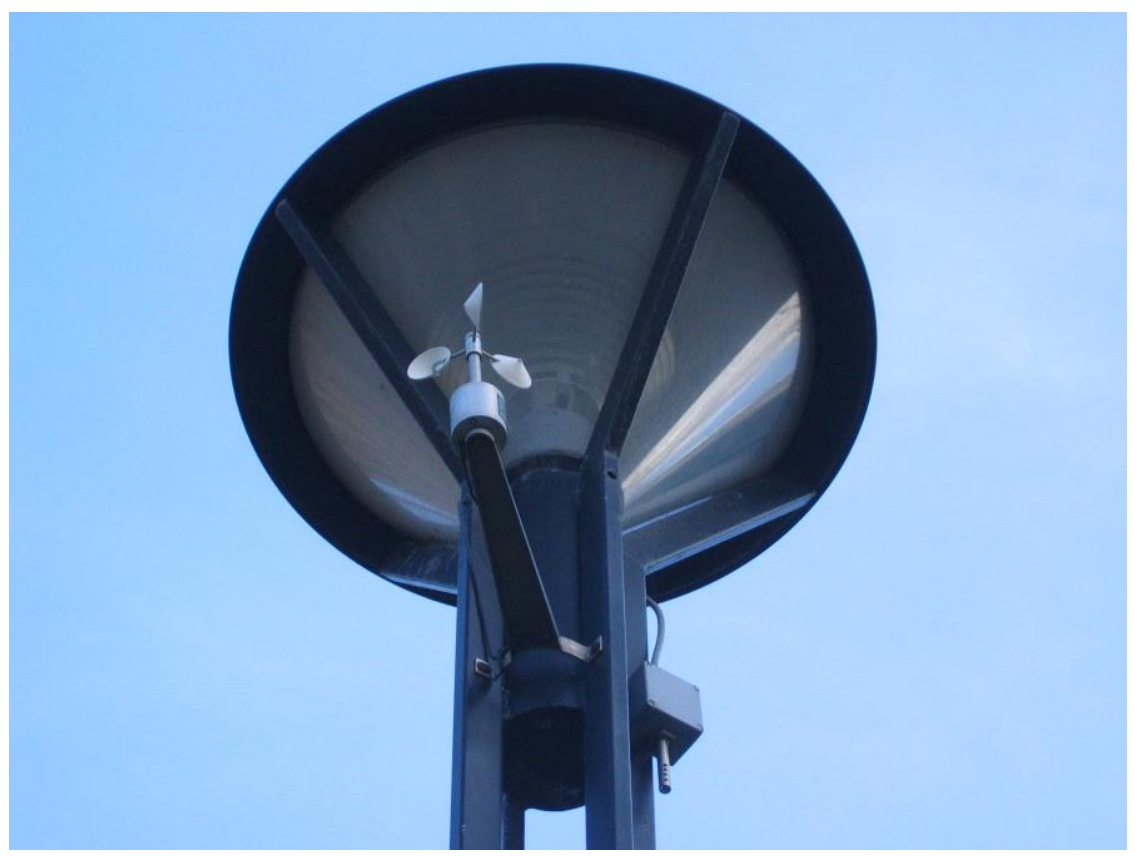

6.6

Steven's painting of the Town Hall

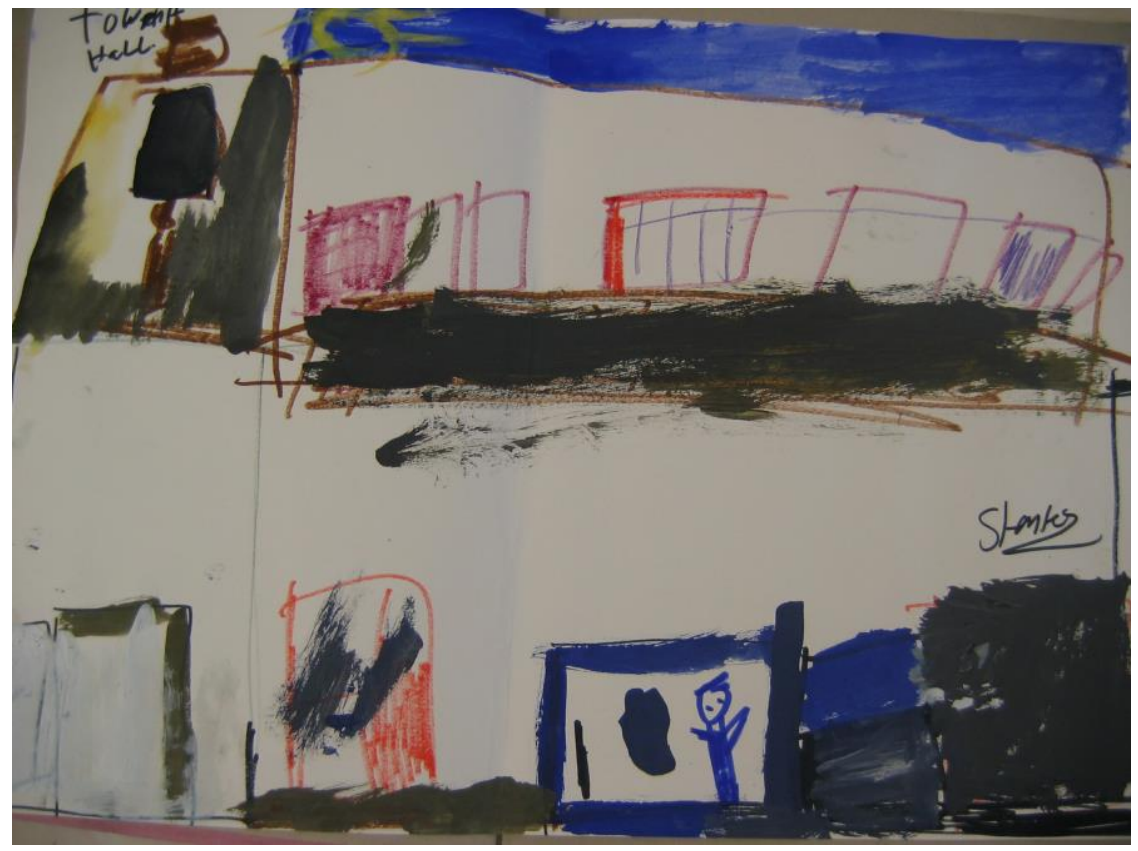




\section{- Useful architecture}

All buildings serve a purpose, however our individual connections to them and the space in which they sit greatly affects the importance that we bestow upon them. Sheffield Town Hall, alongside which the Peace Gardens lies, was important to all SC1 participants' as it was the site of the learning disability parliament, which many attended on a monthly basis. Their ownership over this part of the built environment resulted in a familiarity with the surrounding public space. When given control over the digital camera one participant, Steven, repeatedly chose to photograph the Town Hall rather than the Peace Gardens. This interest was further reflected in the artwork he produced during the drawing workshops (Image 6.6). When asked, "What was the best thing you can remember about the Peace Gardens?" Steven replied, "It was nice and big”. Through further discussion it was revealed that scale and extent of the space, of which he was so appreciative, was inclusive of the Town Hall building itself as well as the external Peace Gardens. Photographs that he identified as being his, "Yeah that's one of mine, the big Town Hall yeah", always placed the open space around this built context. Visiting the Peace Gardens had a purpose for Steven because they represented the limits of his ownership threshold that surrounded the Town Hall.

The example of Steven's interest in the architectural focus during the site visit, illustrates the importance of establishing strong links between the built and open space environments. If buildings within or adjacent to public landscapes are of public use, a greater diversity of people will be attracted to them. At the Town Hall, people with learning disabilities have the opportunity to gather and interact. Reflecting this, the Peace Gardens provides another public space for organised and impromptu events that bring the community together. This sharing and reflection of space relationships, between the interior and exterior, ultimately creates greater social cohesion and ownership of the entire site.

\subsubsection{Summary}

Through exploration of the participants Peace Gardens experience, using the visual communication toolkit, and analysing the written, visual and verbal information generated through employment of the DIDEC programme (Chapter 3), a number of key 
themes were site visit, crucial in understanding their perception of this particular urban public open space. These were:

- The importance of peer photography

- The tendency to create false memory

- The physical reaction to water action

- Participant awareness of safety in the city

- The connection between experiences past, personal and new

- The joy and ownership of landscape narrative

- The need for useful architecture.

\subsubsection{Confronting ghosts amongst the graves}

Sheffield's General Cemetery was the final site to be visited by the SC1 participants. Shortly before the site visit, one further male participant, Brian ${ }^{6}$, joined the SC1 research team, bringing the total number of participants to nine. The site visit took place on the $10^{\text {th }}$ March 2006. The General Cemetery is located approximately two kilometres from the city centre, set back from major public transport routes. As access by public transport was complicated and physically difficult, a private minibus was booked to convey participants to and from the site.

In comparison to other more heavily maintained landscapes previously visited by participants, the General Cemetery had, for many years, survived in a state of relative neglect, and only recently begun to undergo restoration due to a new conservation and maintenance schedule. This therefore provided the opportunity to observe the participants' reactions to a wilder urban space, unlike the polished, formally maintained landscapes they were now relatively familiar and comfortable with.

Once more through application of the visual communication toolkit and DIDEC analysis, a number of themes were generated regarding participants' experience of this landscape that are now discussed.

\footnotetext{
${ }^{6}$ Brian is a pseudonym
} 


\section{- The role of weather}

Of all the SC1 project site visits, the trip to the General Cemetery took place in the least favourable weather conditions, being both cold and slightly wet. On the day of the site visit, with appropriate footwear and clothing preparations, participant behaviour was observed to be relatively unaffected by the adverse weather conditions, an issue that the researcher further explored through semi-structured interview. During interviews participants' responded positively to the weather's effect on their experience: Carol agreed, "Yeah" it was ok for her, Nathalie thought the cold day was, "Good", Mary was a little confused, remembering the day as, "Hot", and Steven thought that the winter weather had additional qualities, "It were a cold day that, a cold day, nice and fresh". However, when given the option, or asked to envisage, what her future experience of visiting other public spaces under similar weather conditions might be, Carol fell back on her learned, ever-cautious, response: "Err, probably stay in if it's wet". With relatively little exposure to placing herself in situations such as the cold weather visit to the General Cemetery, Carol sought the comfort, as we all have a tendency to do, of her safe, internal, home.

\section{- A sense of place}

The General Cemetery was historical one of the richest sites visited with SC1 participants. Its story lay in the gravestones and monuments, the church spire and carved archways, and the lives and names of those remembered there. The dereliction and age of the site seemed, to the researcher, to legitimise the participants' desire to explore the landscape more freely (than for example, at the meticulously-maintained and securitysurveyed Peace Gardens). Some participants (such as Nathalie, Brian and Steven) displayed clearly uninhibited behaviour when they began to clamber up, and onto tombstones, to get closer to the engravings and read the descriptions. This tactile firsthand experience of the site and its elements was a source of great experiential richness for participants (Image 6.7). 
6.7

\section{Nathalie and Brian climbing on the gravestones}

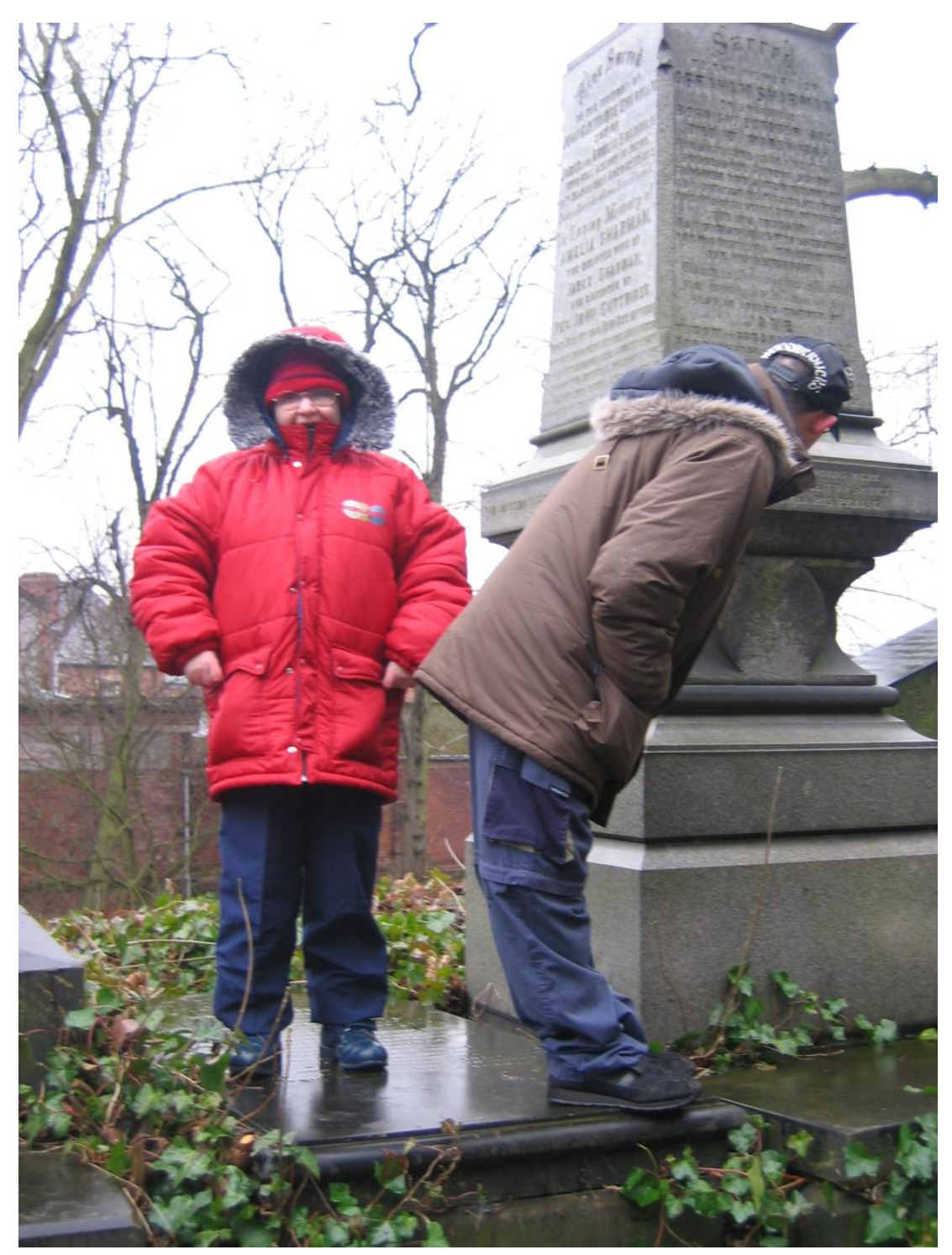

For Steven, the information he gained from the gravestones gave him a knowledgeable authority over the cemetery experience. During his interview he recalled reading: "About James Clarke, about Charlie Chan" and remembered a specific date, “The cemetery, February 1921, 19 th something..." The exact, or inexact, accuracy, with which he recited these, did not lessen their importance to him. It was these details that provided Steven with a tangible, personal connection back to the site experience, guiding him with confidence back through his memories. 


\section{- Safety and security}

Not all participants perceived close, physical contact with the tombstones in such as positive light as Nathalie, Steven and Brian ${ }^{7}$. For Carol, the dereliction of the site (which had delighted others) signalled danger. Although she was disinclined to comment upon, or suggest, any program of increased maintenance or protection, she was acutely aware of the safety issues that arose from the lack of care taken by her peers interacting with such elements:

Researcher: Ok there's the group, and there's a grave. Some of the graves are a bit covered over in ivy, do you think that matters or not really?

Carol: No I don't think it matters

Researcher: What about Brian and Nathalie, having a go and climbing up to have a look at things. Do you think people should be allowed to have a look like that, or not?

Carol: No

Researcher: Why not?

Carol: They could easily fall and break their leg or stuff.

Personal safety awareness had been an important, reoccurring issue for many SC1 participants throughout the course of the project fieldwork. Carol's concern for safety extended from individual objects and instances out into the entirety of the site, and was closely linked with her landscape perception:

Researcher: Ok. There's Nathalie and Brian going up to the church, and the different paths. And we came out into this bit that didn't have any graves and was more grassy. How did that bit feel to you?

Carol: It felt all right

Researcher: Did it feel more like a park or...

Carol: It felt like a park

Researcher: And what would make it a park?

Carol: Making the park safe and stuff

Researcher: So is safety one of the most important things, do you think, for a park?

Carol: Yeah.

The above extract of Carol's interview illustrates her decision to separate the cemetery experience from that of a generalised park. Parks, she perceived, would be naturally safe (and therefore more attractive) due to higher levels of maintenance.

\footnotetext{
${ }^{7}$ Brian is a pseudonym
} 


\section{- Accessibility}

The presently abandoned Anglican chapel supplies the architectural focus of the General Cemetery. Observing this building at a distance it was the natural instinct of the majority of participants to get as close as possible in order to explore the chapel in greater detail. Physical access to the chapel, from the point at which the group entered the site, was by way of a steep, winding, rough surfaced path. For most participants the circulation, surfacing, and gradient was non-problematic. However, for Nathalie, who required use of her wheelchair when walking long distances or up steep inclines, the route to the church was inaccessible. The following interview extracts with Nathalie, demonstrate her experience of this situation:

Researcher: Ok, click again [to move the digital slideshow of photos on] now talk to me about this church Nathalie: It's a big one Researcher: What else do you remember about it? Nathalie: Sitting in me wheelchair half way up

Later in the interview...

Researcher: That's right, and the next one, the church. And why couldn't we get up to that church?

Nathalie: 'Cos it were too far

Researcher: What would have made it better for you in your wheelchair?

Nathalie: Not steep hills

These extracts illustrate how Nathalie was able to quickly identify the key issue (path gradient) that prevented her reaching the chapel to make first-hand contact. Yet what became apparent from studying photographs taken on the day, her words during interview and her final painted canvas, was that she was ultimately content experiencing the chapel at this distance and having the opportunity (as a result of a suitably placed bench) to rest and reflect. For other more physically able participants (and in particular the men amongst the group), the reality that this path was more challenging for some made it all the more attractive. Therefore, one decisive appeal of the site for participants was that it that accommodated (intentionally or otherwise) visitors to experience its landscape on different levels. A key factor in the success of this was the adequate 
provision of seating. Seating ensured the site was accessible to the older and less physically able members of the group as it provided places for respite. When seating was too sparsely spaced, vandalised or neglected (Image 6.8) some members of the group struggled and the whole momentum of the party slowed.

\section{- Appropriate play}

Running had always been one of the most popular forms of play during site visits with the SC1 participants. The General Cemetery was no exception. Most members of the group embarked on running at some point, and the curving, unknown, adventurous nature of the General Cemetery's path network and overgrown landscape only added to the participants' enjoyment of this. In such an informal setting, this type of physical play was totally appropriate. However, two participants, Carol and Steven, brought it to the researcher's attention that they believed that some types of play (by their peers and the general public) were inappropriate. For them, negative play was of a type that resulted in vandalism and the ultimate degradation of the landscape. During Steven's interview he voiced these concerns (as he had done regarding the Peace Gardens) and the measures he believed should be taken to combat them:

Researcher: So do you think it's all right for people to be able to stand on the gravestones? Steven: Yeah, gets in there ... though, they get knocked, they get vandalised Researcher: So what would you do to stop them getting vandalised? Steven: Get a dog, get a policeman round it.

Steven's respect for the landscape and behavioural rules were sometimes at odds with the views of other younger participants. His individual mannerisms and method of verbal communication often resulted in his advice being ignored by his peers. However, when supported by visual prompts (the photographs taken on site) many more participants were willing to enter into and share group discussion with him. 
6.8

\section{Broken bench}

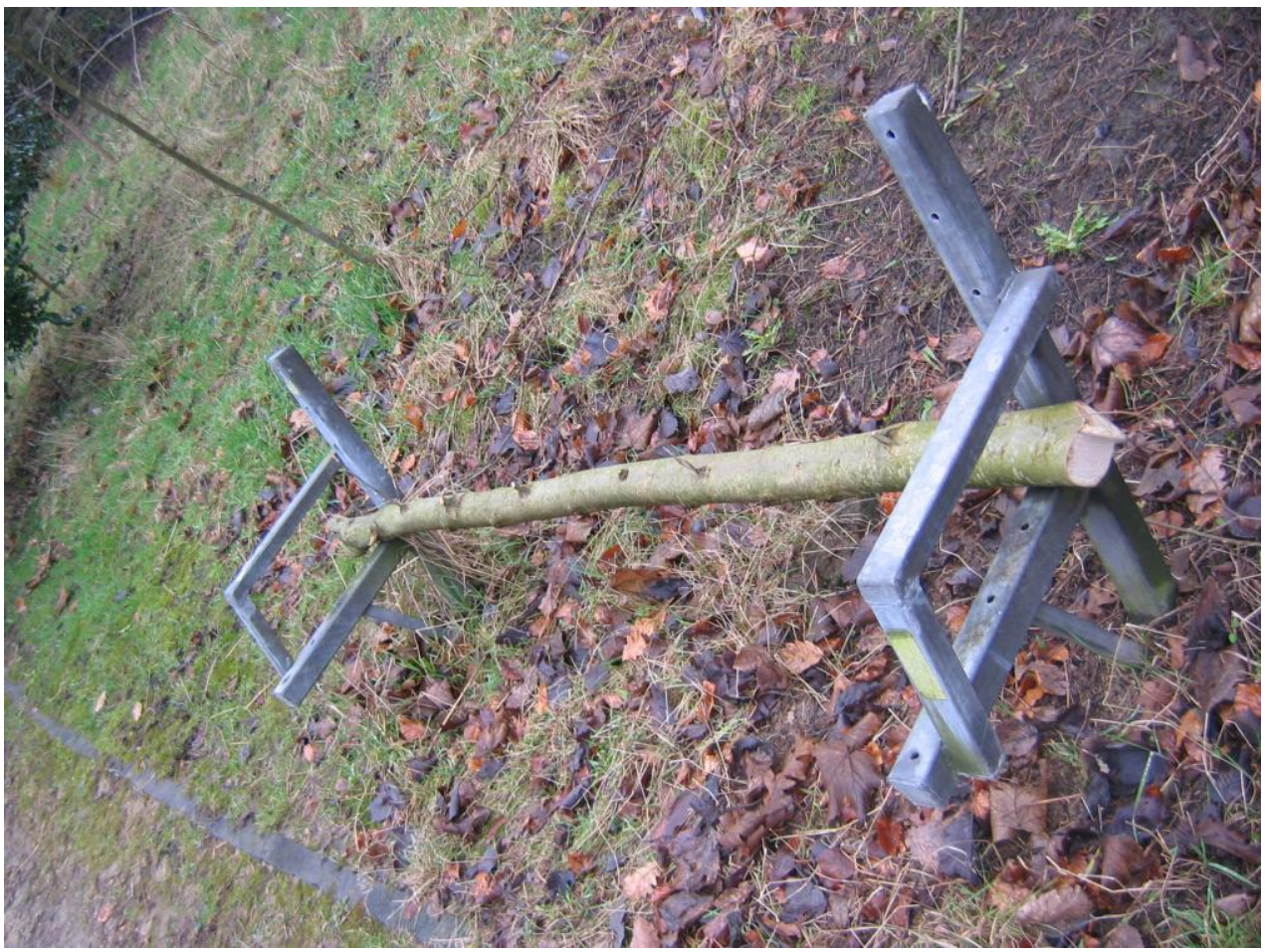

6.9

\section{Meeting the wrestler}

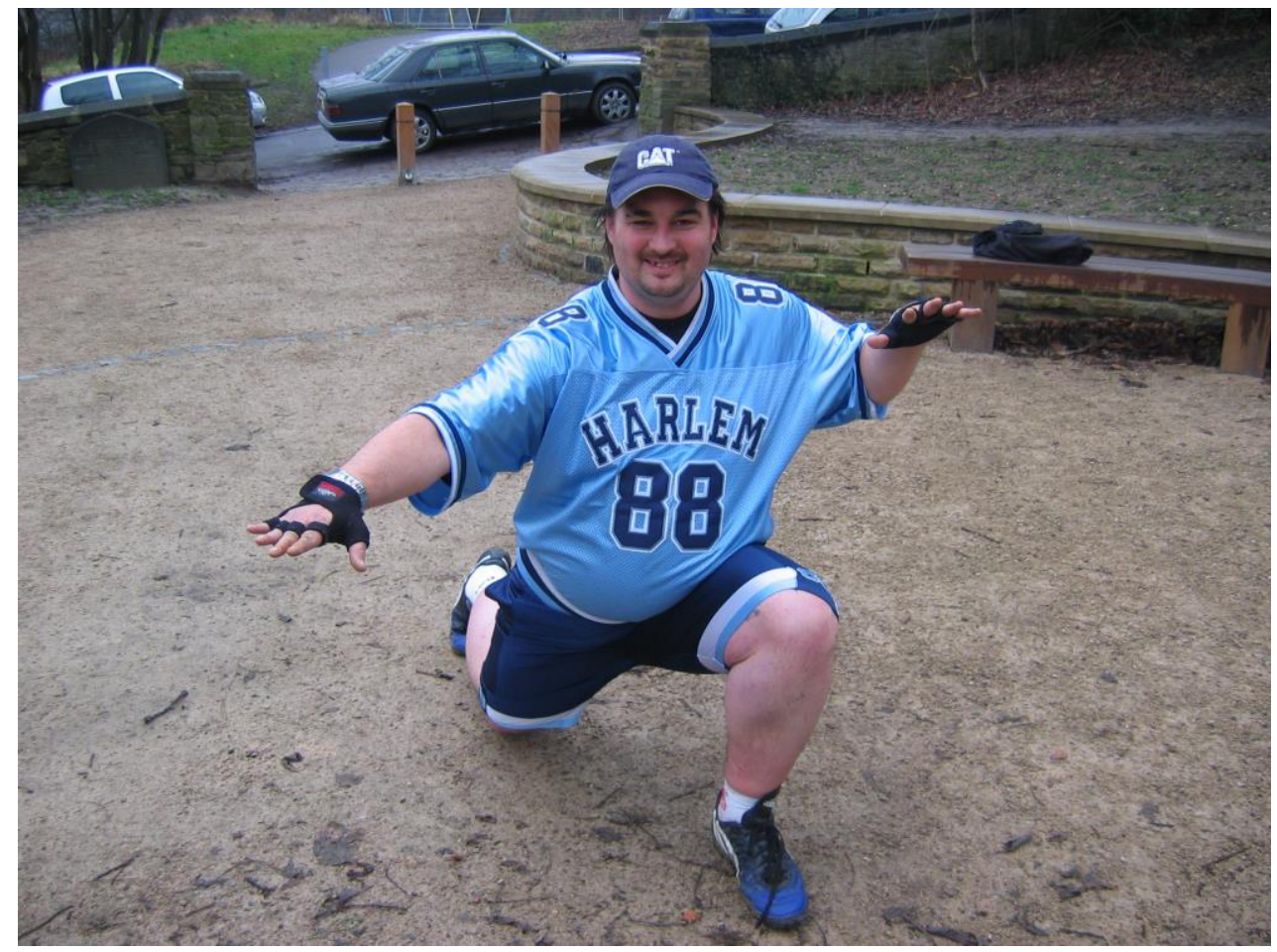




\section{- Social contact and social use}

Steven and Carol were two of the most socially and safety aware members of the group, nevertheless they (like other participants) had no hesitation in approaching members of the public whilst on site. The group's memorable encounter with one such individual, opened up further participant debate as to why, and how people use public open spaces.

Towards the end of Steven's interview, the researcher asked Steven which public open space he had preferred, the Peace Gardens or the General Cemetery? Steven replied, "The Peace Gardens [because there were] lots of people and it were nice and hot that day and all". As the weather on the day in question was only marginally more favourable than at the General Cemetery, focus falls upon the initial part of his response; the people. People watching is often said to be one of the most popular national pastimes. Whilst on holiday, eating lunch or waiting for a bus it is the life that people bring to a space that distracts us from frustration or adds interest to our day. At the Peace Gardens, Graham's narrative of the tramp and the pigeons revealed how this had been achieved through an observational encounter with a stranger. At the General Cemetery, participants made direct and interactive contact with a member of the general public (Image 6.9). Through photo-elicitation all participants, bar Carol, were able to clearly recollect their meeting with this individual. Brian identified him as, "Football, football”, Steven recalled, "Yeah, he was a Wednesday fan...exercising, he needs to get some weight off and all" and Nathalie replied that he was in the cemetery to go, "Jogging". All participants were in agreement that the member of the public was using the cemetery as place in which to exercise, and that parks provided attractive arenas in which to engage in different forms of activity (with further suggestions including golfing and football).

However, it was during Graham's interview, that the issue of actual landscape ownership and sharing of social space was exposed:

Researcher: Yeah, let's look at the next one. There's the group going down the path, so do you remember meeting this guy?

Graham: Yeah

Researcher: Can you remember what he was doing in the park?

Graham: Exercising

Researcher: That's right here he is, so...

Graham: Would he live there or does he own it? 
Researcher: No I think the thing is that people can come and use parks to do whatever kind of exercise they want

Graham: He looks like a wrestler doesn't he.

From this interview and more informal discussions during drawing workshops with Graham, the following was revealed. When engaging with a stranger who was alone, physically larger than himself and exuding confidence within the landscape, Graham naturally assumed that he must have ownership over the space. If Graham had been on his own it would have been unlikely he would have behaved in such a manner. By understanding this attitude of a hierarchical sharing of landscape, it is possible to imagine how some people with learning disabilities might feel incredibly intimidated and cautious about entering, and existing in, public spaces with others. Although low awareness of personal safety, and overwhelming intrigue in those they encountered might encourage some to approach strangers, lack of confidence and experience interacting in mixed social groups could lead to public space exclusion.

\section{- Naming and the development of detail}

The final experiential theme of the General Cemetery site visit was generated by far the most surprising and original encounter. On exiting the site, Graham's attention was drawn to an open coffin propped against the entrance wall (Image 6.10). This 'Yellow Prison' as it became known amongst the participants, did not appear to hold any negative or frightening connotations for the group, rather as Graham described it, "It looks exciting". The product of this personal encounter, as in incidents before, was a strengthening of participant ownership over the site and in addition the reinforcement of a group identity; subsequently all participants referred to this photo as the 'Yellow Prison'. The process of naming was important to both participants who could read and those who could not. Names invented by participants were often visually driven and had associated meanings derived from media sources such as films and television. Existing signage did not often interest participants, however when waiting for the return of the minibus to transport the group back to SC1, Graham noticed a street sign entitled Frog Walk. To Graham these words were both amusing and memorable (more memorable than many of the street signs he passed daily). 
6.10

'The Yellow Prison', a photograph taken by Graham

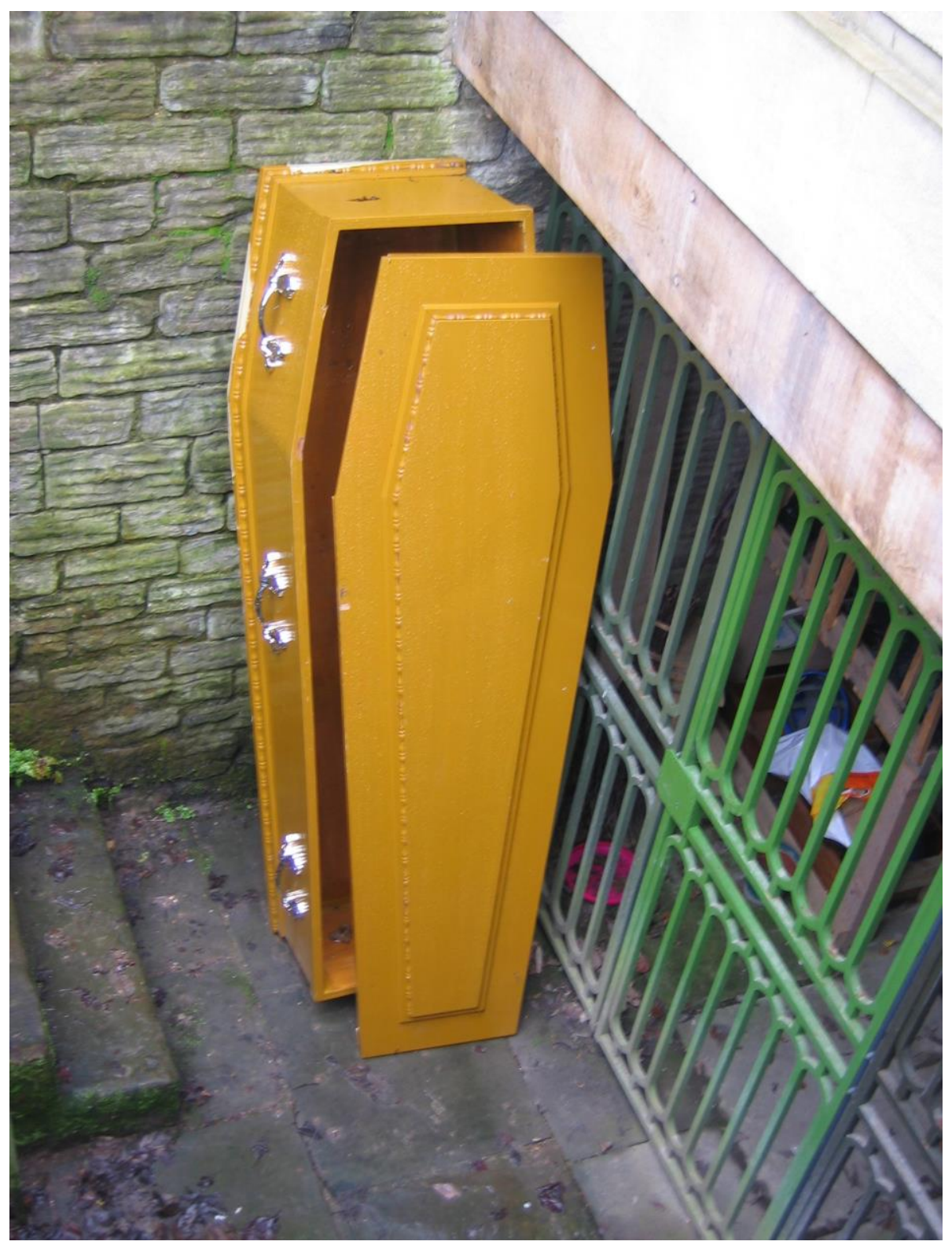

Many place and street names have somewhat obtuse meanings (i.e. names of geographic regions, prominent local nobility or celebrities), and for people with learning disabilities (who have limited or no written language) these do little to aid their progress towards independence when self-travelling. In contrast, words that create strong visual images may be more easily stored and recalled. A fact Graham proved in his exhibition 
painting which included written and drawn reference to: the Yellow Prison, Frog Walk and in addition (of his own invention) Elephant Street and Monkey Road.

\subsubsection{Summary}

What is noticeable when reflecting upon experiential information generated through the site visit to the General Cemetery is that participants paid little or no attention to the condition of the landscape (relatively lowly maintained), and that this had little or no impact upon their enjoyment and affection for the site. The issues that held greatest importance for participants included:

- The role of weather if individuals were not adequately prepared

- The creation of a sense of place experienced first hand through tactile contact

- Landscape safety and security

- Varying levels of accessibility within the site, with suitable provision of seating and understanding of circulation, surfacing and gradients

- Approval of participation in appropriate play that did not lead to personal danger, environmental damage or vandalism

- Familiarity in social contact and sharing the landscape through social use

- Securing landscape ownership and environmental orientation through naming and the development of detail.

\subsubsection{Staff reflections}

On completion of site visits to the Peace Gardens and General Cemetery the researcher asked the member of SC1 staff supporting the project to complete a questionnaire regarding her perspective on the participants' experience of the two landscapes and the project in general. As with previous staff questionnaires, discussion topics were broken down into a series of set themes. The support staff's responses to these are summarised in Table 6.3. The staff member's comments confirm that, from her perspective, the project experience was a positive one for participants and in addition suggest that the visual communication toolkit was effective in revealing greater understanding of the public open space experience of this group of people with learning disabilities. 
Table 6.3

Section 1: Site Visits

\begin{tabular}{l}
\hline Topic for discussion \\
\hline Anticipation and \\
preparation for site \\
visits
\end{tabular}

\section{Staff comments}

- Participants were excited

- Most people like to be out and about but have less opportunity to do so than other members of the public

- One participant was worried about getting tired (therefore a wheelchair was supplied)

- Preparation included internet/book research and a pre site visit to check suitability of paths and access for members

\begin{tabular}{|c|c|}
\hline $\begin{array}{l}\text { Access and } \\
\text { information }\end{array}$ & $\begin{array}{l}\text { - } \quad \text { More toilets would be beneficial } \\
\text { - } \quad \text { Pictorial maps would be better for members } \\
\text { - } \quad \text { Leaflets were popular mementos }\end{array}$ \\
\hline Art and sculpture & $\begin{array}{l}\text { - Sculpture is a positive element in the landscape, more would be } \\
\text { welcome } \\
\text { - Water features provide interest and excitement (visually, audibly, } \\
\text { through form and inherent changeability) } \\
\text { - Sculptural architecture was appreciated by some members } \\
\text { - Individuals will always find their own points of interest } \\
\text { - Sound sculptures could be introduced to more landscapes }\end{array}$ \\
\hline Landform & $\begin{array}{l}\text { - } \text { Everybody enjoyed being in large open spaces and exploring them } \\
\text { - } \text { Different members were happy with different levels of activity } \\
\text { - Some members liked to run about } \\
\text { - Some members liked to relax } \\
\text { - Steep paths at the General Cemetery inaccessible to some members }\end{array}$ \\
\hline Vegetation & $\begin{array}{l}\text { - Only one member commented on vegetation at either site } \\
\text { - Vegetation could be improved by seasonal planting, sculpture } \\
\text { planting, points of interest, colourful and fragrant species }\end{array}$ \\
\hline Safety & $\begin{array}{l}\text { - Some paths at the cemetery were difficult for the wheelchair } \\
\text { - Wary about members overt friendliness towards general public } \\
\text { - Fine line between restriction and protection }\end{array}$ \\
\hline Seating & $\begin{array}{l}\text { - Seating was plentiful at the Peace Gardens } \\
\text { - Increased and repaired seating was needed at the General Cemetery } \\
\text { - } \quad \text { Picnic benches would encourage people to stay for longer on site }\end{array}$ \\
\hline Senses & $\begin{array}{l}\text { - Sound of water is a positive experience for all } \\
\text { - Seeing new places is a valuable experience } \\
\text { - } \quad \text { Different materials and being able to touch them seems important } \\
\text { to members }\end{array}$ \\
\hline Animals & $\begin{array}{l}\text { - } \text { Birds were points of interest } \\
\text { - Animals were popular with members } \\
\text { - Making a connection with another living thing is an important and } \\
\text { positive experience }\end{array}$ \\
\hline Play (activities) & $\begin{array}{l}\text { - Not many opportunities for play at Peace Gardens } \\
\text { - The wide open spaces of the General Cemetery could be used for } \\
\text { games i.e. football and rounders } \\
\text { - } \quad \text { Risks included tripping and dog mess }\end{array}$ \\
\hline
\end{tabular}




\section{Section 2: Photo-elicitation}

\begin{tabular}{ll}
\hline $\begin{array}{l}\text { Topic for } \\
\text { discussion }\end{array}$ & Staff comments \\
\hline $\begin{array}{l}\text { Participant produced } \\
\text { photographs }\end{array}$ & - $\begin{array}{l}\text { Three members (Carol, Graham and Penny) took primary } \\
\text { charge of the digital cameras }\end{array}$ \\
- Other members asked staff to take photos for them \\
- Staff also asked members what they would like photos taken of \\
what they were interested in \\
- Graham's favourite photograph was the weather station and \\
- Cather vane at the Peace Gardens \\
- Hall at the Peace Gardens \\
- Penny took photographs of people \\
\end{tabular}

\section{Section 3: Participant artwork}

\begin{tabular}{ll}
\hline $\begin{array}{l}\text { Topic for } \\
\text { discussion }\end{array}$ & Staff comments \\
\hline $\begin{array}{l}\text { Drawings and } \\
\text { paintings }\end{array}$ & - $\begin{array}{l}\text { Participants enjoyed making their canvases and showed then off } \\
\text { with pride }\end{array}$ \\
- & Nathalie chose to paint the chapel and added her 'rubbing \\
picture' \\
- Graham chose to paint the coffin and Frog Walk sign \\
- Tom chose to paint wrought iron railings from the cemetery \\
- Penny chose to paint a gravestone \\
- Mary chose to paint her peers playing around a grave \\
- Brian left SC1 before he could complete his painting \\
- Gordon painted the lion arch from the General Cemetery \\
- entrance \\
- Carol chose to paint a pathway in the General Cemetery, \\
- Steven painted the coffin
\end{tabular}

\section{Section 4: Interviews}

\begin{tabular}{|c|c|}
\hline $\begin{array}{l}\text { Topic for } \\
\text { discussion }\end{array}$ & Staff comments \\
\hline $\begin{array}{l}\text { Using photographs to } \\
\text { talk about } \\
\text { landscapes }\end{array}$ & $\begin{array}{l}\text { - } \quad \text { Photographs are helpful to some members } \\
\text { - 'Dry' questions can seem abstract } \\
\text { - Having a visual reminder creates focus } \\
\text { - } \quad \text { Eases the response process either verbally or by signalling }\end{array}$ \\
\hline
\end{tabular}




\section{Section 5: Communication}

\begin{tabular}{|c|c|}
\hline $\begin{array}{l}\text { Topic for } \\
\text { discussion }\end{array}$ & Staff comments \\
\hline Communication & $\begin{array}{l}\text { - Some members have verbal communication difficulties and } \\
\text { without the photos and artwork it would be very difficult to } \\
\text { understand their experience } \\
\text { - The photography and artwork highlight exactly what members } \\
\text { enjoyed } \\
\text { - Video and drama could be used as additional communication } \\
\text { methods } \\
\text { - Exhibiting the group work raises the profile of the project and } \\
\text { the participants, it gives the members a sense of achievement } \\
\text { and recognition } \\
\text { - Longer and repeated site visits at different times of the year } \\
\text { would build up a greater sense of individual sites and what } \\
\text { members enjoyed }\end{array}$ \\
\hline
\end{tabular}

\subsection{1}

Mary ${ }^{8}$ admiring her painting in the 2006 Showroom Cinema exhibition

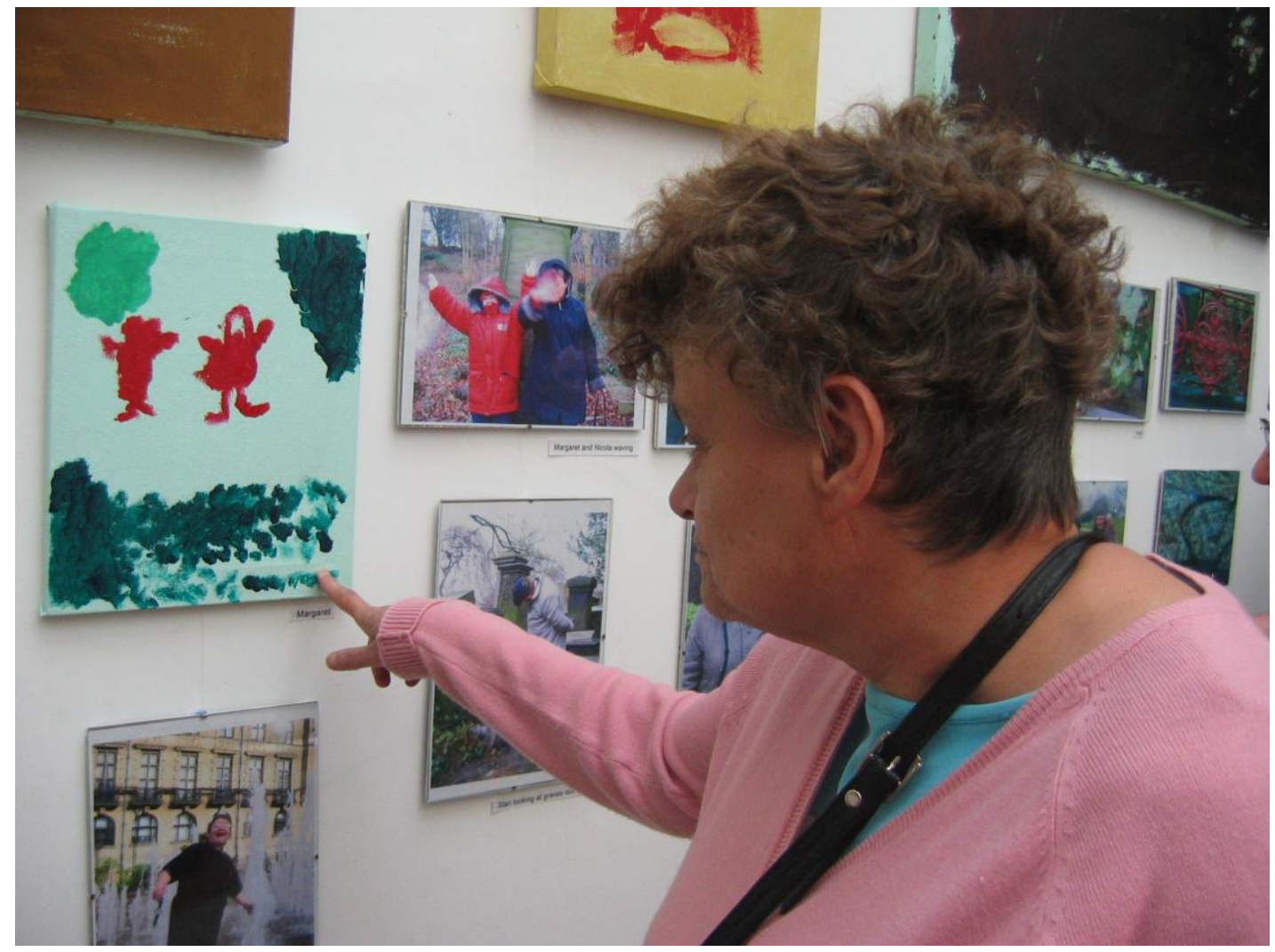

\footnotetext{
${ }^{8}$ Mary is pseudonym
} 


\subsubsection{Showroom exhibition}

Following completion of the practical fieldwork, drawing workshops and semi-structured interviews, participants were asked to produce an individual painting depicting the most important, or memorable, element to them from their experiences at either site. This was the final stage of the visual communication toolkit. All participants chose to reproduce elements from the General Cemetery in their paintings. Elucidated through informal group discussion, the reason for this was that the General Cemetery had been the participants' most recent site visit, and therefore was clearest in their minds. The exhibition was staged once again at the Showroom Cinema in Sheffield city centre (Image 6.11). Having received an overwhelmingly positive reaction to the group's 2005 exhibition there, it was decided to continue to build on this collaboration for the benefit of future projects.

\subsubsection{Participant feedback}

On completion of research at $\mathrm{SC} 1$, a project review was held with participants to obtain feedback on their involvement. The review was informal and structured as a group discussion. The project had been designed to cause no discomfort to participants, and was granted approval by the University of Sheffield Research Ethics Committee.

Nevertheless, it was important to discover whether participation had been positive or negative for those involved. Participant feedback on the project was in every respect positive. During the discussion the researcher asked participants how they would like to see the project develop, and if they could recommend any changes that should be made to its format. However beyond ideas for further site visits, immediate suggestions for improvements were limited, as some participants found hypothetical situations difficult to conceptualise.

\subsubsection{SC1 Conclusion}

The period of main study fieldwork at SC1 began with three aims, to be achieved through three objectives. The first aim was to refine methodological components of the visual communication toolkit. SC1 fieldwork accomplished this aim by repeat employment of the toolkit, exploring the participants' environmental experience of two new public open spaces. Through responding to the comments and experiences of participants, the 
researcher was able to best facilitate toolkit refinement. Positive reactions from the participants to the toolkit, as existing, resulted in no new methodological elements being added. However, the staff questionnaire revealed that visual communication methods might be diversified into film and drama.

The second aim was to gain a greater depth of knowledge about individual participants' open space experience. This aim was also successfully accomplished. With participants' who had been members of the project since commencement of the pilot study, the researcher was able to build upon an existing understanding and knowledge bank, in order to enrich and extract detail from their new environmental experiences. This was most apparent during interviews with Graham. Graham began the project as a shy individual, reticent when revealing any personal information or preferences. By completion of the SC1 main study, Graham was far more confident and forthcoming in his views and the researcher was able to facilitate this, having developed a strong relationship (rich in shared experience) with the participant. For participants' who had joined the project more recently, the researcher's confidence in the toolkit's operation allowed greater concentration on individual experience when employing the different components.

The third and final aim was to develop participants' appreciation and understanding of public open space. Through selection of two different types of public space not previously encountered during the project, participants' experience of a range of landscape types was extended. On an individual participant level these experiences were incredibly rewarding. For Nathalie, new to the project and unconfident in her physical abilities, the site visit to the Peace Gardens was particularly significant. It here she found pleasure and assurance in physical exertion and interaction with the landscape i.e. running through water fountains. Opportunities like this, for the participants' to have personal contact with the environment without the restriction of daily routine ensured their appreciation and understanding of public open space.

Running in conjunction to the SC1 study was the SC2 study in the North East, with new participants, new support staff and new landscapes. The story of this comparative study is now described. 


\subsection{A tale of two studies: part 2}

\subsubsection{SC2 Project arrangement}

Contact with SC2 was initiated in the autumn of 2005. With the cooperation of the college principal it was agreed that the researcher would complete the project in tandem with the Land and Environment BTEC module. This was a taught course run by the Estates Department during the spring and summer semesters of 2006. SC2 provides a range of accredited and life skill courses for young people with learning disabilities between the ages of sixteen and twenty-five. In 2006, SC2 had approximately 120 students in attendance. The majority of these were residential students, living on the college campus for the length of their three-year education. A far smaller percentage of attendees were home students, travelling in and out of the college each day to attend their assigned courses. All students who attended the Land and Environment module in 2006 were residential students.

Prior to commencement of their time at SC2, the needs and vocational aspirations of potential students are assessed in order to determine the most suitable approach to their college education. During their first year at SC2, students are given the opportunity to experience a range of taught courses offered by the various departments. These departments include catering, drama, art, estates and basic skills. At the end of this time, their progress is reviewed and where possible students are encouraged to fine-tune their education in a more vocational direction. Through completion of accredited and specialised courses, the college aims to give students the best educational and experiential grounding that may lead them to obtain post-college work placements and employment. A variety of courses are run by the Estates Department including small animal care, horticulture and the Land and Environment BTEC. The 2006 Land and Environment students were all in their second or third years of college and had shown a previous interest in working with the landscape (through placements with the British Trust of Conservation Volunteers (BTCV)) and had aspirations of future employment in this area. These student participants consisted of five young men aged 18 to 21 , of previously described ethnicities and communication needs.

On the $6^{\text {th }}$ March 2006, the BTEC course tutor invited the researcher to present the project to the students and determine the following: 
1. If the project was of interest to the students.

2. If they would agree to give their consent to participating in the project.

The researcher explained the project by way of a simple PowerPoint presentation ${ }^{9}$ illustrated using plain English and many images. The presentation demonstrated research carried out at SC1 during the pilot study, and the potential research that the students might be involved in at SC2. Regarding the issue of informed consent, the residential status of the students created a time and organisational limitation in gaining access to their parents. This was resolved in the following manner. Whilst at SC2 the college staff were responsible for students safety and well being (in loco parentis), therefore it was agreed with the college that the course tutor would take responsibility for the students consent to be involved, with all project information to be made available to parents and carers (such as the consent documents, project outlines and exhibition information). The project would not deviate from course curriculum and would enrich the students' experience of the module through broadening the teaching methods involved. All gave their consent to be involved, supported by the college and the tutor.

To meet the BTEC module objectives it was decided with the course tutor that the students would visit a range of six local landscapes. The freedom to experience such a variety of landscapes within such a short timescale (fourteen weeks) demonstrated a key difference in the organisation of the research at SC2 compared with SC1 (where only four sites were visited over the course of a number of years). At SC1 financial funds were greatly limited. Therefore, the success of site visits relied primarily on parental contributions to subsidise transport and refreshments for participants. At SC2 all costs were covered by the college: a stock of private transport was at the project's disposal (college minibuses), lunches were catered for by the college kitchens, the cost of equipment was covered in house and the researcher received permission for relatively unlimited printing. The seven landscapes, their categorisation (names created by researcher and staff to distinguish difference relevant to the taught module) and the date they were visited are shown in Table 6.4.

\footnotetext{
${ }^{9}$ Appendices, Chapter 5 Main Studies, Project Introduction
} 
Table 6.4

\section{Site visits with SC2}

\begin{tabular}{lll}
\hline Name of landscape visited & Landscape categorisation & Date and time visited \\
\hline Derwent reservoir, Northumberland & Remote countryside & $6^{\text {th }}$ March $2006(\mathrm{pm})$ \\
\hline Hexham, Northumberland & Town park & $6^{\text {th }}$ March $2006(\mathrm{pm})$ \\
\hline North and South Shields & The developed coast & $13^{\text {th }}$ March 2006 (am - pm) \\
\hline The Quayside, Newcastle upon Tyne & The urban riverside & $20^{\text {th }}$ March 2006 (am) \\
\hline Quakers' Hole, Hexhamshire & The wetlands & $3^{\text {rd }}$ April 2006 (pm) \\
\hline Newton-by-the-sea, Northumberland & The rural coast & $12^{\text {th } J u n e ~} 2006(\mathrm{am})$ \\
\hline Alnwick Gardens, Northumberland & The formal gardens & $12^{\text {th } J u n e ~ 2006 ~(p m) ~}$ \\
\hline
\end{tabular}

The story of these visits and the environmental experiences of the participants they revealed are now discussed.

\subsubsection{The remote countryside and town park}

The first landscape visited on the afternoon of the first day of the project $\left(6^{\text {th }}\right.$ March 2006), was an area of remote countryside comprising moorland, pastoral farmland interspersed with conifer plantations surrounding a large reservoir. This was the participants' introduction to using digital cameras to document their experiences in new environments. Most were nervous and unsure as to the visual subjects they should be recording. Therefore, the researcher assumed responsibility of the camera taking the majority of the photographs. After each photograph was taken, the researcher immediately played back the image to the participants. This increased their curiosity, and over the course of the afternoon the participants began to direct the researcher as to the subjects they wished to be photographed. This resulted in a gradual shift in ownership of the experience from the researcher to the participants. As with SC1 participants, SC2 participants most frequently requested photographs of each other (Image 6.12). The researcher applied tools two (site visit), three (drawing workshop) and five (photoelicitation interviews) from the seven-step visual communication toolkit in order to elicit the experiences of the participants with regard to this site. At this point the reader is 
reminded of the complete seven stages (or tools) in the visual communication toolkit (Table 6.5).

Table 6.5

Participation tools in the visual communication toolkit

\begin{tabular}{|c|l|}
\hline Tool number & Tool name \\
\hline 1 & Informed consent \\
\hline 2 & Site visit \\
\hline 3 & Drawing workshop \\
\hline 4 & Individual canvas workshop \\
\hline 5 & Photo-elicitation interviews \\
\hline 6 & Staff questionnaire \\
\hline 7 & Public exhibition \\
\hline
\end{tabular}

Tool 4, the individual canvas workshop, was reserved until later in the project. The purpose of this was to use the canvas workshop as a means to generate a more informed picture of each participant's perception of public open space experience in the context of having visited all seven landscapes in the research timetable. Having collected a wealth of visual and written data regarding the participants' experience of this first day of site visits, the researcher employed qualitative analysis in the form of the DIDEC programme (see Chapter 3 for further details). In this DIDEC analysis new site specific experience information was added to the existing data spreadsheet, new individual transcript memos were produced as a result of the photo-elicitation interviews, new codes and categories were added to the developing experiential diagrams, which resulted in a the elicitation of a series of themes experientially important to the participants, and now described. 


\section{- Fixation on food}

The provision and consumption of food was a significant and constant feature in the participants' daily routine. One participant in particular, Luke ${ }^{10}$ was quick to make associations between the landscapes he experienced and the activity he most enjoyed:

Researcher: And what would you want to do if you were out in this landscape?

Luke: Eat my sandwiches

Researcher: So you'd have a picnic?

Luke: Aye something like that.

Food provided comfort and reward, an experience common to most of us. However, what is interesting to note is how easily Luke was able to transport the familiar and routine (eating or having lunch) into the unfamiliar and occasional (the rural countryside). His comments over the course of the project revealed how eating was not contextually or environmental driven, rather it was opportunity led. The typology, visual impact, and familiarity of landscape, had little impact as long as he was able to participate in his chosen activity, eating.

\section{- Active experiences}

Participant concentration on the active use of landscape provided an immediate cohesion between group members. This was demonstrated through interview conversation regarding participants' personal preferences when experiencing public open space. When asked to describe why they enjoyed visiting the countryside, participants produced the following answers, "Something to do", "Go on walks", "Go on picnics", "Go on nice walks", "Go for walks", "Go swimming", "Going out and about". All of these answers are related by a focus of doing something, and primarily a physical something. At SC1 a proportion of the participants, mainly female, had enjoyed partaking in observational rather than active behaviour when out in the landscape. For the young male participants at SC2, pleasure came from being fully involved with each other and the environment. This level of involvement generated rewards such as seeing "nice views". Luke expressed how, by putting a little physical effort in, such as choosing to go for a walk, he was personally rewarded, “Long journey...that's why we're smiling, you can see me”.

\footnotetext{
${ }^{10}$ Luke is a pseudonym
} 


\subsection{2}

The SC2 participants in the remote countryside

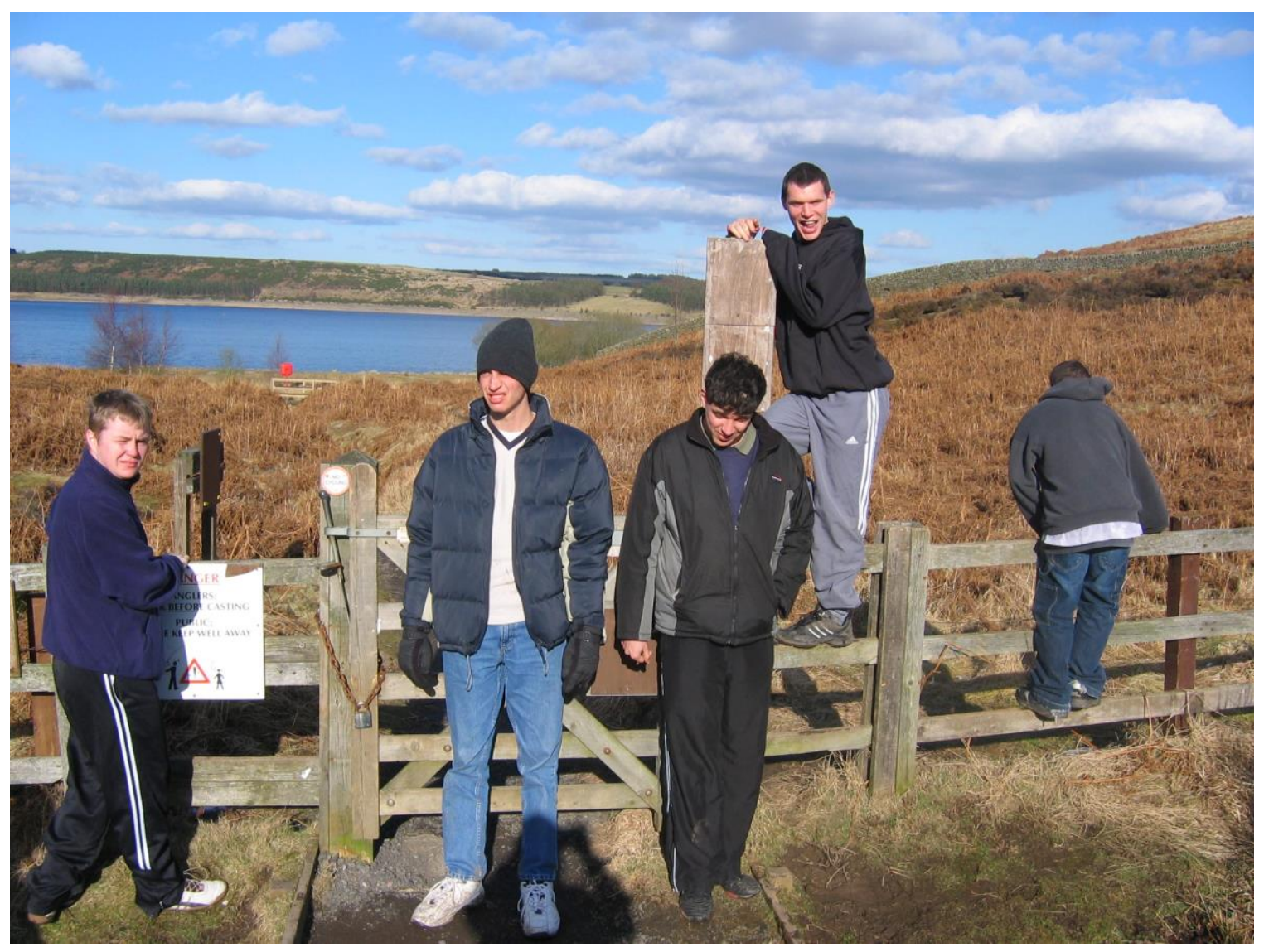

- Weather affected

Beginning the research fieldwork at SC2 at the end of winter, allowed the participants and researcher to experience a range of landscapes through the changing seasons. From winter to spring and spring to summer. As many of the earlier pilot study site visits (with SC1 participants) had taken place during warmer months when the weather was more clement, the researcher was interested to discover what affect, if any, variable and inclement weather had upon the SC2 participants' perception of environmental experience. One participant, Karl ${ }^{11}$ voluntarily drew attention to the weather conditions at the time of the site visit, noting that, "it was a bit cold". However, he continued to say, "When the sun comes out it's nice, you feel like summer". In general cold winter weather

\footnotetext{
${ }^{11} \mathrm{Karl}$ is a pseudonym
} 
had no negative affect on the participants, if they were fully prepared and equipped with warm clothing and suitable footwear. On the other hand, wet weather was a barrier to positive environmental experiences and perceived negatively. Photographs taken during the site visit were effective in generating genuine participant memories of weather conditions at the time, not those expected for the time of year or geographic location.

\section{- The subtext of spaces}

The Land and Environment BTEC, within which the research project was embedded, required students to consider how different landscapes were shaped through human activity and the pattern of land use. As a contrast to the remote countryside that participants were initially introduced to, the first day of site visit finished with a brief journey into the local town centre to present the idea of urban spaces and parks. During their first semi-structured interview, participants were asked to comment upon their previous experiences of urban parks. These conversations were supported by drawings participants had produced to explain their concept of an perfect park with its associated equipment, vegetation, people, activities etc. This process was intended to reveal their perception of urban public open spaces, the type of landscape they instinctively preferred, and why.

Urban parks were, in general, perceived by the participants as positive places to spend time. In parks they enjoyed a range of activities such as skateboarding and using play equipment. However, barriers still existed. These attitudinal barriers were socially constructed and were drawn to the researcher's attention by two participants, Warren ${ }^{12}$ and Karl, in particular. The interview with Warren contained the following exchange:

Researcher: And what don't you like about parks?

Warren: The swings and that

Researcher: So why don't you like swings?

Warren: I think the parks are for the other children now.

During informal discussions throughout the project, Warren talked with the researcher about his awareness of being different, excluded from socialising with other people his age. Outwardly, he displayed a confident attitude choosing to wear clothing with logos of

12 Warren is a pseudonym 
bands he enjoyed listening to, and talking about music shops he loved to visit, where he would buy CD's and other merchandise. Warren identified himself as a Goth and a skater, part of the alternative and underground youth culture. Parks were very important places him, as he perceived this was where people like him to chose to hang out. Warren's drawing of a skate park with ramps (Image 6.13) displays his perfect park and his longing to belong.

\subsection{3}

\section{Warren's skate park}

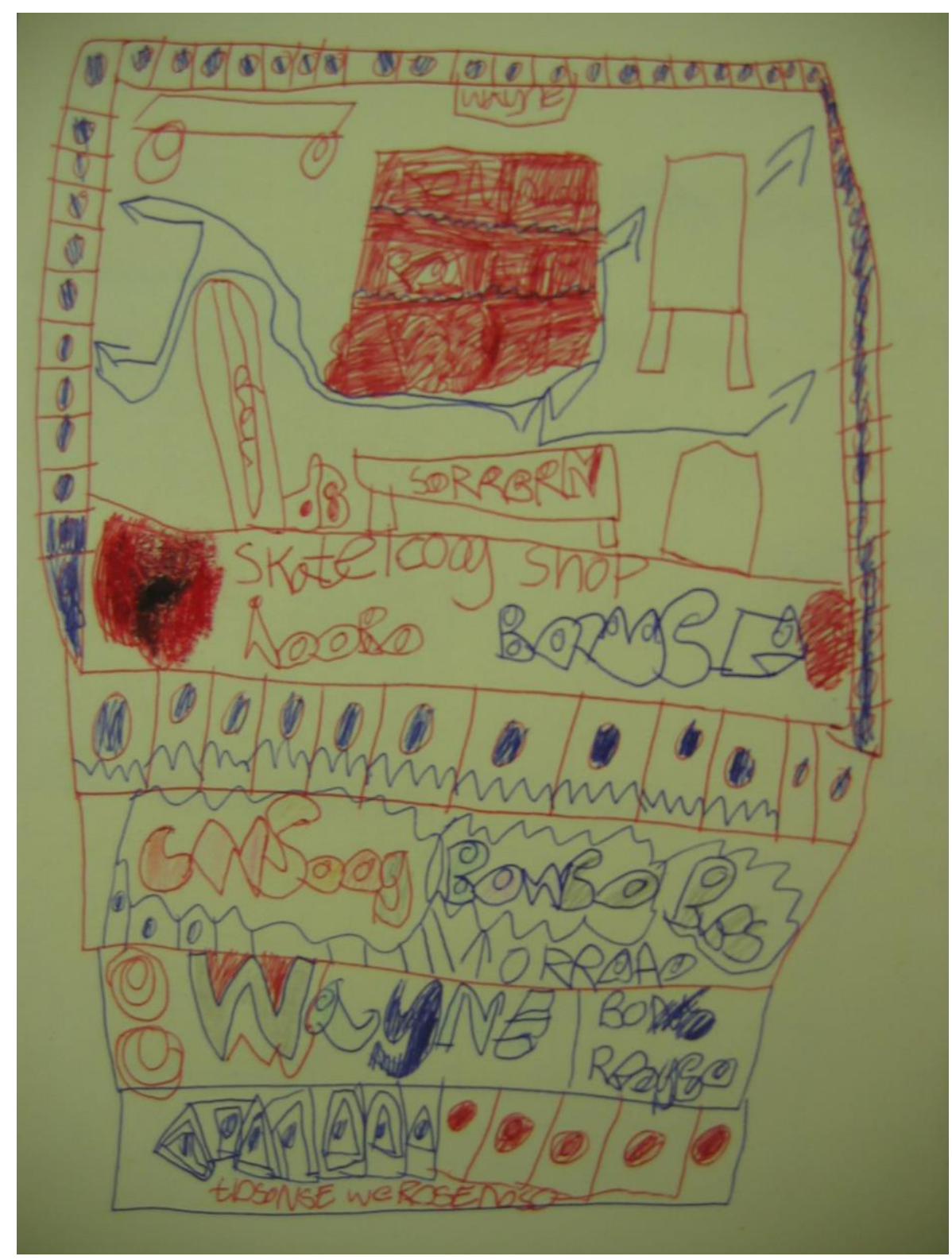


Warren's comment, "I think the parks are for the other children now" is incredibly powerful. It underlines a long history of frustration and rejection. Though Warren had tried to become part of the alternative society he aspired to be like, these attempts had not gained him full integration and he remained an outsider. In conversation, he was eager to hear about the meeting places of teenagers and people who fell into the alternative category like him. However, his responses revealed that he (at this time) had begun to feel that the acceptance that he sought might not materialise and he had to distance himself from his peers. Therefore, the comment "I think the parks are for the other children now".

Karl, like Warren, commented on other park users when discussing the negative aspects of such landscapes. When asked: "What's bad to have in a park, what would stop you going to parks?" he replied: "All the lasses, smashing glass and cans, the mess". Karl's response (and general conversation) hints that he too had experienced some social exclusion in parks. For Karl and Warren, rejection by the opposite sex and their peers, combined with the aggressive behaviour of others, resulted in urban public open spaces that did not provide the freedom they associated with more remote rural landscapes. Remote landscapes allowed them to behave as they pleased without judgement. However, although Karl and Warren shared a general sense of unease about socialising in urban open spaces, their views greatly differed regarding participation in rural environment activities. Karl had great experience of such landscapes through work experience placements with The British Trust of Conservation Volunteers (BTCV) whilst Warren was more familiar with the urban streetscape of his home city. Progression through the project and exposure to a wide range of landscapes was set to challenge these original perceptions.

\subsubsection{Summary}

Early project exposure to two very different landscapes revealed a number of important participant issues. Some issues were personal and some shared by all. The project provided the possibility to explore these in more detail and challenge their hold over participant behaviour. These issues or themes may be summarised as follows: 
- Fixation on food illustrated the comfort of the familiar, daily routine for some participants.

- Participants appreciated the opportunity for active experiences in the landscape.

- The popularity of landscapes was not affected by weather, as long as it didn't rain.

- The subtext of spaces was driven by the social behaviour of others.

\subsubsection{The developed coast}

The second day of site visits commenced a week after the first, on the $13^{\text {th }}$ March 2006.

During the day participants explored an area of coastal landscape between North and South Shields. This area of the coast has a long history of industrial development. Previously an important shipping region, its docks were once flooded with business and fishing boats and ferries crowded its harbour. Today although quieter, it still acts as a hub to transport passengers and goods between the northeast of England and northern Europe. Exploring this edge of developed coastal landscape that cradles the North Sea provided an extreme contrast in environmental experience, from that of the previous week, for the participants. In accordance with their BTEC guidelines, they were able to observe a different typology of landscape and the pattern of land use that had shaped its current design. From this experience, through use of the visual communication toolkit the following experiential themes were revealed during drawing workshops and semistructured interviews.

\section{- Familiar people}

In unfamiliar landscapes and with the possibility of new experiences, the participants treasured the familiar in order to make sense of the unknown. During individual interviews, when faced by a question of which they were unsure, participants returned focus onto the people in the photographs (themselves and their peers), upon whom they could confidently comment. This was a device also observed by the researcher during interviews at SC1. Whilst some environments could not be immediately contextualised or explained by the participants, the actions and appearance of the group could be. As the project progressed, the focus upon people in photographs decreased slightly and participants began to make personal observations regarding the landscapes they 
experienced. However, only by way of a longitudinal research approach could this selfconfidence in the participants be developed. Participants had to be encouraged to trust that it was their opinion that mattered not the production of a right or wrong answer.

In addition, the appearance of familiar people in photographs gave participants the opportunity to distract the course of the interview away from unravelling the environmental experience and instead placing attention upon the interview setting (an Estates Department classroom) or interviewer. This was an organisational issue, as result of limited space and staffing. On occasion the Estates Tutor assigned to the project had commitments elsewhere at $\mathrm{SC} 2$ and the researcher was left alone with all participants. Under these conditions, individual interviews were held in the same room in which the remainder of the group were working. This was frustrating for both the participant and researcher, as interviews were prone to interruption and distraction. These circumstances resulted in focus on people in the room (connected through their appearance in the photographs) that on occasion took priority from the environmental experience under study.

\section{- Previous physical experience}

The second theme that arose as a result of the developed coast site visit was the importance of the participants' previous physical experience of (in this case seashore) landscapes. Of the three participants interviewed, two independently described positive memories of visiting the coast. Luke ${ }^{13}$ explained how he enjoyed the sandy beach environment where people could, "Slide up it, play some football and basketball". Ewan ${ }^{14}$ in contrast preferred rocky cliffs, as they provided a means of informal exercise and challenge. In describing his experiences of rocky cliffs Ewan pronounced, "I think they're good for you". When asked to elaborate on this positive landscape attachment he cited the reason being one of physical challenge; to gain access to the cliffs you had to exert some physical energy, or as Ewan described, "You climb up to them". The third participant to be interviewed was Warren. His reaction to the coastal site visit, and his own previous experience of such landscapes, provided an extreme negative contrast to

\footnotetext{
${ }^{13}$ Luke is a pseudonym

14 Ewan is a pseudonym
} 
that of Luke and Ewan's. The following extract is taken from Warren's interview to demonstrate this:

Researcher: Over there we've got Tynemouth, with nice beaches and stuff

Warren: Oh I don't think I could cope on the beach

Researcher: What would you do if you went on the beach?

Warren: I wouldn't want to go

Researcher: You wouldn't?

Warren: No

Researcher: Why not?

Warren: 'Cos I don't like the sand

Researcher: You don't like the sand?

Warren: No I'd just rather go somewhere else

Researcher: Like the town?

Warren: Yes, I just don't really like going to the beaches 'cos I don't think the beach is really my thing

Researcher: Sorry, you don't want to go to the beaches because?

Warren: I said I don't want to go to the beaches, 'cos I don't think the beaches are really my type of thing. I hope we don't go.

Unlike Luke and Ewan, Warren's responses reveal his fear of the coastline. During his interview Warren's reasoning for this was, “'Cos I don't like sand”. Further into the interview, during informal discussions, and the drawing workshop the researcher learned from Warren that his previous experience of the coast comprised primarily of visits to amusement arcades and the funfairs of Blackpool Pleasure Beach. Experiencing natural beaches, at this point in the project, held little appeal for Warren. Having only negligible experience of such environments, he could not imagine how they would facilitate and entertain him. As a result, Warren chose to disregard unknown landscape experiences in favour of memories of familiar, manufactured environments (such as Blackpool Pleasure Beach).

Importantly, identification of this experiential theme of previous physical experience illustrates how, for SC2 participants', mere observation of the environment does not suffice. To appreciate a landscape they require physical experience of it. Participants, who had a positive reaction to the coastal landscape, were revealed as having had previous experience of engagement in physical activity at similar sites. The participant who displayed a negative reaction to the coastal environment was revealed as lacking in previous contact. Therefore, this participant's environmental memories of the 
coast were vague, and his leisure preferences focused on more manufactured and immediately accessible landscapes. This issue of attraction to instant entertainment is now discussed in the context of a seaside funfair also situated along the length of coastline visited by the participants.

\section{- Instant entertainment}

Towards the end of the developed coast site visit the participants happened upon a locked funfair adjacent to the seashore. Comprising a go-karting track and number of colourfully painted rides and entertainment booths (as depicted in photograph 6.14), the funfair drew immediate interest from all five participants. It was Warren however, who chose to photograph the funfair on the day of the site visit. The researcher observed how taking ownership over the visual communication of this element, strengthened Warren's focus during periods of verbal communication, for example his repeated allusion throughout his semi-structured interview to Blackpool Pleasure Beach. So why were funfairs so appealing to the participants? The funfair at South Shields, and the idea of funfairs in general, appealed to Warren because of "all the different things you can do". For Ewan, funfairs were "very good" as "I think they've got swings in them". Although Luke did not directly comment on the funfair in his interview, like Karl and Simon, in his drawings he depicted the many coloured rides and play opportunities. What was evident from discussion with the participants' was that the allure of funfairs lay in their ability to provide immediate gratification. For very little effort, but at a financial cost, funfair rides deliver a burst of adrenalin through the body. Every sense is manipulated and over stimulated. The smell of frying foods and candyfloss, the sound of people screaming and laughing with an ebbing backdrop of bass and music, the flash of lights and rainbow of brightly decorated stalls, entrances and exits. All these experiences can be bought for a night's entertainment, and indelibly lodge in the customer's conscience, tantalisingly obtainable and desirable. In Karl's drawing (6.15) he recalls the precise names of rides spelling them with confidence (Spanish City, the Walzter, Big Wheel and Boat). This was also true for other participants who drew the funfair. In contrast their written and drawn communication regarding natural environments was not so accurately depicted. 
6.14

Funfair at the developed coast photographed by Warren

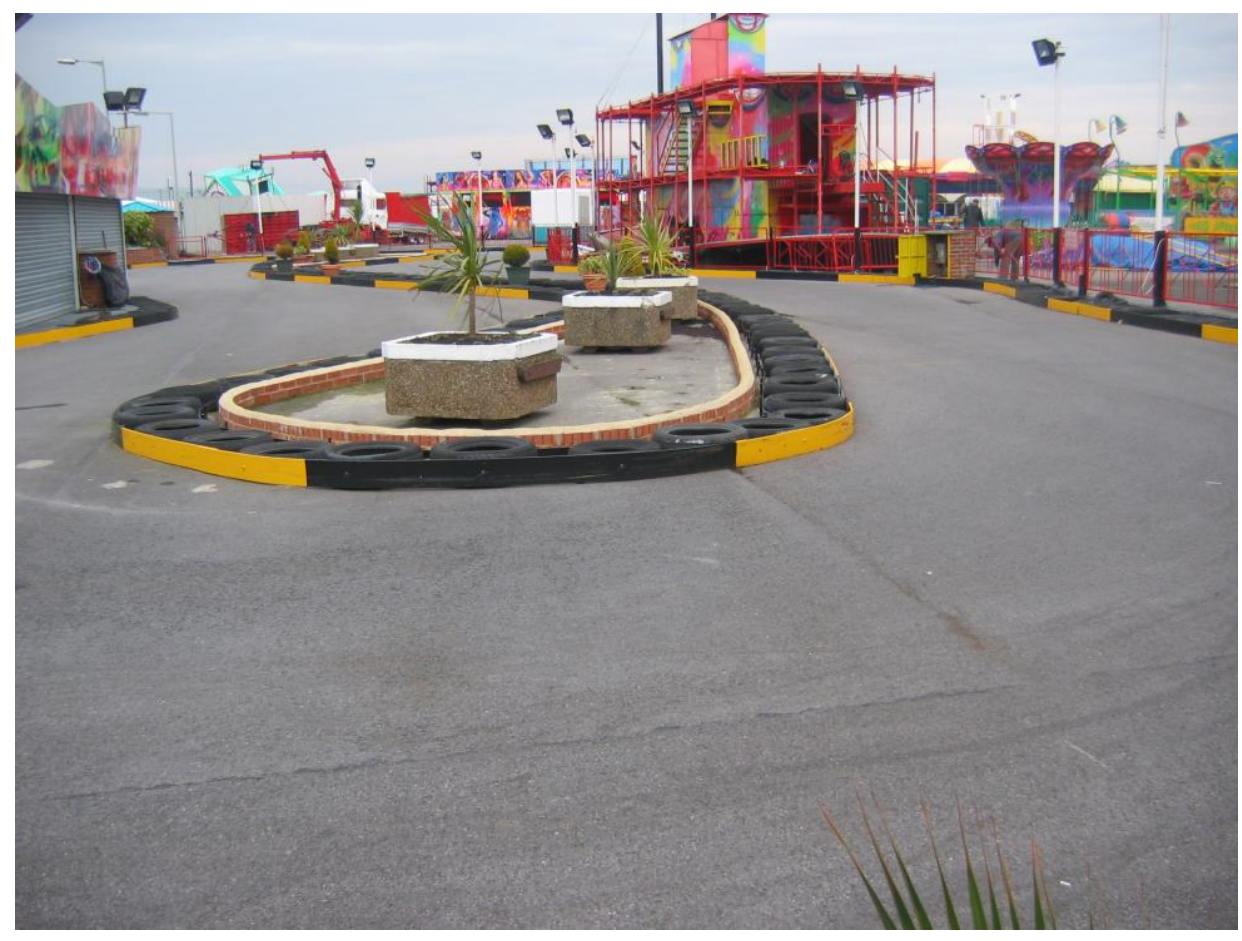

6.15

Funfair at the developed coast drawn by Karl

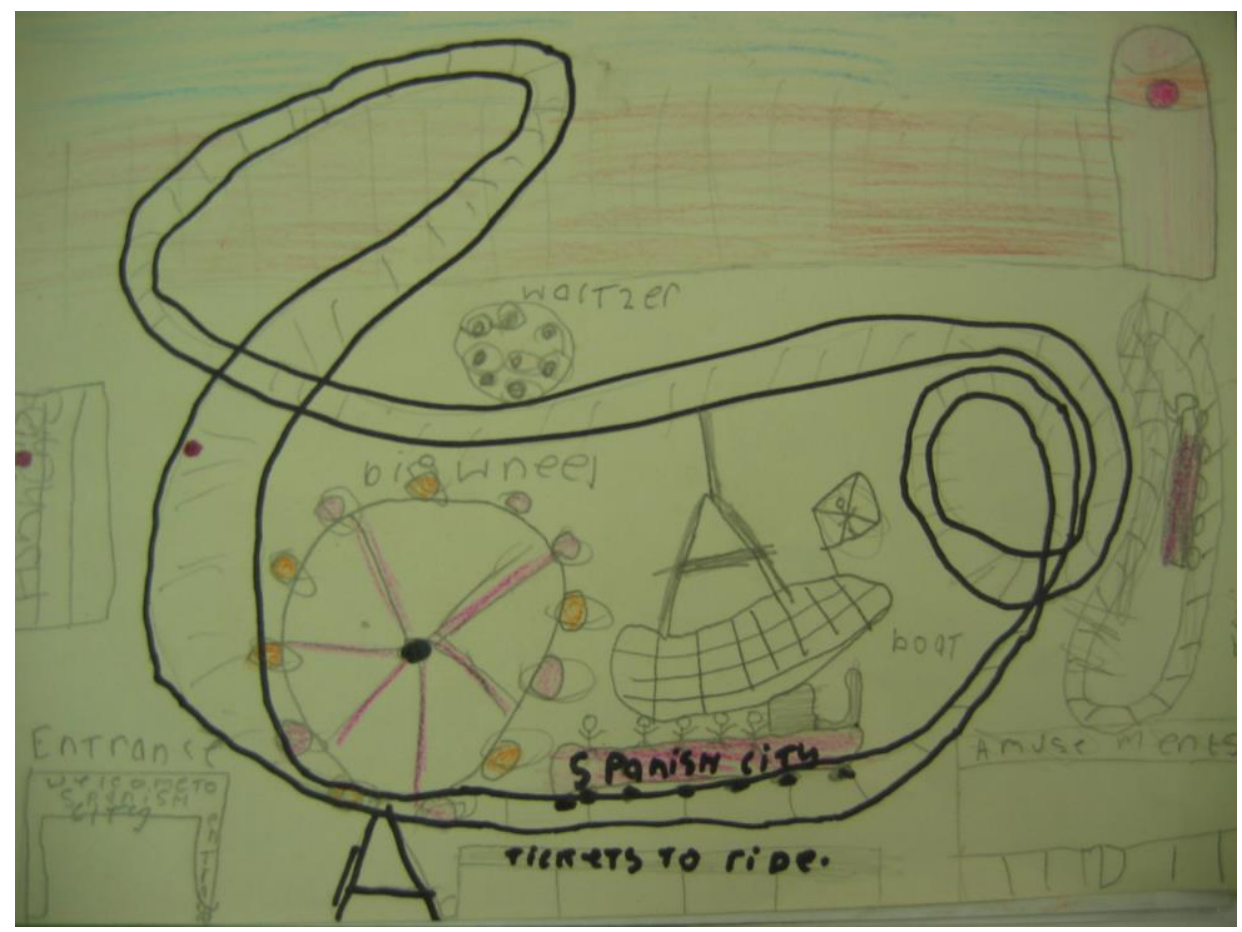


Natural environments were drawn in far less detail and verbal descriptions were often vague and abstract. The choice between instant entertainment provided by the funfair environment, and development of a long-term relationship with the natural landscape was, at this point in the project, an easy one for most SC2 participants to make. Self-gratification was also an element of the final experiential theme revealed by the developed coast site visit.

\section{- Routine rewards}

To meet the students BTEC course objectives, the coastal site visit included the opportunity for individuals to explore in more detail the industries and livelihoods that shaped coastal environments into their current form. At the start of the day, Karl and Simon had shown interest in discovering more about the jobs and lives of those who worked on the fishing boats, ferries and coastguard, and had subsequently captured these nautical images in photographs and drawings. For participants Luke and Ewan, it was the South Shields Fish Quay and associated fish shop that held their interest. Luke's fixation on food and routine, and his influence over his friend Ewan, resulted in the majority of their photographs and illustrations depicting the display of freshly caught fish in the shop window. The burst of colour from the dyed and smoked fillets, that lay side by side with speckled skinned plaice and pink marbled salmon were a great sensory draw for the two young men (6.16). On a cold and grey March day, the familiar salty and smoky smell was overwhelming, and far more colourful than the landscape that surrounded them. Although no fish was bought or consumed, Luke declared the fish to be his favourite coastal experience. The fish shop window gave life to the landscape, and in an out-of-season situation provided experiential warmth that the dormant vegetation, limited sunlight, sparse humanity and wildlife could not. Landscapes, and in particular urban landscapes, are so much more than their ecology. In these landscapes providing impromptu and sensory, yet functional, rewards such as the colourful fish shop, creates a linkage between the familiar and newly explored. Luke's environmental focus for the remainder of the research project at SC2, echoed back to the colours and forms recorded in his photographs of the fish shop. 


\subsection{6}

Smoked fish in the fish shop counter display as photographed by Luke

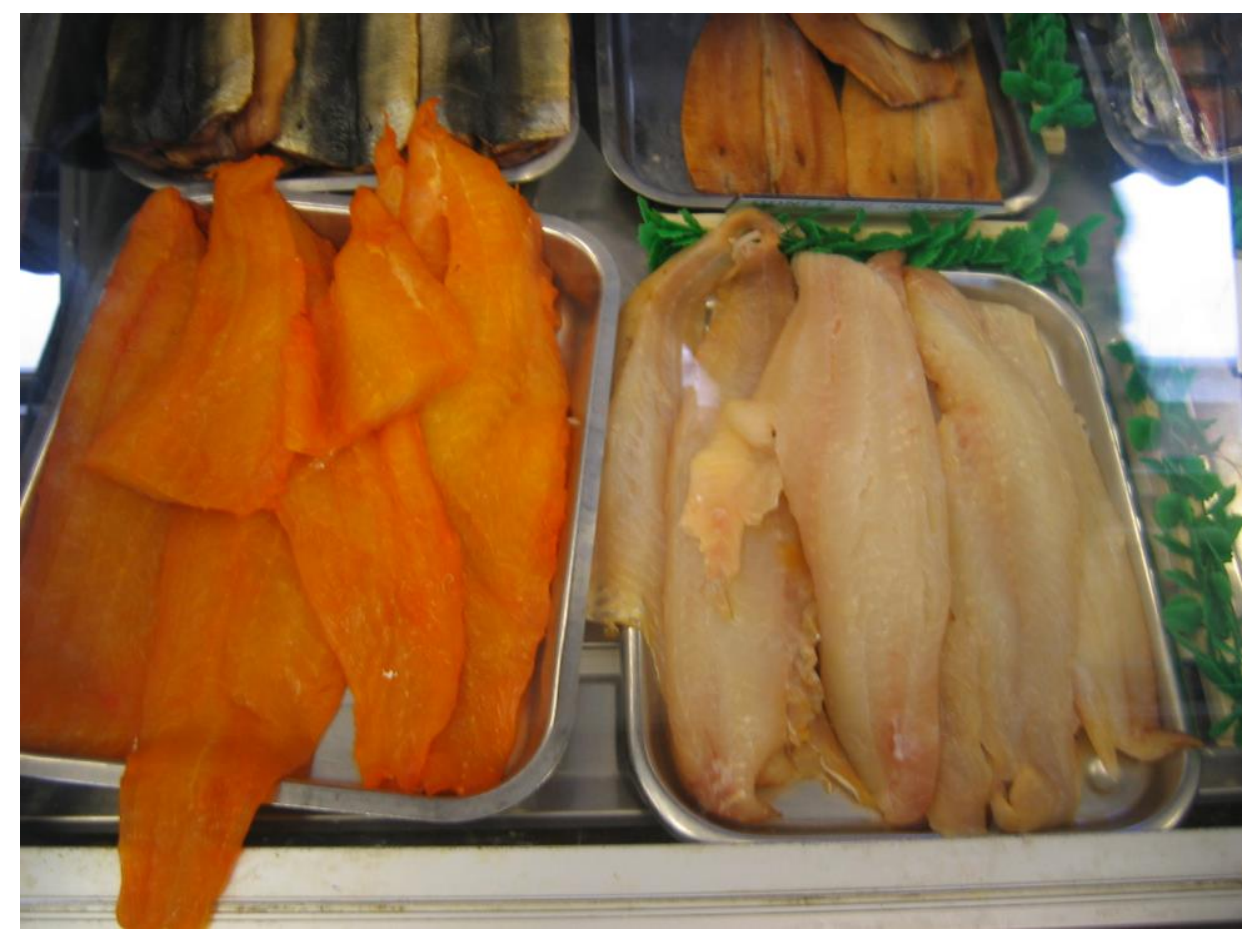

6.17

'Fish and Chips' as drawn by Luke

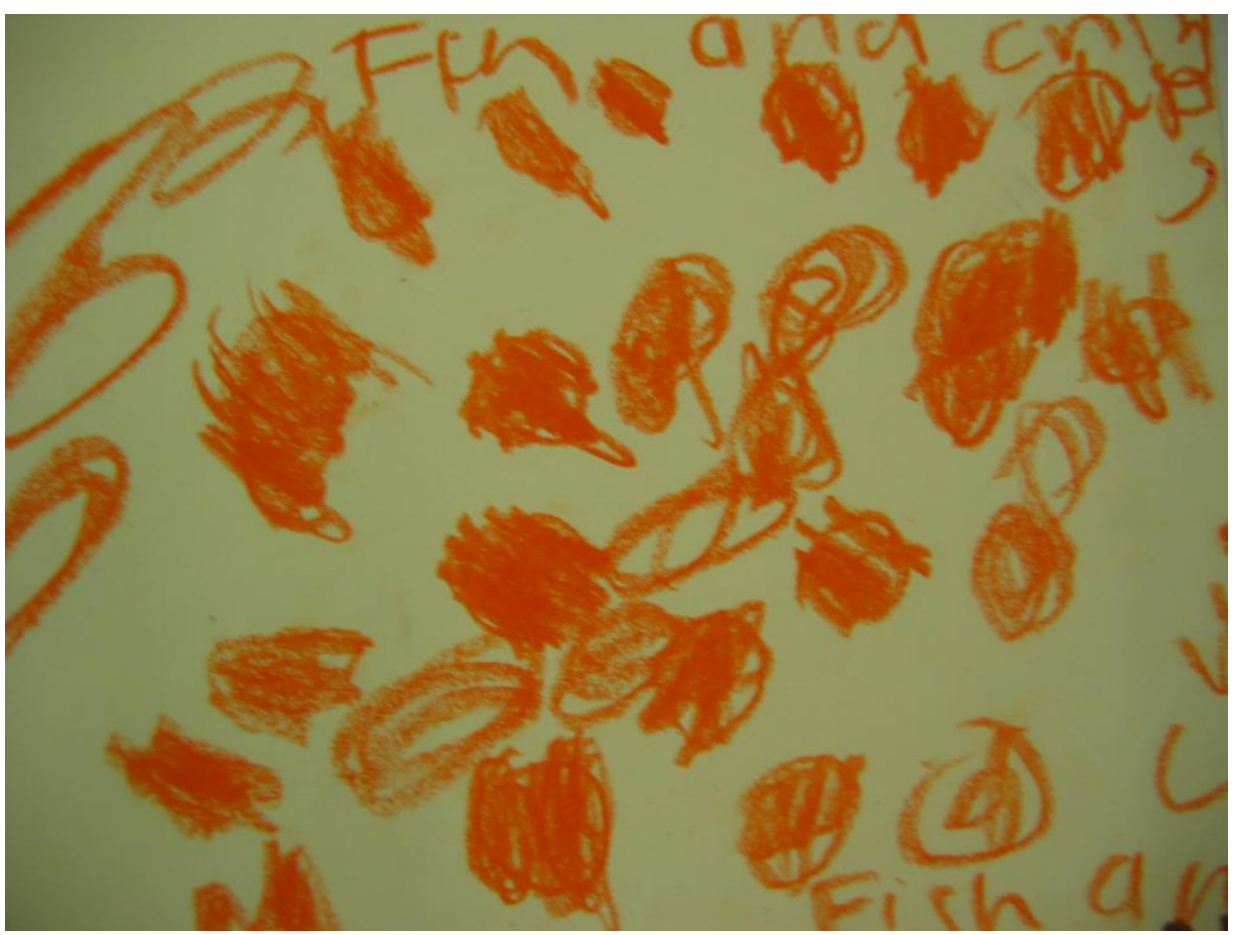


Through his drawings (see 6.17) Luke's idea of this sensory experience evolved and overlapped into his depiction of a landscape, finally realised in his canvas for public exhibition (discussed in detail later in this chapter). This blurring of connections and dreamlike association was a poignant demonstration of the previous lack of landscape and environmental experience, which connected many of the participants from both study centres. When familiar elements were discovered in unfamiliar environments, they were embraced by the participants; they provided grounding and landscape ownership.

\subsubsection{Summary}

At this stage in the project, researcher confidence when using with the visual communication toolkit allowed focus on participant experience to develop more rapidly than had been previously possible. Environmental experiential themes arising from use of the toolkit and subsequent DIDEC analysis to explore the developed coast site visit, are summarised as follows:

- Familiar people were always the preferred focus of participant photographic and verbal attention.

- Previous physical experience of landscape should not be underestimated. Without such encouraging such contact, new natural environments appeared illegible and unattractive to some participants.

- Instant entertainment was always more appealing to participants, than the process of developing landscape appreciation.

- Urban landscapes are complex sensory organisms. By creating routine rewards (smell, texture, colour, form, sound etc.) it was possible to support and encourage the participants to step out into unfamiliar territories.

\subsubsection{The urban riverside}

On the $20^{\text {th }}$ March 2006, SC2 participants explored the urban riverside environment of Newcastle upon Tyne's Quayside. The Gateshead-Newcastle Quayside is a popular destination for both visitors to the city and the local community due to a highly successful redevelopment programme. Historic landmarks such as the famous Tyne 
Bridge and renovated Baltic Flour Mills (now a contemporary art museum and centre) sit alongside new developments including the Sage music hall, Gateshead Millennium Bridge and many hotels, bars and restaurants. Weather conditions were particularly cold on the day of the site visit and this therefore limited the period of time the participants were willing to spend in the outdoor environment. In addition, of all landscapes visited the Quayside was the most familiar to the participants prior to the project. All bar one of the participants had grown up in the North East region. With an already developed level of awareness regarding this site, the participants appeared less motivated to re-examine the environmental detail of the area. However, researcher observation of the participant behaviour and photography on site suggested two potential areas of environmental experiential interest. The importance of these was confirmed during photo-elicitation interviews, drawing workshops and subsequent DIDEC analysis. These two experiential themes are now discussed.

\section{- Iconic landscapes}

The iconic architectural forms that bridge and skirt along the edge of the River Tyne, within the Quayside quarter, dominate the visitor's environmental experience from every angle. In such a dramatic urban landscape, the Tyne Bridge stands as an icon above the rest, immortalised through countless advertising campaigns. On first stepping out of the SC2 minibus, the gaze of all participants, staff and researcher were drawn towards it. During the site visit the Tyne Bridge was, without competition, the most photographed environmental subject by participants (6.18). However, what differed in their approach to photography of this bridge compared with, for example, Luke's smoked fish fillets at South Shields, was the lack of personal connection the participants created with this subject. During interviews and in drawing workshops, the bridge was a popular topic due to its instantly recognisable shape, however it instilled no desire in the participants for further narrative or attachment. There is most definitely a place in architecture and landscape architecture for the creation of iconic structures and environmental forms, which are all the better being driven by a functional need. Nevertheless, such spaces and places are often more for observation and visitation by the masses than habitation and ownership by the individual. The impact of iconic environments draws people to a site, 
but it is the use of that site that keeps them there. This conclusion was supported by on site observation of the participants who, once they had walked the length of the pedestrian river bank and had photographed the Tyne Bridge at varying distances and angles, were quickly distracted by half hidden activity in the side streets, the smell of cooked breakfasts frying at a nearby café and the lighted displays in shop windows. This issue of humanity in open spaces and the instinct to connect with elements on a human scale is now discussed.

\section{- Environmental scale}

Most of the buildings and structures at the Quayside are on a monumental scale that dwarfs the human individual. In order to make sense of these landscape elements, the participants' focused upon tangible human scale details within them, such as the handle of a door, or bolt of a railing (6.19). Behavioural observation of participants on site saw them attempt to open, unscrew, hang off, bend and climb down to these nodes of interest. These actions were not the product of wanton destruction. Rather, they were the physical reaction of the participants attempting to gain understanding and ownership over large structures, unobtainable in their totality. Splitting monumental mass into small, component parts, constructed personal connection with the site. An example of this is shown in the actions of one participant $\operatorname{Simon}^{15}$ (6.19), where he endeavours to open the door to the vestibule that controls operation of the Millennium Bridge.

In discussion back at SC2 remembering this episode encouraged Simon to elaborate on his personal attachment to the Millennium Bridge; the motion of raising and lowering to let boats pass under. Environments that allow the individual contact to satisfy their curiosity with construction are far more successful than those that keep the observer at arms length. Demonstration of the failing of restrictive environments is recalled through the Yorkshire Sculpture Park gallery visit (see Chapter 4, p.76), where participants were disappointed and confused by their environmental experience when refused the opportunity of physical contact. Again, the mantra is repeated that physical contact creates ownership and understanding.

${ }^{15}$ Simon is a pseudonym 
6.18

The SC2 group walking towards the Tyne Bridge, at Newcastle Quayside, as photographed by Simon

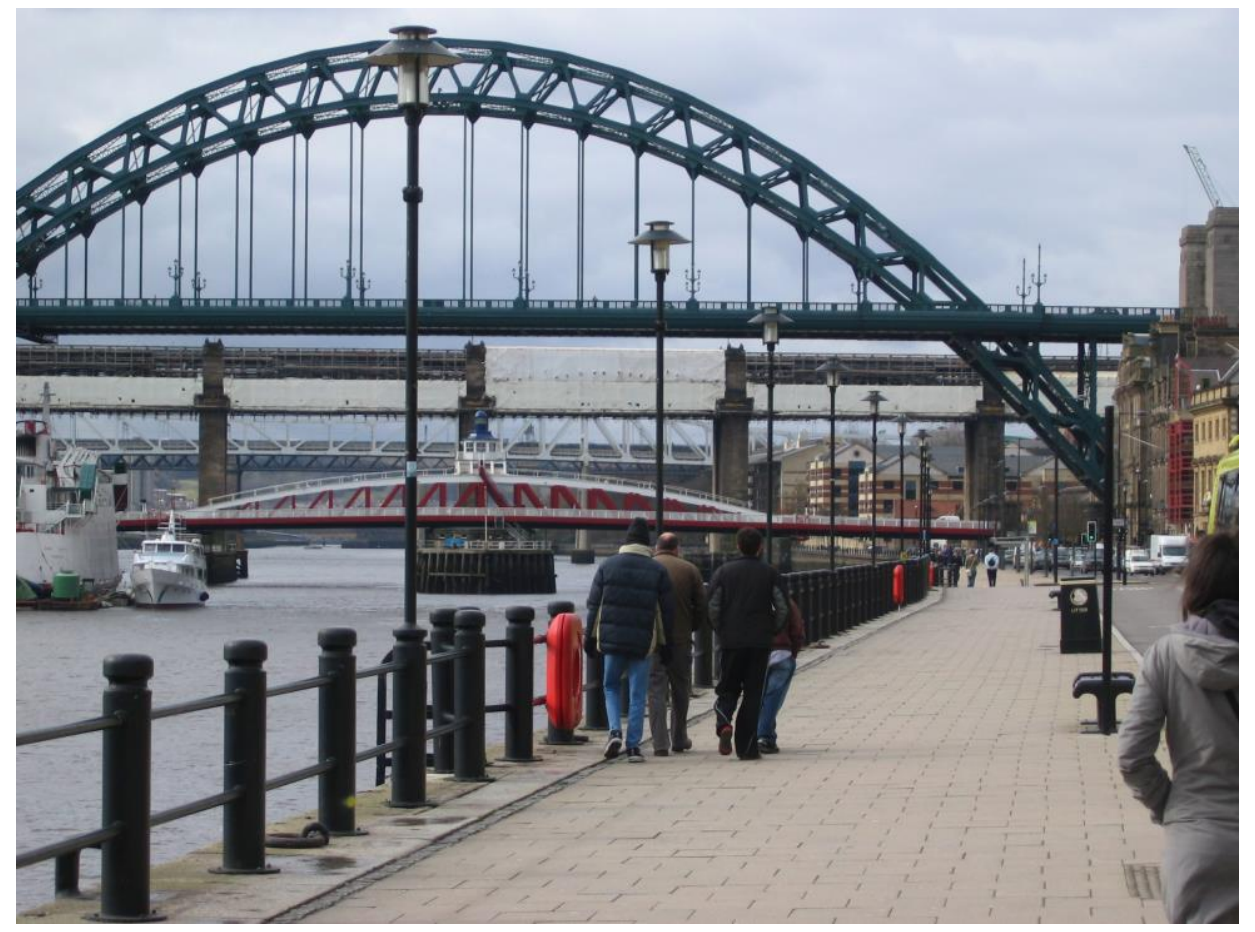

6.19

Karl, Warren and Simon exploring the Gateshead Millennium Bridge

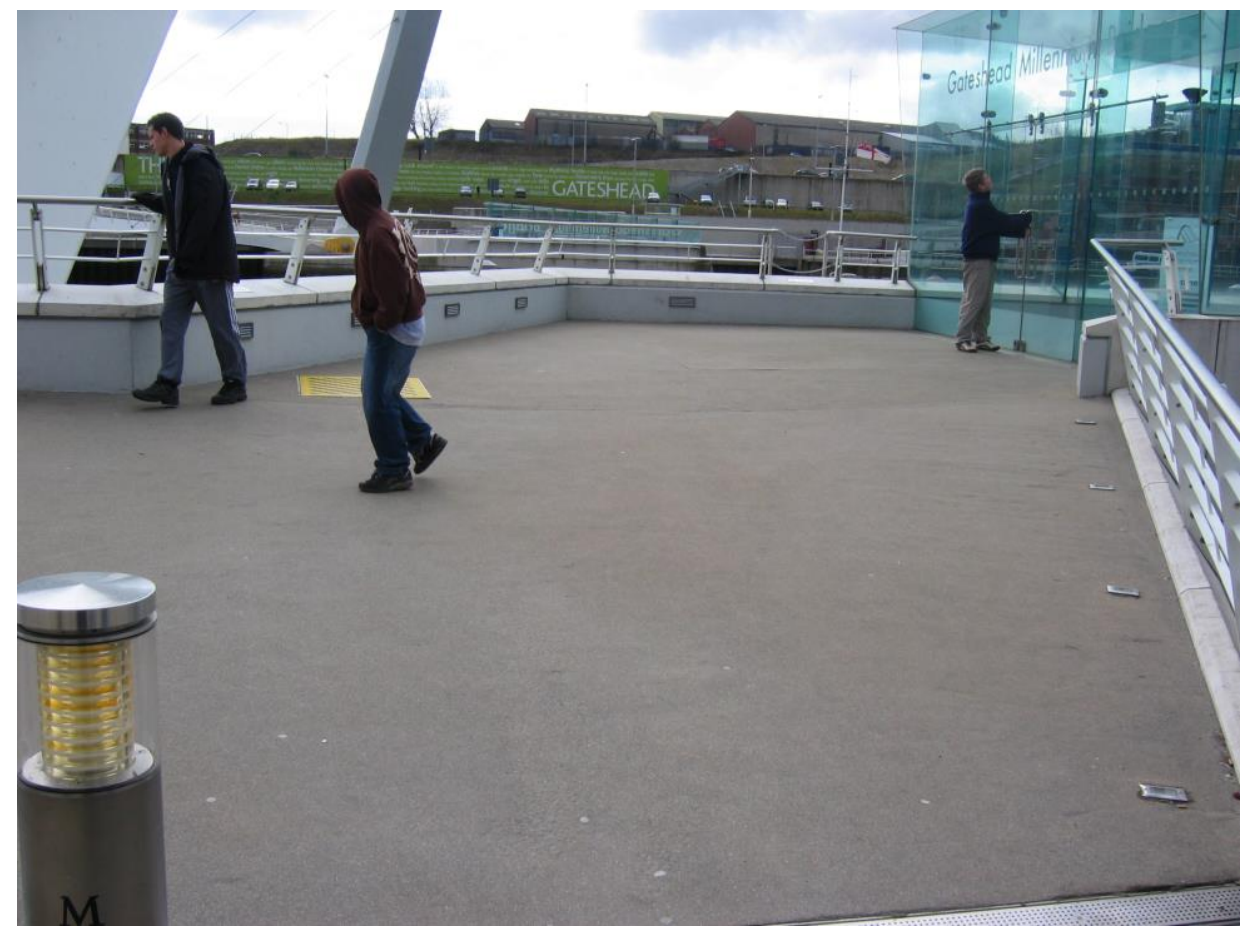




\subsubsection{Summary}

Study of environment interactions by participants at the Quayside was unpacked utilising the visual communication toolkit and DIDEC analysis to produce two intrinsically linked experiential themes. These themes are important in the combined work of the urban planner, landscape designer and architect when evaluating spaces for redevelopment or creating new places of use and habitation.

- The large-scale composition of iconic landscapes that unites visitors to a site through provision of a series of universally accessible vistas and structures.

- Inclusion of detail at varying environmental scales providing stimulation in the landscape and enabling individuals to take possession over the environment.

\subsubsection{The wetlands}

The morning of the fourth week at SC2 (27 $7^{\text {th }}$ March 2006), was used to finish personal art in drawing workshops regarding the urban riverside and developed coast experiences. In the afternoon, participants purchased materials in preparation for construction of their final exhibition canvases. Nearing the project midpoint of working alongside participants and staff at SC2, it was possible to make some intermediate observations. Most noted was the difference in working approach between that of the female staff at SC1 and male staff at $\mathrm{SC} 2$. In contrast to the support the researcher had received during drawing workshops at $\mathrm{SC} 1$, the SC2 male staff member seemed embarrassed to become involved due to the "arty crafty" nature, as he described it, of this part of the toolkit methodology. However, when assisting on site visits and aiding participants' in physical tasks (such as the construction of the large exhibition canvases) the staff member was eager to be involved and quick to volunteer. Whether this was as a consequence of his personal discomfort with visually creative tasks, or due to a masculine perception of the activity, the researcher unfortunately was unable to explore as a result of the staff member's untimely death shortly after completion of the fieldwork.

On the $3^{\text {rd }}$ April 2006, participants began construction of their exhibition canvases aided by the SC2 staff member (6.20). 


\subsection{0}

Warren constructing his exhibition canvas

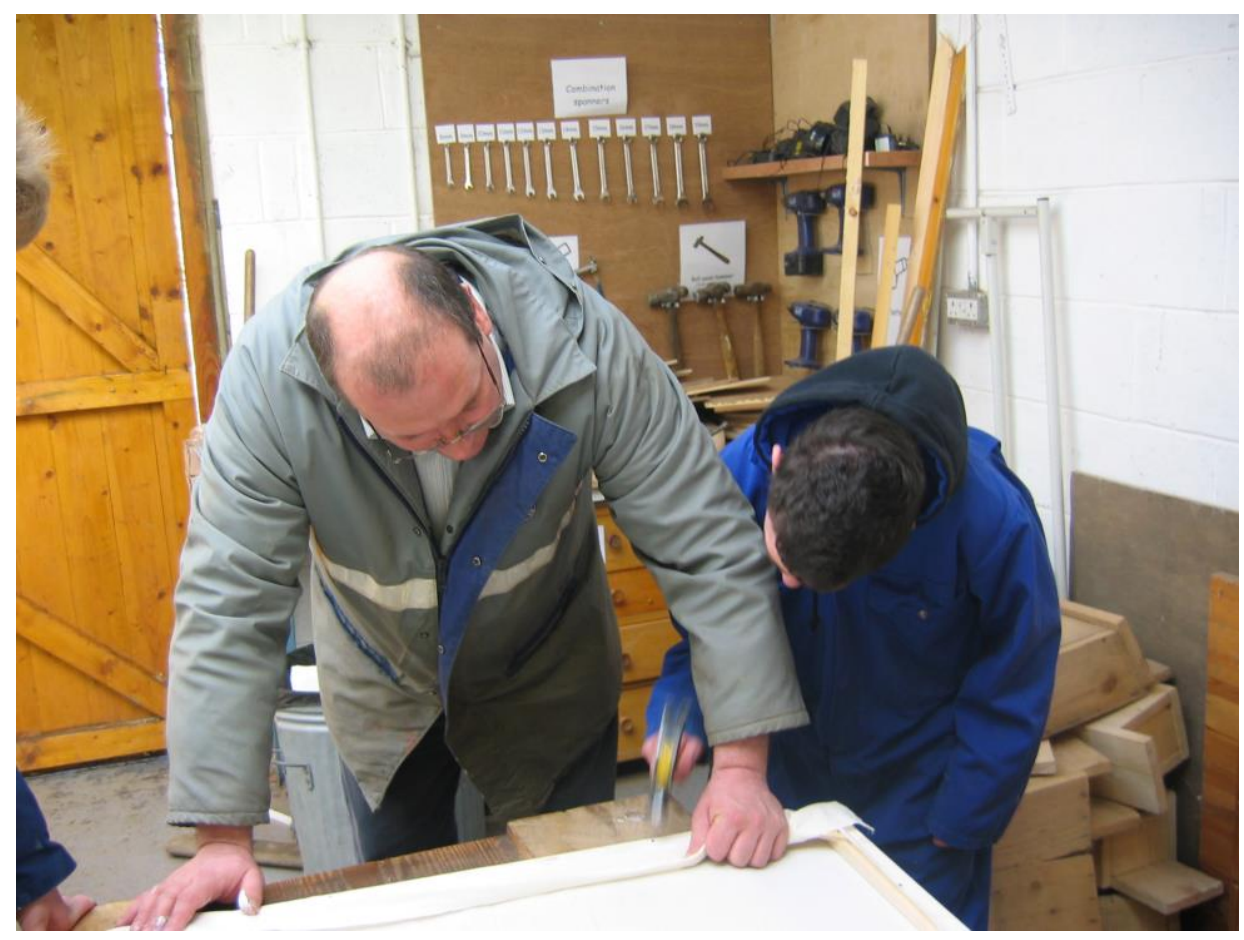

\subsection{1}

Cutting willow wands at 'Quakers Hole Wetlands'

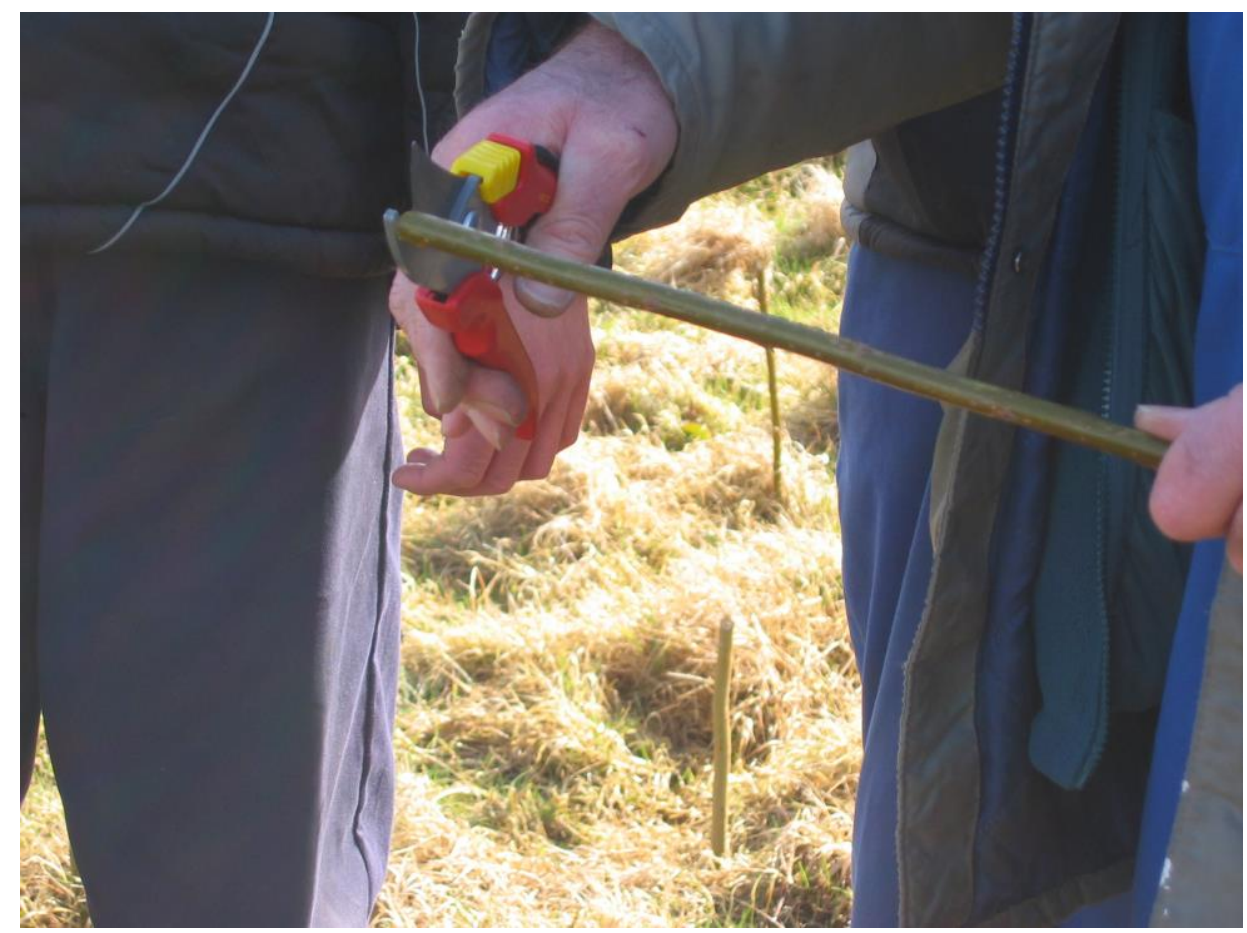


Researcher reflection upon the animated behaviour of participants during this activity identified it as a key turning point in the project. The canvas construction process, initial discussions as to canvas subjects, and realisation that their work would be viewed (outside SC2) within the public sphere, instilled participants with increased pride, ownership and dedication regarding the project output. Participants perceived that if their work was commendable enough to be placed on public display then they wished it to represent the best of their efforts. This observation, but with less personal awareness, was also made by participants during the canvas construction and public exhibition phases of toolkit employment at SC1. For people with learning disabilities who for the majority are the audience for, not producers of, creative attention the exhibition gave their work an increased purpose and social dimension.

During the afternoon, the participants accompanied another of the SC2 Estates Department courses to 'Quaker's Hole' wetlands. The site is an area of semi-natural wetland located south of Whitley Chapel, Hexhamshire, which lies adjacent to the North Pennines Area of Outstanding Natural Beauty (AONB). The area is nine hectares square in extent and is managed by staff and students from SC2. Current conservation activity on site includes willow planting, the clearing of areas and dry-stone walling, with assistance and support from the British Trust of Conservation Volunteers (BTCV). A number of the participants had been previously, or were currently, involved in conservation activity on site (Image 6.21). This created a new dynamic of environmental experience within the landscapes explored by the research project. The 'Quakers Hole' landscape was one they had legitimate ownership over and an existing depth of personal knowledge of. As a result the participants' displayed great social and physical confidence throughout the site visit, and were eager to photograph the fruits of their labours such as the newly planted willow beds. Semi-structured photo-elicitation interviews back at SC2 revealed a dichotomy in participant preference between urban and rural environments, with the Quakers Hole experience unlocking the elements that gave them greatest pleasure from each. The differing advantages of these two landscape typologies are now described. 


\section{- Urban entertainment}

Initially, two of the five participants, Warren and Ewan, professed a preference for urban spaces, whilst Karl and Luke were inclined towards rural environments and Simon remaining undecided as to his preference. Ewan explained his reason for choosing urban spaces as, "Umm I like going to the Metro Centre, I like going to Tesco's to buy some black trousers, I like doing some shopping”. Warren's response was identical. Towns and cities were, "much more better" as a result of, "Just like all the shops and that". Shopping provides a universal method of easy entertainment. For the participants living in a sheltered environment like SC2, the personal, financial toll of shopping outings (although a life skill developed by tutors during their education) was not always obvious to the individual. Students were always eager to have the opportunity to spend money on clothing, food and objects whenever they were outside SC2 (also a theme of site visits with SC1 participants). To individuals, the purchase of goods displayed independence and a record of their life experience. However, such overt causal spending rarely resulted in negative financial consequence. In the sheltered environment of SC2, students were already supplied with accommodation, could go out and see friends, and were provided with food and a range of leisure activities. This lack of financial responsibility and understanding is an important issue in the independence of people with learning disabilities, and was experienced firsthand by the researcher when supporting Karl during his BTCV conservation holiday to Iceland in August 2006. Warren, at this point in the project, was still unable to imagine how rural landscapes could entertain him on an equal level with their urban counterparts. However, during his interview Ewan voiced a delight in countryside activities, which coexisted alongside the personal satisfaction he gained from shopping.

\section{- Rural activity}

Of all SC2 participants, Karl and Luke voiced the strongest personal attachment towards the countryside. Karl had a wealth of active rural landscape experience, and during his semi-structured interview the researcher was able to explore this in detail, facilitated by photographic prompts of the site visit: 
Researcher: Ok, right this is your dry-stone walling that you were talking about. Tell me how you build a dry-stone wall?

Karl: Say like top to bottom, say like at the bottom you need to find where the first one goes, then after that you go all the way round

Researcher: So do you do it in layers up or across?

Karl: Say like, layers up and sometimes layers that way as well

Researcher: Ok, and have you done any dry-stone walling with anyone other than SC2?

Karl: We work with work experience yes

Researcher: Who is your work experience with?

Karl: Erm...

Researcher: Is that the BTCV stuff?

Karl: Yes

Researcher: Ok, and what else do you do when you go to BTCV then?

Karl: I've done my Level 2 tree felling

Researcher: Oh yeah

Karl: I've done bird boxes, bat boxes, dry-stone walling, hedge laying

Researcher: And which bit have you enjoyed the most?

Karl: My Level 2

The training and landscape education Karl received through SC2 and BTCV was led by execution of practical skills during activities such as dry-stone walling, tree felling, hedge laying, creation of bat and bird boxes and willow planting (6.21). This gave Karl a positive and personal connection to the rural landscape. By participation not observation, he shaped and controlled the environment he saw around him. This placed him in a more powerful social position than when he was a visitor to urban open spaces (i.e. parks as previously discussed). Karl saw that between urban and rural environments there was great difference, and gained greater personal peace in those that were rural, "You get like nice and quiet in the countryside". Luke, like Karl, had been involved in conservation activities such as dry-stone walling with BTCV. He also appreciated the countryside for the opportunity to see "All sorts of animals". On the wetlands site visit, Luke drew the group's attention to a cluster of frogspawn and discussed a previous encounter with a deer whilst working on site. These were valuable personal memories for Luke as they displayed to others his knowledge and keen observation of the environment around him, his form of ownership. In the context of researcher observations regarding Luke and Karl's attachment to the countryside, it is possible to revisit Ewan's divided allegiance between rural and urban landscapes. During his interview Ewan communicated a desire to experience both providing he was an active participant. This entailed being an active shopper in cities and an active dry-stone wall constructor when in 
the countryside. His only reservations towards the countryside were related to issues of safety and the unknown:

Ewan: I think you need a path, bit dangerous, very dangerous

Researcher: What could happen?

Ewan: Somebody could fall over, hurt themselves, and go to hospital and an ambulance has to come

Researcher: And do you think the countryside is more dangerous than cities, or that cities are more dangerous than the countryside?

Ewan: I think the countryside is very dangerous

Researcher: Why is it dangerous?

Ewan: You could get lost

However, these interview reflections on the personal threat posed by the countryside were revealed, during the drawing workshop and informal discussions, to be the digested and regurgitated advice of others (such as parents and tutors). Although Ewan was a naturally more cautious participant than some, once he had personal experience of an environment he was confident in his own actions in similar landscape circumstances.

\subsubsection{Summary}

The participants' environmental experience at 'Quakers Hole' wetlands project was key in revealing the conceptual gulf that existed in their understanding and enjoyment of urban and rural open spaces. To summarise:

- Urban entertainment was easily accessible, with shopping providing personal gain through the selection, purchase and ownership process.

- The enjoyment of participation in rural activity was less accessible to those who had no previous experience. However, for those who had such experience, it appeared to give them far greater joy and personal gain than could be delivered through urban entertainment.

\subsubsection{Canvas conceptualisation}

The sixth week working with SC2 participants commenced on the $8^{\text {th }}$ May 2006. The participants continued their canvas construction and painted the finished frames with 
white emulsion. Each individual participant began to write a page of ideas that would frame the design for their final canvas. Participants were encouraged to reflect upon landscapes visited and explored during the project and consider the following:

- Which landscape was most memorable?

- Why was this landscape more memorable than others?

- Which landscape gave most joy?

- Was there a landscape not visited during the project that was particularly important to represent?

- Why was this landscape (not visited during the project) important?

- What particular landscape elements were important?

The participants voluntarily looked to their project drawings and photographs to remind themselves of landscapes experienced during the fieldwork period. The participants were observed to be most comfortable when using these visual resources to assist in communicating their emerging canvas concepts.

The $15^{\text {th }}$ May 2006 was scheduled for the final two site visits of the project. However, due to very adverse weather conditions the fieldwork was postponed until the following week. In place of site visits the participants' were given additional time to work on their canvas concepts. During the day the participants greatly refined their canvas concepts and began to sketch ideas for their composition. Landscapes of water were a uniting theme for four out of five of the participants. Karl chose to depict a coastal scene with a lifeboat as the central theme. Great drama was evoked in this landscape, with the boat rescuing people from a turbulent and dramatic sea. This scene of energy excited him. He discussed how he would paint the lifeboat in dramatic colour in glaring contrast to the dark and swirling water. Ewan chose the fish he and Luke had photographed at the South Shield's fish shop as his central theme. They evoked a personal memory within him, one of a shared moment with a friend. Luke also chose to base his canvas on his experience at the South Shields Fish Quay. He discussed including a variety of elements from that day: the water, the fish, the beach and the boats. Simon focused upon a wall mural he had seen depicting a less modern day sea rescue, with six 
men rowing out on an unforgiving sea in wooden rowing boat. Simon like Karl was interested in the energy water gave the landscape, the movement, power and unpredictability. Unlike the others, Warren chose a green and urban landscape, a skate park, as the environment that held most personal resonance. This was the only landscape to be depicted by a participant that had not been visited during the project. Throughout the course of the study, Warren had discussed with the researcher his love of skate parks resulting from a desired association with alternative young people who hung out there. Of all the participants it was Warren, who whilst verbally maintaining the greatest lack of interest in landscape, indirectly displayed the strongest desire to make use of, and connect with public open spaces.

The site visits planned for the $21^{\text {st }}$ May 2006 were cancelled. The researcher's reliance upon the SC2 support staff to co-ordinate practical arrangements unfortunately was not upheld and transportation and provisions were not organised in preparation. Overseeing the project from a distance (Sheffield to the North-East of England) created a number of organisational difficulties such as this. With limited time left working with the participants the researcher altered the project programme. The participants were asked to begin painting their final canvases. They were informed that two additional site visits would occur after their canvases had been completed, however it would only be possible to explore these final landscapes through the site visit, photography, interviews and the drawing workshop. This was a very regrettable decision to have to make, as to exclude the opportunity of participants choosing to depict these landscapes restricted the palette of environmental experiences they had to select from for their canvas. In order that these experiences might not be absent from the final exhibition it was decided to display the participants photographs, drawings and words generated by these alongside their personal canvases.

\subsubsection{The rural coast}

On the $12^{\text {th }}$ June 2006 the participants visited their penultimate and final landscapes. The first of these was Newton-by-the-sea, a small sandy stretch of sheltered coastline. A number of weeks had elapsed without a site visit, therefore the participants were eager to leave SC2 and explore new landscapes. The Newton-by-the-sea site visit generated one 
of the most important personal changes in any of the SC1 or SC2 participants. Observed by the researcher, was the transformation of Warren's attitude towards rural, coastal environments from something that was to be avoided into a pleasurable and positive experience. This metamorphosis first emerged through his photo-elicitation interview, and is now discussed under the experiential title 'Attitudinal transformation'.

\section{- Attitudinal transformation}

Throughout the project, Warren's attitude to rural landscapes had remained consistent. Having little previous experience of such open spaces, they held little appeal and were always rejected in favour of urban settings. However, the site visit to Newton-by-the-sea marked a crucial turning point in his adoption of rural landscapes into his personal portfolio of positive environmental experiences.

\subsection{2}

\section{Warren on the beach at Newton-by-the-sea}

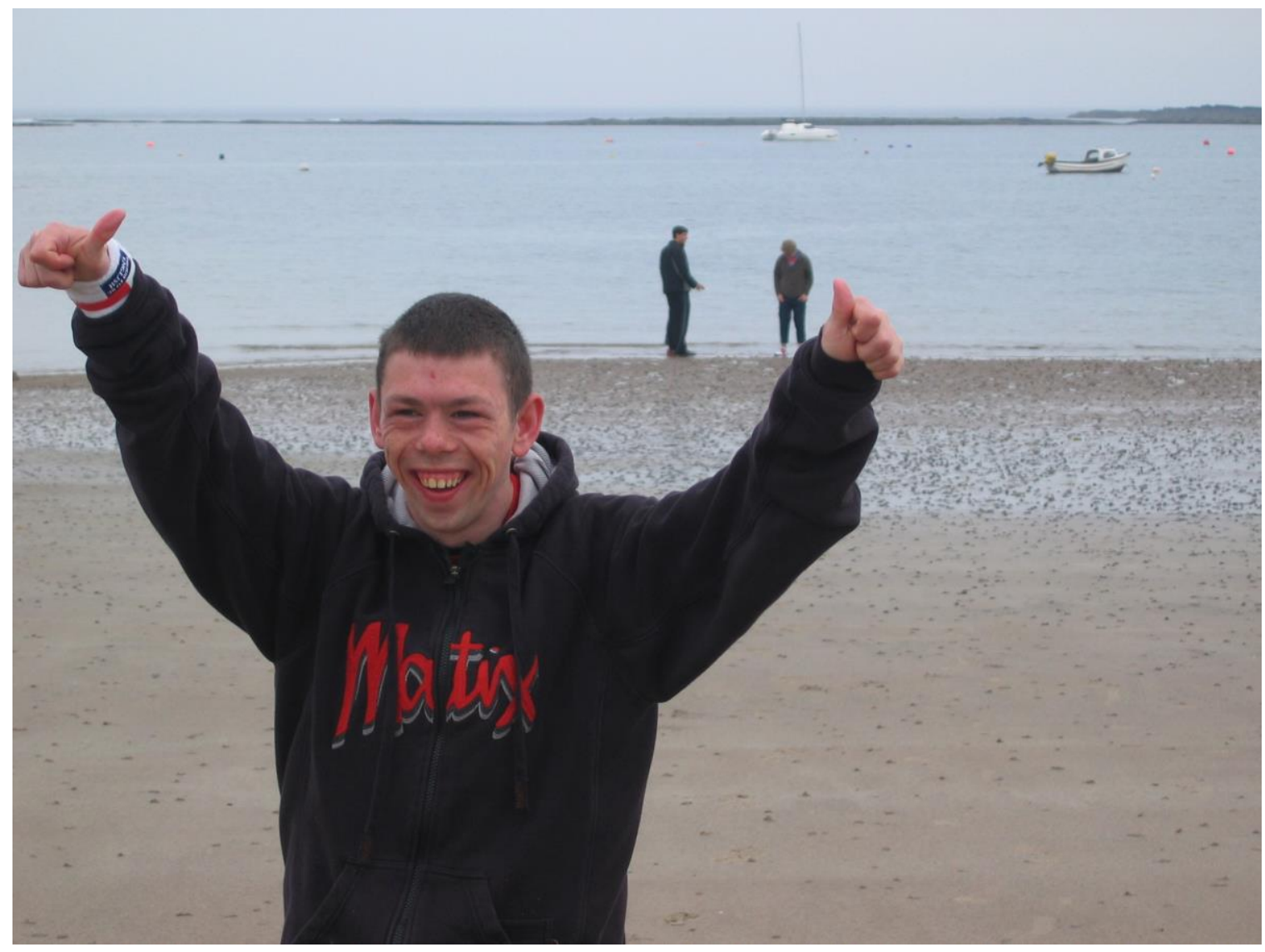


Researcher observations and behavioural notes from the day, record how on arrival at the seashore the participants raced from the minibus down onto the sand to water's edge. During previous rural site visits, Warren had observed his peers from the minibus before taking cautious steps to follow them out into the environment. However, at Newton-by-the-sea Warren was eager to leave the minibus and rushed out across the sand to join his friends. The anticipated sand and beach, that had caused him undue stress in previous interviews, were a source of personal joy and empowerment when experienced firsthand (6.22). In the course of his semi-structured interview the researcher pursued this alteration in Warren's attitude, and as the following extract shows, the participant's progression from that of negative to positive experience was an easy one:

Researcher: So you said to me when we first got here that you didn't want to go on the sand, why didn't you want to go on the sand?

Warren: Well I sort of changed my mind

Researcher: You changed your mind, so it was all right when you got there?

Warren: Yeah

The landscape Warren experienced at Newton-by-the-sea was no more experientially rich that those rural site visits he had participated in earlier in the project. However, the culmination of increased exposure to such landscapes constructed in Warren a personal confidence, with which he was able to approach and experience new environments with greater ease. This theme of attitudinal transformation is summarised, alongside those evolved through participant experience during the final site visit to The Alnwick Garden (see section 6.3.8.1).

\subsubsection{The formal gardens}

The final site visit of the project was to The Alnwick Garden. This landscape was chosen by the researcher and SC2 support staff to provide the participants' with a formal garden experience in contrast to all other environments previously explored. The Alnwick Garden is a relatively new addition to Northumberland's array of historic gardens, which opened to the public in April 2002. Created by the Duchess of Northumberland, The Garden was designed by the father and son partnership of Jacques and Peter Wirtz, of Wirtz International. Inclusion of this site visit within the fieldwork design provided the 
opportunity to expose the participants' to a great variety of highly deliberate landscape experiences during a short allotted time period and within one relatively small area. At The Alnwick Garden the participants explored: the Rose Garden, the Grand Cascade, the Ornamental Garden, the Treehouse, the Poison Garden, the Serpent Garden and the Bamboo Labyrinth.

To concentrate on the experience of this landscape, and avoid previous distractions, the participants' had been provided with packed lunches and encouraged not to bring spending money. However, these precautions proved superfluous. On entering the site, the participants ran from one feature garden to next, eagerly absorbing all environmental experiences the site had the offer, with no thought given to the purchase of food or souvenirs. Ultimately, it was the researcher and the SC2 support staff who had to encourage the participants to curtail their exploration of the site in order to return to SC2 for their evening meal. None of the participants' had previous experience of the site, therefore their reactions and interactions with the landscape could be judged from a position of equal environmental knowledge. During discussions on the day, and reflections in workshops and interviews back at SC2, participants were adamant in their consensus that The Alnwick Garden experience was the most enjoyable project site visit. Two key concepts emerged from DIDEC analysis of the experience; one united the participants' in their appreciation for a specific landscape element (as discussed in 'Water vitality'), and the other that revealed the participant driven assertion for the inclusion of self-directed photo-elicitation in the research toolkit ('Development of personal interest').

\section{- Water vitality}

The dominant visual environmental element at The Garden was water. At the beginning of their exploration of the site, the participants were drawn towards a series of water sculptures. These were examples of kinetic landscape art. The rushing, spraying, trickling, pouring, shooting action of the water, stimulated active participation from the students (6.23). Observing their behaviour, it appeared to the researcher that the students reflected back the energy given out by the water; the water gave them vitality. This conclusion was also drawn during the Peace Gardens site visit with SC1 participants. 
6.23

Karl and Warren getting wet in the water sculpture

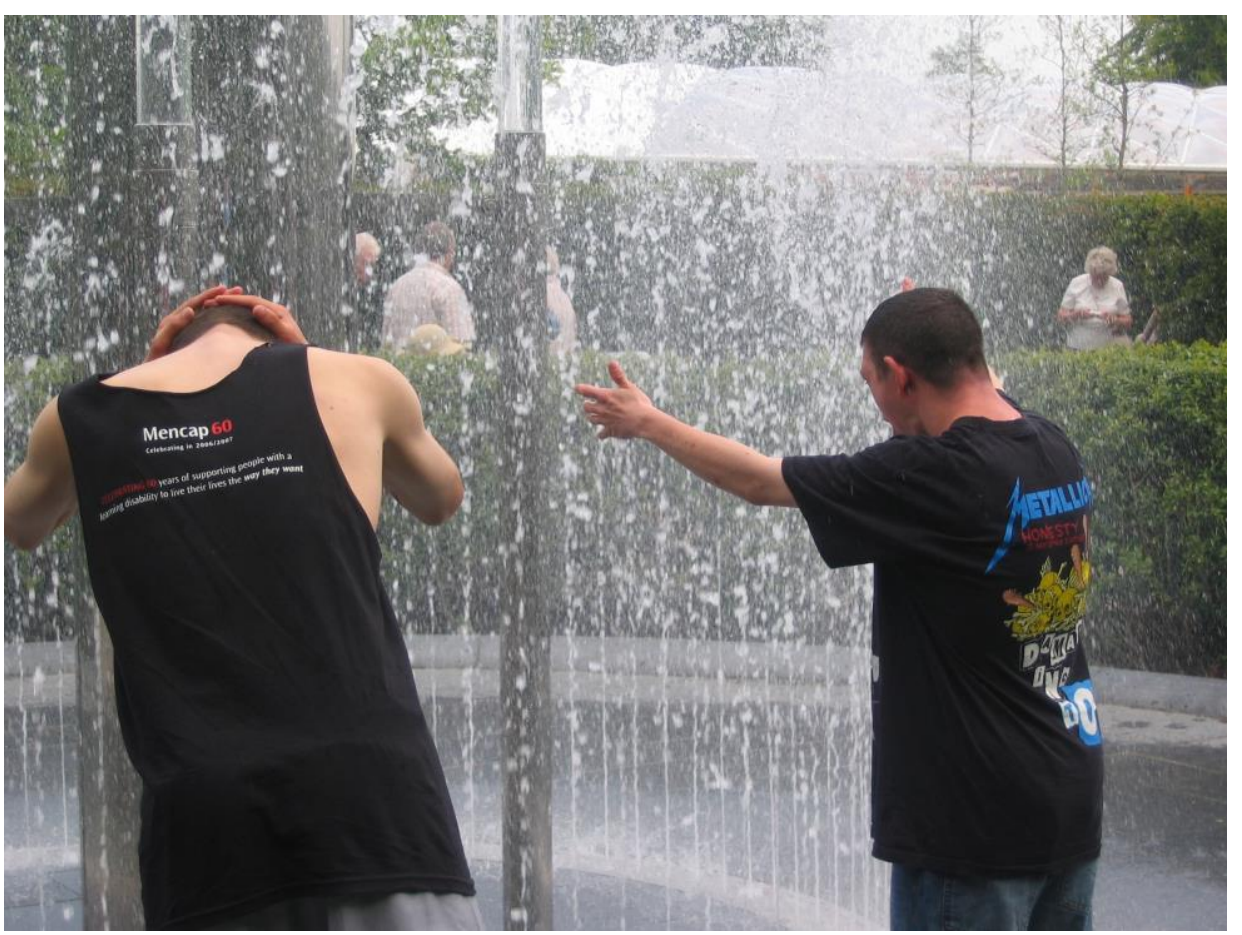

6.24

Ewan "I put my head in the water"

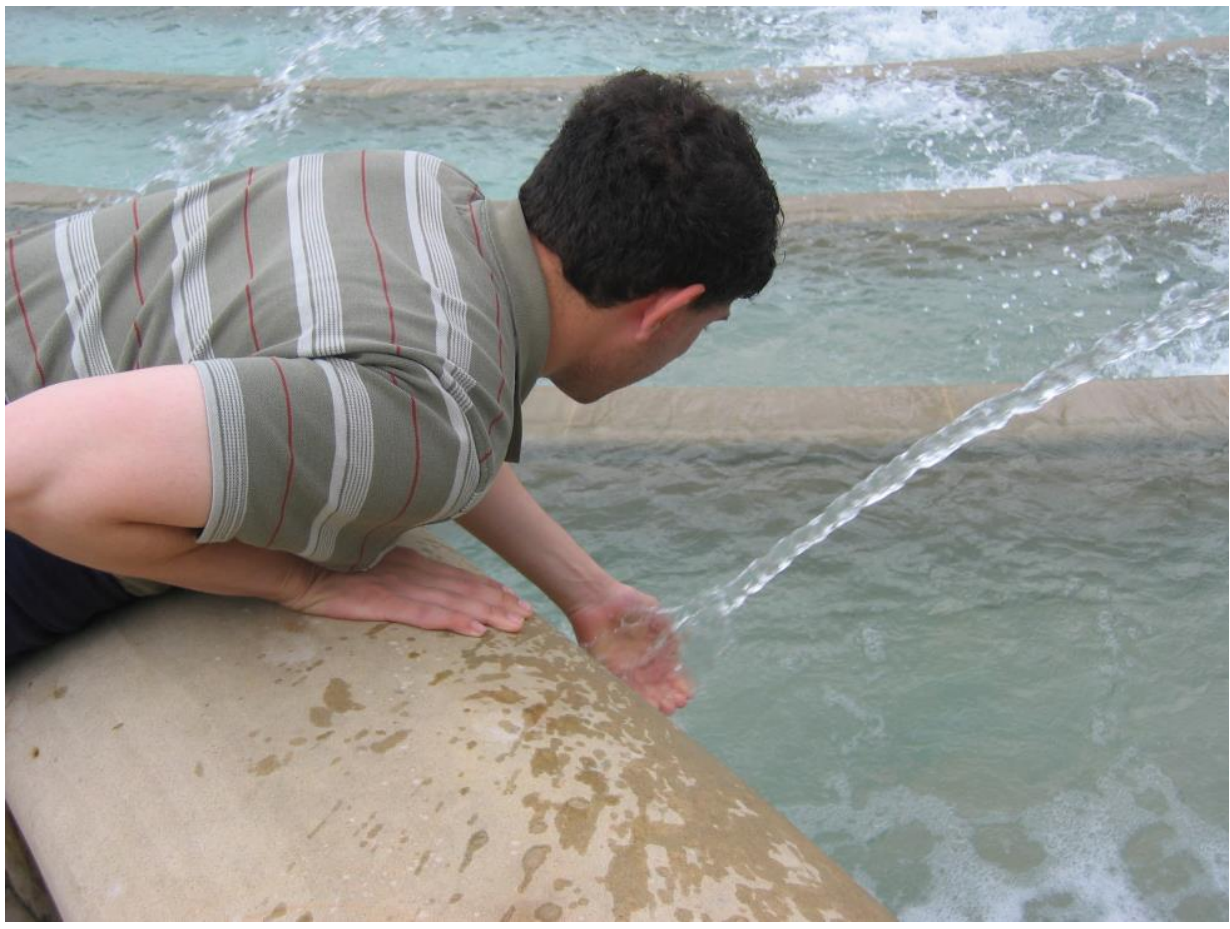


During fieldwork with SC1 participants, Nathalie a physically unconfident member of the group had been greatly stimulated by contact with the site's water fountains. For the SC2 participants, as is the case for most of us, the freedom to physically engage with water had great restorative benefits. On the moment, individuals were activated and captivated by the water, which provided visual, audible and tactile stimulation (6.24). Later, having exhausted their energy supply, the participants were satisfied by choosing to sit and observe the motion of the Grand Cascade, which had a calming effect on all before returning to the minibus. Water interaction at Alnwick Garden was the most popular landscape encounter experienced by participants during the course of the SC2 fieldwork. This was initially reflected by the vast number of digital photographs taken by the participants, and (at the participants' request) by the researcher. Later, during semistructured interviews, when commenting further upon their experiences, water continued to evoke highly positive responses from the participants. Warren was freed from a painful awareness of the critical eye of society, to behave as he instinctively wished, "I like all of that, it's just like it's Welsh noise ... Yeah because I'm a devil!" (6.23), and within the highly maintained and staffed landscape, the rush of water encouraged Ewan to take new risks "I put my head in the water".

\section{- Development of personal interest}

The second observation to be made, came with the researcher realisation that the participants were finally comfortable in using photography to capture personal landscape memories. Personal landscape memories, in this context, are defined as those not associated to the action of their peers, or the subject of universal interest to the group. At $\mathrm{SC}$, where the participants' were older and less swayed by popular group opinion, this ownership over the toolkit methodology (to communicate individual landscape stories and preferences) had developed far more quickly. However, as a result of acute peer awareness among the younger SC2 participants, prior to the Alnwick Garden experience, some group members were reticent to reveal their personal landscape inclinations. Instead they followed the vocal lead of the more dominant participants, as demonstrated by Ewan's attachment to the South Shield's fish quay, a visual and verbal reflection of his admiration for his more assertive friend Luke. 


\subsection{5}

\section{Simon's photograph of the dovecote}

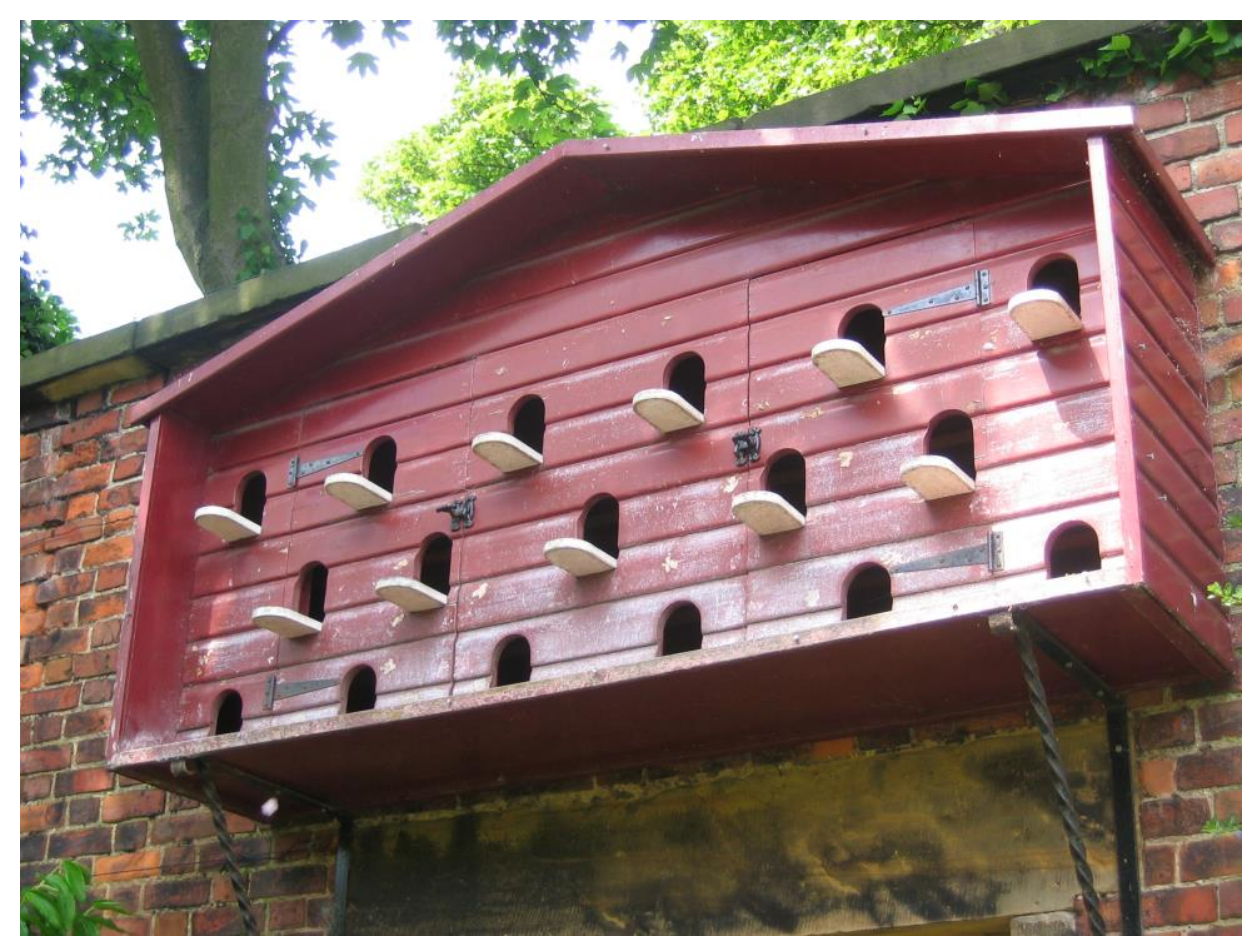

One participant, Simon, had spent much of the project in another participant's (Karl) shadow. At The Alnwick Garden, away from the excitement of the water features, in the calm atmosphere of the Rose Garden, Simon asked the researcher whether he could use the digital camera to document a flock of doves and their dovecote (6.25). The birds and their wooden house inspired no interest in the other participants. However, Simon produced a series of four carefully arranged photographs to capture this element. In subsequent informal photo-elicitation discussions the researcher learned from Simon, that the importance he gave this element in the landscape did not result from any previous personal experience, which was in contrast to the case of many other site photographs. Rather, Simon's attention was caught by the visual impact and intrigue of the dovecote. He was fascinated to discover how it was constructed, where the birds went and appreciated the chosen colour, materials and design. Within the Rose Garden, he paid little attention to the flora surrounding him (which was generally ignored by all the young, male participants) but was captivated by this functional, yet aesthetically pleasing 
birdhouse. The researcher perceived that given greater time working with the visual communication toolkit, such personal preferences and landscape attachments would have become apparent for all the participants.

\subsubsection{Summary}

The final two site visits of the SC2 project (to Newton-by-sea and The Alnwick Garden) generated some of the most interesting and illuminating research observations regarding the public open space experience of this group of young men with learning disabilities. It became apparent that this was as a result of: the growing ease with which the participants utilised the visual communication toolkit, the confidence of the researcher in interpreting the visual and written data generated, the familiarisation of the researcher and participants with one another and the increased exposure of all to a wider range of public open space experiences. These final landscape experiential observations are summarised as follows:

- Attitudinal transformation comes as a result of greater personal exposure to a wide range of public open space experiences.

- The stimulating effect of water and its restorative vitality is an important landscape element.

- Familiarity with the visual communication toolkit allows participants the confidence to communicate a development of personal interest in the landscape.

\subsubsection{Dissemination and reflection: Queens Hall exhibition}

Following completion of the fieldwork including site visits, interviews, drawing workshops and personal canvases, the participants and researcher began preparation for the final public exhibition of the project artwork. A well-known local community arts centre and library (The Queens Halls, Hexham) was contacted and they subsequently agreed to stage the exhibition (6.26). The researcher consulted with the participants as to other work they would like to exhibit alongside their canvases $(6.27-6.31)$. Each participant wished to include photographs from the site visits that told a more personal story of their own landscape experience. In addition the participants created a short 
written description of their canvas, which was exhibited alongside their painting. The exhibition was advertised through the local press and through SC2. The participants assisted by the researcher and SC2 support staff, hung the exhibition at The Queens Hall on the $19^{\text {th }}$ June 2006 . The project artwork exhibition was open to the public until $25^{\text {th }}$ June. Creating a clear research endpoint for the participants (Northway, 2000) had been an important consideration when designing the fieldwork programme. The public exhibition was the visible manifestation of this aim. It provided the opportunity for the participants to publicly display and be proud of their achievements, confirmed the importance with which the SC2 study centre and wider community held their work, and did not afford any participant-researcher dependency beyond the length of the project.

\section{The SC2 exhibition at The Queen's Hall, Hexham, Northumberland*16}

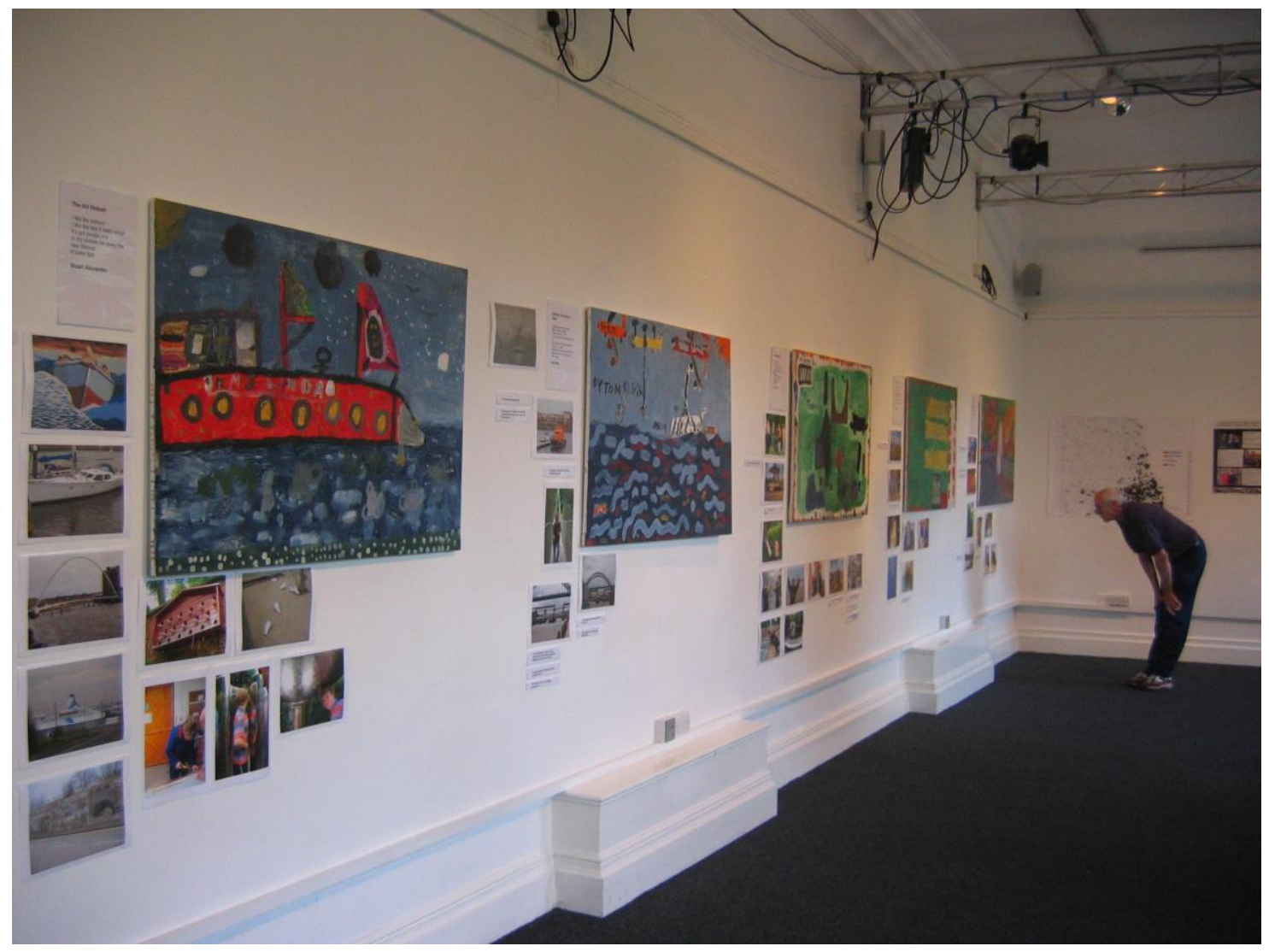

\footnotetext{
16 * The student's work displayed second from the right is not discussed, as although he attended the Land and Environment BTEC he did not participate in the research project.
} 
6.27

Simon with his canvas 'The Old Lifeboat', chosen photographs and writing.

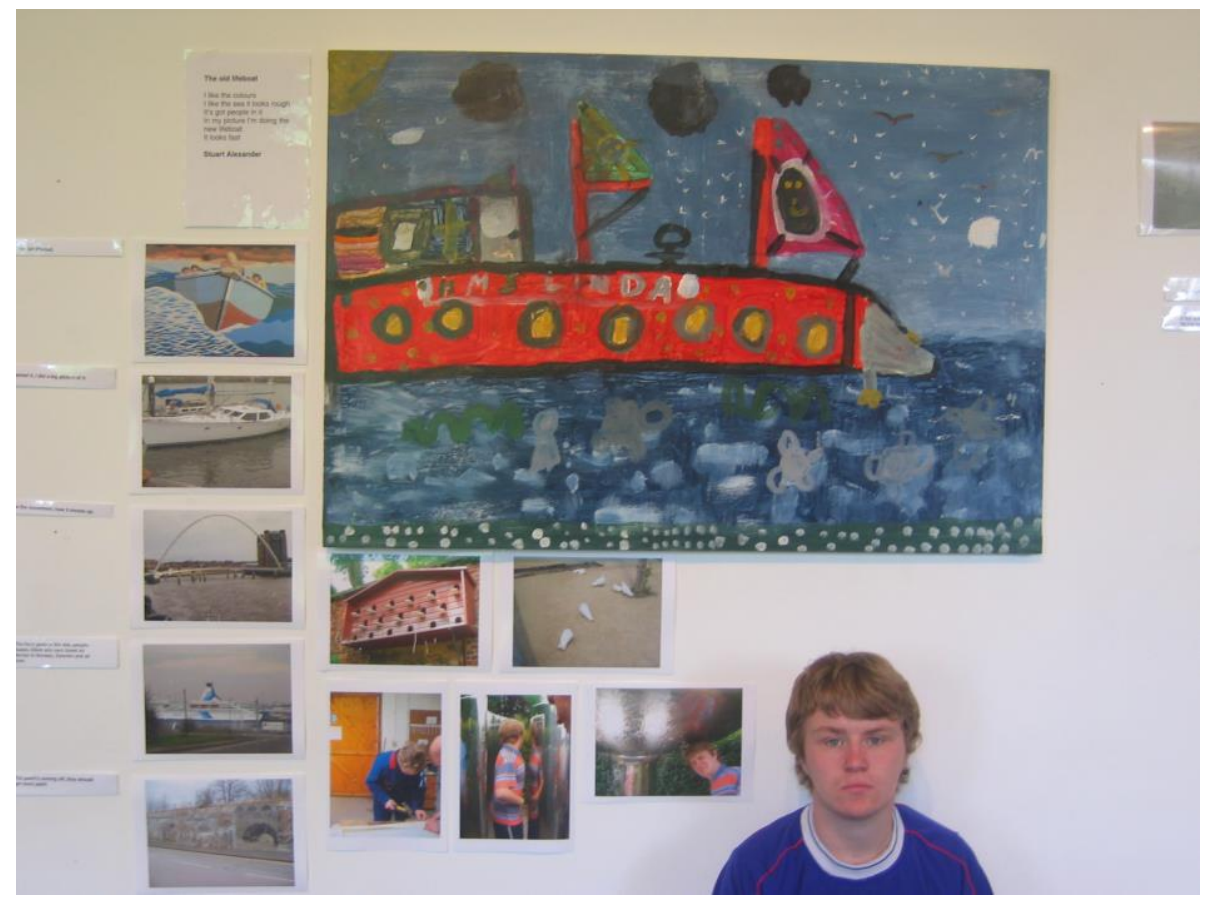

6.28

Karl with his canvas 'Painting the Rescue Boat', chosen photographs and writing.

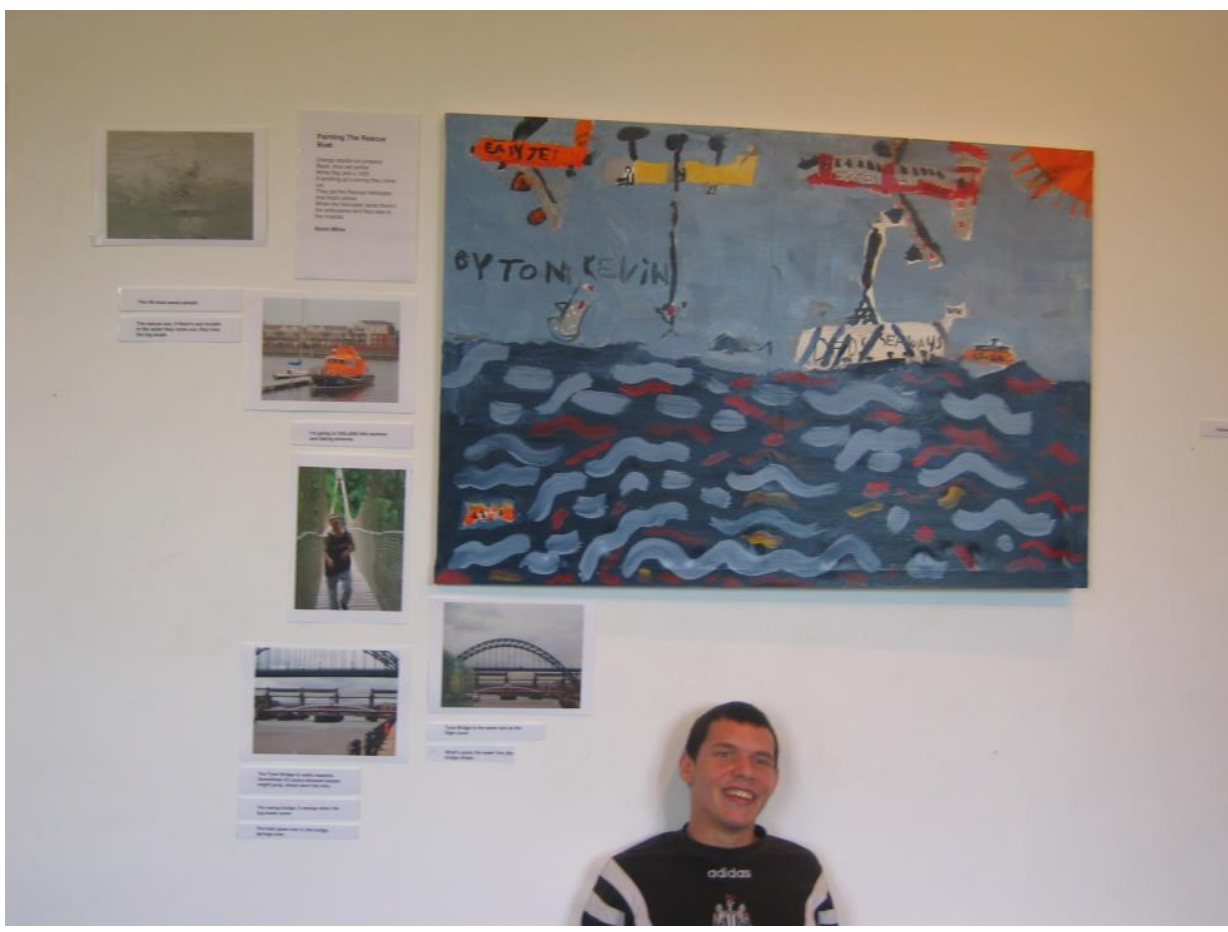




\subsection{9}

Warren with his canvas 'Skateboarding', chosen photographs and writing.

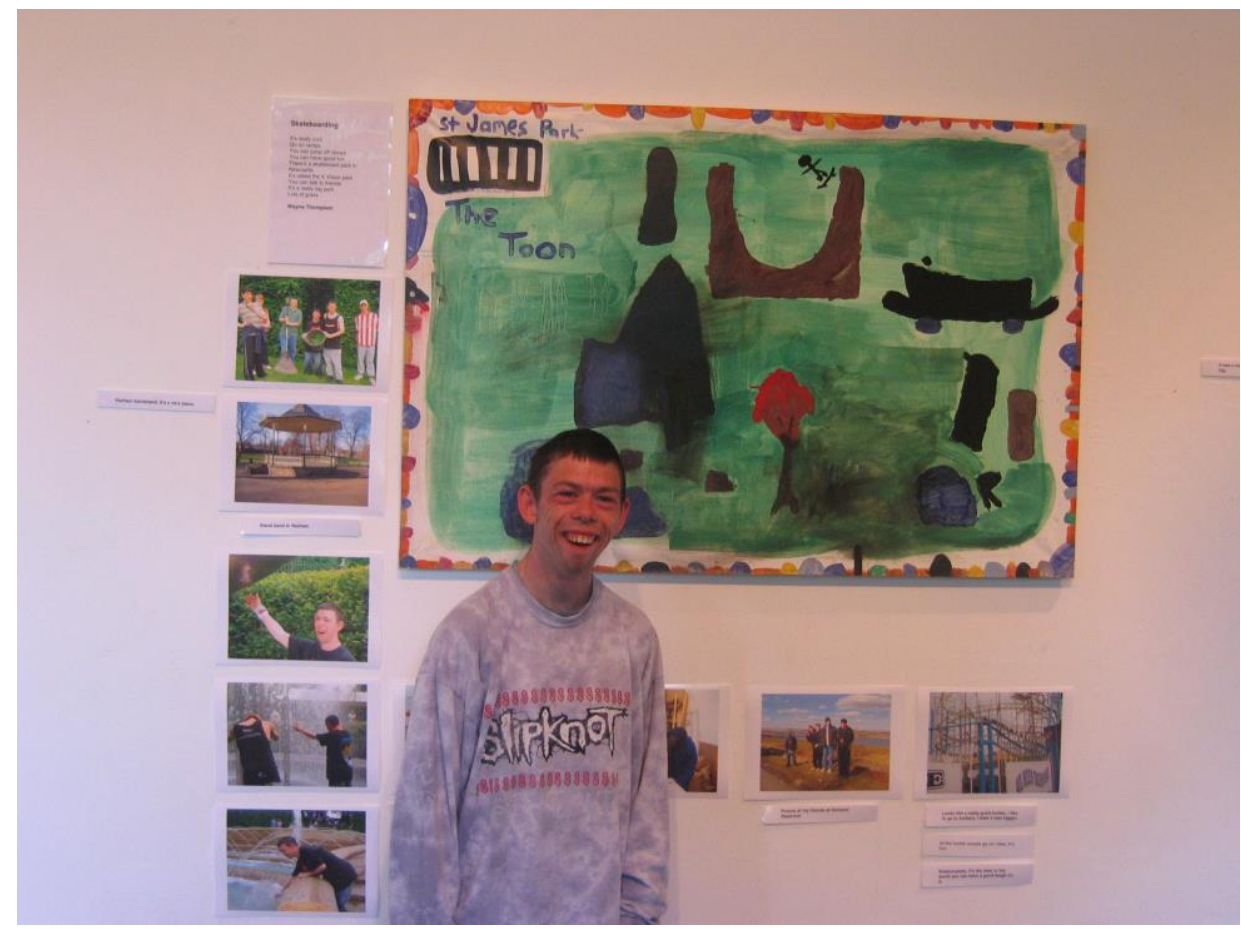

6.30

Luke with his canvas 'The Fish Quay', chosen photographs and writing.

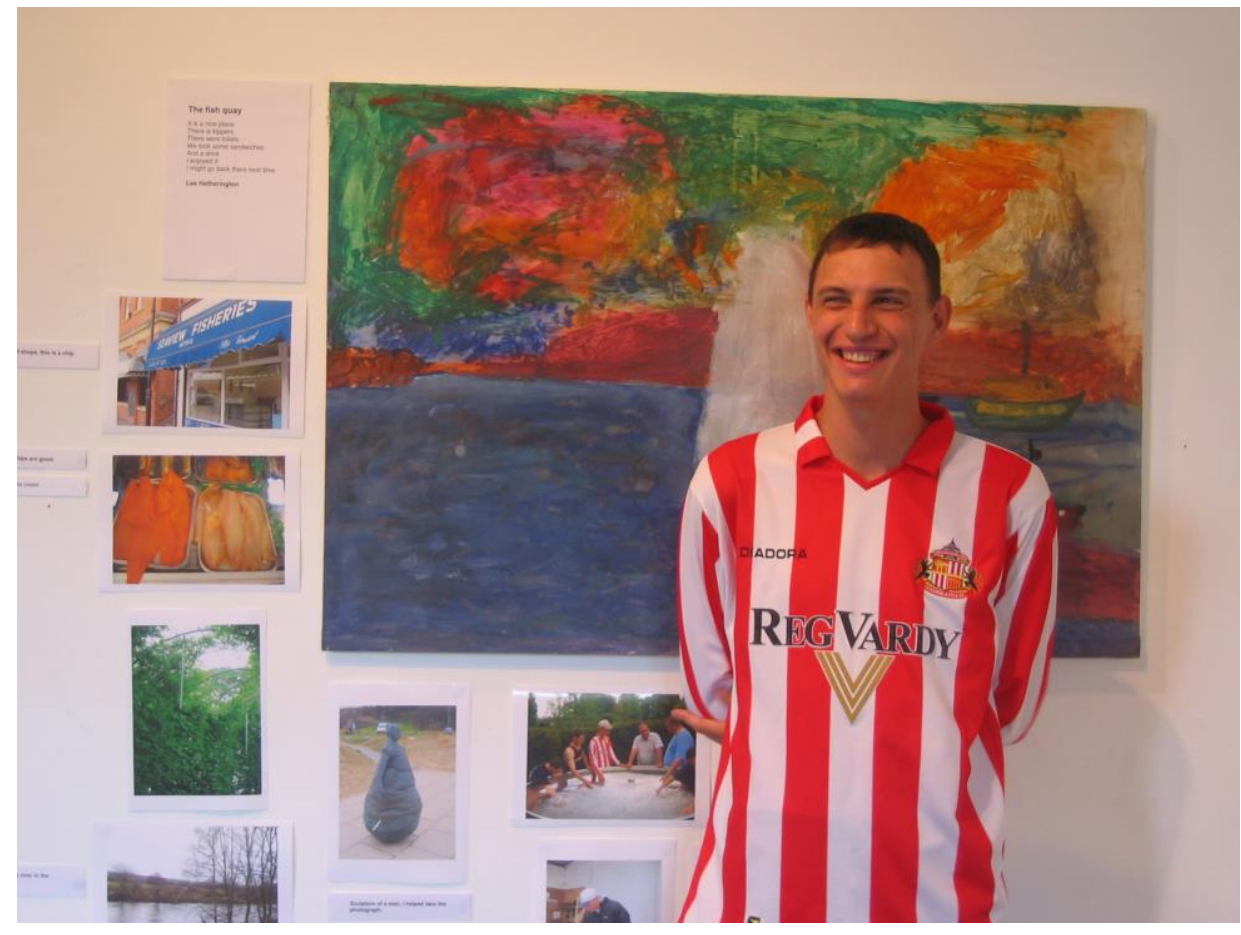




\subsection{1}

\section{Ewan with his canvas 'The Fish', chosen photographs and writing.}

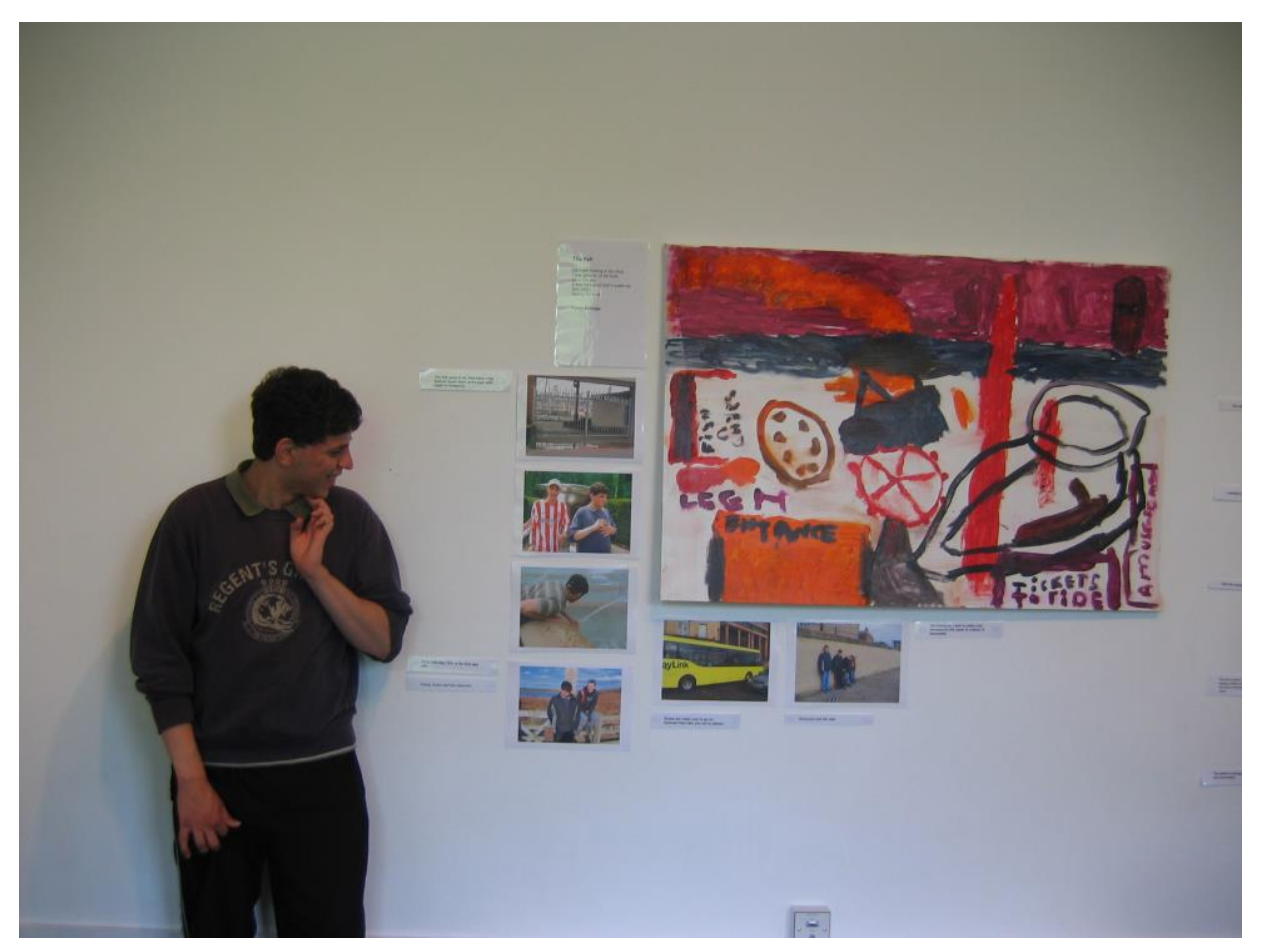

After attending the exhibition, each participant was interviewed a final time to discover his experience of participating in the project and his thoughts on the work he had produced. Simon produced a glowing canvas of red, orange and blue depicting a lifeboat, which he dedicated to his mother (6.27). Earlier, whilst constructing his canvas, Simon talked of being proud of his work, which led to him commemorating his mother in his painting. Simon's written description of his canvas was as follows:

\section{The old lifeboat}

I like the colours

I like the sea it looks rough

It's got people in it

In my picture I'm doing the new lifeboat

It looks fast

During his interview Simon revealed his favourite photographs of the project were of the Millennium Bridge and the dovecote with doves, with his most vivid memory of the project being The Alnwick Garden, "I got soaked that day". According to his interview, 
Simon had enjoyed all aspects of the project with his favourite methodological element being the exhibition and creation of his personal canvas.

Karl, like Simon, had chosen the lifeboat or rescue boat as the focus of his canvas (6.28). His description of his work read as follows:

\title{
Painting The Rescue Boat
}

Orange stands out properly

Black, blue red yellow

White flag and a 1422

If anything goes wrong they come out

They get the Rescue Helicopter

And that's yellow

When the helicopter lands there's the ambulance and they take to the hospital

In his exhibition interview, Karl discussed how he had chosen the rescue boat as exploring the developed coast had been his favourite site visit. However, he also commented upon interactive landscape elements at The Alnwick Garden, such as the rope bridge that excited him because: "It's like if you jump on it, it moves". When asked if he would have enjoyed visiting any other sites during the project Karl replied that the only other place he would have liked to visit would have been St. James football ground (the home of Newcastle United football team). The SC2 research project had given Karl increased confidence in experiencing new landscapes, and from his comments there was no element of the project that he did not enjoy.

Warren's canvas depicted a vast green park complete with skateboarding ramps and jumps (6.29). His description of the scene depicted by his canvas read as follows:

\author{
Skateboarding \\ It's really cool \\ Go on ramps \\ You can jump off ramps \\ You can have good fun \\ There's a skateboard park in Newcastle \\ It's called the X Vision Park \\ You can talk to friends \\ It's a really big park \\ Lots of grass
}


As previously discussed in this chapter the landscape Warren chose to represent, was unique amongst the SC2 participants as it was the only one not visited during the course of the project. Warren's written description of this skateboard park continues to remind the reader of his overwhelming desire for social inclusion with people his own age. That it was an urban park which Warren identified as the place where, "You can have good fun" and "You can talk to friends", echoes the findings of recent research which suggests green open spaces are important arenas for the social development and mental wellbeing of all young people (Nairn et al., 2003; Milligan \& Bingley, 2007). During Warren's individual interview he communicated enthusiastically regarding the final exhibition and his experience of the project as a whole:

Researcher: Ok this is an interview with Warren, at the exhibition at the Queens Hall. So what do you think of the exhibition Warren?

Warren: I think it's great

Researcher: So you think it's great, what's great about it Warren? Warren: It's just really, really excellent, I really like the idea of it Researcher: And are you proud of your work?

Warren: Yeah, I really hope some people do come this afternoon and have a look at it.

The body of work Warren produced, displayed at the Queens Hall, represented a great personal achievement; of which he was keen for all to see. Warren's interview transcript reveals there no part of the project that he disliked. In addition, he was keen to continue to participate in the project; ending his interview with the comment "I'd like to do it again".

Luke's canvas and exhibition portfolio reflected his ongoing fixation with food (6.30). This personal focus was suggested early on during the project, but came to overwhelming prominence during the participants' visit to the fish shop and Fish Quay at South Shields. Luke's canvas of vivid, overlapping blocks of many colours was accompanied by the following written description:

\section{The fish quay}

It is a nice place

There is kippers

There were toilets

We took some sandwiches

And a drink 
I enjoyed it

I might go back there next time

This description, alongside Luke's exhibition interview, includes many indications as to the importance of his daily routine. Within it Luke mentions toilets, sandwiches and drink. Although these tell us little about Luke's landscape experience of the Fish Quay they do suggest the value of providing accessible public lavatories and facilities for consumables in public open spaces. If these are not provided the visitor must anticipate such a need in his or her preparation prior to the site visit. For people with learning disabilities, the task of the family member, personal assistant/carer or support worker to instil in every individual a personal responsibility and an instinct for preparation, is a substantial one. If people with learning disabilities do not gain personal responsibility early in life, it becomes increasingly difficult to change patterns of behaviour, as they grow older. Therefore, the planning and design of public open spaces must understand the wide range of individual needs within the community they serve, and provide for them through inclusive design (Imrie and Hall, 2001). Use of the visual communication toolkit evolved by this study aids this understanding.

Ewan, like Luke, chose to illustrate his experiences at the developed coast on his canvas (6.31). His painting, although entitled 'The fish', depicts a range of brightly coloured fairground rides alongside a sea at sunset. Overlapping these are the outlines of boats and the words 'Tickets to ride'. Ewan's canvas description also hints at confusion and confliction between his personal landscape preferences and his desire to imitate those of his friend Luke:

\section{The fish}

I enjoyed looking in the shop

I took pictures of the boat

It's in the sea

It was very good and it made me very happy

Seeing the boat

Again, although the title of Ewan's written description is 'The fish', much of the text focuses upon the subject of a boat. During his exhibition interview Ewan reveals the extent to which he is socially swayed when asked: "What's your favourite thing in the whole exhibition?" to which he replies: "I think I like my photographs, I like me and 
Lee". The effect of the hierarchical group dynamic amongst the small number of SC2 participants was particularly powerful in the case of Ewan and Luke. Unlike other participants such as Simon and Warren who began the project in the shadow of others but who emerged (through use of the visual communication toolkit) each with a unique voice, Ewan remained unconfident when expressing his personal opinions. In retrospect, having identified the persuasive power of the group dynamic of Luke and Ewan it would have been advantageous to encourage the two participants to work with other group members. However, it was only through employing a longitudinal approach to the research fieldwork that this factor was revealed at all. Ewan concluded his interview saying that he had enjoyed the project and there was nothing he would change.

\subsubsection{Staff perception}

At SC2 the participants and researcher were supported for the majority of the project by a male tutor from the Estates Department. When the group travelled outside SC2 for site visits, or during drawing and canvas workshops where the Estates Department tutor was required elsewhere, a male member of SC2's Learning Support staff assisted the participants. The Learning Supporter was very popular with the participants as he was of a similar age and provided a reassuring and familiar face, having worked alongside them throughout the course of their education and personal development at SC2. On the final day of fieldwork at SC2 the researcher provided both the Estates Department tutor and the Learning Supporter with a questionnaire (identical to those given to staff a SC1). The questionnaire focused upon their experience of the project and their perception of the participants project experience. Whilst the researcher had continued to record personal observations throughout the course of the project, it was important to incorporate the views of all involved. The participants' experiences were explored through site visits, drawing workshops, semi-structured interviews, canvas workshops and the final exhibition. The questionnaire given to the Estates Department tutor and Learning Supporter, aimed to expose valuable, hidden knowledge held by the support staff regarding interactions between: the participants project experiences, their prior environmental experiences, their medical history and their social life (with family, at home, amongst friends, and within their community). Themes developed in staff 
questionnaires during the pilot study, were adapted for the comparative studies at SC1 and SC2 with specific reference to the sites and work undertaken there. Tragically, the Estates Department Tutor passed away shortly after completion of the fieldwork at SC2 and was therefore unable to complete his questionnaire. The Learning Supporter completed and returned his questionnaire, his responses are shown in Table 6.6.

The Learning Supporter's comments confirm that, from his perspective, the project experience was a positive one for participants and in addition, suggest that selfdirected photography was a particularly useful alternative communication method for the participants. The Learning Supporter also cites physical interaction with the landscape, through devices such as sculpture, to be an important means by which the participants learnt about the environment. The Learning Supporter concludes his comments by wishing greater publicity for the project so that the participant work produced would have had the opportunity to reach a wider audience.

Table 6.6

\section{Section 1: Site Visits}

\begin{tabular}{|c|c|}
\hline $\begin{array}{l}\text { Topic for } \\
\text { discussion }\end{array}$ & aff comments \\
\hline $\begin{array}{l}\text { Anticipation and } \\
\text { preparation for site } \\
\text { visits }\end{array}$ & $\begin{array}{l}\text { - The students were excited about visiting different places and } \\
\text { types of landscapes. } \\
\text { - The students were interested to see how the landscape changed } \\
\text { from inland to coast. } \\
\text { - There were personal worries prior to the site visits. } \\
\text { - Preparations included checking all had medication who required } \\
\text { it. } \\
\text { - Mobility problems were taken into account when selecting sites } \\
\text { to visit. }\end{array}$ \\
\hline $\begin{array}{l}\text { Access and } \\
\text { information }\end{array}$ & $\begin{array}{l}\text { There were no facilities (disabled parking, toilets etc.) on site } \\
\text { during visits to the remote countryside, rural coast and the } \\
\text { wetlands. } \\
\text { - } \quad \text { All other site visits had suitable facilities. } \\
\text { - The sites could have been improved through accessible toilets, } \\
\text { seating and better footpaths. } \\
\text { The group made use of site leaflets to help them remember what } \\
\text { they had done and seen. } \\
\text { - Photographs taken on site were also useful during individual } \\
\text { work to link written statements. }\end{array}$ \\
\hline
\end{tabular}




\begin{tabular}{|c|c|}
\hline Art and sculpture & $\begin{array}{l}\text { - Sculpture was a positive element in the students' landscape } \\
\text { experience. } \\
\text { - The sculptures at Alnwick Garden were most successful as they } \\
\text { allowed students to learn through their senses. } \\
\text { - Students reacted differently to the sculptures, as some take more } \\
\text { notice of their surroundings than others. } \\
\text { - The texture of the sculptures was the most stimulating element. } \\
\text { - All sculptures could be improved by being more 'hands on' so } \\
\text { the students could touch them to understand how they worked. }\end{array}$ \\
\hline Landform & $\begin{array}{l}\text { The students reacted differently to being in large open spaces, } \\
\text { some students found it strange, and other students were fine } \\
\text { with all aspects of being in an open space. } \\
\text { - The students appeared more dependent on the staff when } \\
\text { outside of SC2 due to a lack of confidence. } \\
\text { - The students all enjoyed being outside. } \\
\text { - Outside the atmosphere was different and the students supported } \\
\text { each other. } \\
\text { - There were no physical barriers or mobility issues whilst out on } \\
\text { site. } \\
\text { With verbal prompting the students could identify different } \\
\text { landscape types. } \\
\text { Alnwick Garden was the most important site visit to the whole } \\
\text { group as it provided the most things to do. }\end{array}$ \\
\hline $\begin{array}{l}\text { Landform } \\
\text { (continued) }\end{array}$ & $\begin{array}{l}\text { - As individuals: Luke, Simon and Warren enjoyed the trip to the } \\
\text { developed coast, Karl enjoyed the urban riverside and Ewan's } \\
\text { favourite was the remote countryside. }\end{array}$ \\
\hline Vegetation & $\begin{array}{l}\text { - Students were uninterested in vegetation during the site visits. } \\
\text { - Footpaths could be improved if they were kept clear of } \\
\text { vegetation, and grass and plants were kept short. }\end{array}$ \\
\hline Safety & $\begin{array}{l}\text { - No safety issues arose during the site visits. } \\
\text { - The students were not safety conscious. }\end{array}$ \\
\hline Seating & $\begin{array}{l}\text { - The remote countryside did not provide adequate seating. } \\
\text { - However, generally seating was adequately located. }\end{array}$ \\
\hline Senses & $\begin{array}{l}\text { - Sound was not always a positive element of site experience - } \\
\text { some students did not like loud noises. } \\
\text { - The students enjoyed touching things on site. }\end{array}$ \\
\hline Animals & $\begin{array}{l}\text { The students had no contact with animals whilst out on site. } \\
\text { - Some of the students would not know the difference between } \\
\text { wild and domesticated animals - which could be a health and } \\
\text { safety issue. } \\
\text { - It would be beneficial for the students to learn which animals } \\
\text { they should and should not approach. }\end{array}$ \\
\hline
\end{tabular}

Section 2: Photo-elicitation 


\begin{tabular}{ll}
\hline $\begin{array}{l}\text { Topic for } \\
\text { discussion }\end{array}$ & Staff comments \\
\hline $\begin{array}{l}\text { Participant } \\
\text { produced } \\
\text { photographs }\end{array}$ & $\bullet \begin{array}{l}\text { Personally witnessed Warren and Ewan using the digital camera } \\
\text { during site visits. }\end{array}$ \\
& - $\begin{array}{l}\text { The students took photographs whilst visiting the remote } \\
\text { countryside, the rural and developed coast and the urban } \\
\text { riverside. } \\
\text { Once the students were shown how to use the camera, they } \\
\text { could use it independently. }\end{array}$ \\
- & $\begin{array}{l}\text { Students used the photographs to help inform their paintings. } \\
\text { Students enjoyed taking photographs as it proved they had been } \\
\text { involved and showed others what interested them. }\end{array}$ \\
\hline
\end{tabular}

\section{Section 3: Participant artwork}

\begin{tabular}{lcl}
\hline $\begin{array}{l}\text { Topic for } \\
\text { discussion }\end{array}$ & Staff comments \\
\hline $\begin{array}{l}\text { Drawings and } \\
\text { paintings }\end{array}$ & - Students enjoyed the drawing and painting workshops. \\
& - $\begin{array}{l}\text { Luke chose to paint the Fish Quay, Simon a boat, Karl a sea } \\
\text { scene, Ewan the coast and Warren a skateboard park. }\end{array}$ \\
& - The drawing workshops helped students focus for their canvas. \\
& - Students enjoyed communicating visually and verbally. \\
\hline
\end{tabular}

\section{Section 4: Interviews}

\section{Topic for Staff comments}

discussion

\begin{tabular}{l}
$\begin{array}{l}\text { Using photographs } \\
\text { to talk about } \\
\text { landscapes }\end{array}$ \\
\hline
\end{tabular}

\section{Section 5: Communication}

\section{Topic for Staff comments}

discussion

Communication $\quad$ - Using visual communication greatly helped most students, as they do not have very good literacy skills.

- In addition for students with limited verbal communication, Makaton, Pec's and British Sign Language (BSL) could be used.

- The project has helped the students distinguish between different types of landscape.

- The project could have been improved through greater exhibition publicity so more people would have had the chance to see the display. 


\subsubsection{SC2 Conclusion}

The period of study fieldwork at SC2 began with four aims, to be achieved through four objectives. The first and most general aim was to discover what affects participation in the experience of public open space by young men with learning disabilities. Through employment of the visual communication toolkit working with SC2 participants over a period of fourteen weeks, this aim was achieved and an interesting phenomenon revealed. The factor that most greatly affected the young men's participation in new landscape experiences was their prior experience of landscapes of a similar typology. For example Warren, who had little experience of rural environments, continued to communicate a preference for urban landscapes until the penultimate site visit to Newton-by-the-sea. The project exposed Warren to many different rural and urban landscapes, and from this point of broader personal experience he began to positively enjoy interactions with the rural environment.

Alongside experience in the participants' equation for enjoyment of landscape, sat opportunity for active participation. Landscapes that did not encourage the participants to experience direct tactile stimulation were far less popular than those who's planning and design understood and incorporated this element. As the SC2 Learning Supporter, who assisted the group, commented in his questionnaire: "The sculptures at Alnwick Garden were most successful as they allowed students to learn through their senses". Both the researcher and the Learning Supporter noted that the participants benefited when they had the opportunity to be 'hands on'; touching or using elements in the landscape helped them understand how the environment worked. An example of this occurred where participants were involved in conservation work with BTCV. Through shaping the landscape and learning new skills, a process of active participation was achieved resulting in individual landscape ownership and greater personal confidence.

The second aim of the SC2 study was to test the use of the visual communication toolkit within a limited time frame. This aim was strongly linked to the third, to test the toolkit's viability for producing relevant environmental information within the course of a taught module. The length of academic term for the Land and Environment BTEC set out a finite number of weeks over which the project fieldwork could be completed. With careful planning and organisation, the seven-stage visual communication toolkit was 
utilised in its entirety within a fourteen-week period to reveal the experiences and landscape understanding of the participating students. Repeat employment of the toolkit's methodological elements within this time frame resulted in greater participant familiarity and confidence when using visual communication methods. Creating a set end to the fieldwork period (the Queens Hall exhibition), in advance of the project commencing, was beneficial to the researcher and participants. Firstly this aided development of, and adherence to, a strict research timetable. Secondly the exhibition created a visible, public conclusion to the project. And finally, the exhibition gave the students an opportunity to take pride in their work and share their achievement with the wider community.

The final aim of the SC2 study was to develop the participants' appreciation and understanding of public open space. This was accomplished through study of a range of landscapes and the parallel refinement of the toolkit. The visual communication methodologies employed firstly revealed hidden experiential information and then suggested the research direction to enhance the individual participant's landscape experience. For example, where some participants had shown particular interest in landscapes that contained water (such as the developed coast and urban riverside), the researcher responded to this appreciation through a site visit to Alnwick Gardens, where water was used as a central design device in the landscape. The toolkit was also tailored to each individual. For some participants, communicating competently during semistructured interviews remained difficult; therefore greater attention was given to on site photo-elicitation and more informal dialogue. For others, the canvas workshop was particularly effective in focusing new dimensions to experience, yet the drawing workshops produced vague and disparate results so less time was spent on this. Taking a more individually tailored approach to the site visits and subsequent workshops encouraged the participants to develop and voice their individual environmental preferences. In turn this built a foundation for future landscape experiences, where participants' felt confident voicing personal leisure choices. In this respect the project aimed to be emancipation tool, reflecting the guiding principles of choice and rights in Valuing People (Department of Health, 2001). 


\subsection{Conclusion: SC1 and SC2 similarities, differences, successes and limitations}

Use of the visual communication toolkit and DIDEC analysis within the context of the $\mathrm{SC} 1$ and SC2 comparative studies was a research success. Through application of the toolkit a greater level of information regarding the public open space experience of the participants was revealed. With few, if any, participatory research studies focusing upon this area the experiential findings generate a new contribution to knowledge. Adaptation of the toolkit to suit a participant's particular communication needs demonstrate that it may be tailored to the individual. The research timetable at SC2 illustrates how the toolkit is effective when utilised within a relatively short term study. This has positive implications for its feasible application within the landscape design and planning process, when used to extract hidden landscape preferences and aversions of this greatly underrepresented group. The other notable methodological success of the comparative studies was the public exhibition. At SC1, the idea of a public exhibition had been developed and tested over the course of a number of years, through the pilot study and main study fieldwork. At SC2 the exhibition was built into the fieldwork prior to commencement, and was for the participants one of the driving attractions of the project. The exhibition succeeded on a personal and public level. It was personally gratifying to the participants to see their work displayed, and it drew great public interest through the local press, further expressed through the comments of those who visited the exhibition. The final positive conclusion to be drawn from the words of the participants and support staff involved was that project participation itself was a positive experience. Throughout the course of the fieldwork there were no negative reactions to the research. At SC1 such a strong participant-researcher foundation was laid, that a subsequent research project ${ }^{17}$ to continue the existing collaboration and commitment to visual communication was organised.

As with all research, the work completed at SC1 and SC2 did present visible limitations. Overwhelmingly, for the research to be a success a longitudinal approach to the fieldwork was required. Without allowing sufficient time to familiarise oneself with

\footnotetext{
17 'Excuse me, I want to get on: negotiating the city' (The University of Sheffield (Knowledge Transfer Opportunities Fund), 2008).
} 
the participants and their individual approaches to communication, application of the toolkit would be null and void. Any results produced would be mere lip service and an insult to a section of the community that is already misunderstood and undervalued. Longitudinal studies do involve a large time and resource commitment; however the depth of phenomenological understanding revealed pays dividends.

It has been previously acknowledged within this thesis that the arena of learning disability research is now saturated with small-scale qualitative studies (such as this one, one might argue) whilst more consequential large-scale quantitative enquiries remain thin on the ground (Ramcharan \& Grant, 2001). However, the researcher believes that the relatively unique multi-disciplinary nature of this study legitimises its research place and purpose. It is hoped that the visual communication toolkit evolved by this research and placed within the sphere of landscape architecture, creates an initial, solid building block for further, and perhaps more quantitative, study and application. Being a study of such small scale, the researcher can make no claims that the findings (as outlined in Chapter 7) are applicable across the national learning disability population. The experiential findings are contextually dependent - that being they are the researcher's personal qualitative results, derived working with a specific participant group at a specific time.

So what, across the two study centres, united the participants' experience of public open space?

1. Increased confidence: significantly every participant became more interested, and less cautious, about experiencing new landscapes as project fieldwork at both study centres progressed. This similarity suggests that all learning disabled participants involved had a lack of previous environmental experiences to draw on. During informal discussions between the researcher and participants at both study centres it emerged that many had not visited any of the local landscapes explored during the project (within a predominantly city radius at $\mathrm{SC} 1$, and county radius at $\mathrm{SC} 2)$.

2. Photo-elicitation: for all participants photo-elicitation was the most popular communication method utilised during fieldwork. Photo-elicitation, resulting 
from participant self-directed photography or researcher photographs observing participant-environment interactions, stimulated the participants throughout the project. Photographs were used during interviews, drawing workshops, the creation of canvases, the public exhibition, and as impromptu talking points with family and friends outside the project.

Whilst a number of important similarities are identifiable between the project responses of the participants at the two study centres, prominent differences in experience also exist.

1. Age: a key factor in how the participants chose to interact with the landscape resulted from the difference in age of the participants at the two study centres. At $\mathrm{SC} 1$, participants varied in age from those in their late 20's to those in their mid 60 's. The majority of SC1 participants fell within an age range of 40 to 60 . Being older and more used to a sedentary lifestyle, many of the SC1 participants, particularly those who were female, enjoyed observing rather than physically interacting with the landscape. Whilst the site visits generated excitement and anticipation amongst the older participants just as with the younger individuals, the older participants appeared more content during drawing workshops back at the study centre. At SC2, the participants were all male and far younger aged 18 to 21. This group of participants revelled in active participation with the landscape, and in contrast to those at SC1 were often most restless and unsettled during the drawing workshops at the study centre. Unfortunately, without the opportunity to involve young female participants of a similar age in the research at SC2 it was impossible to gauge whether the dominant factor in the preferred form of landscape participation was age or gender. Of the younger (those in their late 20's and early 30's) female participants at SC1 most communicated and displayed a joy for active participation with the landscape, i.e. Nathalie's experience with the fountains during the Peace Gardens site visit. However, to truly understand the role or age and gender further study would be required. 
2. Health: the participants' current state of health also contributed to how environmental experience differed between participants at the two study centres. Closely linked to age and lifestyle, it was observed that those in a poor state of physical or mental health or those with physical impairments (information gained from their support workers) were, at least initially, far more cautious whilst out on site. This affected their form of landscape participation (observatory or interactive) and the type of landscape which they preferred (the more passive or the more challenging). Generally the fitter SC2 participants preferred landscapes which incited physical interaction, whilst amongst those SC2 participants who were in a lesser state of health observing and meandering through the landscape sufficed.

3. Daily routine: difference in landscape experience was also affected by the individual's daily routine and lifestyle. For many SC1 participants who spent the majority of their time in the home environment both urban and rural public open spaces were a new experience. For the younger SC2 participants, the urban environment and the green spaces within it, such as parks and skate parks, were both familiar and, for some, more attractive than the unfamiliar rural landscapes. Again, participant progression through the project and exposure to a wider range of landscape experiences increased the familiarity and enjoyment of public open spaces for many, if not all the participants.

4. Group dynamics: the final factor to be discussed, influencing difference in communication of landscape and project experience, is that of group dynamics. The SC1 participants were far less affected and susceptible to peer pressure than those at SC2. Among the small group of young male participants at SC2 there existed a very visible and verbal hierarchy. Friendships within this were controlled by the more dominant member of the pair or group, and opinions were swayed in this way. Individual landscape preferences were not always voiced and mimicry of the lead group members sometimes occurred. At SC1 participants tended to interact solely with the researcher and support staff and were often 
unaware of their peers and their outlooks. In this way it was sometimes easier to determine the individual landscape preferences and dislikes of the SC1 participants compared with those at SC2.

The following chapter, Chapter 7, Toolkit and Findings, aims to refine the volume of experiential information collected during the fieldwork period. Using the DIDEC approach (Chapter 3) to qualitative analysis, Chapter 7 asks what conclusions can be drawn from this study, and whether use of the visual communication toolkit can start to unlock the phenomenon of public open space experience by people with learning disabilities. 


\section{Chapter 7}

\section{Toolkit and Findings}

\subsection{Introduction}

Use of the visual communication toolkit, in the context of the two localised studies at SC1 and SC2, resulted in the production of a variety of data including: 46 participant interview transcripts, four completed staff questionnaires, staff notes and observations, a researcher journal and many hundreds of participant images (photographic and drawn). Of the total 18 participants, three had little to no spoken language and were therefore absent from the verbal interviews. However, these participants were included in every other stage of the methodological process.

The success of the toolkit can be assessed to a certain extent by the quantity, quality and variety of information produced. Without generation of the toolkit, and with reliance upon traditional communication methods, this information would be absent. The toolkit can be further tested through DIDEC analysis (see Chapter 3, Methodological Approaches in Analysis) of the data, and any emerging experiential information. If the researcher envisages the toolkit as an interpreter between the aims of the landscape professionals (spoken in one language) and the experience of the participants (spoken in another), the participant data produced is a complex transcript that, although potentially rich in information, is relatively unintelligible to professionals. In order to understand this transcript, DIDEC analysis is employed as a translator, reviewing participant experience and translating it into tangible themes employable in the creation of inclusive policy, practice and design. Concrete uses and applications for the toolkit can thus be identified, thereby validating it.

This thesis was led by the question, "How may we better understand the public open space experience of people with learning disabilities?" In order to answer this question the research had a primary aim of producing a toolkit of effective communication methods with people with learning disabilities. Referring back to Chapter 1, Introduction, the researcher foresaw how successful completion of this primary aim, would facilitate three associated secondary aims, which were to: 
- Help to create an open process of communication between the developers of public open space and people with learning disabilities.

- Suggest how public open spaces might be improved for people with learning disabilities.

- Reveal social factors that influence people with learning disabilities experience of public open space.

In considering the research products generated by these aims, the researcher subdivides them into the following two significant results categories:

1. The visual communication toolkit - which has significant communication and personal development dimensions for people with learning disabilities.

2. The experiential findings (six key themes and one central premise) -which are contextually generated by the visual communication toolkit, but have the capability to provide significant insight into the place perception of people with learning disabilities.

In this chapter the researcher first considers the resultant toolkit, with discussion of its individual communication methodologies and how they are best employed.

\subsection{The Toolkit}

As someone once told me, different tools are designed to do different jobs. Assembling a toolkit of kitchen utensils to bake a cake is very different from choosing a set of tools to build a set of shelves. However, what these toolkits share is a sense of methodological order, whereby the use of one tool to accomplish a particular task leads to the natural employment of another thereby bringing the process one step closer to the final goal. When baking a cake you must use a wooden spoon to cream together the butter and sugar before turning to a whisk to combine the eggs. When building a set of shelves you must use a tape measure to determine the lengths of wood required before moving on to a saw to cut them. Not all recipes and woodwork require the exact same tools, to be used in the 
exact same order; nevertheless understanding the principles behind the process allows you to successfully adapt each toolkit to meet a particular contextual need.

This research project generated a visual communication toolkit which can be used to elicit meaningful information regarding the public open space experience of people with learning disabilities. Within the toolkit there lies seven different tools. Each tool allows the owner of the toolkit to bolt, nail, weld or join a new piece of information onto the structure of public open space experience by people with learning disabilities. Under different contextual circumstances, the toolkit owner may wish to focus more upon certain elements of their participants' experience and be uninterested in the detailing of others. Understanding that different tools will allow the owner to accomplish different tasks comes as a result of familiarity with the toolkit as a whole. For the prospective owner of this visual communication toolkit, a 'how to' guide (complete with handy hints) for each tool is now provided:

\subsubsection{TOOL 1: Informed consent}

This tool is essential if a researcher or practitioner wishes to employ the toolkit. Without informed consent, any research completed utilising the rest of the tools is meaningless. Without informing participants of the purpose of the research they will be involved in and outlining the subsequent tools they/the researcher will have at their/the researcher's disposal, the suggestion of working together towards a commonly understood goal is an artificial one. In addition, informed consent means informed consent. Just as the toolkit as a whole aims to break down barriers to communication, the format of informed consent produced, must reflect the requirements of the recipients. Before embarking on any participatory project, the researcher must gain a level of understanding about those people they will be working with and be confident that any information they disseminate to them is appropriate. This means exploring (even at this initial stage) a variety of communication methods i.e. verbal, written, visual, symbolic and physical. Within one potential participant group there may be a wide range of communication needs. Therefore to include all the researcher must be able to be flexible in their presentation of information. If a support agency is involved in the project, they too should be involved in the process of informed consent. It is in the researcher's best interests to make the 
research process as transparent as possible from the start. In this way, potential organisational hold ups and worries are avoided where possible. When working with any group of participants the researcher is accountable for their wellbeing throughout the course of the project. Clearly outlining research intent from the start provides the most foolproof method for a successful collaboration.

\subsubsection{TOOL 2: Site visits}

A key finding of this research was that if participants' did not experience an environment directly, they had little interest or notion of it indirectly. Without inclusion of site visits within the toolkit methodology, eliciting any experiential information regarding people with learning disabilities participation in public open space would have been very difficult. Through the course of the project the researcher discovered that participant conceptualisation of new experience was always closely linked to prior experience (see Chapter 4 and 6). Learning disability participants require sensory contact with the environment under study, in order that they may feel competent commenting upon their personal preferences and influences.

The organisation of site visits with people with learning disabilities requires a great deal of preparation on the part of the researcher, and a great deal of assistance on the behalf of the support agency. Some sites may be difficult to access using public transport for a number of reasons. These reasons may include: no public transport is available between the study centre and site at a suitable time, no transport route travels directly between the two sites or that some participants' may have physical mobility impairments which exclude certain modes of public transport as viable options.

Therefore, if the participants and researcher are to rely upon private transport to reach the landscape study site, there may be additional cost implications. Whether these are built into the research budget, absorbed by the support agency or alternatively covered by the participants' and their families, is a matter for careful consideration and discussion before commencement of fieldwork. Once a site visit has been decided upon, a preparation checklist for the researcher and support agency staff must be produced to ensure the participants are safe and comfortable whilst on site. An example of such a list might comprise the following: contacting the site staff/owner regarding wheelchair accessibility 
and accessible toilet facilities, ascertaining all participants who require regular medication are provided for, ensuring a first aid kit is to hand, providing a suitable ratio of staff/volunteers to support participants, organising consumables (food and drink dependent on the length of the site visit), checking participants have on (or with them) appropriate dress, ensuring mobile phone contact is possible between the staff, researcher and support agency and providing an accessible itinerary of the day for participants.

Whilst on site the role of the researcher is one of observer and enabler. In introducing participants to new environmental situations, the researcher asks them to leave the safety of their familiar home or support agency environment and step out into the unknown. Participants will display a variety of reactions, physical and emotional, to this. The researcher must be able to both objectively observe the situation, whilst assisting where necessary. Participants encountering new landscapes may be unaware of physical and social dangers and be eager to experience all the environment has to offer without displaying understanding of personal safety. Therefore the researcher must retain acute awareness of where, what and who the participants are involved with at all times. This being said, the researcher must never actively restrict the participants natural reaction to the environment, unless it is seen that this will endanger the individual. It is this instinctive behaviour, which when observed, recorded, discussed and analysed, provides the key to understanding how public open space may be better designed to meet the needs of people with learning disabilities.

The site visit tool contains another important thread which holds the entire toolkit together; that of photography. Photography runs throughout the toolkit linking and easing one tool with another; just as we might deem a can of oil essential in keeping all individual car tools and components in prime condition to work together. It is envisaged that potential owners of this toolkit (researchers and landscape architecture professionals) may have already encountered photography with use of the first tool, informed consent. During informed consent, the toolkit owner may have chosen photography as an accessible communication method to enable potential participants to make an informed choice whether or not to be involved. During site visits, photography is introduced to the participants as a means for them to record what they see and experience (self-directed 
photography) and in addition have their environmental interactions recorded by the researcher (from an observation perspective). Digital cameras were utilised throughout the fieldwork of this thesis due to their ease of operation, low financial implication (printing was not always necessary and images could be saved and viewed digitally) and the ability to immediately play back images. However other forms of photography and cameras might also be employed, these might include using traditional single lens reflex cameras (SLR), digital SLR's, disposable cameras or Digital Versatile Disc/Digital Video Disc (DVD). For many participants being the photographer and not just the photographic subject will take some time to acclimatise to. This may be made a more natural process through continued and consistent use of the digital cameras both on site visits and during the daily routine of activities at the support agency. Indeed, exposure to photography in this manner was found to develop such passion in a number of this study's participants that they purchased their own cameras and began voluntarily recording their home and daily life experiences. Photographic recording of environmental experiences will develop from both a researcher and participant perspective as the project progresses. As the participant is further exposed to a/or a number of environment/s their personal interest in such places and what meaning they hold refines. This should be encouraged. No longer merely seeing a space they begin to connect with it and elements that give them pleasure. Likewise the researcher, as their understanding of their participants' refines over time, is likely to begin recording more meaningful observations of participant - environment interaction; avoiding a 'shoot it if it moves' philosophy.

\subsubsection{TOOL 3: Drawing workshop}

The third tool in the toolkit is the drawing workshop. This tool begins to unravel the participants' site visit experience without reliance upon verbal or written communication. Drawing workshops are most effective if held shortly after the site visit to the public open space under consideration. If too much time elapses between the site visit and drawing workshop, the focus of the drawing workshop may become vague in the minds of the participants. Under these circumstances, actual memories and experiences may be replaced by more recent occurrences and distractions. The drawing workshop gives participants the opportunity to express how they felt about the site visit, using 
photographic prints from the day as primary visual prompts. Whether all or only a selected few photographs are used by the participants (to recreate and develop their personal site experience) is at the discretion of the researcher. Some participants may find it useful to use a patchwork or collage of many images, whilst others may choose to focus upon one specific captured element. By reintroducing the photographs the participants are provided with a springboard from which they may leap off into expressing their individual experiences through a variety of artistic media. The choice of media is only restricted by the financial budget, the imagination and inventiveness of the researcher and support agency staff and the preferences of the participants. During the fieldwork of this thesis, for example, participants utilised the following media and techniques: collage, brass rubbing, acrylics, pencil drawing, poster paints, paper making (the embedding of handmade paper with small objects found on site), and pen and ink. The drawing workshop begins the journey of personal participant experience and communication. A number of consecutive drawing workshops should be held after the site visit. These allow time for the individual participant's to become familiar with a number of artistic media and techniques, and make an informed choice as to the visual method(s) which they find most effective in communicating their experiences. During the drawing workshops the role of the researcher is multidimensional. Firstly, the researcher demonstrates and assists participants in exploring a range of media and techniques. Then, whilst participants apply their chosen technique(s) to communicating their site experiences, the researcher engages the group and individuals in informal discussion regarding their choices. At this stage, the drawing workshop tool begins to elicit possible experiential themes (be it social or environmental) that have a significant bearing upon the participants' environmental experience. The researcher records these themes as reference points for the semistructured interview, to be used later in the toolkit. Such themes may be of personal importance (to the individual participant) or reflect a shared experience (across the participant group).

During the fieldwork of this thesis, the researcher chose to contain all the work produced by participants within individual participant books. These volumes were the personal property of the participants, and were returned to each individual at the end of the project. The participant books satisfy a number of purposes. Firstly they give 
ownership of the project over to the participants; as more work is added to the book week by week, the participant's individual journey through the project emerges. Secondly, the participant books provide a useful visual reference point, alongside photographs, during semi-structured interviews. Thirdly, they ensure work does not go 'missing'. During the fieldwork at SC1, some participants were prone to 'pocket' resources ( pencils, paper etc.) and work produced. By encouraging participants to place all work produced within their participant books, and reassuring individuals that the book was their property to keep after the project was completed, less work was removed from the study centre.

\subsubsection{TOOL 4: Individual canvas workshop}

Following the drawing workshops participants are introduced to the fourth tool in the toolkit, the individual canvas workshop. This tool is only implemented after all the site visits and drawing workshops have been completed. The canvas workshop is the culmination of the participants' individual exploration of their reaction to a landscape (or in some cases public open space experience as a general rule). Personal ownership over the individual canvases lies entirely with the participants, from frame construction to exhibition mounting. Participants have the opportunity to select all particulars of their canvas including the frame size, dimensions and media used etc. The researcher must ensure that each participant produces an individual piece of work, which results from his or her individual journey through the project, and that displays individual focus. For the participants, the canvas workshop is a crucial turning point in the project; it is here that participants reach the realisation that their work will be viewed publicly. Therefore, it is at this point when intensified project interest and energy is injected into their work. Through informal discussion during the drawing workshops, the researcher and participants will have begun to clarify the environmental/social element(s) of landscape that each participant is particularly interested in. During canvas workshops at SC1 and $\mathrm{SC} 2$, the participants approached construction and painting of their canvases from a number of angles. Some participants carefully planned their composition, colour palette, canvas size etc. whilst others were happy to paint and repaint their canvas until they were satisfied with the image displayed. In order to avoid distraction from the original canvas impetus, it is suggested that the researcher encourages participants to set down a canvas 
title and if possible (as at SC2) a short canvas description at the beginning of the canvas workshop. By doing this, if repainting of the canvas does occur, the exhibition audience (and the researcher) are still able to determine the original environmental experience that drove the participants' individual canvas production.

\subsubsection{TOOL 5: Photo-elicitation interviews}

Completion of the canvas workshop signifies the end of production of physical, visual work by the participants' utilising tools one to four from the toolkit. The toolkit now takes the researcher into a new stage of analysis and reflection. Unlike many qualitative methodologies, such as traditional approaches to phenomenology and grounded theory, this visual communication toolkit has already generated a vast amount of experiential information by the time the researcher employs the tool of semi-structured photoelicitation interviews. Earlier in this chapter, the researcher asked the reader to think of the toolkit as an interpreter facilitating dialogue exchange between the professional designer and the learning disability participant. The fifth tool of photo-elicitation interviews can be thought of as foreign language phrase book when placed in the hands of the visual communication toolkit owner. The interviews provide the opportunity for a personal dialogue between the participant and the researcher to begin.

Having picked a subject for conversation (which in this research context is public open space experience) the toolkit owner uses the photo-elicitation interview to ask simple questions about complex participant experiences. The 'phrase book' or photoelicitation element of the interviews, introduces topics for conversation through the use of visual prompts. Before the interview begins, the researcher must have a clear idea of the range of topics they wish to discuss. These topics will have emerged through observation of the participants on site, photographs taken on site, artwork produced during the drawing workshops, informal conversation with participants and the production of individual canvases. Just as someone might when practising a foreign language ease them self into the discussion by introduction of simple conversation topics, such as greetings, travel, food etc., and this same sensitivity should be employed regarding interviewing participants. Awareness that you are placing the participant in a new and potentially worrisome position, as an interviewee, should be respected and responded to by the 
researcher. Photo-elicitation interviews that start with general conversation to put the participant at ease, before beginning the focused discussion, are far less intimidating than those which put the participant and their opinion under the spotlight from the start. The use of photographs taken on site and photographs of/or presentation of actual participant artwork is a great leveller in the power dynamic of the photo-elicitation interview. With both the researcher and participant absorbed in unravelling their meaning and importance, at points it is difficult to tell who is driving the interview. The researcher must not be afraid of leaving some questions unanswered if the participant shows no interest in their content. Likewise the researcher must be flexible to unplanned ideas and concepts emerging from the words of the participant, and allow freedom within the interview to follow these new lines of inquiry. Giving the participants the time to voice their own stories, without pressure to conform to a right or wrong answer, was found to reveal some of the most poignant and useful experiential information. If time allows, it is suggested that follow up interviews focusing on one project element, be it the individual canvas theme, a part of one particular site visit or an individual drawing, should be held. At SC2 the researcher discovered that, although follow up interviews (as with the majority held with the learning disability participants) could be short in words, they had the capability of clarification. Specific ideas that the researcher had developed when studying the previous interview transcripts could be posed, and a greater understanding of individual participant behaviour gained.

As it has been stated before, three out of eighteen of the participants in this study had no spoken language and therefore it was deemed futile to try and engage them in a formal oral dialogue. If other qualitative methodologies had been employed, where the semi-structured interview plays the key role in data collection, these three voices would have been absent from the final research conversation. However, this was not an issue when using this toolkit. Neither would it be for the potential toolkit owner. With so many tools at your disposal one tool may be easily omitted, replaced by further and more creative use of the others to suit your individual purpose. This only confirms the flexibility of this toolkit, as a means to include all communication needs. 


\subsubsection{TOOL 6: Staff questionnaire}

To engage in any participatory research project, with any group of people with learning disabilities requires the researcher to also engage with the social or educational organisations that support them. In this way it has been shown that, by this thesis and other studies, the researcher is far more likely to gain access to, cooperation with and support for participant involvement. If fieldwork is to be carried out in direct conjunction with a learning disability support agency (such as was the case at the study centres of $\mathrm{SC} 1$ and SC2), the researcher must have awareness from the start of both the influence upon, and primary knowledge of, the participants which support agency staff hold. It is unlikely that the researcher will be left to work alone with such vulnerable participants', therefore throughout the project there will be a staff presence on hand to observe and assist. As the researcher noted in Chapter 6 Main Studies, support staff have access to a wealth of experience and insight regarding interactions between participants' prior environmental experiences, their medical history and their social life (with family, at home, amongst friends, and within their community). It is information of this type and personal nature which it may not be possible for the researcher to gain firsthand during the course of the project. Therefore these important staff perceptions are revealed through employment of tool six, the staff questionnaire.

As this tool does not target direct communication with the participants, a different and more methodologically mechanical approach, in the form of a questionnaire, may be taken. The questionnaire allows the researcher to elicit the maximum amount of experiential information from the support staff without making great demands on their time. The format of the questionnaire emerges from themes regarding participant environmental experience, extracted through the employ of tools two to five in the visual communication toolkit. For example, if the site visit had shown art and sculpture to be an important element of public open space experience for the participants, also appearing in photographic images chosen and drawn images produced during drawing workshops, with further evidence significance emerging in the individual canvases and photoelicitation interviews, the researcher could be assured that this was a subject worthy for discussion in the staff questionnaire. When posing questions for the support staff, the researcher must consider the many dimensions of each theme for discussion. Regarding 
the topic of art and sculpture in this thesis, the researcher asked for staff response to the following:

- Whether art and sculpture was a positive or negative element in the landscape?

- What sculpture/art in particular attracted attention, and why?

- Was there any difference between male and female reactions to the sculptures?

- Did any of the following play a part in the participants' enjoyment of the sculptures:

form, texture, materials, and size?

- How could the sculptures have been improved?

- Would any other forms of artwork have enriched the participants' experience of the park?

The research merit of staff questionnaires lies in their ability to provide additional experiential information allowing a greater depth of understanding regarding participant answers to be revealed. The tool of the questionnaire is highly adaptable. The researcher may wish to issue staff with more than one questionnaire, dependent upon the length and type of research project undertaken. Just as the other tools in the visual communication toolkit are employed in response to participant behaviour, the questionnaire has the capability to be responsive to the project as a whole. In the course of this thesis, themes developed in staff questionnaires during the pilot study were adapted for the comparative study with specific reference to the sites and work undertaken with, and by, participants in the comparative study. As will be seen later in this chapter, analysis of all data collected by employment of the toolkit resulted in the emergence of a number of significant contextual themes. The staff questionnaire is significant in the evolution and focus of this data collection, as it provides the researcher a midway opportunity in the project to check their intuitive observations of participant behaviour, with those who have greater experience working with the group.

\subsubsection{TOOL 7: Public exhibition}

The final tool in the visual communication toolkit is the public exhibition. Abiding by a commitment to a participatory research approach requires that the researcher to take great care when considering how they will 'end' the research (Northway, 2000). The nature of the toolkit necessitates employment over a longitudinal period, which in turn encourages 
the development of strong relationship bonds between the researcher and their participants. It was this researcher's own experience that those friendships which developed between researcher and participants at both study centres (and in particular at $\mathrm{SC} 1$ where the researcher was a familiar figure in the participants weekly routine for over four years), were highly beneficial and important to all involved. Nevertheless, a natural and obvious conclusion to the research is required and for some participants this may be a more difficult concept to deal with than for others. When considering this issue, the researcher must understand that as Northway rightly states: "it is important not to make assumptions: people with learning disabilities are not a homogenous group. Their situations, views and preferences will vary and so the implications of undertaking participatory research will vary from one individual to another" (Northway, 2000, p.33). For example, one participant at SC1 found the researcher's actual day of departure incredibly upsetting to the point where they refused to join the leaving party. Their belief that if they were not present, the researcher would not leave. Other participants, especially those younger men at SC2, were less concerned about the researcher's impending absence. It is hypothesised that this may have been as a result of their more extended existing social network, which meant departure of one individual had a lesser effect than with participants at $\mathrm{SC} 1$, in addition to the shorter length of time involved at $\mathrm{SC} 2$.

Whilst the removal of researcher presence from the lives of the participants requires careful consideration, the orchestration of a public exhibition prepares the participants for project detachment in a highly accessible and understandable manner. The public exhibition is the visible research climax for the participants. All artwork and experiences they have produced and recorded over the course of the project are considered for inclusion in the display. The public exhibition is not an exercise in academic finesse. Rather, it should be thought of as the opportunity for the researcher to facilitate the participants in taking public ownership over the dissemination of their project findings, in a manner that is comprehensible to them and their peers. The individual canvases form a focus for each participant's project experience but complementing and supplementing this may be any, or all, of the following: participant and researcher photographs, participant books (which show a developmental record of the 
research journey), written descriptions and titles for artwork, mounted drawings. In addition at SC1 and SC2 the researcher always included an explanatory poster detailing: the project's aims and objectives, the source of funding, the methodologies employed, a brief synopsis of the findings and future research suggestions.

The ethical implications of staging a public exhibition of work in which photographs depicting potentially vulnerable individuals will be displayed, calls for the researcher to consider carefully their approach. In all exhibitions at SC1 and SC2 participant names did not appear alongside their individual photographs. However, participants were often very proud of their work and in particular their individual canvases and accompanying written descriptions which they chose to autograph of their own free will. Under these circumstances, the researcher felt it was decidedly wrong to ask participants to cover up or remove their signatures, as this act would be one of disregarding great personal achievement.

The choice of venue in which to stage the exhibition is an important one. A number of considerations are suggested in deciding the location. Firstly, that the building is accessible, enabling participants and their families to visit the exhibition in their own time without worry of physical, sensory, information barriers etc. Secondly, that the venue is one regularly used by the local community. Therefore a natural audience arena for exhibition viewing is created. Thirdly, that the staff and management of the venue are sensitive and supportive of the participants and the project as a whole. In addition it is vital that the staff are briefed on the project and who should be connected for further enquiry, in the event that visitors require extra information. Fourthly, if possible, it is advised to try and attach the exhibition to an existing awareness week, arts festival etc. As a result the event will receive greater publicity and ultimately reach a larger audience than if staged in isolation. Publicity itself is the final key in selecting and constructing a successful exhibition. At SC2 the only criticism in support staff questionnaire feedback was that the level of publicity for the exhibition should have been higher. By working in conjunction with a learning disability support organisation the project will have natural dissemination potential amongst the local learning disability community. In addition the researcher should consider the local press (television, radio, newspapers), the Internet and hard copy publicity (posters, flyers etc.). 


\subsubsection{Summary}

By following the previous described guidelines laid down in this chapter, future researchers employing these techniques have a toolkit at their disposal, which is immediately and easily operational. This study evolved and applied the visual communication toolkit within the academic realm of landscape architecture. However, the author does not believe its employment is restricted to this one field. It is anticipated that the toolkit might equally and successfully put into operation in any situation where a profession, be it health, social, design etc., wishes to more meaningfully incorporate and understand the views of its learning disabled clients or community.

\subsection{Experiential findings}

The second set of significant research results, generated during qualitative analysis, are the experiential findings; the six key themes and central research premise. The researcher's unique methodological approach to qualitative analysis was previously explored in Chapter 3 under the acronym DIDEC. DIDEC analysis is the ellipsis for a five step programme which comprises: creation of a data spreadsheet, individual transcript memos, diagramming ${ }^{1}$, elicitation of key themes and central premise and comparative analysis. Within the context of this landscape research study DIDEC analysis of data generated by the toolkit, facilitated production of a series of secondary results. These are now described as the six key themes (daily life experience, communication methods, environmental choice, social experience, activity in the landscape and experiential benefits) and central research premise (limited environmental experience).

\subsubsection{THEME 1: Daily life experience}

During the first step of DIDEC analysis (the data spreadsheet) and the creation of individual transcript memos, the codes 'daily routine', 'routine patterns' and 'familiar', appeared on numerous occasions, in reference to the environmental experiences of many participants across both study centres. Exploring this further through diagramming (see

\footnotetext{
${ }^{1}$ Diagrams, produced during DIDEC analysis, exploring each of the six key themes (Images 7.4 - 7.9).
} 
Image 7.4) revealed a number of important relationships. These relationships showed key interactions between the participants' daily routine, the rules they lived by, the control (and protection) exerted on them by others (primarily family but also peers) and their associated dependency, which limited the level of independence they maintained over their life choices and daily experience. It was perceived that all participants experienced a considerable degree of dependency be it on family, carers or support staff. This dependency had positive (protection, community, familiarity and security) and negative (restriction, rules, routine, control and low self confidence) connotations. If participants chose, or wanted, to leave the security of their daily routine to experience new situations (such as visiting public spaces) they were often unprepared for, daunted by, or unrealistic in their expectations.

7.1

\section{Brian's ${ }^{2}$ depiction of himself and his friends}

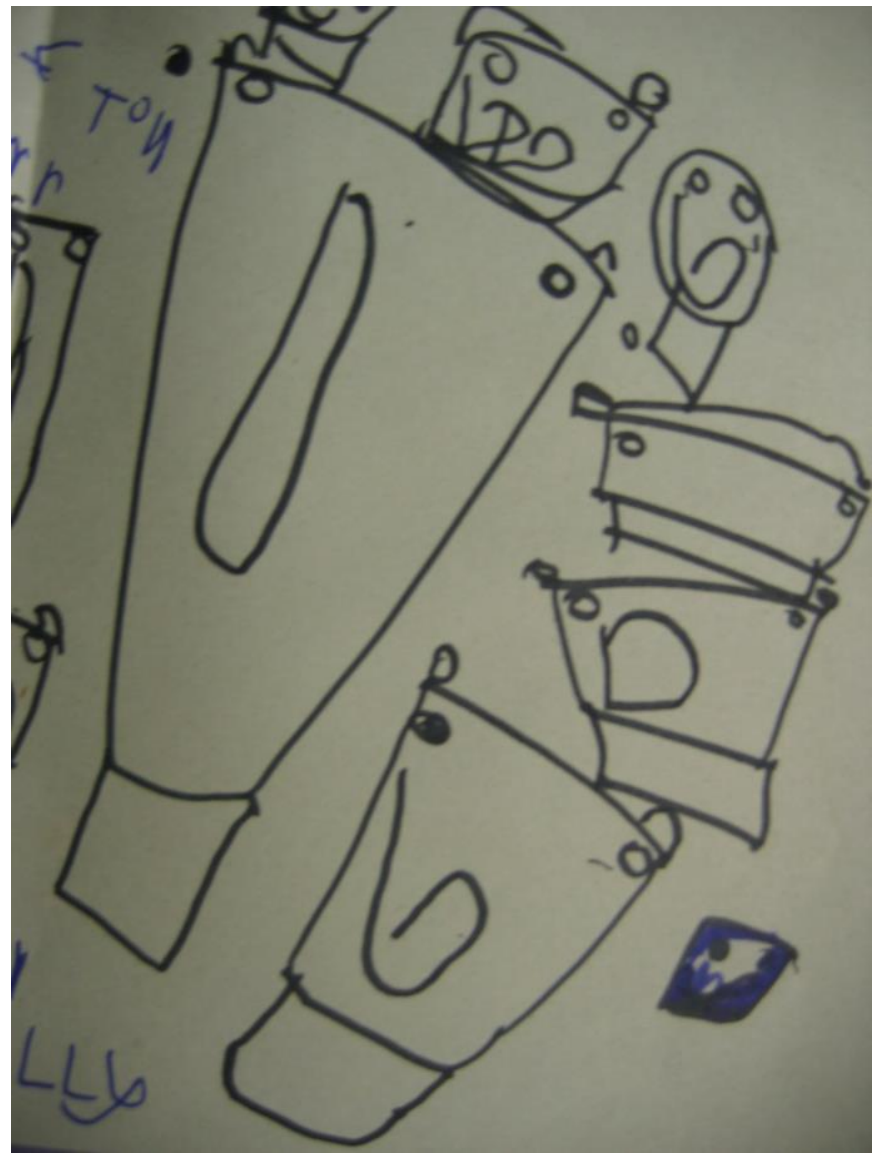

${ }^{2}$ Brian is a pseudonym. 
Evidence of a reliance upon familiar faces, and familiar places, appeared early in the project with participants choosing to photograph or illustrate their environmental experiences by way of personal portraits which contained family, support workers and (even) transport drivers (Image 7.1). Of all familiar environments experienced the one which held fundamental importance, in providing participant security, was home. As previous research has suggested, daily life experience was dominated by activities in the home environment that centred on television (McConkey et al., 1981; Atkinson, 1985; Saxby et al., 1986; Brown, 1994; Beart et al., 2001; Ryan, 2005). Outside the home environment, the weekly routine of the SC1 participants (often unchanged for years or decades) focused on attending the Day Service Centre and work placements with their learning disabled peers. As a result of attending the learning disability college, participants from the North East study centre had a greater degree of variation in daily life experience, but it was uncertain if, and how, the breadth of their life experiences would develop after they graduated from the college. Participants were curious and eager for new experiences, yet sought security in explanation of the everyday.

\subsubsection{THEME 2: Communication methods}

Through DIDEC analysis, the visual communication toolkit developed by this research was found to be of experiential importance in itself (see Image 7.5). All participants, without reliance upon verbal or written communication, could express a preference, dislike or reaction to the experience of public open space. As a result, participants experienced a number of important and emancipatory personal benefits, which included: development of knowledge, a means to break from daily routine, ownership, pride, confidence, self-advocacy and public visibility.

The act of photo novella (or auto-photography/self-directed photography), where participants controlled the cameras in order to discuss the environment as they saw it, proved particularly popular and became a powerful tool of empowerment (Wang and Burris 1994; Hurworth 2003). As in the study by Aitken and Wingate (1993) the participants chose to take many photographs of their peers (posing or caught in action shots) even if they themselves did not participate. Other popular subjects included the community transport van, and posing with signs, maps or landmarks (even if they were 
not, or could not be, read). These photographs (further explored through artwork) were chosen by participants to prove that they had actually experienced the landscape. Without these images the visits held little meaning and were unlikely to be remembered. Image 7.6, illustrates how of all communication methods utilised within the toolkit, the semistructured photo-elicitation interview generated the most mixed participant reaction. The majority of participants found being placed in an individual, focused and recorded conversation, a new and unfamiliar experience as exemplified by initial behavioural unease with participants enquiring, "when will it be over?" or, "is that it, can I go?" However, many participants did settle into the interview situation. Those who did found it enjoyable, and appreciated a rare indication of professional value being placed upon their personal opinion. A few remained concerned regarding the formality of the situation (in comparison to the informality of other communication tools). Some displayed nervousness at being placed in a position where they perceived they must answer correctly (even though no right or wrong answer was expected). For all who partook in the semi-structured interviews, photo-elicitation provided the concrete means by which oral dialogue could occur. Of the three research participants who did not partake in the interview sessions, as they had little to no verbal communication, their contribution did not go unheard. Their visual, behavioural and gestural language was exact and information laden in communicating their experiences and perceptions. In evaluating the wider implications of appropriate communication methods with people with learning disabilities, the example of the semi-structured interview demonstrates how a reliance on verbal communication alone does not facilitate participation in research, policy, practice of life. What is required is a closely woven tapestry of techniques capable of supporting the person with learning disabilities, which can accommodate for any inflexibility and fragility within one communication method, with flexibility and strength in another.

\subsubsection{THEME 3: Environmental choice}

The theme 'Environmental choice' describes the range and appeal of the different public open spaces, which become available to people with learning disabilities once they leave the security of their home environment. Through DIDEC analysis, during diagramming, environmental choice was broken down into two key categories, new environmental 
experiences and previous environmental experiences (see Image 7.6). This analytic distinction explains what drives people with learning disabilities to make the environmental choices they do. During the course of the research it was observed that participants initially favoured repetition of previous environmental experiences (places they had visited with family or carers) over the new. When presented with the choice, many chose everyday urban (primarily indoor) experiences such as going to a café or shopping.

Researcher: Do you ever come into town with your auntie and go to the Peace Gardens? Graham: No

Researcher: Where do you go?

Graham: Castle Market. We meet our cousins in town, they come down, me cousin weren't down 'til today, she were painting me cousin's bedroom.

By choosing to repeat previous environmental experiences, people with learning disabilities maintain a degree of daily or weekly routine. The journeys that join elements of this routine act as a web extending out from the home environment to reach a series of personal, familiar environmental nodes, collectively held together as the individual's total local environmental experience. As the extract above from an interview with Graham demonstrates, the participant regularly visited the city centre but only to experience one indoor environment within the context of a very structured family outing. Although Graham was born and had lived in the city of Sheffield for over 45 years, this routine remained unchanged with little variation to take in other experiences. Public open spaces such as the Peace Gardens, which lay within a short distance of Castle Market, were never added to the routine or indeed experienced on an occasional basis. It is sometimes difficult to determine whether the routine of previous environmental experiences is one dictated to the individual by others, or has been adopted by the individual as a set series of experiences with which they feel satisfied, confident and happy. However, for families and support workers abiding by a routine requires considerably less preparation and organisation than supplementing the individual's palette of existing environmental experiences with those that are new or unfamiliar.

In choosing a new environmental experience, people with learning disabilities must leave the security of the familiar to face an array of decisions as to the type of 
landscape they wish to visit and suitability of that landscape to meet their needs as an individual. Responsibility for these decisions is often shared between the individual and their parent, guardian, carer or support worker. These decisions are reliant upon prior information and significant preparation, which requires a commitment (both financial and time) from the supporter to research the practicality of the new environmental experience. Preparation for new environmental experiences includes appropriate advice on (and provision of) clothing, supply of medication, food and drink, and research regarding site facilities such as toilets, seating, physical access, admission charges and disabled parking. Designers and managers of public open spaces must also maintain awareness of how to provide and prepare for the range of potential users accessing their sites. This is an issue brought to prominence in the UK by the work of the Sensory Trust and in particular their publication Making Connections which contains advice on, "how information and interpretation are best provided, what motivates people to visit sites, how people can be encouraged to use and get involved in sites, relevant legislation and policy and aspects relating to site layout" (Sensory Trust, 2001).

When these preparations are in place, people with learning disabilities appear far less constrained in their behaviour towards the environment and are, in addition, far more welcoming of new environmental experiences in general. New environmental experiences are added to the individual's web of existing experiences. Over this they take ownership, and public open space experience as a whole becomes a familiar and positive element in their regular routine. When removed from reliance upon the security of the familiar, the people with learning disabilities involved in the research communicated no clear distinction or favouritism between urban or rural experiences. For the younger men with learning disabilities suggestion of visitation to environments that provided singular, active experiences, such as theme parks or skate parks, were seen to be the most highly anticipated and sought after. In the study, older people with learning disabilities were less likely to choose such environments, as physical activity was not always their highest priority particularly amongst the women. However, such environments did appeal on the level of instant entertainment (even in the observation of others who were actively participating) and more importantly that facilities such as toilets, places to sit and places to eat would also be present. 
In discussing the environmental choices that people with learning disabilities make we return to earlier participant work completed near the beginning of the project, and the idea of a 'park' (the word used by the researcher with people with learning disabilities to describe public open space), which remains a complex one. All individuals involved in the research had their own interpretation of this word and its associated meaning, for example from golf course to duck pond (Image 7.2). This interpretation and description continues to become more individualised and intricate as the project progresses. Through the project participants are exposed to a greater range of environmental experiences, which further challenges their existing understanding and preconceptions. In choosing new environmental experiences we all consider what we have previously enjoyed and use this as a template for what we may enjoy in future. If your previous experiences are limited, what you choose to experience tomorrow may only vary from past experiences if you are given access to information regarding the wider range of experiences on offer. Ensuring that such information is communicated in ways that are easily available to people with learning disabilities is essential in enabling them as individuals to broaden and enrich their experience of life.

\subsubsection{THEME 4: Social experience}

Parks and other open spaces provide public arenas for a range of social experiences. Visitors to parks may choose to arrive individually, in pairs, with friends, with family or in large groups. In the park environment no one individual has a greater right to use of the space than any other. Parks allow the opportunity for formalised and informal interaction. Parks create spaces and routes for accidental meetings, first time conversations and organised gatherings. Being with friends was one of the key attractions of parks for the learning disabled participants (Image 7.3). Positive social experiences in public open spaces benefit both the person with learning disabilities and society. The individual enjoys a sense of belonging and safety in the environment, and in turn society is encouraged to humanise and understand the behaviour of people with learning disabilities from a point of view of acceptance and (hopefully) inclusion (see Image 7.7). However, current park use by a number of the participants was not one of positive social experience. Instead, their clearest memories of parks, identified as predominately urban 
open spaces, was direct or indirect involvement in negative social experiences. Direct involvement pertains to situations when the individual experiences negative encounters on site, such as rejection, exclusion, bullying and hostile observation.

Indirect negative social experience describes the reaction of individuals witnessing negative behaviour by other park visitors toward the environment or members of society. The reaction is such that it instils belief in the individual that there may be personal danger in sharing that environment with others who behave in such a manner. Both direct and indirect negative social experiences contribute to, and influence how, the person with learning disabilities perceives the landscape itself.

Researcher: Ok, so in your park you could be there all day long. What's bad to have in a park, what would stop you going to parks?

Karl: All the lasses, smashing glass and cans, the mess.

Indirect and direct negative social experiences may be collectively described as antisocial behaviour. This was a theme apparent not only in the concerns of the study participants but also in the minds of the wider learning disability community. Antisocial behaviour as described by those in attendance at the 'Our Parks and Gardens' Peoples' Parliament (2006) includes: "people smoking, bad people, bullies, swearing, people messing about in the water, people throwing fireworks and motorbikes". The indirect experience of this antisocial behaviour was the creation of negative landscapes where people with learning disabilities encountered: "chewing gum on the floor, dirty toilets, grass not cut, bad walkways and pavements, dog mess, no bins, rubbish, vandalism, graffiti, not safe at night, broken swings, bad seating, dead fish and rubbish dumped in the pond". Once a landscape holds negative social and environmental connotations for the participant, they were unwilling to repeat the experience:

Researcher: And what don't you like about parks?

Warren: The swings and that.

Researcher: So why don't you like swings?

Warren: I think the parks are for the other children now.

DIDEC analysis reveals how the 'other' status, which Warren gives to young people using the park, marks the boundary line of exclusion between him and them. 
7.2

"What is a park?": SC1 participant group drawings from the introduction day, 2004.

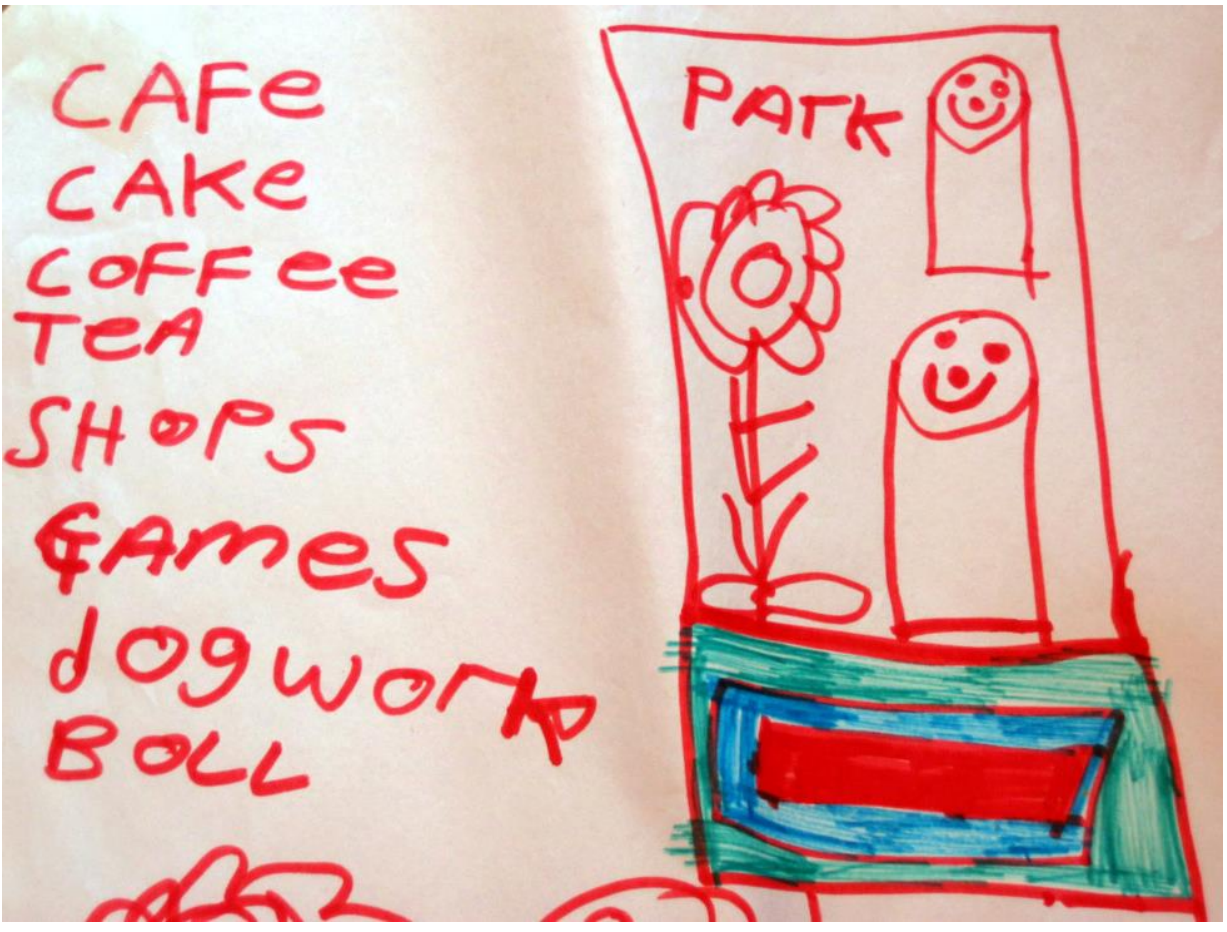

7.3

SC1 pilot study participants and staff socialising at the Yorkshire Sculpture Park.

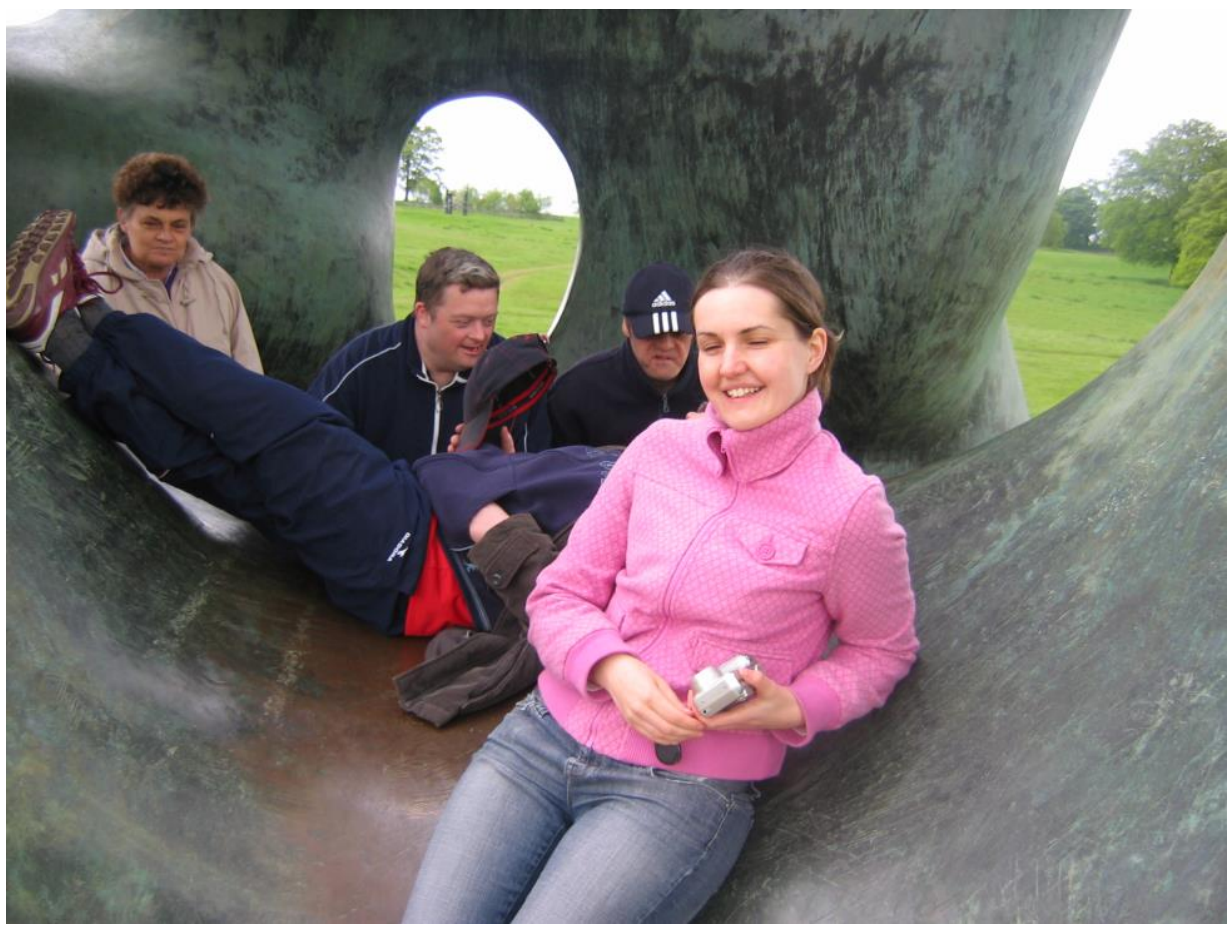


Therefore, the creation of positive social experiences is a powerful factor in encouraging more people with learning disabilities to use public open spaces. As the individual with learning disabilities ages, they build up a history of positive and negative social experiences. Their memory of the arenas in which negative experiences took place becomes increasingly static and they are less willing to undertake new experiences that might result in similar negative interactions. Facilitating positive social experiences is the responsibility of designers and managers of public open space. Research participants and learning disability attendees of the Peoples' Parliament suggested the following design and management additions: telephones in parks (where they could get help and advice), houses for people with learning disabilities around the edge of the park (which were safe, with great views, from where the park could be easily accessed), community cafés (where they could meet people), more places to sit down (where they could rest and observe others if they didn't want to be actively involved), more rubbish bins (that might dissuade other park users from littering) and better lighting (to enhance security, visibility and the natural length of day for which parks could be safely used).

\subsubsection{THEME 5: Activity in the landscape}

The fifth theme 'Activity in the landscape' is closely linked to both 'Social experience' and 'Environmental choice'. DIDEC analytic exploration of this theme revealed how the pattern and type of landscape activity undertaken by people with learning disabilities is initially determined by previous social experiences (inclusion/exclusion, positive/negative) and by preparations made in advance of new activities (the responsibility for which lies with the individual and/or their supporter) (see Image 7.8). If past social experiences in the landscape have been positive, and the individual /supporter is adequately prepared and informed regarding the environment and the opportunities for activity it has to offer, the choice of activity in the landscape is then influenced by personal preference, age and to a lesser degree gender.

Participants in the study varied greatly in their preferred choice of activities. Although not a rule, in general the more extrovert, younger men were drawn to physical activities such as: swimming (an activity imagined during interview), "hard play" (the name given by one participant to activities that included play fighting, climbing and 
running), skateboarding, hedge-laying, tree felling, dry-stone walling and the construction of bird and bat boxes (the last four activities were previously undertaken with BTCV). Physical activities, such as those listed, greatly benefit the individual providing the occasion to be physically challenged, to engage in problem solving, to have physical contact with the environment and other people, to encourage freedom of behaviour and the idea of independence, to legitimise the worth of adult play and to promote personal and environmental exploration. Below, Graham although one of the slightly older male participants, identifies the opportunity for physical activity as being his favourite use of open spaces:

Researcher: Great, now just two more questions, what was the best thing about the park? Graham: Running about.

In contrast the more introvert, older and generally female participants prefer to engage in observational activities. The size and careful design of parks should allow discreet yet effective division between areas where loud and active pursuits take place, and spaces of sanctuary. In these spaces individuals find escapism from people, sound and stimulus and have appreciation of the environment " $\cos$ its quiet" as one participant commented. By partaking in quiet, observational activities individuals have the opportunity to overcome initial wariness regarding the environment and, if they choose, progress to active participation.

Activity in the landscape is not only driven by the desires of the individual but is assisted by the design of the environment and the facilities there present. A 'facility' is defined as "an opportunity, the equipment, or the resources for doing something" (Thompson (Ed.), 1995). The findings of this research indicate that onsite facilities may be subdivided into three distinct categories: facilities that enable access, facilities that inform and facilities that entertain. Facilities that enable access comprise those additions to the landscape that aid all visitors to use the space as equals. Participants' and the audience of the Peoples' Parliament cited the most important of these being:

- More staff

- Accessible toilets (more toilets with facilities for people with learning disabilities) 
- Flexible seating

- More places to sit down

- Clear/better footpaths (interestingly the word 'ramp' was rarely if ever used)

- Obvious routes

- More rubbish bins (clean and tidy parks)

- Good lighting

Facilities that provide information allow the visitor to make choices about their individual landscape experience and the activities they may undertake. Information is an important consideration prior to the site visit, on arrival and throughout the excursion (again previously identified by the Sensory Trust). Information should be provided in differently accessible formats in order that it may be received and understood by the majority not the minority of the population. The support staff at SC1, where possible, utilised websites as their primary information source prior to the site visits. The most successful websites were those that contained both written descriptions and pictorial aids (that might be shared with the participants), and contact details such as email addresses/telephone numbers in order that site staff might be made aware in advance of the group's upcoming visit and requirements. Once onsite, the need for information was driven by the participants. Individuals were always keen to collect leaflets, yet their importance lay in being visible, physical mementos rather than information to shape their experience of the day. Suggestions of more effective onsite information include: simpler maps, legible journey markers and more pictorial based signage.

The third and final subdivision of landscape facilities refers to those that provide entertainment. 'Being entertained' appeared a more important issue, within landscape activity, for the younger generation of participants. Knowing what you could 'do' once you arrived at a site reflected their preference for physical activity over observational participation. 'Doing' for these participants meant skateboarding, risking the rides at funfairs, going to music festivals, getting soaked in water fountains and engaging actively with the landscape through physical work (such as that experienced with BTCV). The advertisement of such entertainment had the additional social importance of drawing other members of the public to the site. Parks and open spaces that provide an arena for 
large social gatherings, such as those that might occur at a festival, are exciting places to be for all visitors. Of suggested importance is the annual scheduling and accessible advertisement of such events in order to attract more (and younger) people with learning disabilities to use public open spaces on a regular basis.

\subsubsection{THEME 6: Experiential benefits}

The theme of experiential benefits was the final of the six themes to emerge from DIDEC analysis of the words, art, photographs and actions of the participants (see Image 7.9). This theme does not sit as a static observation, but rather develops as people with learning disabilities experience more and varied types of landscape which fine tune their personal tastes and preferences. Being 'out and about' was a phrase commonly used by the participants to describe their visits to open spaces during the project. This in itself had positive connotations and benefits. It described experimentation and new personal experiences away from the familiar home environment. Closely aligned to the concept of new personal experiences is that of personal discovery. This experiential benefit was one communicated by many of the participants, evoked through joyful behaviour and comments such as, "my type", "get to know", "good for you", "spread arms", and "acting out". From the analysis of the photographic cues that generated these comments, what is revealed is a shared sense of developing ownership and ease with public open space. This is most noticeable when manifest physically, as in the observation of the SC1 staff member who saw participants "spread arms". This simple phrase pertains to participants being freed from the restraints of everyday rules and routines to use their bodies and the space in which they stood without restriction or fear of reprimand. For some participants personal discovery was taken a step further, whereby confidence in the space led to true behavioural freedom and development of individual characterisation, with one participant declaring at the Alnwick Garden: "I'm a devil", and another responding to sculptural stimuli at the Yorkshire Sculpture Park with the words: "I'm an Indian".

Environmental rewards gained through participation in the experience of public open space are broken down into three subcategories, those that are physical, ephemeral and associated or experiential. Physical environmental rewards are those that come as a result of direct contact with the environment, predominantly through the sense of touch. 
Physical interaction with the landscape may be wholly active such as climbing, jumping and running, or rather more passive such as walking, sitting or stroking a surface. Ephemeral rewards are less direct than those driven by physical contact, instead they refer to the pleasure received by way of associated memory. A key example of an ephemeral environmental reward is found in the experiences of Graham at the Peace Gardens, who seeks and finds familiarity and beauty in a weather vane and his linked affection for plastic windmills in his back garden at home. Below is an extract from Graham's interview illustrating the ephemeral reward he gains from these objects:

Researcher: What are the ones at home that you've got?

Graham: Windmills

Researcher: And what colours are they?

Graham: All different colours, that one me cousin Julie bought me it's all red. When the sun shines on it, it leaves a pattern on the fence, it makes a pattern when it's going round

Researcher: Oh that's brilliant, so have you got these all in your back garden?

Graham: Yes

Researcher: So does it make patterns when it's sunny, or when it's cloudy?

Graham: Sunny

Researcher: And what else do you like about the windmills?

Graham: The way they move, the way they go fast and then slow down

Researcher: What makes them go faster?

Graham: The wind

Researcher: So when you made, because we started making a little one, erm would you like to make a bigger one?

Graham: Yeah

Researcher: And would you have it in your back garden or put it here?

Graham: Have it in our back garden.

The third category of environmental rewards, are those that are experientially driven. Whilst these may be gained through physical contact or ephemeral encounters they generally refer to an interactive situation which produces a change in the individual's behaviour or attitude towards the landscape. A fieldwork example which generated a number of experiential rewards for one participant is found in the coastal encounters of Warren at SC2. At the beginning of the project Warren's behaviour and attitude towards rural, and particularly seashore, environments was one of detachment and dislike. As Warren progressed through the project he was provided with the opportunity to challenge his preconceptions of these environments through interaction. His cumulative experiences of these spaces altered his original attitude toward them, and he was able to begin the 
process of accessing personal rewards from the environment. Personal rewards that Warren gained through these experiences include: ownership, happiness, relaxation, excitement, freedom, self-expression, pride, awareness of surroundings, group solidarity, confidence, and independence.

\subsubsection{Diagramming the six key themes}

Over the page may be seen six hand crafted diagrams, produced with DIDEC analysis, which link relationships between categories pertaining to each of the six key themes. 
7.4 Diagramming 'Daily life experience'.

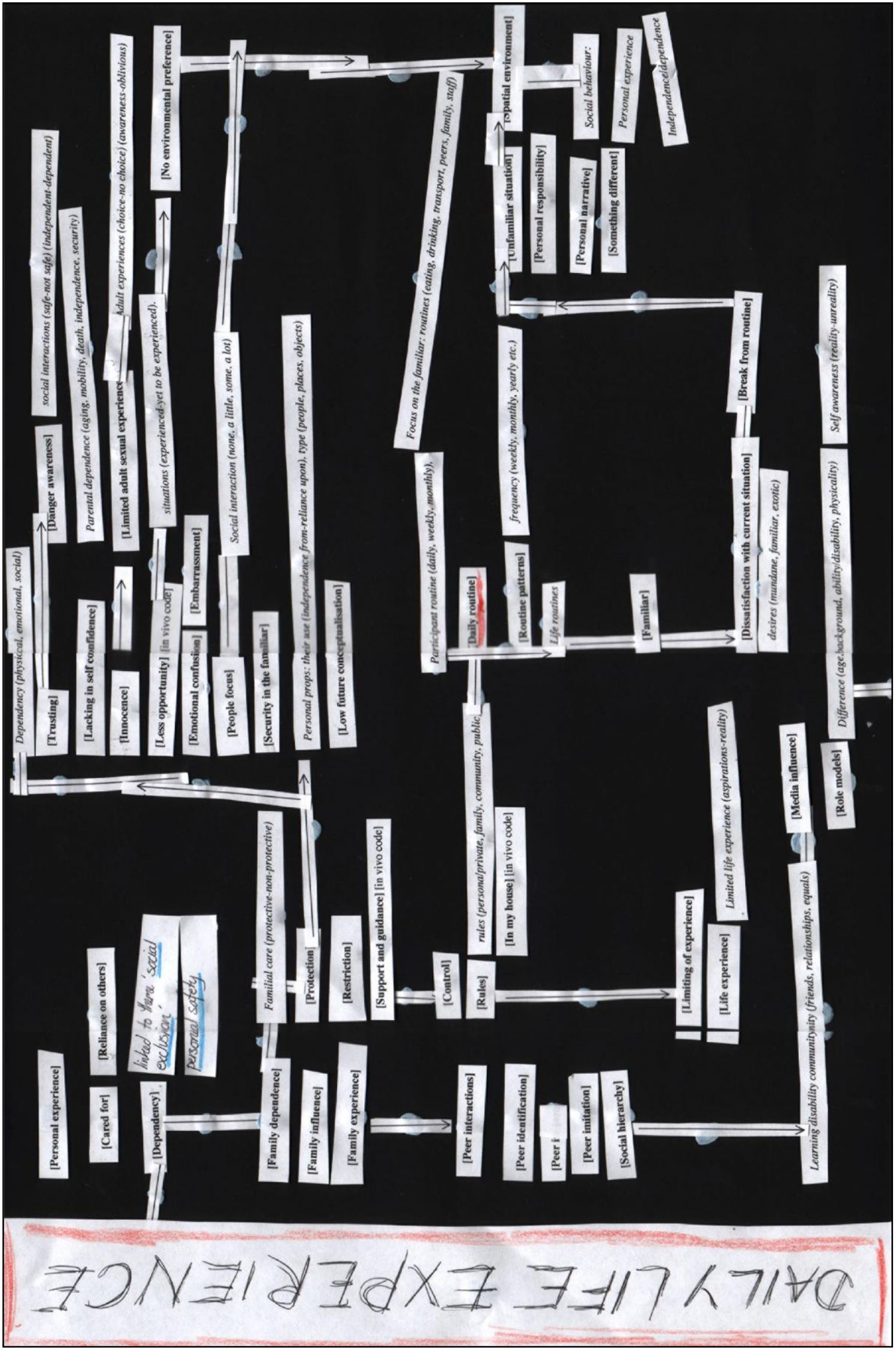


7.5 Diagramming 'Communication methods'.

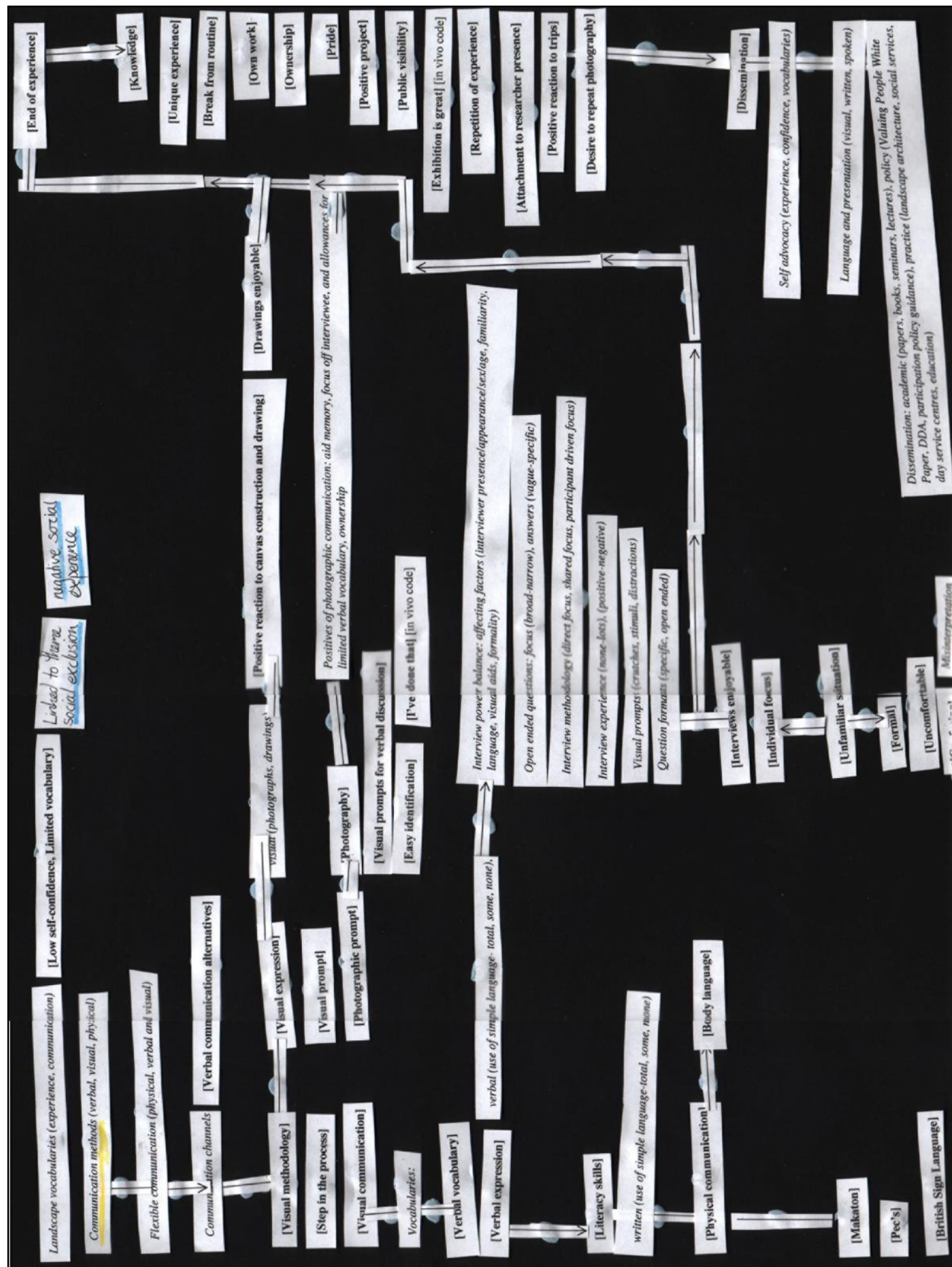

\section{SOOHL ZW NOILAINAWWNOD}




\subsection{Diagramming 'Environmental choice'.}

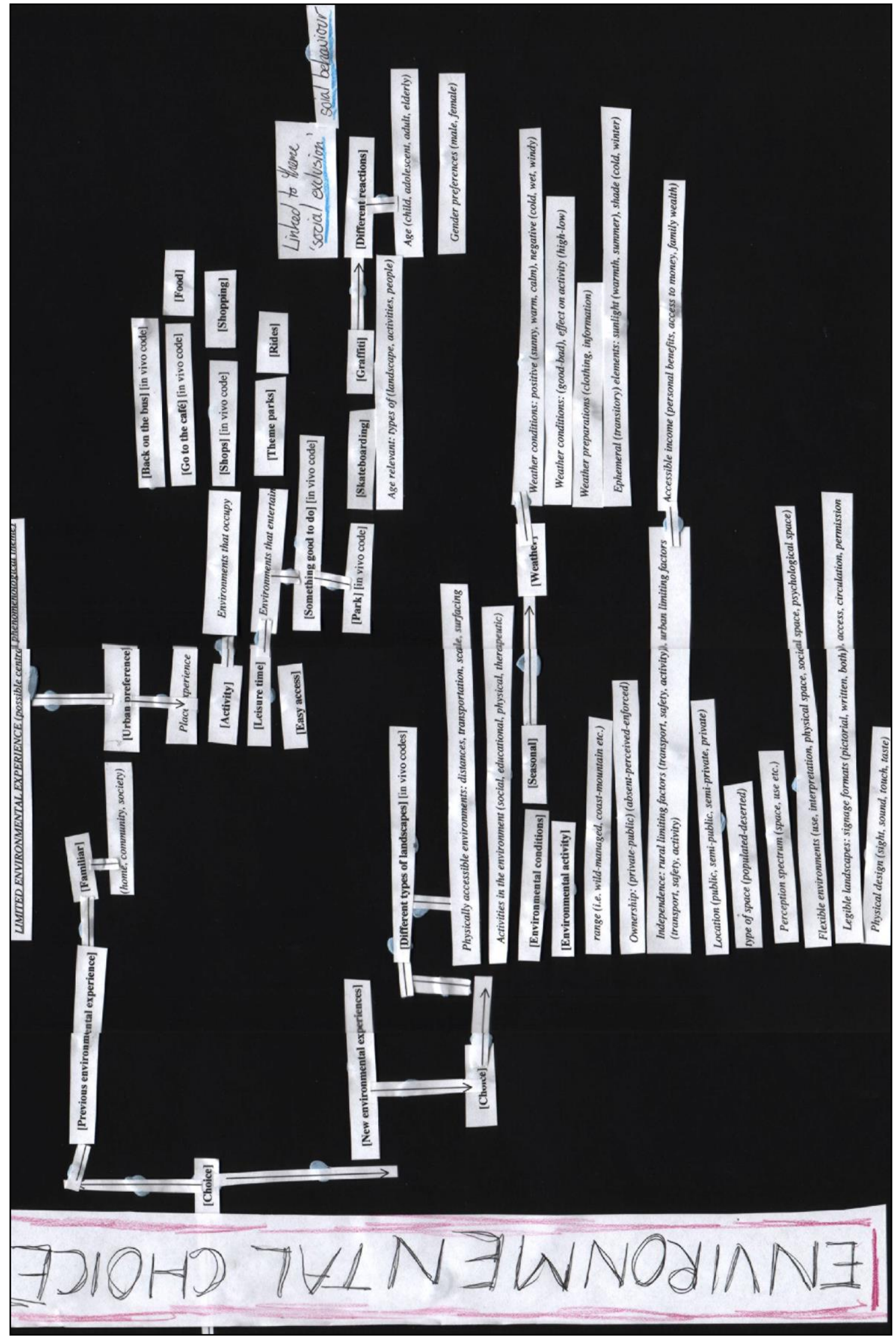




\subsection{Diagramming 'Social experience'.}

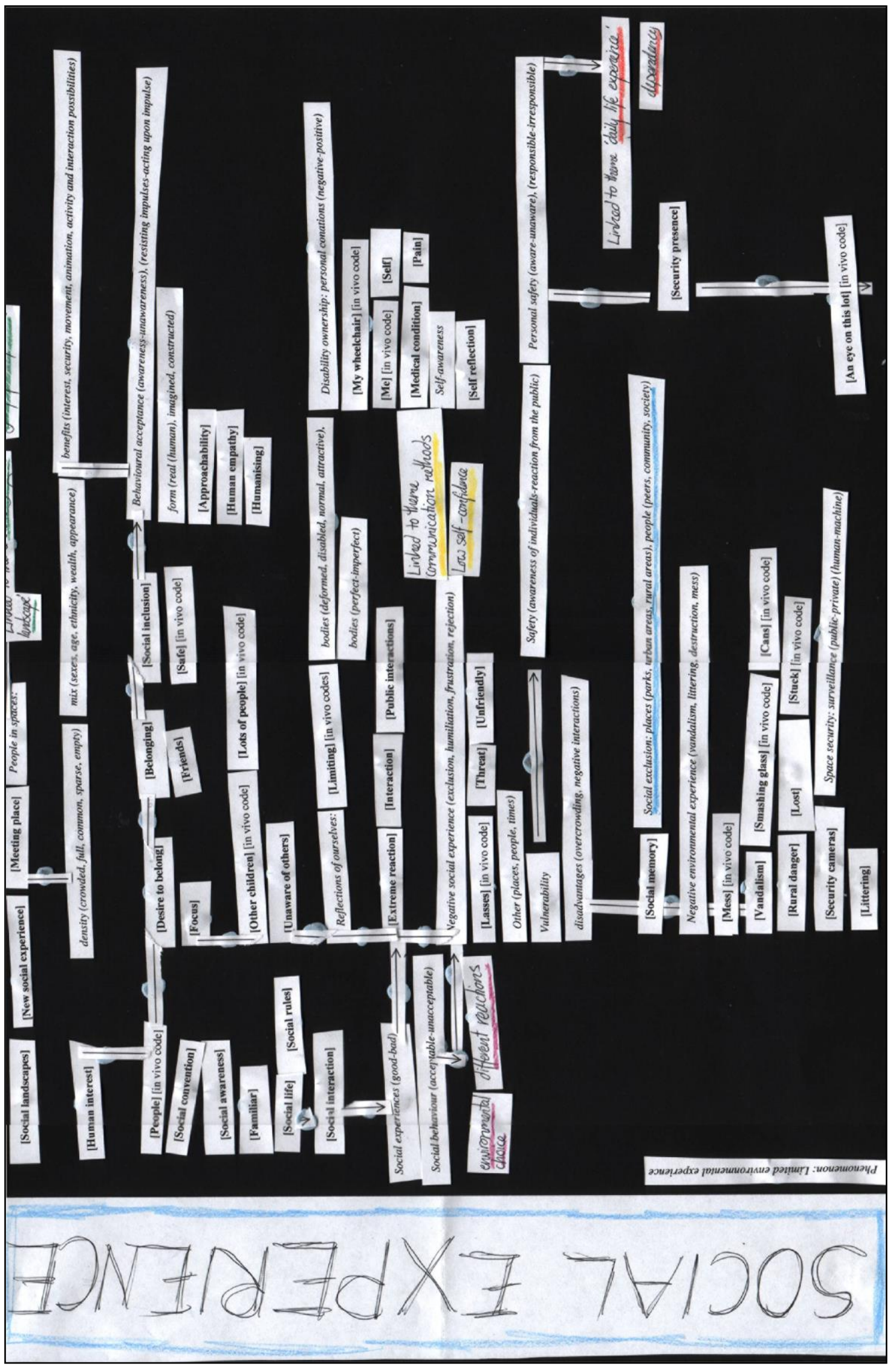


7.8 Diagramming 'Activity in the landscape'.

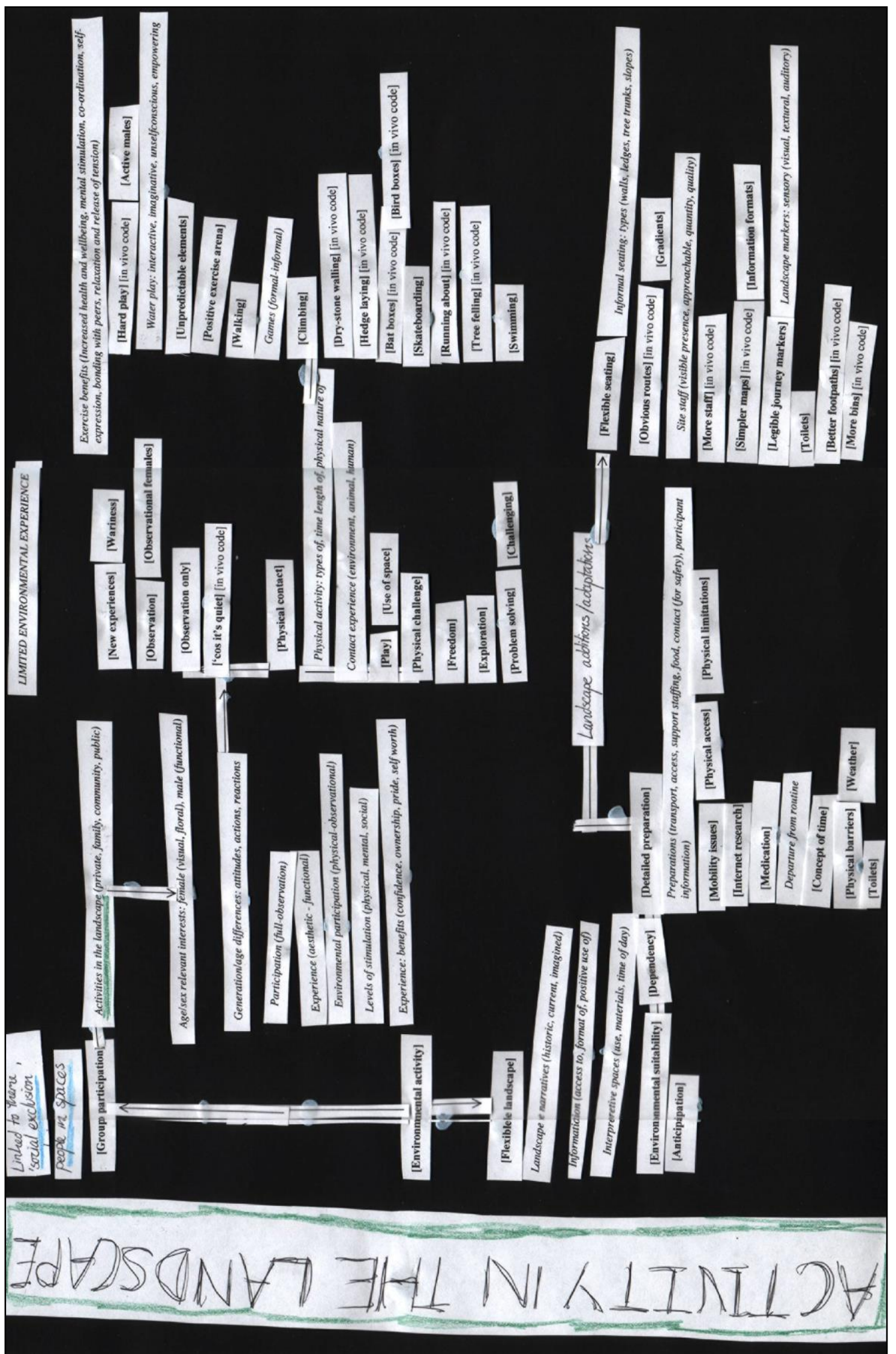


7.9 Diagramming 'Experiential benefits'

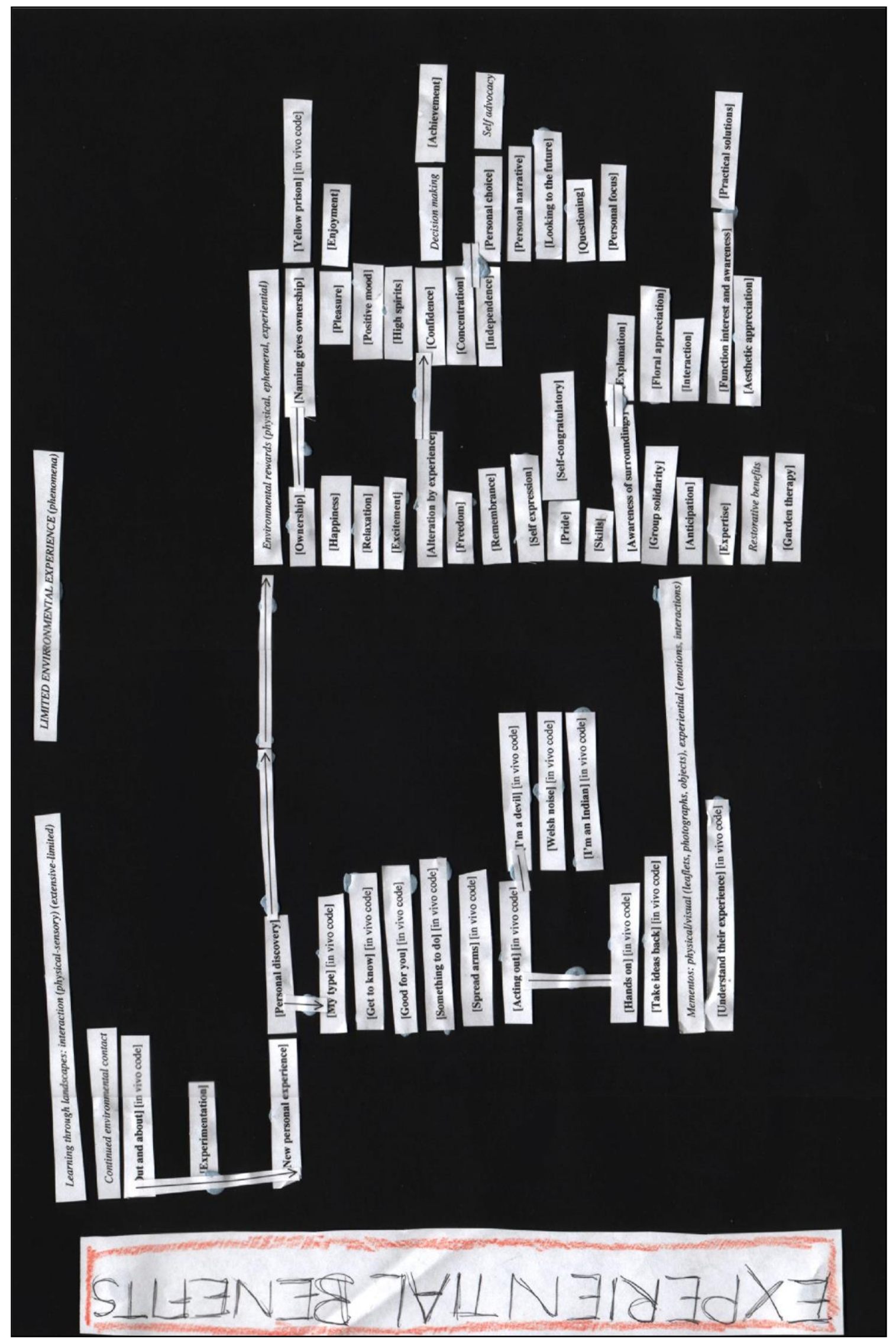




\subsubsection{CENTRAL PREMISE: Limited environmental experience}

The six key themes, daily life experience, communication methods, environmental choice, social experience, activity in the landscape and experiential benefits, are interactive factors in the central premise of the research, which is revealed to be limited environmental experience (Diagram 7.10). Limited environmental experience explains the current (but not unchangeable) situation of the study participants, and has implications for the wider learning disability population. During the course of the research it became increasingly apparent that although the initial project design had been to expose participants to a range of public open spaces both familiar and unfamiliar, the majority of participants had little or no previous open space experience and therefore most site visits were on unfamiliar territory. So why do people with learning disabilities have limited environmental experience? Well, this can be explained by way of interaction between the six key themes, through the negative cycle of 7.10. Diagrammatically this is shown by way of the cycle of red arrows.

We begin with theme of daily life experience. The current routine of the participants' daily life experience is primarily restricted to assisted transference between indoor environments such as the home, Day Service Centre and Further Education College. This routine does not include regular exposure to parks or other public open spaces. Breaking from this daily routine (sometimes constructed over decades) can present a stressful experience for both the person with learning disabilities and their family, personal assistant/support worker/carer. So what key factor can aid or hinder the transition for the person with learning disabilities to expand their daily or weekly routine to include experience of public open space?

The primary factor is communication. Use of accessible communication methods facilitate a stream of information to flow between parties in order that decisions are taken and choices made. The term 'parties' refers to the various organisations and individuals who are involved in this decision making process. This might include: the person with learning disabilities, their parent or guardian, their support worker and support agency, the local council department responsible for public open spaces and the private owner/charity of certain parks and gardens (such as English Heritage, The National Trust, The Alnwick Garden Trust etc.). 


\subsection{0}

Understanding 'limited environmental experience' and the potential for 'increased environmental experience'.

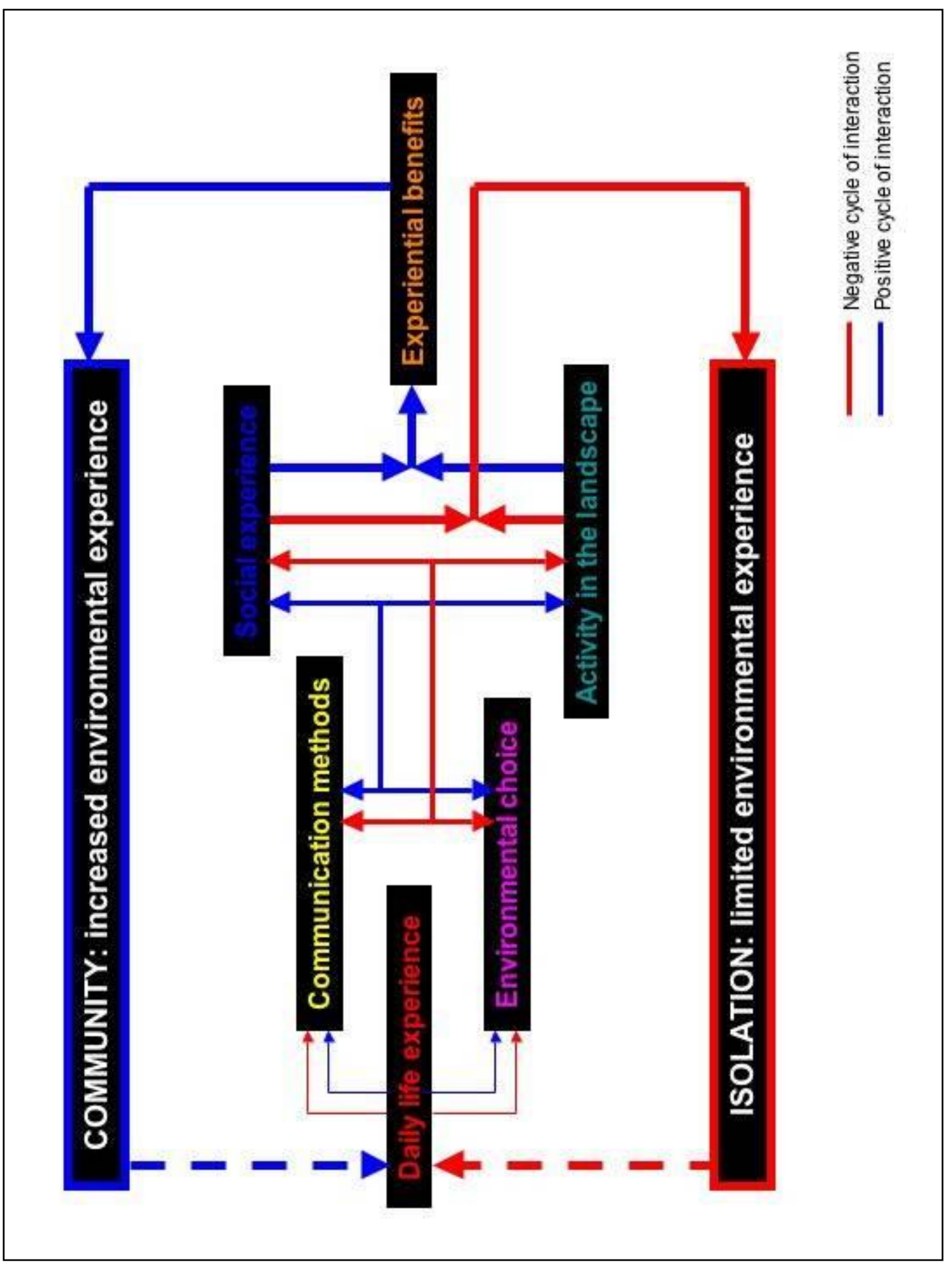


The present situation is one whereby the person with learning disabilities does not access information regarding the range of environmental experiences available to them as a result of inappropriate communication methods. Similarly, even if they make a choice they may be unable to voice their preference as those parties who facilitate their environmental experience are unaccustomed to participating in discussion which may rely on alternative communication methods (such as those outlined in the visual communication toolkit) and a greater commitment of time from the individual and/or organisation.

If we make the positive assumption that people with learning disabilities have some (if even a little) previous experience of public open spaces, and have access to means of communication which enables them to voice their opinions, why are they not making the environmental choice to extend their experience to include landscapes with which they are unfamiliar? Why are they choosing to repeat past experiences? The reason (and here we begin to see a cycle developing) is that familiar landscapes, which are part of the routine, are far easier (and safer) to conceptualise than unfamiliar landscapes which may introduce the individual to a whole new set of uncertainties regarding personal behaviour, preparation, activities, access, facilities, other users etc. For individuals who currently live a life of relative dependency, to independently take responsibility for such a decision may be beyond their control.

The social experience of public open spaces is also important in discouraging or encouraging people with learning disabilities to continue to participate in visitation to such places. Even if a space is familiar and has become part of a person's daily or weekly routine, negative social encounters may result in the individual becoming uncomfortable when visiting the space. Where a severe negative social experience has occurred, such as bullying, the individual may refuse to continue to use the space or experience similar spaces as they perceive them to be potential sites of comparable danger. At this point the negative cycle of limited environmental experience is enforced; individuals seek safety in their daily routine and remove themselves from the dialogue of new environmental choice.

As we progress through the cycle of interrelated experiential themes (Image 7.10), the impact each theme has upon the next intensifies due to the legacy of experiences that 
precedes it. By the time we reach activity in the landscape the individual to whom the situation pertains is set far down the path of either negative or positive interactions which greatly influence the activities in which they will participate. However, other factors do come into effect, such as age, health, personality and gender, and the negative cycle may still be broken at this point if the individual engages in positive activities be it observational or physically interactive. Parks and open spaces may encourage positive activity through responsive, inclusive design that takes account of individual needs.

If a person with learning disabilities does not experience public open spaces as part of their daily life experience (weekly routine), cannot communicate on an equal level to make new environmental choices, has only negative social experiences and does not participate in activity in the landscape they will not gain the experiential benefits which such spaces can provide. They are caught in a cycle of limited environmental experience that is only reinforced as they age. However, Image 7.10 does not only show how the six key themes interact to produce the current situation of the participants' limited environmental experience, but also that a positive outcome can occur; that of increased environmental experience (depicted through the cycle of blue arrows). Increased environmental experience sees individuals participating in the public open space on an equal level with others, as included and active members of the community. For this to occur, within the remit of the research findings, the following must happen:

- Visits to public open spaces become a regular feature in the daily life experience of people with learning disabilities.

- The families/guardians of people with learning disabilities, support agencies and owners/managers/designers/planners of public open space adopt visual and other alternative communication methods to facilitate access to information, discussion and decision making for the individual.

- Individuals are supported and encouraged to make new environmental choices and extend their collective public open space experience.

- Designers and planners of public open spaces are sensitive to the social needs of people with learning disabilities and create spaces where safe, positive social interactions occur (a key feature of safety being the presence of staff on site). 
- Designers and planners of public open spaces actively involve people with learning disabilities in the design process to discover how they would choose to use a site and the types of activities they wish to engage in.

- Finally, that the experiential benefits of public open spaces are not undervalued due to lack of a tangible nature. We are only beginning to understand what potential benefits people with learning disabilities may gain by using public open spaces. Up until recently little has been planned or designed for this to occur. Our view of what those experiential benefits should or might be is just that, our view. We as professionals and researchers have rarely asked or applied the means to ask, and our responsibility to do so is long overdue.

\subsection{Conclusion}

In this chapter we have seen the culmination of data collection and DIDEC analysis through the production of two sets of significant results. The visual communication toolkit (the primary result) holds within its cache, seven participation tools: informed consent, site visit, drawing workshop, individual canvas workshop, photo-elicitation interview, staff questionnaire and the public exhibition. It has been shown how each of these tools functions, and is adaptable, as an individual means to elicit experiential environmental information. In addition we have seen that when these tools are applied together and in sequence, the previously hidden landscape experiences of people with learning disabilities are made visible and understandable to design professionals, alive with startling detail and focus. The second set of significant results come as a consequence of the primary; the six key experiential themes and central research premise. We have seen how employment of the toolkit results in production of a large quantity of participant produced/related landscape information. When this was qualitatively analysed (using DIDEC) six experiential themes were revealed that have the capability of producing a negative or positive cyclical condition for the participant with learning disabilities. These themes are: daily life experience, communication methods, environmental choice, social experience, activity in the landscape and experiential benefits. In general, most participants are currently caught in a negative situation whereby their existing and future prospect is one of limited environment experience. 
However, the results show that it possible to break this negative cycle (with the aid of the visual communication toolkit and other factors such as political will) to facilitate progress along a positive path to increased environmental experience. If this path is followed, then the individual is able to obtain a range of personal benefits from his or her environmental experiences and is further encouraged to maintain contact with his or her local public spaces.

The aim of the research was to produce a means by which the participation of people with learning disabilities in the experience of public open space might be better understood. This has been achieved, although the research has obvious limitations. Primarily as a result of being a longitudinal qualitative study it is small scale, and therefore the results are subjective and not quantifiable. However, with little other information available in this area this study provides a jumping off point for future research. In the final chapter of this thesis the author will conclude as to the success and relevance of the research, its potential contribution to the development of the field of landscape architecture, how people with learning disabilities might benefit from the visual communication toolkit in other spheres of participation and decision making, and its future application beyond the research arena of its current employment. 


\section{Chapter 8}

\section{Conclusion}

\section{"The benefits of green and grey - an opportunity to reverse exclusion"}

\subsection{Introduction}

This study set out to answer the question: "How may we better understand the public open space experience of people with learning disabilities?" This is an important question as it seeks to tackle the largely ignored issue of significant social exclusion in our shared exterior spaces. Previously, people with learning disabilities have been absent from both architecture, as identified by Imrie and Hal (2001) and landscape design consultation (let alone participation) due to the incorrect assumption by professionals and researchers alike that their views are too difficult to extract, as espoused by Seeland and Nicolè (2006). This exclusion extends beyond the field of architectural studies, where to date people with learning disabilities suffer from a general legacy of under-representation within the social sciences (Gleeson, 1999; Hall, 2004).

\subsection{Research response}

The researcher's reply to these misplaced beliefs and exclusionary practices was to work in partnership with people with learning disabilities to produce three research outputs (a visual communication toolkit, new approach to qualitative analysis (DIDEC) and set of experiential findings) that facilitate understanding of the participation of people with learning disabilities in the experience of public open space. The research implications of these three outputs are now discussed.

\subsubsection{Visual communication toolkit}

The visual communication toolkit removes plausibility from previous excuses (as outlined above), which seek to avoid the inclusion of the learning disability community within participatory design and planning practice. It comprises seven stages: informed consent, site visit, drawing workshops, individual canvas workshop, photo-elicitation 
interviews, staff questionnaire and public exhibition. In addition to being an effective means of landscape participation, the toolkit is doubly valuable as an implement of social empowerment. Whilst Valuing People (2001) chose to disregard the role that exterior environments, such as parks, have to play in enriching the lives of people with learning disabilities, this research maintains that use of the communication toolkit within this context will greatly contribute towards Valuing People's four defining principles of rights, independence, choice and inclusion. This is achieved in the following manner:

- The toolkit facilitates the right people with learning disabilities have to be involved in the creation of public open spaces that meet their needs.

- The toolkit encourages independence through dialogue which utilises appropriate communication methods regarding personal experiences and future preferences.

- The toolkit enables people with learning disabilities to make choices as to the type of public open spaces which best suit their requirements and interests.

- The toolkit promotes inclusion by providing planners and designers of public open space with methods to involve people with learning disabilities in the decision making process.

When employed with the necessary cooperation of learning disability organisations, consented access to their members, support of their volunteers, and use of material resources, this toolkit then becomes a powerful instrument of landscape participation. The toolkit's natural siting is as an activation and inclusion device for people with learning disabilities within the arena of public debate. There, through the adoption of alternative and appropriate communication methods, it breaks down some of the more long-standing criticisms of communicative approaches (particularly in planning practice), by leveling the discourse playing field and encouraging all stakeholders to discuss and exchange information by means more inclusive to all.

\subsubsection{DIDEC analysis}

In addition to the visual communication toolkit, the study also contributes to current knowledge by means of two further research products. Chapter 3 told the story of the study's novel analysis programme (DIDEC), from its theoretical foundations through subsequent evolution into application. DIDEC, applies a combination approach to 
analysis and comprises a five phase series of data spreadsheet, individual transcript memos, diagramming, elicitation of key themes and central premise and comparative analysis. DIDEC enables thorough and inclusive analysis of data from a wide range of sources, including participant artwork, researcher observations, literature, secondary observations (by support staff), interview transcripts and photographs. The clear structure of DIDEC suggests its suitable application as an approach to analysis more widely in qualitative research. In particular, the researcher believes that the cross-referencing (between the visual and written data) that occurs within DIDEC provides a truly rich phenomenologically driven means by which to gain a more truthful understanding of those experiences which we do not have personal familiarity with or reference to. Importantly, it is through this process that access (when it is consented to) is obtained into the unexplored worlds of those who have been previously neglected or sidelined by society. Later in this chapter, the researcher discusses other underrepresented communities for whom the visual communication toolkit and approach to analysis might also prove potent in encouraging emancipation.

\subsubsection{Experiential findings}

The final research product to be drawn upon in this conclusion is the set of experiential results elicited through use of DIDEC (Chapter 7, Toolkit and Findings). Whilst these findings are contextually generated by the visual communication toolkit, they have the capability to provide significant insight into the place perception of people with learning disabilities. These findings comprise six key themes, daily life experience, communication methods, environmental choice, social experience, activity in the landscape and experiential benefits, which interact to result in the central research premise of the existing limited environmental experience of people with learning disabilities. In this final chapter the researcher looks to advance this current negative situation and begins with the tag line "The benefits of green and grey - an opportunity to reverse exclusion”. Green and grey refers to the extremes of the public open space spectrum, and everything in between. Traditional images of open spaces are represented by the 'green': parks lush with vegetation, complete with leafy trees, rich lawns and borders of many coloured flowers. The 'grey': bears witness to the more modern and 
urban, those spaces that are hard surfaced, three-dimensional patchworks of many materials, highly designed, highly monitored, reflecting, responding and interacting with the built forms that they surround. And then, the 'in betweens': the personal, small spaces which contain both elements soft and hard, old and new and which exist in various states of care and neglect. As foreseen by Urban Green Spaces Taskforce (2002), all these spaces have the potential to reverse social exclusion and promote inclusion. However, in reality this can only occur when we truly understand why people with learning disabilities are currently excluded from using public open spaces, and what would encourage them to use them in future. The communication toolkit enables this conversation to take place by identifying six areas (the key themes) for change.

Within these experiential findings, use of appropriate communication methods are identified as being central to empowering people within learning disabilities to engage with, be heard and effect change. Earlier in this thesis, the researcher explored how the current professional culture of architects and landscape architects has become established, with particular reference to the writings of Habraken (2005). In addition, through the work of Turner (1976), we have seen how existing power dynamics between governance, professionals and the community have segregated one sector from another. This separation of stakeholders (including people with learning disabilities) and professionals is reinforced by dominance of inappropriate communication methods, and the supposition that the general populace know less about the everyday environments that they encounter, than those who hold a professional position. This second claim is a clear fallacy and as Habraken states, "Environmental knowledge is not the privileged expertise of any profession, it is based on the common experience of a people" (Habraken, 2005, p.63). Therefore, is communication the answer? One argument against the rise of communicative approaches (predominantly in the field of planning) has been that by merely purporting to enter into dialogue with stakeholders, professionals are not addressing the issue of how to extract pertinent information (Tewdwr-Jones and Allmendinger, 1998). The experiential findings of this research, where appropriate communication methods were identified, modified and employed, tackle this argument at its practical foundations. By aligning individual (and in this case visual) communication methods with individual needs, the experiences and views of one of our most 
marginalised communities has become visible with no excuse for exclusion. This conclusion is further explored later in this chapter when the researcher asks (within the remit of operational considerations) whether being able to talk freely with one another, and be understood, is enough? Or can we identify restrictions outside direct relations?

The theme social experience was critical to many of this study's participants in determining their ongoing participation with public open spaces. Negative social experiences (such as bullying or exclusion) resulted in participant awareness (particularly in the younger men) of 'difference'. In order to be accepted by society, disabled people often find themselves attempting to adopt 'non-disabled' behaviour (such as some of the female participants in Hansen's 2002 study). The learning disability participants in this study were not all as self-aware as those in Hansen's work, therefore self-identification of bodily appearance or behavioural difference was not as apparent as 'feelings' of confused rejection. Hansen and Philo (2007), have suggested an alternative to continuing to stress the difficulties disabled people face struggling to do things 'normally' in a non-disabled world. Instead they write that we should consider "the simple, wholly unexceptional normality of doing things differently, and acknowledging, tolerating and maybe even (cautiously) celebrating the many and hugely varied ways in which things can be done" (Hansen \& Philo, 2007, p.502). The experiences of the participants in this study demonstrate a journey for many from nervous, inhibited behaviour towards a joyful acceptance (and even celebration) of personal identity (which occurred most prominently in the stories of Warren and Nathalie). This occurred in public open spaces. By celebrating an individual's way of self-expression as part of a spectrum of everyday behaviour (of which we are all a part) people with learning disabilities have the opportunity to become confident in their self worth.

Providing environments in which people may be free to behave naturally, means providing environments that accommodate a range of behaviour. As this study showed, with a relatively small group of participants, this can mean anything from wide-open spaces at one end of the spectrum, to small, protected, personal spaces at the other. We have witnessed through exploration of the theme environmental choice in Chapter 7, how exposure to an increased number of parks and public spaces enables individuals to tailor their environmental preferences. Therefore, in concurrence with Parr (2007) the 
researcher would suggest a governmental commitment to maintaining and creating a diversity of public spaces, so that "More generally, and in recognition that not all people may easily embody versions of active citizenship, socially inclusive cities should support a range of green spaces for varied community use" (Parr, 2007, p.558).

The process of fieldwork undertaken in this study revealed that people with learning disabilities gain many experiential benefits from utilising public open spaces. However, the study primarily addressed only those personal benefits that were obtained through experience by visitation. The SC2 participants were alone in experiencing the direct transformation of an environment as a result of their actions, which occurred just once, at Whitley Chapel Wetlands. Overall, the study participants' contribution was therefore principally one of knowledge (in the realms of research, policy and practice), for which they are rightly entitled to feel pride and ownership. The benefit of their unique understanding was however rarely, if ever, actualised through either physical and/or practical change to the environments they encountered. In her work Hester Parr has observed people with mental health problems undertaking restoration of public open spaces, and has stated that this provides a means to enable "new versions of social citizenship relevant to people traditionally marginalised in mainstream society" (Parr, 2007, p.540). Where people with learning disabilities are given the opportunity to make similar contributions, which benefit the wider community, there is no reason to suppose that this should not also be the case. At Whitley Chapel Wetlands, the contribution of the participants (through various conservation projects) was again segregated from the daily life of the community by being located on a remote, private piece of land. In addition the participants were not engaged on the conservation project as paid employees, but as student volunteers (where they gained experience but no income or noticeable public exposure for their work). Many bureaucratic obstacles currently exist in the employment and paying of ethical wages to people with learning disabilities, just as they do for Parr's participants. This is therefore a key issue, which the government must address in order that people with learning disabilities can valued (whilst obtaining wider experiential benefits) when they are engaged in landscape activity. In this way true social transformation can occur. 


\subsection{Benefits and beyond}

Currently the potential benefits which people with learning disabilities gain from green and grey remain relatively unexplored and intangible due to lack of research in this area. This study begins to unpick the complex web of interacting factors that prevent or promote people with learning disabilities from profiting from public open space experiences. Recent research has suggested that even the act of viewing, if not directly participating with, green space has many health benefits aiding "short-term recovery from stress or mental fatigue, faster physical recovery from illness and long-term overall improvement on people's health and well-being" (Velarde et al., 2007, p.199). Besides which we perceive social benefits such as inclusion, community development and citizenship as suggested by the Urban Green Spaces Taskforce (2002). Nevertheless, in knowing so little regarding how this social group experiences public open space it would be premature to suggest that these are the only or most important benefits. As this study has shown through the lived example of the participants, people with learning disabilities present situation of limited environment experience constitutes a focused reflection of overall limited experience. This extends into many realms of life where they lack independence and control (education, relationships, employment, health care and travel but to name a few). To reach a position of increased environmental experience, where benefits for the individual and society may be abundantly harvested, requires a number of key issues to be addressed (the six themes as identified in Chapter 7). In life, the promise of social participation and inclusion for people with learning disabilities will only be achieved when political will, material resources, practice and research methods facilitate their worth as valuable members of the community.

\subsection{Operational considerations}

Whilst use of the toolkit by landscape professionals, researchers and others will ultimately extend our understanding of this little considered area of study, there remain two significant implications for its application; that of time, and that of support from those in governance (and therefore widespread implementation by those in the planning and design professions).

The greatest constraint, and yet one of the toolkit's most potent qualities, in 
achieving meaningful participation of the learning disability community is the adoption of, and commitment to, a longitudinal approach. The recent research report 'Community participation: Who benefits?' commissioned by the Joseph Rowntree Foundation (JRF), identifies six core influences to participation. Grouped by way of interrelated pairs, these influences are described under the three key terms of inequity, exclusivity and dependency (Skidmore et al., 2006). This illustrates how encouraging the community to become involved and participate in decision-making processes is a highly complex issue. In addition, the JRF report specified that local authorities must involve other citizens (who might not normally be engaged or volunteer to be included in community participation) in order that current practice might be improved. The visual communication toolkit, created in conjunction with the longitudinal approach, provides one method by which issues such as inequality, exclusivity and dependency, within current community participation processes, may begin to be addressed. However, this longitudinal approach requires a lasting commitment by national government, local government and other partners with associated financial implications. As an operational issue, this must be addressed and accepted if the participation process is to be inclusive and successful. The toolkit cannot be employed retrospectively; inception of its methods must occur at the commencement of the participation process.

This research has shown how members of the learning disability community should not be defined by any label that presumes that their needs, preferences and chosen communication methods are as one. However, development of the powerful selfadvocacy movement has sometimes left those less vocal, less assured people with more complex communication needs behind. Returning to Aylott (2001) (Chapter 2), we have seen how it may be easier for the government and society to believe that some individuals do not need a high level of support to actively participate and ultimately become emancipated. Certainly, this would be the more financially palatable option. Yet, as this research has demonstrated firsthand, in order that emancipation can take place, time and resources must be invested so that communication and participation is tailored to the individual. This research involved a range of participants of different ages, genders and abilities with the visual communication toolkit proving easily adaptable to meet the needs of all concerned. Nevertheless, the researcher is aware that there are people with very 
complex communication and support needs, for whom the toolkit might, as yet, not be so successful in promoting their move towards emancipation and more positive environmental experiences. This however does not mean that in future the toolkit might not be further developed, with the consented participation of such individuals, to response to their personal requirements. The many methodological approaches encompassed by the umbrella of the toolkit are not tedious constraints because of their multitude and the time required to employ them. Instead they offer an initial communication kit to which tools may be added or subtracted depending on participants and context.

Reflection now turns to the second operational consideration; how governance ultimately determines adoption of the toolkit as a collaborative method (on a large-scale or national level) by the planning and design professions. Regarding the issue of communication as a means to empowerment (first considered in this thesis through the debate surrounding communicative rationality in Chapter 2), the researcher is confident that the approach and visual communication toolkit evolved through this study has worth in addressing this issue to the critics of communicative and collaborative approaches. Where Tewdwr-Jones and Allmendinger (1998) debate how difficult and unlikely it is that diverse sections of the community can be included, the visual communication toolkit has proven how those formally seen at the outer edges may be central to a focused and progressive discussion. The approach taken by the researcher to identifying and collaborating successfully with some of society's currently most powerless and invisible stakeholders also challenges opponents to communicative planning, and in future one hopes communicative landscape and urban design. However, the researcher agrees with Healey $(1997 ; 1999)$ that issues still surround the practical effectiveness of collaborative approaches such as the visual communication toolkit, as a result of the attitudes and institutional nature of the planning and architectural professions who are still (for the most part) 'deeply embedded in routines of state procedure, and allowed to privilege certain interests over others' (Healey, 1999, p.1133). Without a dramatic shift in government policy at a national level, hope of implementing change and broadening the professionals' view of, and engagement with, community participation and communicative action, is unlikely to be anything but (on an optimistic level) incremental and (on a realistic level) individual. 
Shifting focus to the power dynamics directly surrounding the participants in this study, emergent from analysis was the importance placed upon the role of the carer (parents, guardians or family members) in facilitating people with learning disabilities to have positive environmental experiences. In enabling people with learning disabilities to participate in leisure activities, carers face great financial, time and access challenges. Therefore, although unexplored during this study, the voice of carer is identified as extremely pertinent. The researcher suggests, that involving carers more directly throughout the research process (be it through interview or informal discussion) would be highly beneficial. In this way, a more in depth portrait might be painted of the historic factors that have contributed to the person with learning disabilities current perception of public open spaces. However, the researcher asserts that it is critical that this must not dominate or overshadow the first-hand experiences of the person with learning disabilities. The use of this toolkit (alongside the ongoing advance towards independence driven by the self-advocacy movement) challenges carers to recognise a shift in their relative power balance and their ability to respond appropriately. By openly involving carers, future researchers demonstrate that they understand the pressures that such people face, and are interested in finding ways and means by which to assist them.

\subsection{Broader implications}

This study has produced results, in the form of the visual communication toolkit, research approach and analysis and experiential findings, which have worth in application beyond the field of the participation of people with learning disabilities in landscape architecture. These broader research implications are identified as forming two key areas of future study. The first of these is learning disability participation, and the second is healthy spaces for life inclusion. These are now discussed.

\subsubsection{Learning disability participation}

The six key themes produced by this research (daily life experience, communication methods, environmental choice, social experience, activity in the landscape, and experiential benefits), begin to identify a pattern of interacting factors that have the potential to be transferable when unravelling a person with learning disabilities 
experience of many environments and decision making situations i.e. health, housing, education or accessing travel.

For example, if we focus on the experience of a woman moving into new more independent accommodation after having lived with her family. The woman's previous daily life experience, her routines, her family's routines and the habitual space they shared, will have considerable impact on how she adjusts to new arrangements. The communication methods employed (ideally individually responsive, such as the visual communication toolkit) to facilitate discussion as to how she wishes to live, will have an impact. The housing choices she makes will be determined (to an extent), by how accessible the housing conversation has been to her. If the right communication methods are employed and her daily life experience is taken into account, this will have an obvious positive impact. The social experience she gains by moving into new accommodation will come as a result of all the previous interacting factors, and has an impact. If the woman has positive social experiences (resulting from decisions which are responsive as to how she wishes to share the space i.e. with others or not) she is more likely to be involved and engage in activities in the home environment, and this will have an impact. If a positive path is taken through all these interacting factors, the woman will gain experiential benefits from her new accommodation, with the result of an increased living experience.

As can be seen from the above example, the experiential findings and toolkit of this research support a person centred planning approach, as developed by Valuing People (Department of Health, 2001). The 2007 'Valuing People' and Research: The Learning Disability Research Initiative, which reviewed Valuing People funded research projects (completed since 2001), spoke of the concern that "more recent research continues to demonstrate that information intended to be accessible to people with learning disabilities is not necessarily effective... [and that] further research is also required to evaluate improvements in understanding due to accessible information across diverse populations of people with learning disabilities" (Grant and Ramcharan, 2007, p.108). Abiding by the principle of "Nothing about us without us" this research answers these concerns through a communication toolkit driven by the experiences and responses 
of people with learning disabilities, with no assumption that one size (one communication method) fits all.

\subsubsection{Healthy spaces for life inclusion}

Beyond learning disability research, the approach to participation evolved here has great potential (to be effective) when employed with other socially excluded groups. In the introduction to this thesis, the researcher refers to the recent PSA Delivery Agreement 16 (2007), in which adults with moderate to severe learning disabilities were acknowledged as in need of additional support as one of its four "at-risk client groups". The three other vulnerable groups identified by the PSA are:

\section{Care leavers \\ 2. Adult offenders under probation supervision}

\section{Adults in contact with secondary mental health services}

(PSA Delivery Agreement 16, 2007, p.3)

Of these three groups it is the third group, adults in contact with secondary mental health services, who the researcher believes could most benefit from use of the toolkit in situations of self-advocacy and decision-making. For those who might find participating in formal, verbal and written communication exchanges difficult, frustrating or intimidating, adaptation of the toolkit to meet their specific needs creates a more informal and less pressured process of involvement. Just as people with learning disabilities have suffered a legacy of exclusion, people with mental health issues remain marginalised and misunderstood. The toolkit seeks to amplify the voices of those society has no right to, yet continues to, exclude. Within this context, the researcher identifies Mind, the UK's leading mental health charity, as a possible researcher collaborator (in place of Mencap as in this study).

Two further social groups, for whom the toolkit has the potential to improve environmental participation are identified as older people with sensory and communication impairments, and asylum seekers and refugees. During the aging process, which affects us all, the likelihood of developing sensory or communication impairments 
increases. Older adults with Alzheimer's, dementia or those who have recently suffered from a stroke (which has altered or reduced their verbal communication) still retain the right to be included in the discussion of what comprises landscapes which promote their mental, social and physical well being. Understanding the elements and factors, which encourage the older community to participate in such environments, is likely to be of long-term benefit to us all. In order to develop strong, trusted research partnerships with members of this social group, the researcher identifies the charities Age Concern and The Alzheimer's Society as informed support organisations and potential collaborators. The current need for translation of this toolkit into operation with older people (as a means of longitudinal, qualitative study) is identified in a recent publication of Garuth Chalfont working in this area, who states:

"that research in dementia care might benefit from the application of insights from Environment-Behaviour Studies (EBS) which seeks to understand how people and environments interact. This type of approach is more ethnographic and anthropological than the intervention studies normally used, which follow the medical model. There are relationships between people and buildings that can only be understood by observing interactions over time, as one informs the other. Both physical spaces, and how they are used, are the result of ongoing interaction. We cannot separate what people do from where they do it".

(Chalfont, 2008, p.151)

The final social group is the asylum seeker and refugee population. They too remain one of the UK's most hidden, and yet again misunderstood (and on occasion maligned) communities. In a world driven by globalisation and torn apart by natural and man-made disasters, population migration is an obvious by product. Immigration over centuries produces a more diverse population, and is ultimately beneficial, yet today's political climate and media marginalisation has warped many personal perspectives. As a result those entering the country to seek asylum are often alienated. In Sheffield, UK, landscape researcher Clare Rishbeth has focused upon cultural diversity in landscape experience, in particular that of first generation migrants. Two of Rishbeth's recent research studies Walking Voices (2006 - 2007) and Viewfinder (2004 - 2005) have explored landscape perception by first generation migrants using a range of qualitative 
methodologies. The visual communication toolkit generated by this study is seen by the researcher as being a complementary approach to Rishbeth's work. The toolkit does not rely upon written or verbal communication and therefore facilitates dialogue between the researcher and participants who may not share a first language, while utilising visual methods to uncover the personal in place perception. Its extension into this area of study has the potential to make visible within communities the great richness that populations of varying ethnicities hold. Identified as a potential collaborator and advisor when working with ethnic populations is the Black Environment Network (BEN), which currently works to promote ethnic environmental participation.

\subsection{The hereafter's already here}

This research did more than fulfill its aims and objectives. It provided the researcher with a means by which to observe and engage with the worlds of people whose experiences were different from her own. Once this knowledge was embedded it became impossible to remove. The research collaboration developed with participants and staff at Sheffield Mencap, and with the wider South Yorkshire learning disability community through the self-advocacy group Speaking Up For Action (SUFA), has already resulted in the successful application of a six month research project "Excuse me I want to get on: negotiating the city" (funded by the Knowledge Transfer Opportunities Fund, University of Sheffield). The study, which began in January 2008, focuses upon the development and employment of further visual communication techniques (including film-elicitation). As a result, the study aims to enable people with learning disabilities in Sheffield to increase their independence and self-advocacy when travelling through the city to use services and social spaces. The study also seeks to enhance public practice by working in partnership with local transport service provider (Stagecoach Supertram). In addition, as an outcome of research completed during this $\mathrm{PhD}$, and through collaboration with research colleagues Dr Kevin Thwaites and Ian Simkins, the researcher has secured a Research Fellowship to continue developing work begun here through a two-year study entitled Experiential Landscape funded by the Leverhulme Trust (September 2008 September 2010). Thank you again to all who were part of this progression. 
III.

\section{References}

Afonso, A. I. (2004) New graphics for old stories: Representation of local memories through drawings, in: S. Pink, L. Kürti and A. I. Afonso (Eds) Working Images: Visual Research and Representation in Ethnography. (London, Routledge).

Age Concern, www.ageconcern.org.uk, accessed 27/05/08 at 17.56.

Aitken, S. C. \& Wingate, J. (1993) A Preliminary Study of the Self-Directed Photography of Middle-Class, Homeless, and Mobility-Impaired Children, The Professional Geographer, 45(1), pp. $65-72$.

Alberti, L. B. (1996) On the Art of Building in Ten Books [De re Aedificatoria], trans. Joseph, Rykwert, Neil, Leach and Robert, Tavernor. (MIT Press, Cambridge, MA).

Al-Kodmany, K. (1999) Using visualization techniques for enhancing public participation in planning and design: process, implementation and evaluation, Landscape and Urban Planning, 45, pp. $37-45$.

The Alnwick Garden, www.alnwickgarden.com/about the garden/index.asp, accessed 12/01/08 at 14.03 .

Altman, B. M. (2001) Disability Definitions, Models, Classification Schemes and Applications, in: G. L. Albrecht, K. D. Seelman and M. Bury (Eds.) Handbook of Disability Studies (London, Sage Publications Ltd).

The Americans with Disabilities Act (ADA) (United States Public Law 101-336, 104 Stat. 327) (1990).

Aylott, J. (2001) The new learning disabilities white paper: did it forget something? British Journal of Nursing, 10(8), pp. 512.

The Alzheimers Society, www.alzheimers.org.uk, accessed 1/06/08 at 16.36.

Balandin, S. (2003) Happily ever after: communicating results to participants in research, Journal of Intellectual \& Developmental Disability, 28(1), pp. 87 - 89.

Balaram, S. (2001) Universal design and the majority world, in: Preiser, W. F. E. \& Ostroff, E. (2001) Universal Design Handbook (New York, McGraw-Hill Professional).

Banks, M. (2001) Visual Methods in Social Research (London, Sage Publications Ltd).

Barnes, C. (1997) Care, Communities and Citizens (Longman, Harlow, Essex).

Bartram, R. (2003) Geography and the Interpretation of Visual Imagery, in, N. Clifford, \& G.

Valentine (Eds.), Key Methods in Geography (London, Sage Publications).

Beart, S., Hardy, G., Buchan, L. (2004) Changing Selves: a Grounded Theory Account of Belonging to a Self-advocacy Group for People with Intellectual Disabilities, Journal of Applied Research in Intellectual Disabilities, 17(2), pp. $91-100$.

Black Environment Network (BEN), www.ben-network.org.uk, accessed 30/5/08 at 17.05.

Booth, W. (1998) Doing Research with Lonely People, British Journal of Learning Disabilities, 26(4), pp. $132-134$.

Browning, P., Thorin, E. \& Rhoades, C. (1985) A national profile of the self help/self advocacy groups of people with mental retardation, Mental Retardation, 22(5), pp. 226 - 230.

Buchecker, M., Hunziker, M. and Kienast, F. (2003) Participatory landscape development: overcoming social barriers to public involvement, Landscape and Urban Planning, 64, pp. 29 46.

Burton, M. and Kagan, C. (2006) Decoding Valuing People, Disability and Society, 21(4), pp. $299-313$. 
Bury, M. (1996) Defining and Researching Disability: Challenges and Responses, in: C. Barnes and G. Mercer (Eds.) Exploring the Divide: illness and Disability (Leeds, The Disability Press).

Butler, R. \& Parr, H. (Eds) (1999) Mind and body spaces: geographies of illness, impairment and disability (London, Routledge).

Butler, R. \& Parr, H. (Eds) (1999) Outside the walls of the asylum (London, Athlone).

Buxó, M. J. (1999) '...que mil palabras', in De la investigación audiovisual. Fotografía, cine, vídeo, televisión (Barcelona: Proyecto A Ediciones).

Cahill, C. (2007) The Personal is Political: Developing new subjectivities through participatory action research, Gender, Place \& Culture, 14(3), pp. 267 - 292.

Cambridge, P. \& Forrester-Jones, R. (2003) Using individualised communication for interviewing people with intellectual disability: a case study of user-centred research, Journal of Intellectual \& Developmental Disability, 28(1), pp. 5 - 23.

Chalfont, G. (2008) Design for Nature in Dementia Care (London and Philadelphia, Jessica Kingsley Publishers).

The Chronically Sick and Disabled Persons Act 1970 (London, DHSS).

Clements, J., Rapley, M., \& Cummins, R. (1999) On, to, with-vulnerable people and the practices of the research community, Behavioural and Cognitive Psychotherapy, 27, pp. $103-115$.

Cochrane, A. (1998) Illusions of power: interviewing local elites, Environment and Planning A, 30 , pp. $2121-2132$.

Cockerill, H. (2002) Supporting communication in the child with a learning disability, Current Paediatrics, 12, pp. $72-76$.

Cocks, E. \& Cockram, J. (1995) The participatory research paradigm and intellectual disability, Mental Handicap Research, 8(1), pp. 25 - 37.

Collier, J. (1979) Visual Anthropology in Wagner, J. (Ed.) Images of Information (Beverly Hills, California, Sage).

Collier, J. \& Collier, M. (1986) Visual Anthropology (Albuquerque, University of New Mexico Press).

Collier, J. Jr and Collier, M. (1992) [1967] Visual Anthropology. Photographs as a Research Method (Albuquerque, University of Mexico Press).

Cone, A. (2000) Self advocacy group advisor activities and their impact/relation to self advocacy group development, International Journal of Disability, Development and Education, 47(2), pp. $137-154$.

Crawley, B. (1982) The feasibility of trainee committees as a means of self advocacy in adult training centres in England and Wales (unpublished $\mathrm{PhD}$, Manchester), cited in, A. Whittaker (Ed.) Supporting Self-advocacy (London, Kings Fund Centre).

Crawley, B. (1988) The Growing Voice: a Survey of Self-advocacy Groups in Adult Training Centres and Hospitals in Great Britain (London, Values into Action).

Crawley, B. (1990) Advocacy as a threat or ally in professional practice, in, S. Brian \& G.

Wistow (Eds.) The Roles and Tasks of Community Mental Health Teams (Avebury, CRSP).

Danielsson, H. \& Svensk A. (2001) Digital pictures as cognitive assistance, in C. Marincek, C.

Bühler, H. Knops \& R. Andrich (Eds.) Assistive Technology Research Series: Volume 10.

Assistive Technology: Added Value to the Quality of Life (Amsterdam, IOS Press).

Danielsson, H., J. Rönnberg \& J. Andersson (2006) What am I doing in Timbuktu: personenvironment picture recognition for persons with intellectual disability, Journal of Intellectual Disability Research, 50(2), pp. 127 - 138.

Darke, R. (1975) The Context for Public Participation in Planning, South Yorkshire (Sheffield, Sheffield Centre for Environmental Research: Occasional Papers).

Denzin, N. K. \& Lincoln, Y. S. (1998) Introduction: entering the field of qualitative research, in N.K Denzin and Y.S. Lincoln (Eds.) The Landscape of Qualitative Research. Theories and Issues (Thousand Oaks, Sage). 
Department for Transport, Local Government and the Regions (2002) Green Spaces, Better

Places: Final report of the Urban Green Spaces Taskforce (Wetherby, DTLR).

Department of Health (2001) Valuing People: A New Strategy for Learning Disability for the $21^{\text {st }}$

Century, CM5086 (London, HMSO).

Department of Health and Social Security (1971) Better Services for the Mentally Handicapped, Command 4683 (London, HMSO).

The Disabled Persons (Employment) Act (1944) (London, HMSO).

Disability Discrimination Act (1995) (London, HMSO).

Disability Rights Commission (2003) Creating an Inclusive Environment,

www.drc.org.uk/library/publications/services_and_transport/creating_an_inclusive_environm.asp $\mathrm{x}$, accessed 4/06/07 at 17.27.

Disability Rights Commission (2003B) Good Signs - Improving signs for people with a learning disability (Disability Rights Commission).

Dyrberg, T. B. (1997) The Circular Structure of Power. (Verso, London).

Edexcel (2004) W009886 Unit specifications - Entry 1, 2 and 3 - Edexcel Entry Level BTEC

Certificate in Skills for Working Life (Land based) - Issue 2.

Elliott, R., Fischer, C. T., Rennie, D. L. (1999) Evolving guidelines for publication of qualitative research studies in psychology and related fields, British Journal of Clinical Psychology, 38(3), pp. $215-229$.

Ely, M., Anzul, M., Friedman, T., Garner, D., \& McCormack Steinmetz, A. (1991) Doing

qualitative research: Circles within circles (London, The Falmer Press).

Enable (1999) Stop it! Bully and harassment of people with learning disabilities (Glasgow,

Enable).

Finney, N. and Rishbeth, C. (2006) Engaging with Marginalized Groups in Public Open Space

Research: The Potential of Collaboration and Combined Methods, Planning Theory and Practice, $7(1)$, pp. $27-46$.

Finklestein, V. (2004) Representing Disability, in: J. Swain, S. French, C. Barnes and C. Thomas (Eds) Disabling Barriers-Enabling Environments, Second Edition (London, Sage Publications).

Fougeyrollas, P., R. Cloutierbergeron, H. Càté and G. St-Michel (1996) Quebec Classification

"Disability Creation Process" (Québec, International Network on the Disability Creation

Process).

Fischler, R. (1995) Planning theory as culture and experience, Journal of Planning Education and Research, 14(3), pp.173 - 177.

Flyvberg, B. (1998a) Rationality and Power. (University of Chicago Press, Chicago, IL).

Flyvberg, B. (1998b) Empowering civil society: Habermas, Focault and the question of conflict, in Cities for Citizens, Eds. M. Douglass, J. Friedmann. (John Wiley, Chichester, Sussex). Forester, J. (1989) Planning in the Face of Power. (University of California Press, Berkley, California).

Forester, J. (1996) Beyond dialogue to transformative learning: how deliberate rituals encorage political judgement in community planning processes, Democratic Dialogues: Theories and Practices Ed. S. Esquith. (University of Poznan, Poznan).

Foucault, M. (1967) Madness and Civilisation: The History of Madness and an Age of Reason. (Tavistock, London).

Fougeyrollas, P. and B. Line (2001) Disability: An Interactive Person-Environment Social Creation, in: G. L. Albrecht, K. D. Seelman and M. Bury (Eds.) Handbook of Disability Studies (London, Sage Publications Ltd).

Garner, R. (2003) Which Came First, The Chicken or The Egg? A Foul Metaphor for Teaching, Radical Pedagogy, http://radicalpedagogy.icaap.org/content/issue5_2/04_garner.html, accessed $10 / 7 / 07$ at 17.36 .

Geddes, P. (1915) Cities in Evolution (London, Williams and Norgate). 
Geffroy, Y. (1990) Family photographs: a visual heritage, Visual Anthropology, 3 (4), pp. 367 410.

Gibson, T. (1981) Planning for real (London, HMSO).

Gilbert, T. (2004) Involving people with learning disabilities in research: issues and possibilities, Health and Social Care in the Community, 12(4), pp. 298 - 308.

Gill, C. J. (1994) Questioning continuum, in B. Shaw (ed.) The Ragged Edge (Louisville, KY: Avocado Press).

Glaser, B. (1978) Theoretical Sensitivity (Mill Valley, CA, Sociology Press).

Glaser, B., Strauss, A. (1967) The Discovery of Grounded Theory (Hawthorne, NY, Aldine

Publishing Company).

Gleeson, B. (1999) Geographies of disability (London, Routledge).

Goddard, H. H. (1912) The Kallikak Family: A Short Study of Hereditary Feeble-Mindedness

(New York, Macmillan).

Goldsmith, S. (1997) Designing for the Disabled. The New Paradigm (Oxford, Architectural

Press).

Goodban, A., Goodban, D (1990a) Horticulture therapy: a growing concern, part 1, British

Journal of Occupational Therapy, 53, pp.425 - 429.

Goodban, A., Goodban, D (1990b) Horticulture therapy: a growing concern, part 2, British

Journal of Occupational Therapy, 53, pp.468 - 470.

Goodley, D. (1997) Locating self-advocacy in models of disability: understanding disability in the support of self-advocates with learning disabilities, Disability and Society, 12(3), pp. 367 379.

Goodley, D. (1998) Appraising self-advocacy in the lives of people with learning difficulties (Unpublished PhD Thesis) (Sheffield, University of Sheffield).

Goodley, D. (1999) 'Disability Research and the "Researcher Template": Reflections on Grounded Subjectivity in Ethnographic Research', Qualitative Inquiry, 5(1), pp. 24 - 46.

Goodley, D. (2000) Self-advocacy in the Lives of People with Learning Difficulties (Buckingham, Open University press).

Grant, G. and Ramcharan, P. (2007) Valuing People and Research: The Learning Disability Research Initiative (Overview Report) (DH Publications).

Graungaard, A. H., Skov, L. (2006) Why do we need a diagnosis? A qualitative study of parents' experiences, coping and needs, when the newborn child is severely disabled, Child: care, health and development, 33(3), pp. $296-307$.

van Gunsteren, H. R. (1998) A theory of citizenship: Organizing plurality in contemporary democracies (Boulder CO, Westview Press).

Habermas, J. (1981) Theorie des Kommunikativen Handelns, Band 1: Handlungsrationalitat und gesellschaftliche Rationalisierung. (Suhrkamp Verlag, Frankfurt am Main).

Habraken, N. J. (2005) Palladio's Children. (Taylor and Francis, London).

Hall, E. (1999) Workspaces: refiguring the disability-employment debate, in: R. Butler \& H. Parr (Eds) Mind and body spaces: geographies of illness, impairment and disability (London, Routledge) pp. 138 - 154.

Hall, E. (2000) 'Blood, Brain and Bones': Taking the Body Seriously in the Geography of Health and Impairment, Area, 32, pp.21 - 29.

Hall, E. (2004) Social geographies of learning disability: narratives of exclusion and inclusion, Area, 36(3), pp. 298 - 306.

Hampton, W. A. (1975) Research into Public Participation in Structure Planning, in, Coppock, J.

T and Sewell, W. R. D. (Eds.) Public Participation in Planning (Wiley, forthcoming).

Hansen, N. E. (2002) 'Passing' Through Other People's Spaces: Disabled Women, Geography and Work. (PhD thesis, University of Glasgow)

Hansen, N., Philo, C. (2007) The Normality of Doing Things Differently: Bodies, spaces and disability geography, Royal Dutch Geographical Society, 98(4), pp.493 - 506. 
Harris, A. (1971) Handicapped and Impaired in Great Britain (London, HMSO).

Harper, T. L., Stein, T. (1995) Out of the post-modern abyss, Journal of Planning Education and Research, 14(4), pp.233 - 244.

Healey, P. (1992) A planner's day: knowledge and action in communicative practice, Journal of the American Planning Association, 58, pp. 9 - 20.

Healey, P. (1993) The communicative work of development plans, Environment and Planning B:

Planning and Design, 20, pp.83 - 104.

Healey, P. (1996a) Collaborative planning in a stakeholder society, paper presented to the University of Newcastle 50 ${ }^{\text {th }}$ Anniversary Conference, 25-27 October; copy available from the author, Department of Town and country Planning: University of Newcastle Upon Tyne, Newcastle Upon Tyne.

Healey, P. (1997) Collaborative Planning, Shaping Places in Fragmented Societies (Macmillan, London).

Healey, P. (1999) Deconstructing communicative planning theory: a reply to Tewdwr-Jones and Allmendinger, Environment and Planning A, 31, pp.1129 - 1135.

Healey, P. and Hillier, J. (1996) Communicative micropolitics: a story of claims and discourses, International Planning Studies, 1(20), pp.165 - 184.

Heath, H. and Cowley, S. (2004) Developing a grounded theory approach: a comparison of Glaser and Strauss, International Journal of Nursing Studies, 41, pp. 141 - 150.

Hillier, J. (1993) Discursive democracy in action, paper presented to the Association of European Schools of Planning Congress, Lodz, Poland, July; copy available from author, Centre for Architecture and Planning Research, Curtain University, Perth, Western Australia. H M Government (2007) PSA Delivery Agreement 16: Increase the proportion of socially excluded adults in settled accommodation and employment, education or training (London, HMSO).

Holland, J., Thompson, R. and Henderson, S. (2004) Feasibility Study for a Possible Longitudinal Study: Discussion Paper, www.Isbu.ac.uk/inventingadulthoods/feasibility_study.pdf, accessed 12/03/08 at 13.45. Hurworth, R. (2003) Photo-Interviewing for research, Social Research Update, 40, pp. 1 - 7, http://www.sru.soc.surrey.ac.uk/SRU40.html, accessed 10/02/05 at 11.17.

Husserl, E. (2001) Logical Investigations, Volumes 1 \& 2, Trans. J.N. Finlay (Ed.) with translation corrections and with a new Introduction by Dermot Moran. With a new Preface by Michael Dummett. London and New York: Routledge. A new and revised edition of the original English translation by J. N. Findlay. London: Routledge \& Kegan Paul, 1970. From the Second Edition of the German. First edition, 1900-01; second edition, 1913, 1920. Husserl, E. (1963) Ideas: A General Introduction to Pure Phenomenology. Trans. W. R. Boyce Gibson. New York: Collier Books. From the German original of 1913, originally titled Ideas pertaining to a Pure Phenomenology and to a Phenomenological Philosophy, First Book. Newly translated with the full title by Fred Kersten. Dordrecht and Boston: Kluwer Academic Publishers, 1983. Known as Ideas I.

Imrie, R. and Hall, P. (2001) Inclusive Design - Designing and Developing Accessible Environments (London: Spon Press).

Innes, J. (1995) Planning theory's emerging paradigm: communicative action and interactive practice, Journal of Planning Education and Research, 14(4), pp.183 - 189.

Jones, J. (2000) A total communication approach towards meeting the needs of people with learning disabilities, Tizard Learning Disability Review, 5(1), pp. 20 - 26.

Kaplan, S. (1995) The restorative benefits of nature: towards an integrative framework, Journal of Environmental Psychology, 15, pp.169 - 182.

Kneale, J. (2001) Working with groups, in, M. Limb \& C. Dwyer (Eds.) Qualitative Methodologies for Geographers (London, Arnold). 
King, S., M. Conley, B. Latimer and D. Ferrari (1989) Co-design: A Process of Design

Participation (New York, Van Nostrand Reinhold).

LeCompte, M. D., Schensul, J. J. (1999) Designing and Conducting Ethnographic Research: 1

(Ethnographer's Toolkit) (U.S, AltaMira Press).

Lee, R. M. (1993) Doing Research on Sensitive Topics (London, Sage Publishers).

Lennox, N., Taylor M., Rey-Conde T., Bain C., Purdie D. M. \& Boyle F. (2005) Beating the barriers: recruitment of people with intellectual disability to participate in research, Journal of Intellectual Disability Research, 49(4), pp. 296 - 305.

McDowell, L. (1992) Valid games? A response to Erica Schoenberger, Professional Geographer, 44(2), pp. $212-215$.

McGhee, G., Marland, G. R., Atkinson, J. (2007) Grounded theory research: literature reviewing and reflexivity, Journal of Advanced Nursing, 60(3), pp. 334 - 342.

Mace, R. (1985) Universal Design, Barrier Free Environments for Everyone (Los Angeles, Designers West).

Mace, R. (1988) Universal Design: Housing for the Lifespan of All People (Washington, D4C: U4S4 Department of Housing and Urban Development).

Mansell, J. and Ericsson, K. (1996) Conclusion: Integrating Diverse Experience, in: J. Mansell and K. Ericsson (Eds.) Deinstitutionalization and Community Living: Intellectual Disability Services in Britain, Scandinavia and the USA (London, Chapman \& Hall).

Mansell, J. and Beadle-Brown (2004) Person-Centred Planning or Person-Centred Action? Policy and Practice in Intellectual Disability Services, Journal of Applied Research in Intellectual Disabilities, 17, pp.1-9.

Mencap (2000) Am I making myself clear? Mencap's guidelines for accessible writing (London, Mencap).

The Mental Deficiency Act (1913).

Milligan, C. and A. Bingley (2007) Restorative places or scary spaces? The impact of woodland on the mental well-being of young adults, Health \& Place, 13(4), pp. $799-811$.

Mind (The National Association for Mental Health), www.mind.org.uk, accessed 1/06/08 at 18.15 .

Minkes, J., Townsley, R., Weston, C. \& Williams, C. (1995) Having a voice. Involving people with learning difficulties in research, British Journal of Learning Disabilities, 23(3), pp. 94 - 98. Mitchell, P. (1997) The impact of self advocacy on families, Disability and Society, 12(1), pp. 43 $-56$.

Murphy, J. (1998) Talking Mats: speech and language research in practice, Speech and Language Therapy in Practice, 11 - 4, http://www.speechmag.com/archives/joanmurphy2.html accessed 31/10/06 at 14.42.

Nairn, K., R. Panelli and J. McCormack (2003) Destabilizing Dualisms: Young people's experiences of rural and urban environments, Childhood, 10(1), pp. $9-42$.

The National Assistance Act (1948) (London, HMSO).

Nehring, J., Hill, R. (1995) The Blackthorn Garden Project, Sainsbury Centre for Mental Health, 134 - 138 Borough High Street, London, SE1 1LB.

Nirje, B. (1992) The Normalization Principle Papers (Uppsala, Sweden, Centre for Handicapped Research. Uppsala University).

Norris, C. (1985) The Contest of Faculties: Philosophy and Theory After Deconstruction.

Methuen: London.

Northway, R. (2000) Ending participatory research? Journal of Learning Disabilities, 4(1), pp. 27 -36 .

Oevermann, U. (1991) Genetischer Strukturalismus und das sozialwissenschaftliche Problem der Erkärung der Entstehung des Neuen. Aus: Müller-Doohm S., 1991: Jenseits der Utopie (Frankfurt, Suhrkamp). 
Oliver, M. (1983) Social Work with Disabled People (London and Basingstoke, The Macmillan Press Ltd).

Oliver, M. (1990) The Politics of Disablement (Houndmills, The Macmillan Press Ltd).

Oliver, M. (1996) Defining Impairment and Disability: Issues at Stake, in: C. Barnes and G.

Mercer (Eds.) Exploring the Divide: illness and Disability (Leeds, The Disability Press).

Oliver, M. (2004) If I had a hammer: the social model in action, in: J. Swain, S. French, C.

Barnes and C. Thomas (Eds), Disabling Barriers-Enabling Environments, Second Edition

(London, Sage Publications).

Orobitg Canal, G. (2004) Photography in the field: Word and image in ethnographic research, in:

S. Pink, L. Kürti and A. I. Afonso (Eds.) Working Images: Visual Research and Representation in Ethnography (London, Routledge).

Ostroff, E. (2001) Universal design: the new paradigm, in: Preiser, W. F. E. \& Ostroff, E. (Eds.)

Universal Design Handbook (New York, McGraw-Hill Professional).

Page, J. K. (1974) On the design of systems for effective user design participation in urban designs (Sheffield, UK, Sheffield Centre for Environmental Research).

Paget, S. (2008) Aspects of the Professional Role of the Landscape Architect - exemplified through the development of School Grounds. Doctoral thesis: Swedish University of Agricultural Sciences, Uppsala.

Pain, R (2004) Social Geography: Participatory Research, Progress in Human Geography, 28(5), pp. $1-12$.

Park, D., Radford, J. \& Vickers, M. (1998) Disability studies in human geography, Progress in Human Geography, 22, pp. 208 - 233.

Parmenter, T. R. (2001) Intellectual Disabilities - Quo Vadis?, in: G. L. Albrecht, K. D. Seelman and M. Bury (Eds.) Handbook of Disability Studies (London, Sage Publications Ltd).

Parr, H. (2007) Mental health, nature work, and social inclusion, Environment and Planning D:

Society and Space, 25, pp.537 - 561.

People First (1996) Speak Out for Equal Rights Workbook Two, Equal People Course Book (London, People First).

Philo, C. (2004) A Geographical History of Institutionalised Provision for the Insane from Medieval Times to the 1860's in England and Wales: The Space Reserved for Insanity. (Edwin Mellon Press, Lewiston, New York).

Price, R. and Stoneham, J. (2001) Making Connections: a guide to accessible greenspace (UK, Sensory Trust).

Race, D. G. (2002) The historical context, in: D.G. Race (Ed.) Learning Disability - A Social Approach (London, Routledge).

Ramcharan, P. \& Grant, G. (2001) Views and Experiences of People with Intellectual Disabilities and Their Families. (1) The User Perspective, Journal of Applied Research in Intellectual Disabilities, 14, pp. $348-363$.

Richardson, A. \& Ritchie, J. (1989) Developing Friendships: Enabling People with Learning

Disabilities to Make and Maintain Friends (London, Policy Studies Institute).

Richardson, T. (1996) Foucauldian discourse: power and truth in urban and regional policy making, European Planning Studies, 4(3), pp.279 -292.

Rishbeth, C. (2006) Rwanda in Sheffield; the local/global distinctiveness of greenspace, in:

Mcdonald, S. and Symonds, J. (Eds), Materializing Sheffield: Place, Culture, Identity. (Sheffield, Humanities Research Institute)

Rose, G. (1996) Teaching Visualised Geographies: towards a methodology for the interpretation of visual materials, Journal of Geography in Higher Education, 20(3), pp. 281 - 293.

Ryan, S. (2005) 'Busy Behaviour' in the 'Land of the Golden M': Going Out with Learning Disabled Children in Public Places, Journal of Applied Research in Intellectual Disabilities, 18, pp. $65-75$. 
Sanoff, H. (2000) Community Participation Methods in Design and Planning (New York, John Wiley \& Sons, Inc.).

Schoenberger, E. (1991) The corporate interview as a research method in economic geography, Professional Geographer, 44, pp. 180 - 189.

Schoenberger, E. (1992) Self-criticism and self-awareness in research: a reply to Linda

McDowell, The Professional Geographer, 44(2), pp. 215-218.

Seeland, K. \& Nicolè, S. (2006) Public green space and disabled users, Urban Forestry and Urban Greening, 5, pp. 29 - 34.

Sempik, J., Aldridge, J. and Becker, S. (2005) Health, well-being and social inclusion.

Therapeutic horticulture in the UK (University of Bristol, The Policy Press).

Shakespeare, T. (2006) Disability Rights and Wrongs (Oxon, Routledge).

Shakespeare, T. (2006) The blooming of a hundred flowers: activism, academia, and the disability studies challenge (Disability Studies Association Annual Conference, Lancaster).

Sibley, D. (1995) Geographies of exclusion: society and difference in the west (London, Routledge).

Siegel, P. E. \& Ellis N. R. (1985) Note on the recruitment of subjects for mental retardation research, American Journal of Mental Deficiency, 89, pp. 431 - 433.

Silvers, A. (2002) The Crooked Timber of Humanity: Disability Ideology and the Aesthetic, in M. Corker \& T. Shakespeare (Eds.) Disability/Postmodernity: Embodying Disability Theory, pp. 228 - 244. (Continuum, London).

Simons, K. (1992) Sticking Up for Yourself: Self-advocacy and People with Learning Difficulties (York Publishing Services Ltd., Joseph Rowntree Foundation).

Simson, S. P., Straus, M. C. (Eds) (1998) Horticulture as Therapy: Principles and Practice. (Haworth Press, New York).

Skeffington, A. M. (1969) People and Planning: Report of the Committee on Public Participation in Planning (Ministry of Housing and Local Government, Scottish Development Department, Welsh Office, HMSO).

Skidmore, P., Bound, K. and Lownsbrough, H. (2006) Community participation, Who benefits? (York Publishing Services Ltd., Joseph Rowntree Foundation).

Slater, S. B., P. Vukmanovic, T. Macukanic, T. Prvulovic, and J. L. Cutler (1974) The Definition and Measurement of Disability, Social Science and Medicine, 8, pp. $305-8$.

Smith, D. W. (2005) "Phenomenology", The Stanford Encyclopedia of Philosophy (Winter 2005 Edition), Edward N. Zalta (ed.), URL = http://plato.stanford.edu/archives/win2005/entries/phenomenology/ accessed 7/5/08 at 12.20.

Stainton, T. (1994) Autonomy and Social Policy: Rights, Mental Handicap and Community Care (Aldershot, UK, Avebury).

Stalker, K. (1998) 'Some Ethical and Methodological Issues in Research with People with Learning Difficulties', Disability and Society, 13(1), pp. 5 - 19.

Starks, H. and Brown Trinidad, S. (2007) Choose Your Method: A Comparison of Phenomenology, Discourse Analysis, and Grounded Theory, Qualitative Health Research, 17(10), pp. $1372-1380$.

Strauss, A. \& Corbin, J. (1998) Basics of Qualitative Research, Second Edition (London, London Sage).

Stuttaford, M. and Coe, C. (2007) The "Learning" Component of Participatory Learning and Action in Health Research: Reflections from a Local Sure Start Evaluation, Qualitative Health Research, 17(10), pp. $1351-1360$.

Sutcliffe, S. \& Simons, K. (1993) Self-advocacy and Adults with Learning Difficulties: Contexts and Debates (Leicester, NIACE).

Tewdwr-Jones, M. and Allmendinger, P. (1998) Deconstructing communicative rationality: a critique of Habermasian collaborative planning, Environment and Planning A, 30(11), pp.1975 1989. 
Thompson, D. (Ed.) (1995) The Concise Oxford Dictionary of Current English (Ninth Edition) (Oxford, Clarendon Press).

Thompson, R. (2007) The Qualitative Longitudinal Case History: Practical, Methodological and Ethical Reflections, Social Policy \& Society, 6(4), pp.571 - 582.

Thwaites, K. \& Simkins, I. (2007) Experiential Landscape: an approach to people, place and space (London and New York, Routledge).

Todd, S. (2000) Working in the public and private domains: staff management of community activities for and identities of people with intellectual disability, Journal of Intellectual Disability Research, 44, pp. $600-620$.

Torre, M. E. and Fine, M. (2006) Participatory Action Research (PAR) by youth, in: Lonnie, R. Sherrod, Constance, A. Flanagan, Ron Kassimir \& Amy, K. Bertelsen (Eds) Youth Activism: An International Encyclopaedia (Westport, CT, Greenwood Publishing Group).

Tregaskis, C. (2004) Applying the social model in practice: some lessons from countryside recreation, Disability \& Society, 19(6), pp. $601-611$.

Tregold, A. F. (1909) The Feebleminded - a social danger, Eugenics Review, 1, pp. 97 - 104. Turner, J. F. C (1976) Housing by People: towards autonomy in building environments. Marion Boyars Publishers ltd: Great Britain.

Turner, T. (1996) City as Landscape: A Post-Post Modern View of Design and Planning (London, E. and F. N. Spon).

Union of Physically Impaired Against Segregation (1976) Fundamental Principles of Disability (London, Union of Physically Impaired Against Segregation).

United Kingdom Census (1851).

The University of Sheffield (2007) Ethics Guidance (Principle of consent)

http://www.shef.ac.uk/researchoffice/support/winning/ethics/staff.html accessed 8/7/07 at 17.54. Urban Green Spaces Taskforce (2002) Green Spaces, Better Places (London, Department for Transport, Local Government and the Regions).

Valentine, G. and Skelton, T. (2007) The right to be heard: Citizenship and language, Political Geography, 26(2), pp. $121-140$.

Velarde, M. D., Fry, G. and Tveit, M. (2007) Health effects of viewing landscapes - Landscape types in environmental psychology, Urban Forestry and Urban Greening, 6(4), pp.199 - 212. Walmsley, J. \& Johnson, K. (2003) Inclusive Research with People with Learning Disabilities. Past, Present and Futures (London and New York, Jessica Kingsley Publishers).

Wang, C. \& Burris, M. A. (1994) Empowerment through Photo Novella: Portraits of Participation, Health Education Quarterly, 21(2), pp. 171 - 186.

Wang, C. \& Burris, M. A. (1997) Photovoice; Concept, Methodology and Use for Participatory Needs Assessment, Health and Behaviour, 24(3), pp. 369 - 387.

Ward Thompson, C. (2002) Urban Open Space in the $21^{\text {st }}$ Century, Landscape and Urban Planning, 60, pp. $59-72$.

Whiteneck, G. G. and P, Fougeyrollas (1996) Environmental Factors Task Force Position Paper: Environmental Factors and ICIDH, ICIDH and Environmental Factors International Network, 8(3) pp. $14-18$.

Whiteneck, G. G. and P, Fougeyrollas, and K, A. Gerhart (1997) Elaborating the Model of Disablement, Assessing Medical Rehabilitation Practices: The Promise of Outcomes Research (Baltimore, Brookes).

World Health Organisation (1980) International Classification of Impairments, Disabilities and Handicaps: A Manual of Classification Relating to the Consequences of Disease (Geneva, World Health Organisation).

World Health Organisation (1999) ICIDH-2 International Classification of Functioning and Disabilities, Beta-2 draft, short version (Geneva, World Health Organisation).

Zarb, G. (1997) Researching Disabling Barriers, in: C. Barnes and G. Mercer (Eds.) Doing Disability Research (Leeds, The Disability Press). 
IV.

\title{
Appendices
}

\begin{abstract}
All supporting information (the appendices) is contained within the 'Hidden Voices' CD attached to the back cover of this thesis. This information, referring to various thesis chapters, is catalogued below.
\end{abstract}

\section{Appendices contents}

\section{Methodological Approaches in Analysis}

- Data analysis_Part 1

- Data analysis_Part 2

- Data spreadsheet

\section{Pilot Study}

- Our Parks and Gardens (introduction presentation)

- Semi Structured Interview (SSI) format

- Staff questionnaire

\section{Evolved Methodology}

- Informed consent:

- Ethics consent form

- Ethics participant information sheet

- Ethics tutor information sheet

\section{Main Studies}

- Project introduction (SC2 presentation) 